\title{
A Landscape Analysis of Surface Coal Mine Permits in the Coal River Watershed of West Virginia
}

Lafe Joseph Kunkel

West Virginia University

Follow this and additional works at: https://researchrepository.wvu.edu/etd

\section{Recommended Citation}

Kunkel, Lafe Joseph, "A Landscape Analysis of Surface Coal Mine Permits in the Coal River Watershed of West Virginia" (2011). Graduate Theses, Dissertations, and Problem Reports. 3284.

https://researchrepository.wvu.edu/etd/3284

This Thesis is protected by copyright and/or related rights. It has been brought to you by the The Research Repository @ WVU with permission from the rights-holder(s). You are free to use this Thesis in any way that is permitted by the copyright and related rights legislation that applies to your use. For other uses you must obtain permission from the rights-holder(s) directly, unless additional rights are indicated by a Creative Commons license in the record and/ or on the work itself. This Thesis has been accepted for inclusion in WVU Graduate Theses, Dissertations, and Problem Reports collection by an authorized administrator of The Research Repository @ WVU. For more information, please contact researchrepository@mail.wvu.edu. 


\title{
A Landscape Analysis of Surface Coal Mine Permits in the Coal River Watershed of West Virginia
}

\author{
Lafe Joseph Kunkel \\ Thesis submitted to the \\ College of Agriculture, Natural Resources and Design \\ at West Virginia University \\ in partial fulfillment of the requirements \\ for the degree of \\ Master of Science \\ in \\ Agricultural and Resource Economics \\ Submitted to \\ Michael P. Strager, Ph.D., Chair \\ Jerald J. Fletcher, Ph.D \\ Charles B. Yuill \\ Department of Resource Management \\ Morgantown, West Virginia \\ 2011
}

Keywords: Landscape Analysis, Coal Mine Permitting, Spatial Analysis, Water Quality

Copyright 2011 Lafe Joseph Kunkel 


\begin{abstract}
A Landscape Analysis of Surface Coal Mine Permits in the Coal River Watershed of West Virginia
\end{abstract}

Lafe Joseph Kunkel

In Appalachia, coal mining is a vital economic activity. Steps must be taken to ensure the future of the coal mining industry as well as the ecological sustainability of the landscape. By examining the effects of landscape disturbance on stream water quality, disturbance thresholds can be calculated from stream conductivity measurements in various segment level watersheds that contain varying levels of landscape disturbance. These thresholds can indicate how much landscape disturbance can be allowed in a segment-level watershed before water quality depreciates past certain conductivity levels or levels necessary to support macroinvertebrate life. This analysis was conducted on the Coal River USGS 8 digit watershed located in the southern coalfields of West Virginia and incorporated landscape classification techniques to classify the Coal River Watershed for disturbance from mining, forestry, and construction activities. Extensive landscape analysis was performed using GIS and spatial analysis techniques in order to examine the current ecological condition and health of the Coal River watershed, as well as its vulnerability to additional mining related disturbance slated to occur within 15 surface coal mine permit boundaries currently under review by the West Virginia Department of Environmental Protection.

Using multivariate linear regression of independent landscape disturbance variables along with the response variable of summer stream conductivity field sampling measurements, a multivariate linear conductivity model was developed for application to study areas of interest. Through the delineation of hydrologic catchment areas for each of 15 mine permits under review, current summer stream conductivity estimates were calculated using the multivariate linear conductivity model at the outflow point of each catchment area. These current conductivity estimates were then used to determine how much additional mining could be supported by the catchment areas, and in turn, the permits under review. This study concludes that out of the 15 permits under review, 2 have already been disturbed past the maximum allowable conductivity threshold, 1 is at the maximum, and the remaining 12 can carry varying amounts of additional mining. An environmental policy can be created from this analysis taxing marginal increases in mining related disturbance relevant to the current stream conductivity levels within the hydrologic catchment area containing the proposed disturbance. 


\section{Acknowledgements}

I would like to thank a number of people for their support throughout the pursuit of my masters degree in Agricultural and Resource Economics and the writing of this thesis. Without these people, my completion of this endeavor would not have been possible. First and foremost, I would like to thank my father, Wallace Kunkel. Without his undying support and encouragement, the completion of my masters degree would have been very difficult. My father has always been my biggest supporter in every goal I have ever pursued, and he has been a very crucial factor to my successes. Thanks for everything dad.

I would also like to thank my advisor and chair of my graduate committee, Michael Strager, for all of his guidance and assistance in the writing and completion of my thesis work. Dr. Strager provided me with a fantastic research opportunity from which my thesis work was drawn, along with the guidance needed to see the project through to completion. I would like to thank Dr. Michael Strager and Dr. Jerrald Fletcher for the funding opportunities provided to me for my masters education, without this funding graduate education would have not have been a viable option for me after my undergraduate education. A thank you also goes out to Charles Yuill for being the third member of my graduate committee as well as the insightful feedback and insight into my thesis work.

A very special thank you goes out to the support staff of the Resource Management department at West Virginia University. Lisa Lewis and Melanie Jimmie have been extremely kind and helpful to me throughout my masters education, and I cannot thank them enough for 
all of their support. These ladies create a very pleasant environment in the department and are always happy and positive. There have been two different NRAC program specialists during my time in the ARE program, Kelly Street and Danielle Blosser, both of which I would like to thank for their assistance in various situations.

A big thank you goes to the West Virginia University Rifle Team for the opportunities provided to me throughout my undergraduate and graduate education at West Virginia University. The Rifle Team provided me with an athletic scholarship for my time on the team, as well as the opportunity to be the assistant coach for the team throughout my post eligibility period during my undergraduate education through my graduate education. The rifle team is the reason I came to West Virginia University, and a very influential reason that I stayed at West Virginia University for graduate school. The rifle team has been a huge part of my life throughout my time at West Virginia University, and I can't give enough thanks to this outstanding group of people and the tradition they embody. 


\section{Table of Contents}

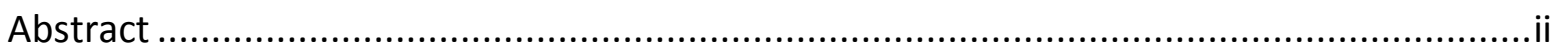

Acknowledgements.....................................................................................................

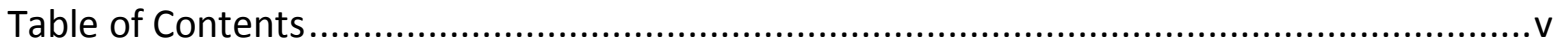

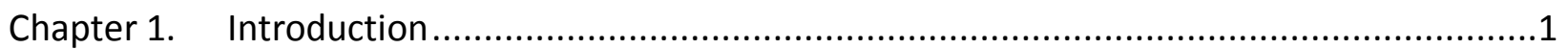

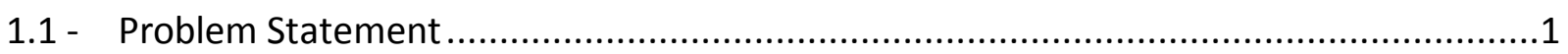

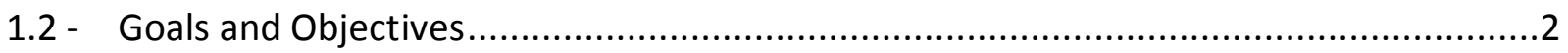

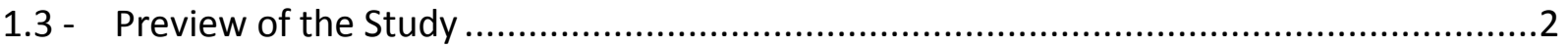

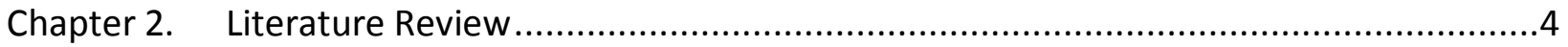

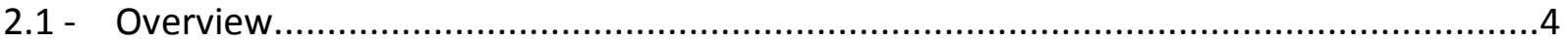

2.2 - Mountain Top Removal: Background and Environmental Impact .................................

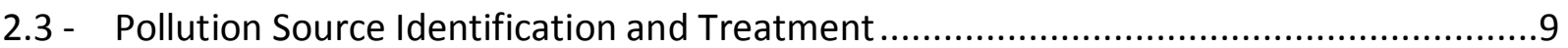

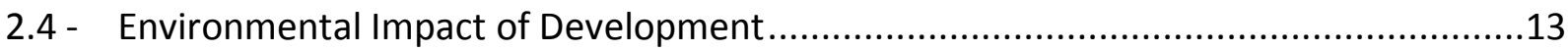

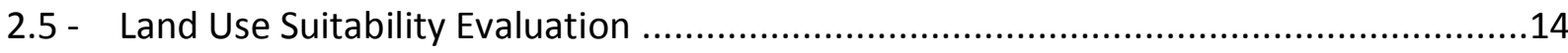

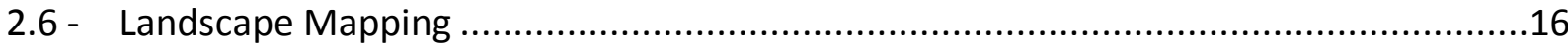

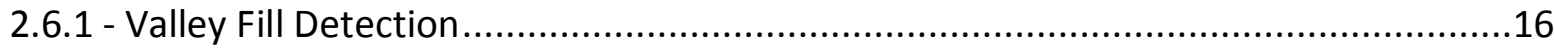

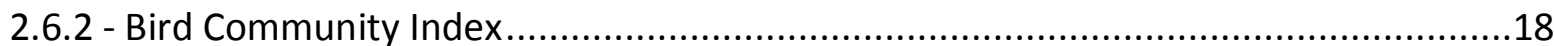

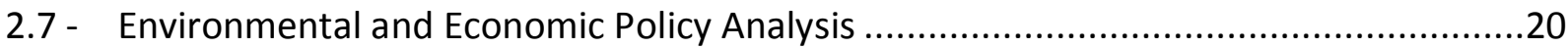

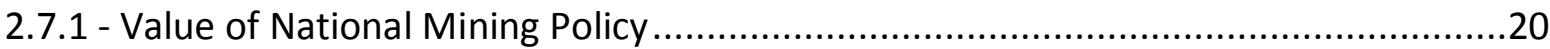

2.7.2 - Interaction Between Environmental Regulation and Trade....................................24

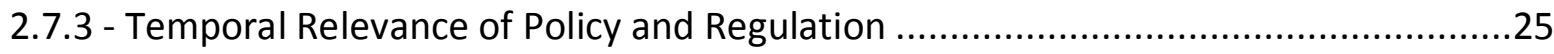

2.7.4 - Environmental Regulation ..................................................................................

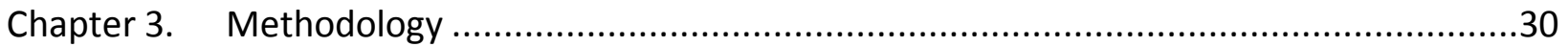

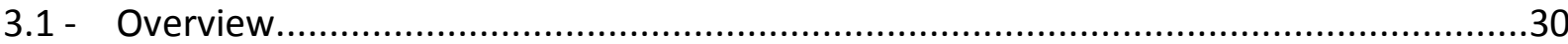

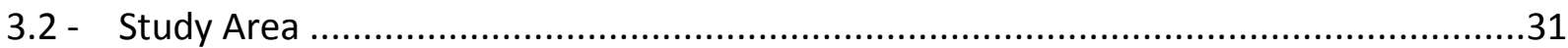

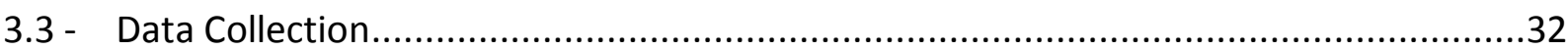

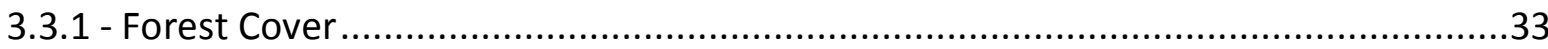

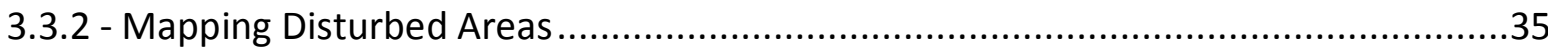

3.3.3 - Slopes Over 25 Degrees.....................................................................................

3.3.4 - Forested Areas over 25 Degree Slope ..................................................................39

3.3.5 - Headwater Forested Watersheds .........................................................................40

3.3.6 - Forested Riparian Areas ...................................................................................

3.3.7 - Forested Areas Critical to Water Quality ………..............................................42 
3.3.8 - Mining Related Disturbance Inside Permits Under Review ............................43

3.3.9 - Forests Critical to Water Quality Within Surface Mining Permits Under Review ......44

3.3.10 - Mining Related Disturbance Outside of Mining Permit Boundaries ....................45

3.3.11 - Headwater Watersheds Affected by Surface Mining.......................................47

3.3.12 - Ecological Land Units.............................................................................49

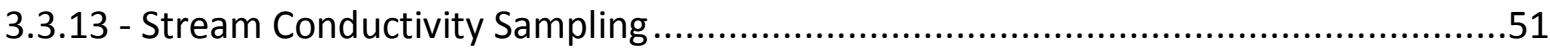

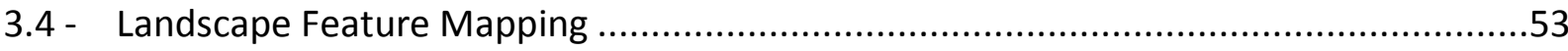

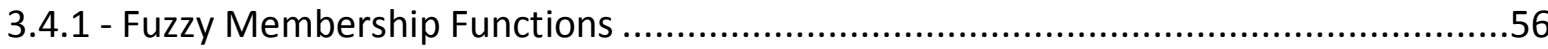

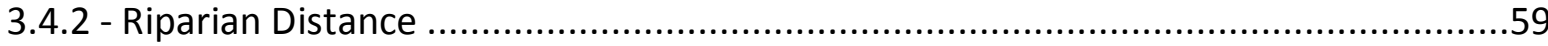

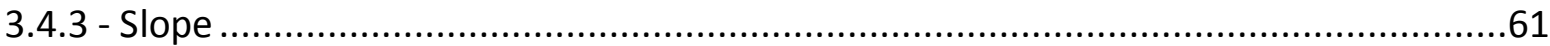

3.4.4 - Combined Fuzzy Memberships .......................................................................63

3.4.5 - Hydrologic Catchment Study Area Selection ...................................................65

3.4.6 - Landscape Characteristic Variables................................................................67

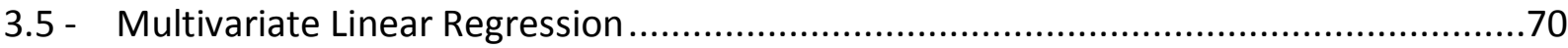

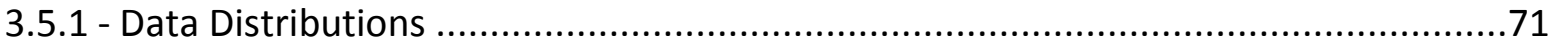

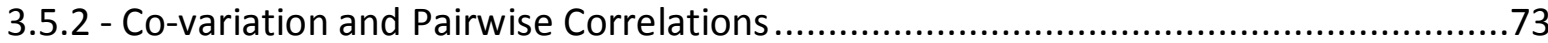

3.5.3 - Uni-variate Regression Analysis ....................................................................77

3.5.4 - Stepwise Multiple Regression....................................................................... 77

3.6 - Application of Multivariate Linear Conductivity Model to Surface Mine Permits Under

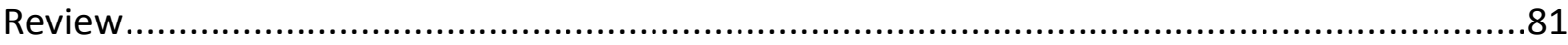

3.6.1 - Delineating Hydrologic Catchment Areas for Permits Under Review ......................81

3.6.2 - Predicting Summer Stream Conductivity Using Multivariate Linear Conductivity

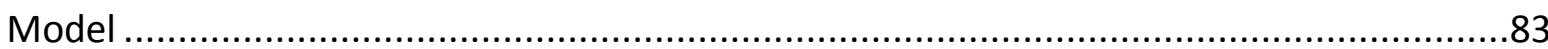

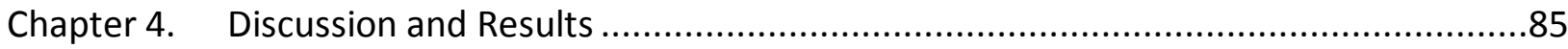

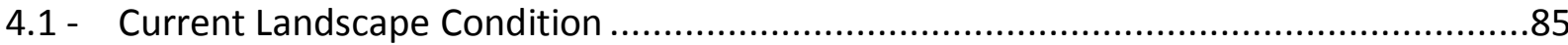

4.1.1 - Multivariate Linear Regression (First Iteration) ............................................87

4.1.2 - Multivariate Linear Regression (Second Iteration) ...........................................89

4.2 - Multivariate Linear Conductivity Model ..........................................................91

4.3 - Potential for Economic and Environmental Policy in West Virginia's Coal Industry ......94

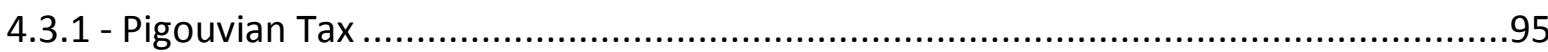

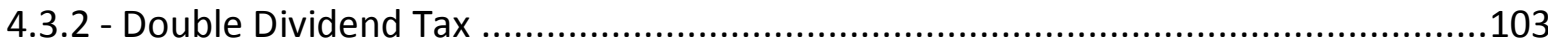

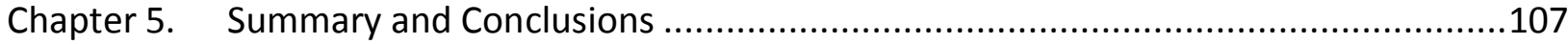

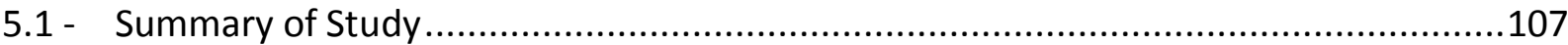




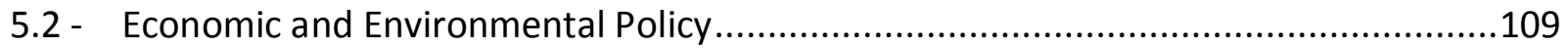

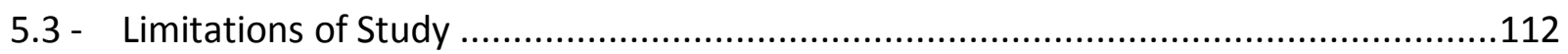

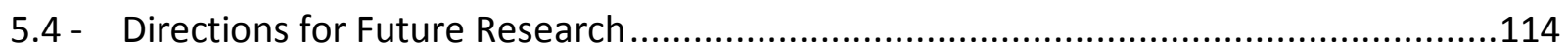

\section{List of Tables and Figures}

Table 3.4.6-1: Landscape disturbance within delineated study areas .....................................69

Table 3.4.6-2: Critical forest classifications within delineated study areas ..............................70

Table 3.6.2-2: Summer stream conductivity calculations for each hydrological catchment area

Table 3.6.2-1: Independent landscape variable summary for each hydrological catchment area

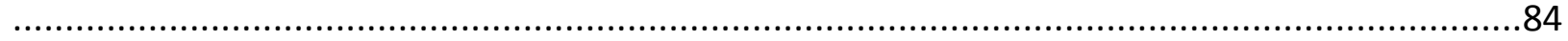

Table 4.2.1: Stream health conditions for each hydrological catchment area ..........................91

Table 4.2.2: Maximum increases in disturbance for each hydrological catchment area ..............92

Table A.1 - ZCC Pumping Capacity, WV DEP (2007) .........................................................118

Figure 3.2.1 : 10 Digit Watersheds in Southern Coalfield of West Virginia ................................31

Figure 3.2.2 : 12 Digit Watersheds in Coal River 10 Digit Watershed .....................................32

Figure 3.3.1: Mapped forested areas in the Coal River watershed as of 2009 ..........................35

Figure3.3.2: Disturbed areas within the Coal River Watershed .................................................37

Figure 3.3.3: Slopes over 25 degrees in the Coal River Watershed..........................................3

Figure 3.3.4: Forested areas on slopes over 25 degrees ........................................................39

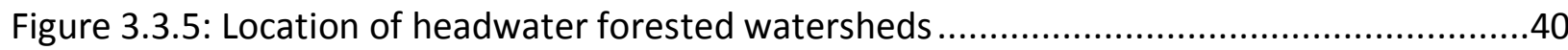

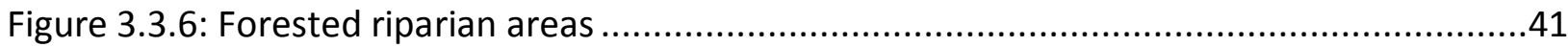

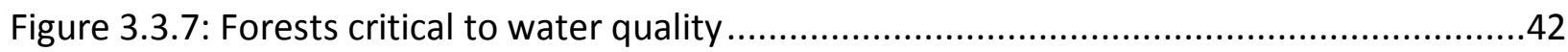

Figure 3.3.8: Mining related disturbance inside permits under review ....................................43

Figure 3.3.9: Forests critical to water quality within the surface mine permits under review.....45

Figure 3.3.10: Mining related disturbance outside of the mine permit boundaries....................46

Figure 3.3.11: Impacts of mines in review to headwater watersheds ....................................48

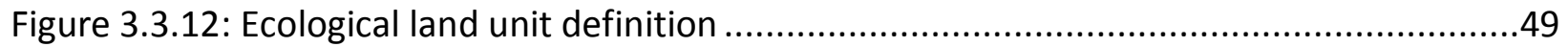

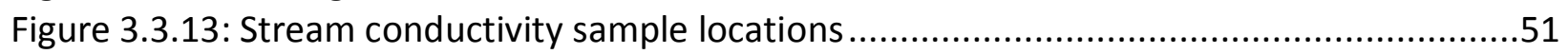

Figure 3.4: Binary inputs and output of forests critical to water quality ..................................56

Figure 3.4.1: Fuzzy membership functions of critical forest input parameters ..........................58

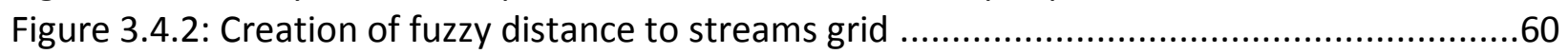

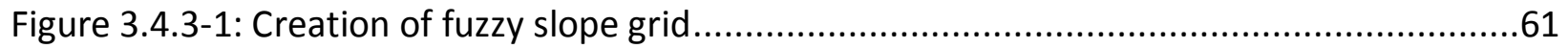

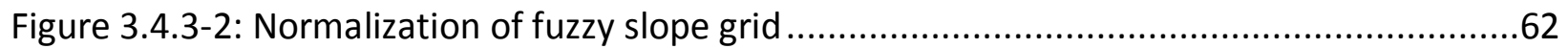

Figure 3.4.4-1: Fuzzy logic critical forest reclassification .......................................................63

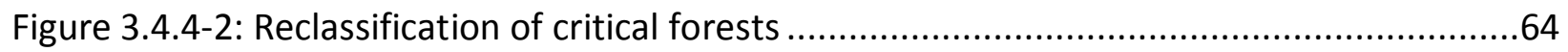

Figure 3.4.4-3: Extracting forested areas from critical forest grid to create final critical forest

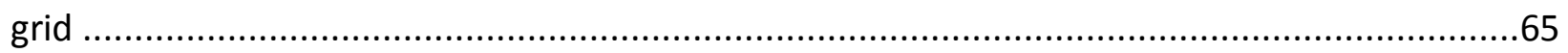

Figure 3.4.5: Study area delineations using Mass Balance Accumulator .................................66

Figure 3.4.6-1: Landscape disturbance within delineated study areas ....................................67

Figure 3.5.1: Independent landscape variable data distributions ............................................72 
Figure 3.5.2-1: Co-variation among independent landscape variables ................................74

Figure 3.5.2-2: Full pairwise correlations among independent landscape variables .................76

Figure 3.5.3: Uni-variate regression analysis for independent landscape variables ..................79

Figure 3.5.4: Stepwise multiple regression for independent landscape variables....................80

Figure 3.6.1: Water quality study area delineation for surface mine permits under review .......82

Figure 4.1.1: Multivariate linear regression (first iteration) .........................................8

Figure 4.1.2: Multivariate linear regression (second iteration) .............................................90

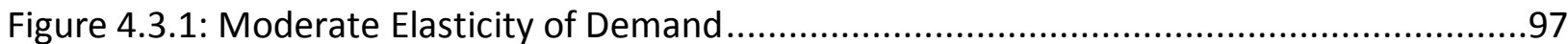

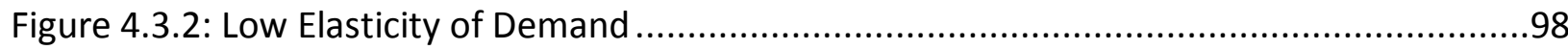

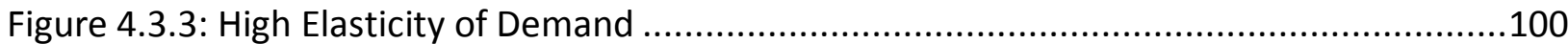

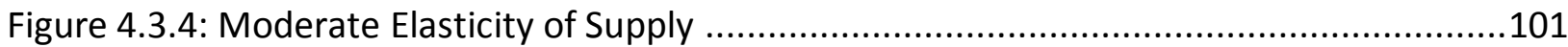

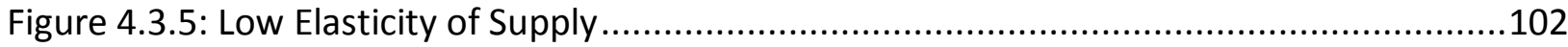

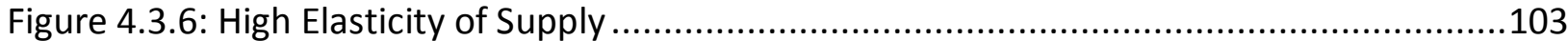

Figure 4.3.7: Labor Market of West Virginia ..............................................................105

Figure 4.3.8: Market for Units of Volume of Total Dissolved Solids .....................................106

Figure A.1: Mining permits in relation to source water protection zones.............................119

Figure A.2: Bird Community Index for the Coal River watershed........................................119

Figure A.3: Louisiana Waterthrush habitat impacts from mine permits under review ............119

\section{Appendix A}

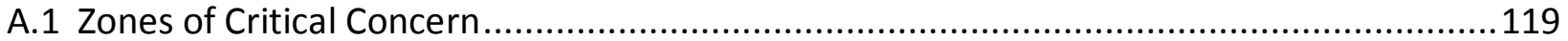

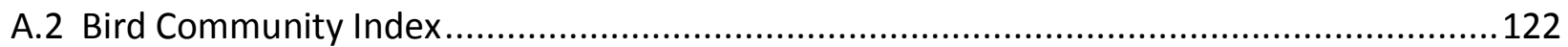

A.3 Louisiana Waterthrush Habitat Modeling ........................................................... 124

A.4 Surface Mine Permits Under Review : Descriptions

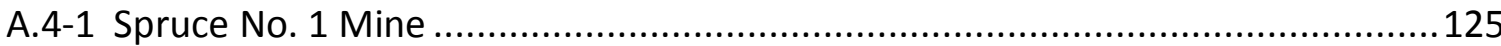

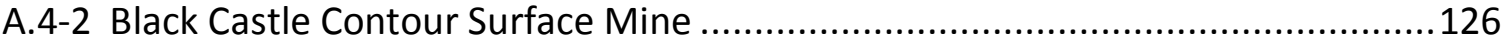

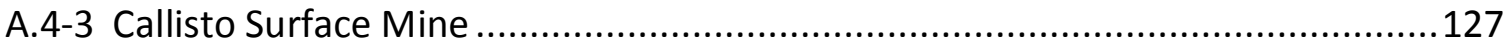

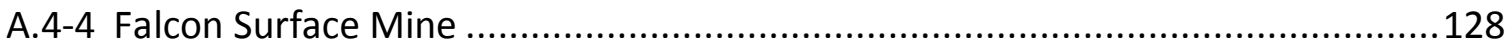

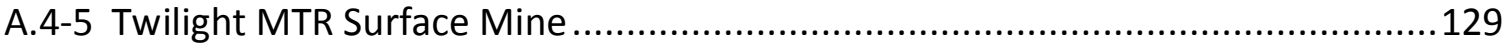

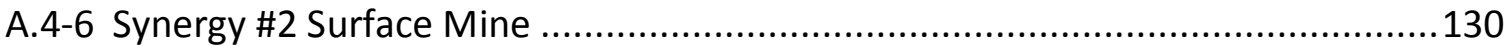

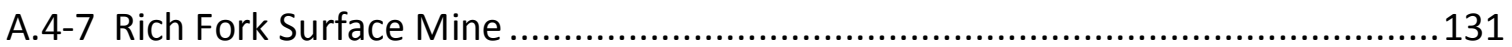

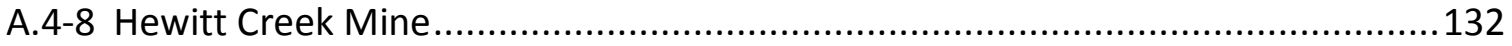

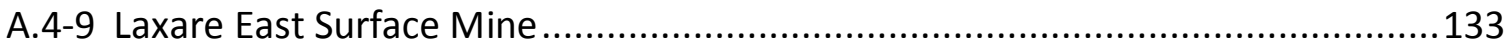

A.4-10 Locust Fork Surface Mine ....................................................................... 134

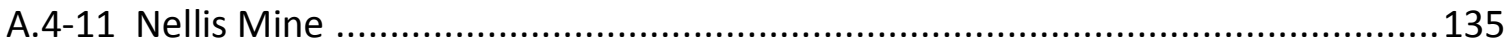

A.4-12 Boone North \#5 Surface Mine ..................................................................... 136

A.4-13 Joes Creek Surface Mine ........................................................................... 137

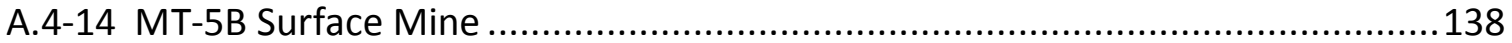

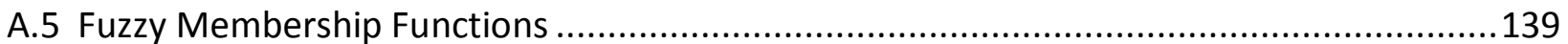

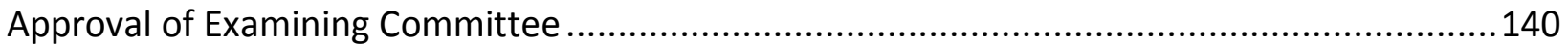




\section{Chapter 1. Introduction}

\section{1 - Problem Statement}

The coal mining technique of mountaintop removal and the resulting valley fills have been shown to adversely impact the health and ecological sustainability of watersheds in the state of West Virginia (Freund and Petty, 2007), (Hartman et al. 2005), (Petty and Thorne, 2005), (Pond et al. 2008), (USEPA, 2000), (USEPA, 2009). Failure to consider the current environmental damage already caused by mountaintop removal mining operations within a watershed as well as the sensitivity of a watershed to additional mining operations can lead to a rapid degradation of that watershed's ecological sustainability. The need exists for more thoughtful consideration of current landscape condition and the impacts of additional mine disturbance on cumulative downstream water quality. This consideration includes the analysis of the landscape condition in terms of all types of current disturbance, as well as the physical characteristics of the landscape that make it more or less sensitive to disturbance.

The complete halting of coal mining in West Virginia is not a viable option based on the economic importance of the industry. Therefore, the location of future mining operations in areas less sensitive to disturbance is an essential element to the sustainability of the coal mining industry in the state to assure approved permits from State Department of Environmental Protection.

This study incorporated a multivariate linear regression to examine the effects of various landscape disturbance variables on down- stream conductivity levels. A linear conductivity model was created and applied to show the current ecological condition of the 
landscape being investigated based on stream conductivity, as well as future disturbance scenarios to show the future effects of proposed mining operations. The scenarios developed in this study could be utilized by state and federal environmental agencies to grant or deny proposed mining operations based on their future effects on landscape health.

\section{2 - Goals and Objectives}

The goal of this study was to spatially and quantitatively map mining and non-mining related disturbance in the Coal River watershed in order to analyze the current ecological condition of the landscape, as well as to predict the environmental effects of future disturbance on the landscape and downstream waterways. By examining the effects of landscape disturbance on stream water quality, disturbance thresholds can be calculated from stream conductivity measurements in various segment level watersheds that contain varying levels of landscape disturbance. These thresholds can indicate how much landscape disturbance can be allowed in a reach level watershed before water quality depreciates past certain conductivity levels or levels necessary to support macro-invertebrate life. This analysis was conducted on the Coal River USGS 8 digit watershed located in the southern coalfields of West Virginia. The

Coal River Watershed contains 24 NRCS 12 digit watersheds and 4,229 segment level watersheds, which are watershed drainage areas delineated for individual stream segments.

\section{3 - Preview of the Study}

Extensive landscape analysis was performed using GIS and spatial analysis techniques in order to examine the current ecological condition and health of the Coal River watershed, as well as its vulnerability to additional mining related disturbance slated to occur within 15 
surface coal mine permit boundaries currently under review by the West Virginia Department of Environmental Protection. In addition, various ecological landscape variables were calculated and summarized in order to determine not only the current condition of the landscape within the Coal River watershed, but also predict what could happen in the future if additional mining was allowed to occur in different parts of the study area.

With the analysis of these different ecological variables and their effects on downstream water quality, decisions can be made regarding acceptable locations and extents for landscape disturbance in the Coal River Watershed. The true question is how much mining can occur in the segment level watersheds before conductivity thresholds are exceeded. Up to what level does incremental mine disturbance no longer make a negative difference to water quality in terms of conductivity and macro-invertebrate species richness? Where should future mining disturbance occur in the Coal River Watershed to prevent the achievement of this critical point of degradation? How does each analyzed landscape characteristic contribute to the decrease in water quality if disturbed? These questions are addressed in the "Current Landscape Condition" and "Application of Multivariate Linear Stream Conductivity Model" sections of this study, where current landscape disturbance is mapped and statistically analyzed to find the effects of mining related disturbance on downstream water quality. The goal of this study is to spatially and quantitatively map mining and non-mining related disturbance in the Coal River watershed in order to analyze the current ecological condition of the landscape, as well as to predict the environmental effects of future disturbance on the landscape and downstream waterways. 


\section{Chapter 2. Literature Review}

\section{1 - Overview}

The benefits of coal mining must be studied from an economic position, the annual net value of coal produced, what the coal is used for, and the jobs that the coal industry provide to the people living in coal mining regions. The negative effects of coal mining must also be studied, such as the environmental impacts of coal mining on the landscape supporting it and public safety concerns for the people living in coal mining areas. Possible solutions must also be examined in terms of the potential for economic and environmental policy to regulate mining related disturbance to allow the sustainability of the industry. These policies should limit disturbance to areas of a landscape able to support the activity, and should also include abatement methods to restore ecosystems that have already been damaged as a result of mining.

\section{2 - Mountain Top Removal: Background and Environmental Impact}

Coal mining has been the backbone of West Virginia's economy since the early 1800's, with records of early settlers in the western sections of Virginia mining coal as early as 1810 near the town of Wheeling in the northern panhandle of the state (West Virginia Office of Miners' Health Safety and Training, 2002). Most of the coal mined in West Virginia for the next 20 years was for local and other domestic industrial consumption, and a small percentage of coal was exported to distant markets by navigable rivers (West Virginia Office of Miners' Health Safety and Training, 2002). The construction of railroads in the coal fields of West Virginia drastically increased the commercial coal industry in the state (West Virginia Office of Miners' 
Health Safety and Training, 2002). Between 1840 and 1860 many coal companies were organized, and corporations were created under the laws of Virginia for the purpose of encouraging financial investments from foreign countries (Eggleston, 1996).

With the outbreak of the Civil War, all mining operations in the Kanawha Valley ceased (Eggleston, 1996). Confederate troops set up camp in the valley, destroying all navigational locks and dams to prevent the transport of coal and other supplies by river (Eggleston, 1996). In the northern part of the state, the Elkins and Fairmont coal fields remained active, providing coal for the Union via the Baltimore and Ohio Railroad. After the Civil War, an awakening of interest in the State's mineral resources brought a new era of development and growth for the coal industry (Eggleston, 1996). By 1880 there were extensive operations in Mineral, Monongalia, Marion, Fayette, Harrison, Ohio, Putnam, and Mason counties. West Virginia's southern coal fields were not opened until about 1870, though they were known to exist much earlier. One of the major southern coal fields was the Flat Top-Pocahontas Field, located primarily in Mercer and McDowell counties (Eggleston, 1996). The Flat Top Field first produced coal in 1883 and grew quickly from that time. Operations were consolidated into large companies, and Pocahontas Fuel Company, organized in 1907, soon dominated the other companies in McDowell County (Eggleston, 1996). With the completion of the major rail lines in 1883 , the coal production in West Virginia totaled nearly 3 million tons in that year alone (West Virginia Office of Miners' Health Safety and Training, 2002).

With this rapid expansion of the coal industry in West Virginia, the first mine safety laws were created by the State Legislature on February 22, 1883. The main priority of these new safety laws was to appoint a mine inspector to review mines for proper drainage and 
ventilation. Further changes to the mining laws were made in 1887 due to pleas by the state Mine Inspector (West Virginia Office of Miners' Health Safety and Training, 2002). This new legislation was passed in 1897 , and the number of inspection districts increased to four, and a new position was also created for a Chief Mine Inspector. From the years 1897 to 1904, coal production in West Virginia increased by almost $125 \%$, and in 1905 , the West Virginia Department of Mines was created to control this rapid expansion of the industry (West Virginia Office of Miners' Health Safety and Training, 2002). Due to the rapid mechanization of the coal extraction process after 1936, underground mining operations increased rapidly (West Virginia Office of Miners' Health Safety and Training, 2002). Surface mining operations at a large scale did not start until 1914. With the development of mechanical shovels and draglines, the process of removing overburden has become much easier, making surface mining the largest method of coal extraction in West Virginia since the early 1970's (Appalachian Voices, 2000).

The West Virginia Department of Mines created in 1905 remained until 1985, at which time it merged with other various state regulatory agencies. The resulting agency was the West Virginia Department of Energy. This newly founded agency later became known as the West Virginia Division of Energy. Further reorganization occurred in 1991 which places the state mine health and safety divisions of the West Virginia Division of Energy into a new agency called the West Virginia Office of Miners' Health Safety and Training. This agency currently employs 109 staff members, including 80 mine safety inspectors, who work out of five regional offices with their headquarters located in the state capitol of Charleston (West Virginia Office of Miners' Health Safety and Training, 2002). 
The method of mountain top removal for the extraction of coal is a relatively new practice in terms of the history of coal mining in Appalachia. This technique was first implemented in the early 1970's as an extension of the previous practice of strip mining in the region (Appalachian Voices, 2000). Mountain top removal has become the main method of coal extraction in West Virginia, Kentucky, Virginia, and Tennessee (Appalachian Voices, 2000). The popularity of this extraction method is due to the fact that it allows for a very complete recovery of coal in a given seam, and at the same time, greatly reducing the number of workers required to extract the coal in comparison to previously used extraction methods (Appalachian Voices, 2000). The process of mountain top removal involves first clear cutting existing forest cover, and then using explosives to remove as much as 600 feet of the mountaintop to remove overburden and expose the coal seam. The waste overburden is then either transported to other areas, but most commonly is deposited into adjacent valleys, often times burying streams. The maximum allowable size for a valley fill set by the EPA is 250 acres (U.S. EPA, 2000).

In 1972, an amendment was introduced to the Federal Water Pollution Control Act (known as the Clean Water Act or CWA) to provide the statutory basis for the NPDES permit program and the basic structure for regulating the discharge of pollutants from point sources to waters of the United States. Section 402 of the Clean Water Act specifically required EPA to develop and implement the NPDES program (U.S. EPA, 2009). The basis of the Clean Water Act was enacted in 1948 and was called the Federal Water Pollution Control Act, but the Act was significantly reorganized and expanded in 1972. "Clean Water Act" became the Act's common name with amendments in 1977. The Clean Water Act made it unlawful to discharge any 
pollutant from a point source into navigable waters, unless a permit was obtained. EPA's National Pollutant Discharge Elimination System (NPDES) permit program was created to control pollutant discharges (U.S. EPA, 2009). Point sources are discrete conveyances such as pipes or man-made ditches. Individual homes that are connected to a municipal system, use a septic system, or do not have a surface discharge do not need an NPDES permit; however, industrial, municipal, and other facilities must obtain permits if their discharges go directly to surface waters (U.S. EPA, 2009).

Mountain top removal mining operations, and the resulting valley fills, have many negative effects on the landscape as well as the local ecosystems (Hartman et al., 2005). Valley fills can greatly alter the dynamic of headwater streams by increasing sedimentation, stream conductivity, and also by altering hydrologic regimes downstream of the valley fill (Hartman et al., 2005). There is suspicion that this increased sedimentation and conductivity can have harmful effects on macro-invertebrate communities downstream of the fills (Hartman et al., 2005). In a study conducted by Hartman et al., (2005), four pairs of streams were selected in southern West Virginia as representatives of watersheds containing valley fill mining operations. The stream pairs were selected due to their similar environmental characteristics and conditions, with only one of the two streams in each pair containing a valley fill in its headwaters.

These streams were sampled for water chemistry and sedimentation levels at various locations. The streams containing valley fills in the headwaters contained notably higher levels of conductance, but surprisingly did not have elevated levels of fine sediment (Hartman et al., 2005). The streams that included fills at the headwaters exhibited increased levels of $\mathrm{Na}, \mathrm{K}, \mathrm{Mn}$, 
$\mathrm{Mg}, \mathrm{Ca}, \mathrm{Ni}$ and $\mathrm{Fe}$ in comparison to their paired streams with no fills in the headwaters (Hartman et al., 2005). These valley fill streams also contained far lower levels of Ephemeroptera, Coleoptera, Odonata, Non-insects, Scrapers, and Shredders than reference streams (Hartman et al., 2005). Upon further investigation, the streams with valley fills in the headwaters experienced an increase in specific conductance and metals downstream of the valley fill. There was not much difference, however, between valley fill streams and non valley fill streams in reference to stream biota (Hartman et al., 2005).

Macroinvertebrate and fish indices are a critical measure of water quality in mined Appalachian watersheds. In a study conducted by Pond et al. (2008), macroinvertebrate communities where characterized from 37 small streams in West Virginia, including 10 streams with no mining activities in their respective watersheds, and 27 streams with valley fills in their respective watersheds. These samples were assessed by using family and genus level taxonomic data (Pond et al., 2008). There were multiple lines of evidence concluding that these valley fills significantly damage the biological condition of the streams in their watersheds, including: a shift in species diversity, a loss of Ephemeroptera taxa, and significant changes in water chemistry. The differences between these streams associated with valley fills in their watersheds and streams not associated with valley fills indicate that the differences in community structure were in fact caused by the mining activities (Pond et al., 2008).

\section{3 - Pollution Source Identification and Treatment}

Chakrabarti et al. (2001) investigated the importance of detecting and properly treating hazardous waste in an efficient and economical manner prior to starting various construction processes. The wide spread dumping of hazardous waste is detrimental to many natural 
resources, such as ground water, surface water, soils, and air (Chakrabarti et al. 2001). The implementation of hazardous waste treatment and disposal facilities (HWTDF's) on a micro scale level is one solution to this problem. The location of these proposed sites is determined by a suitability analysis conducted using remote sensing, constraint mapping, a groundwater pollution potential index, and a site by site pollution severity index. Through this analysis, the HWTDF's can be located to centrally treat multiple contaminated sites, providing a more economical solution than working on a site by site basis, or constructing one single large facility that would not effectively serve all of the effected sites (Chakrabarti et al. 2001).

Freund and Petty (2006) examined the response of fish and macroinvertebrate bioassessment indices to water chemistry in a mined Appalachian watershed using multi-metric indices based on benthic macroinvertebrate and fish populations to specific stressors resulting from mining activity. The responses of both a fish-based index and a benthic invertebrate based index due to acid mine drainage related stressors in 46 stream sites within the Cheat River watershed of West Virginia were examined. It was found that water chemistry varied greatly among the tributaries of the Cheat River, and the benthic invertebrate based index was highly responsive across a wide range of acid mine drainage stressor levels (Freund and Petty, 2006). Additionally, negative impacts to macroinvertebrate communities were observed at low stressor levels compared to West Virginia state water quality standards. Compared to the benthic invertebrate based index, the fish based index was much less responsive to localized water quality conditions. Despite relatively good water quality in some streams, low fish diversity was observed, showing that regional conditions may have more effect on fish populations in this localized study area than water quality degradation due to acid mine 
drainage (Freund and Petty, 2006). This study concluded that bio-monitoring strategies in watersheds where mining related disturbance is present should include both benthic invertebrates as well as fish in order to provide consistent indicators of both local and regional conditions (Freund and Petty, 2006).

Acid mine drainage resulting from underground coal mining is not the only source of chemical pollution to Appalachian watersheds. Acid precipitation resulting from the burning of coal in the process of electricity production is also a major source of pollution (Petty and Thorne, 2005). In a study conducted by Petty and Thorne (2005), a measurement of the functional value of streams in terms of their potential for Brook trout introduction was calculated as a function of the expected Brook trout spawning intensity and juvenile survival rate (Petty and Thorne, 2005). Multiple potential restoration programs were analyzed using an ArcGIS model to determine optimal alternatives to restoring the damaged areas of the watershed (Petty and Thorne, 2005). By estimating the weighted potential recruitment area for each stream segment, restoration priorities and optimal restoration techniques were identified in the upper Shavers Fork watershed in West Virginia. The results of this study showed that the particular watershed being analyzed had lost almost $80 \%$ of its original juvenile recruitment potential due to acid precipitation (Petty and Thorne, 2005). Out of the 145 stream segments that were studied within the watershed, 8 critical stream segments alone composed almost $20 \%$ of the total loss.

Acid mine drainage abatement is very important to the current and future health of watersheds in the Appalachian region and can take place before, during, or after mining has occurred. A study by Funk (1993) focused on post mining water treatment on the watershed 
level determined that looking at abatement on a watershed level, rather than a site by site basis, produces more realistic interactions among water and pollution flows, providing more accurate treatment alternatives (Funk, 1993). Finding a balance between the most effective treatment alternative and the least cost solution for meeting specific water quality standards was accomplished through a cost-minimizing mixed integer programming model. Four possible policy goals were also set with models constructed for each individual policy goal (Funk, 1993). The most cost efficient solution to the treatment of acid mine drainage was determined to be the use of ammonia to treat the entire acid load at one particular site, although it is noted that the treatment could have taken place at any stream node (Funk, 1993). The model chosen was also dependent on the policy goals to be achieved, and in one model treatment was based on a complete treatment of acidity at every stream node in order to restore the entire study area for recreational use (Funk, 1993).

Another study focused on minimizing the cost of acid mine drainage abatement examined the choice of the optimal technology vs. the cost of the optimum technology (Zucker, 1992). This study focused on the Sovern Run watershed in West Virginia as the study area, due to the damage caused to the watershed by acid mine drainage. This watershed drained into various fisheries downstream, and through acid mine drainage treatment, the downstream waterways could be restored to their full potential as a fishery (Zucker, 1992). Based on previous knowledge of acid mine drainage treatment technology, hydrated lime was determined to be the least cost alternative of treatment over the course of a 20 to 30 year treatment horizon. This treatment technique also presents the least amount of downstream ecological risk. The results of this study showed that with the implementation of these 
abatement techniques, the potential net benefits from the restored fisheries far outweighed the annual abatement treatment costs (Zucker, 1992).

When funding for acid mine drainage abatement is limited, watersheds must be selected for abatement based on the severity of the ecological damage present (Strager, 1995). Using a combination of multiple-criterion decision making framework and a compromise programming algorithm, 9 watersheds in West Virginia affected by acid mine drainage were ranked in terms of the order in which they should receive treatment (Strager, 1995). A distance based multiple-criterion decision making framework technique called compromise programming was used in order to create a model to determine which watersheds were more preferred for abatement based on each weight set and evaluation criterion (Strager, 1995). These rankings can also be changed based on an individual organization's preferences toward the ranking criteria (Strager, 1995).

\section{4 - Environmental Impact of Development}

Deng et al. (2009) conducted a study that focused on assessing the damaging effects of rapid urbanized-development on the environment. Urbanization is a constantly increasing trend throughout the world, and it is changing the landscape in many negative aspects (Deng et al., 2009). One of the biggest problems with urbanization is the abuse of natural resources needed to support these ever growing urban areas with no regard for the detrimental changes in the structure of the ecosystems being infringed upon. This damage has sparked the creation of developmental policies that are starting to design and implement guidelines and regulations to create sustainable cities and urban areas (Deng et al., 2009). Landscape metrics can categorize 
hard to interpret landscapes into identifiable patterns and reveal some properties of the ecosystems that could not otherwise be observed (Deng et al., 2009).

After pre-processing images, various hybrid classifications were created to detect urban land use change. Analysis on imagery from two consecutive dates was used to enhance the change information. This composite image was then classified into change and non-change pixels, to better identify the areas that required more attention and analysis. These areas were used to analyze various changes in land use, but the one that was most important to the researchers was the change in land use from agricultural to urban land. In order to ensure that these methods of classification were valid to the research, commonly used methods of postclassification were also conducted (Deng et al., 2009). In this post-classification, two images from different dates are independently classified and labeled. The area where change is detected is then extracted through the direct comparison of classification results. These new composite land use maps were then decomposed even further to pre-date and post-date land use into separate thematic images, which were in turn used to construct a land use conversion matrix (Deng et al., 2009). The results of this study helped to show the vast effects of rapid urbanization in these study areas.

\section{5 - Land Use Suitability Evaluation}

Dengiz, et al. (2003) investigated the importance of accurate land use suitability evaluation to support the world's ever growing population, while also preserving our very fragile natural ecosystems and resources. First conducted manually with paper maps and various methods of cartography, land use evaluation has been conducted for the past few decades, but not to the extent that it needed to be to achieve the level of self sustainability 
needed in our world today (Dengiz et al. 2003). Later on, in the late 1990's, GIS and remote sensing techniques were implemented in Thailand to further analyze these land suitability issues and create comprehensive land use suitability databases, focusing on land use, soil suitability, socio-economic factors, and rainfall. These studies found that agricultural lands were being used in a manner that was not improving socio-economic conditions in the region, but also was not using the land to its potential (Dengiz et al. 2003). The main objectives of this research were to determine land resources and their suitability classes for land use types in the Beypazar region near Ankara. The FAO Framework (1977) for Land Evaluation was applied to the study area $(29,128$ ha) to assess land suitability for four major land use (dry farming, irrigation, forage and forest-Rangeland) groups, using the Denol and Tekeb computer model (Dengiz et al. 2003).

Each land mapping unit, or LMU, was evaluated based on soil and vegetation characteristics. By using characteristics for texture, slope, erosion, stone quantity, depth, organic matter, etc. for each LMU, a digital soil database was created. In the end, 19 different land use types, or LUT's, were created, and the land requirements for each of those land use types were also created. From here, all of the LUT's were automatically spread to corresponding land use groups using the ILSEN computer model (Dengiz et al. , 2003). The final outcome from this state of data processing was the creation of a suitability map for agricultural land use. This suitability map was then incorporated into the soil database for each LMU. These composite maps were used to create a rain-fed agriculture suitability map, and irrigated agriculture suitability map, a forage suitability map, a potential land use suitability map, and a suitability map for agricultural use (Dengiz et al., 2003). 


\section{6 - Landscape Mapping}

The ability to spatially and temporally map the current physical form as well as temporal changes that have occurred within a landscape, various methods of topographic mapping and analysis must be utilized. The creation of accurate and current digital elevation models (DEM's) and digital terrain models (DTM's) are an essential part of landscape analysis and feature mapping. The comparison of multi-temporal terrain comparison can also be used to detect changes that have occurred within a landscape over a specified period of time.

\subsection{1 - Valley Fill Detection}

In order to analyze the effects that mountain top removal and the resulting valley fills have on a watershed, the individual valley fills must first be identified. One way of accomplishing this is with the use of landscape change detection, which is a technique that has become very well known in the remote sensing community (Shank, 2003). Shank experimented with change detection to detect valley fills in the southern coalfields of West Virginia using multi-temporal elevation data sets. This technique has not been widely explored due to the fact that adequate data has been unavailable for sensitive landscape change analysis. The area in which Shank's (2003) study was focused, the southern coalfields of West Virginia, is constantly experiencing major changes to the physical landscape due to mountaintop removal coal mining and adjacent valley fills. The main purpose of Shank's study was to create an accurate inventory of the valley fill locations, using existing datasets (Shank, 2003). Current mining permit maps are incomplete, and there is no way to tell if fills are planned or existing (Shank, 2003). Manual searches of aerial imagery are also inaccurate due to errors of omission. This created the need 
to devise a method of automatically identifying potential valley fills from accurate multitemporal elevation data (Shank, 2003).

Shank (2003) started the analysis with the basic idea that by subtracting the new elevation grid from the old elevation grid, the resulting positive values would indicate filled areas, while negative areas would indicate cut areas. These results are only as accurate as the input datasets. Reclassifying elevation differences under a specified threshold as null values eliminated some of the errors, but left a very crude change map showing only large magnitude changes (Shank, 2003). Calculating a value for this reclassification threshold by summing the error standards for the datasets led to slightly more accurate results, but the output still contained artifact errors. These problems resulted in the creation of 3 metrics to more accurately identify a fill area.

The first metric stated that valley fills should exhibit a relatively large elevation difference variance (Shank, 2003). This is due to the fact that valley fill depths are large at the center of the fill area, and taper off toward the back and sides. The second metric stated that valley fill operations are most often located immediately adjacent to cut operations due to transportation costs of moving overburden. This fact identified the potential to be able to delineate large cuts, and then set a buffer to select the resulting adjacent fill areas. Identifying cut areas would be more accurate then identifying fill areas with the subtraction of elevation grids because the elevation variance is much higher in the center of a cut where the mountaintop has been removed, and then tapers off to the outsides of the cut area (Shank, 2003). The third metric states that a valley fill should have a single drainage point located at the toe of the fill area (Shank, 2003). This means that the entire fill area should be mostly contained 
within a watershed calculated upstream from the drainage point (Shank, 2003). This drainage point can be identified by a point of high flow accumulation, which in turn can be used to delineate a watershed. This method will only work on completed valley fills, as a partially completed valley fill will not exhibit all of these characteristics. The variance metric proved to be the most effective, resulting in this metric receiving a potential weight score twice as large as the other two metrics. The other two metrics were effective in identifying small partially completed valley fills that were not necessarily identified by the variance metric, and were still used in the overall biased combined scores to reduce the number of errors of omission (Shank, 2003). Out of the 161 identified potential fills, 119 were concluded to be the result of mining, 28 showed no evidence of disturbance, 5 were decided to be fills unrelated to mining, and the remaining 9 could not be identified (Shank, 2003).

\subsection{2 - Bird Community Index}

There are many different indicators of landscape health present in any study area, but one of the most important indicators of biotic integrity is based on songbird community composition (O'Connell, 1998). Created by the Penn State Cooperative Wetlands Center, the Bird Community Index $(\mathrm{BCl})$ was prepared for the United States Environmental Protection Agency's Environmental Monitoring and Assessment Program (EMAP) to facilitate assessments of ecological condition and varying scales (O'Connell, 1998). The creation of the $\mathrm{BCl}$ is one of the first attempts to create and apply ecological condition indicators at a regional scale. The $\mathrm{BCl}$ is composed of multiple biological metrics, and ranks bird communities at sample locations with the proportional representation of 16 behavioral and physiological response criteria. Proportions of "specialist" and "generalist" communities, viewed as indicators of structural, 
functional, and compositional ecosystem elements, determine landscape condition ( $\mathrm{O}^{\prime}$ Connell, 1998). Due to the fact that songbirds are present throughout a wide variety of habitat types, the $\mathrm{BCl}$ is intended to integrate ecological conditions across a large physiographic region exhibiting diverse land-cover attributes and intensities of human use (O'Connell, 1998).

The final $\mathrm{BCl}$ score for a study area is the sum of three sub-scores based on individual guild ranks:

- $\quad V 1=$ the sum of the functional guild ranks.

- $\quad \mathrm{V} 2=$ the sum of the compositional guild ranks.

- $\quad \mathrm{V} 3=$ the sum of the structural guild ranks.

The sites exhibiting the highest $\mathrm{BCl}$ scores indicate the highest integrity bird communities. Due to the fact that the overall $\mathrm{BCl}$ contains information from the three sub-scores, rankings of functional, compositional, and structural integrity among study areas with different overall $\mathrm{BCl}$ scores are comparable (O'Connell, 1998).

The National Environmental Policy Act (NEPA) requires federal agencies to integrate environmental values into their decision making processes by considering the environmental impacts of their proposed actions and reasonable alternatives to those actions. To meet NEPA requirements federal agencies prepare a detailed statement known as an Environmental Impact Statement (EIS). EPA reviews and comments on EISs prepared by other federal agencies, maintains a national filing system for all EISs, and assures that its own actions comply with NEPA (U.S. EPA, 2009). 


\section{7 - Environmental and Economic Policy Analysis}

In order to better understand the shortfalls or advantages to U.S. policy and regulatory frameworks, the frameworks of other nations can be investigated in like industries. By understanding the problems that have been faced, resolved, or are still plaguing other countries and their mineral resource industries, the U.S. mining industry can be better analyzed and diagnosed, resulting in a more comprehensive and clearly defined policy and regulatory framework. It is easy to say that the best solution to the negative environmental externalities that result from mineral extraction can be solved by ceasing mining operations all together, but that is very unrealistic. Mineral extraction is an inevitable industry throughout the world, and the need will constantly increase as the population continues to grow, increasing our need for natural resources. It is not a matter of if mining will occur, but rather when and where, and what can be done to minimize the environmental impacts.

\subsection{1 - Value of National Mining Policy}

The creation and enforcement of a national mining policy greatly enhance the future of a mineral extraction industry. The mining industry in Ireland is a good example of how a properly structured policy and regulatory framework can help ensure the sustainability of a mineral extraction industry, while at the same time, maintaining efficiency in production. Large scale mining investment in Ireland first took place in 1961, and due to large advances in mineral extraction technology, coupled with a crude permit process, the average time between mineral deposit discovery and production was about 3 years (Dooley and Leddin, 2005). By 1997, this time span between discovery and production increased to 11 years, mostly due to environmental debates and an unclearly defined regulatory framework (Dooley and Leddin, 
2005). Due to these long delays, there has been a drastic decrease in the rate of discovery in new deposits, which has resulted in currently permitted mine sites being over-mined with decreasing rates of return (Dooley and Leddin, 2005). The implementation of a clearly defined and comprehensive policy and regulatory framework would greatly increase the overall efficiency and competitiveness of the Irish mineral extraction industry.

The approach taken by the Irish mining industry to display the need for a national mining policy document, according to Dooley and Leddin (2005), was to first identify the advantages and disadvantages to such a document being created, as well as identify inefficiencies in the current regulatory framework. One of the advantages to the creation of this document would be the increase in mining operations in Ireland, which in turn, would create more mining jobs. The West Virginia Coal Industry provides about 30,000 direct jobs in WV, including miners, mine contractors, coal preparation plant employees and mine supply companies (West Virginia Office of Miners' Health Safety and Training, 2002). Taxes paid by the coal industry and by utility companies that make electricity using West Virginia coal account for two-thirds, or over $60 \%$ of business taxes paid in the state of West Virginia. Not only does the coal industry pay approximately $\$ 70$ million in property taxes annually, but the Coal Severance Tax adds approximately \$214 million into West Virginia's economy each year. Out of the Coal Severance Tax revenue collected each year, approximately $\$ 24$ million of that tax revenue goes directly into the Infrastructure Bond Fund, which is distributed to all 55 counties in the state of West Virginia (West Virginia Office of Miners' Health Safety and Training, 2002). The West Virginia coal industry payroll is approximately $\$ 2$ billion per year, and the coal is responsible for 
greater than $\$ 3.5$ billion per year in gross state product (West Virginia Office of Miners' Health Safety and Training, 2002).

Based on the issues raised by Dooley and Leddin (2005), mineral policies and the promotion of mining activities remain at a level that is not beneficial to Ireland. The authors claim that a greater effort put forth by the Irish government would greatly enhance Ireland's attractiveness to mineral investment. A faster and more efficient permitting process, along with a more clearly defined regulatory framework, would also increase Ireland's appeal to investors. Although no mining policy can replace the value of large mineral deposits, it can affect the risk/reward ratio for investors. Dooley and Leddin (2005) point out that the creation and implementation of a national mining policy document could greatly increase mineral production efficiency, as well as increase a country's international competitiveness in the mineral industry. This document must meet a balance of the needs of both the mining industry and the environmentalists in order to be an overall success, which is nearly impossible to accomplish according to the authors.

Mtegha, Cawood, and Minnit (2006) believe that in order to create a national mineral policy that accommodates the views and interests of varying groups that allows for a wide acceptance of decisions, the stakeholders that will be affected by the policy must be involved in the policy creation process. The main advantage of this strategy, according to the authors, is that it creates localized policy instruments, as well as an implementation of mineral policy with which stakeholders can identify. This type of process presents a new challenge to traditional policy creation strategies in developing economies, but allows for the potential realization of national objectives. Traditionally, governments have mineral policies that were developed with 
the goal of attracting outside investment (Mtegha, Cawood, and Minnit 2006). This leads to a public perception that the profits from mineral production only benefit the government or private companies, while the local people have to deal with the negative externalities, such as environmental damage. Mtegha, Cawood, and Minnit (2006) explain how developing a minerals policy in South Africa proved to be a challenging endeavor due to the historical private ownership of mineral rights and the apartheid system, which denied the majority of black people the opportunity to engage in economic activities.

Full participation of stakeholders accounts for several factors in policy creation and implementation. These factors include the concept of sustainable development, environmental movements, international financial institutions' requirements, human rights, indigenous peoples' organizations and local communities, and information technologies (Mtegha, Cawood, Minnitt, 2006). Local communities are often ignored in terms of governance, and state employees often will not admit or consider that they are less knowledgeable then local populations who are more in touch with their own natural resources (Taylor, 1998). Desired results are not often obtained by using state of the art solutions because local communities were not included in the decision making processes. Policy creation and implementation is very different in developing countries than in developed countries, mainly due to the fact that developing countries contain fewer natural resources than developed countries (Taylor, 1998). South Africa's national minerals policy, for example, is the outcome of a compromise on key mineral development issues (Mtegha, Cawood, Minnitt, 2006). 


\subsection{2 - Interaction Between Environmental Regulation and Trade}

The interaction between environmental regulation and trade is a very crucial factor in the creation of regulatory and policy frameworks (Marconi, 2009). Classical models have mainly examined the impact of environmental regulation on comparative advantage (Copeland and Taylor, 2003). Richer countries, which tend to have higher demands for environmental quality, also tend to impose more stringent environmental policies in order to minimize pollution (Mtegha, Cawood, and Minnit, 2006). The development of environmental policy models has mainly taken place in closed economy frameworks where pollution is treated as either a complimentary input (Ricci, 2007) or as a production externality (Peretto, 2008). The main objective of Marconi's study is to add more information into the current debate on the effectiveness of policy actions to minimize pollution in isolation in a non-cooperative globalized world.

A general equilibrium model of trade, pollution, and technological changes was used by Marconi. The theoretical study area was broken into two regions, North and South, both producing differentiated sets of polluting consumption goods. The North is assumed to be the richer region with environmental concerns and wishing to minimize pollution, and the South is the poorer region with much less environmental concern. In order to minimize pollution, the North imposes a unilateral tax on domestic production, thereby imposing an added cost on domestic firms, which in turn would reduce their international competitiveness. According to Marconi, this tradeoff can be eliminated by considering pollution as a by-product of consumption, and by imposing a unilateral green tax on consumption. By shifting the burden of this tax to domestic consumers who are consuming these polluting goods, world consumption 
(and production in the long run) of these polluting goods would be reduced unless technological change compensates. By shifting the focus from pollution as a by-product of production to pollution as a by-product of consumption, a unilateral green tax on consumption could overcome competitiveness and carbon leakage problems, and result in a rise in welfare and reduction in pollution worldwide as explained by the results of Marconi's analysis. This is due to the fact that a green tax on consumption affects both import and domestic prices in the same way. For this green tax to be effective, the market must be large and wealthy enough to offer the right incentives to invest in new technologies that will cause pollution reduction (Marconi, 2009).

\subsection{3 - Temporal Relevance of Policy and Regulation}

Mineral extraction regulations and policies must be kept up to date to keep up with the evolving environmental concerns and regulations worldwide. The Chinese government is in the process of revising their mineral resource laws with the intention of forming a base for the growth and continued development of China's small scale mining industry (Shen, Dai, and Gunson, 2009). Shen, Dai, and Gunson (2009) explain that the small scale mining sector in China implements very rudimentary extraction techniques with little regulation and a lack of long term planning or control. There are many negative externalities resulting from these small scale mining operations, such as environmental damage, personal safety issues, inefficient mineral extraction, negative health and social impacts on local communities, and the spread of illegal mining. Shen, Dai, and Gunson (2009) point out that as a result of these externalities, China has undertaken two large-scale legislative efforts on mineral resources since the mid-1980s. The first involved the creation of the Mineral Resources Law in 1986, with implementation rules 
appearing in 1994. The second was a major revision to the 1986 Mineral Resources Law in 1996, and a package of regulations was issued in 1998. For the first time in its history China had a systematic set of rules concerning mineral exploration and production rights, and the transfer of these rights (Shen, Dai, Gunson, 2009).

Over the last two decades, some additional regulations have been introduced, as shown in Shen, Dai, and Gunson (2009). A comparatively integrated legal system has been established, including the laws, administrative regulations, departmental rules, and local regulations and rules. At the local level, the local people's congress and their standing committees across China, with the exception of Shanghai, have gradually set up their own local regulations. Fujian, Hubei and Guangdong provinces have also stipulated their own regulations on quarries (Shen, Dai, and Gunson, 2009). In addition to legal developments, the management and allocation of mineral resources significantly changed and legal administration was greatly enhanced, according to the authors. Although they explain that some problems still exist with the current mineral resource law. There are still unclearly defined legal boundaries for the small scale mining sector. Based on suggestions from various Chinese government departments, organizations, and experts, the authors discuss how a new mining law revision will be amended to the 1996 Mineral Resources Law. The main purpose of the new amendment is to "improve the mining by enhancing mineral resource management, implementing a methodical sciencebased mining strategy, improving the Chinese mining investment environment, and realizing more sustainable development in mining" (Shen, Dai, and Gunson, 2009, pg. 154). 


\subsection{4 - Environmental Regulation}

Mountain top removal mining and valley fill operations are permitted by state and federal surface mining and environmental protection agencies. Individual mine permits are regulated under the Surface Mining Control and Reclamation Act (SMCRA) by the Office of Surface Mining (OSM) and by delegated States under OSM oversight (U.S. EPA, 2009). Additionally, several specific sections of the Clean Water Act apply. These specific sections are implemented by the EPA, the U.S. Army Corps of Engineers (USACE) and individual states authorized to implement portions of the Clean Water Act. Two Clean Water Act permits are relevant to mountain top removal mining and valley fill operations. The USACE issues a permit related to Section 404 of the Clean Water Act (33 U.S.C. § 1344) for the discharge of dredged and/or fill material. This permit includes the valley fill itself and the fill necessary to create a sediment pond below the valley fill (U.S. EPA, 2009). The second permit is issued by either the EPA or an authorized state agency related to Section 402 of the Clean Water Act (33 U.S.C. § 1342). The Section 402 program is also known as the National Pollutant Discharge Elimination System (NPDES). The NPDES permit includes the discharge from the sediment pond and any storm water associated with the mining activity (U.S. EPA, 2009).

Both permitting programs prohibit activities or discharges that cause or contribute to violations of numeric or narrative state water quality criteria (U.S. EPA, 2009). While numeric criteria protect a water body from the effects of specific environmental hazards, narrative criteria protect a water body from the effects of pollutants that are not easily measured, or for pollutants that do not yet have numeric criteria, such as chemical mixtures, or suspended and bedded sediments (U.S. EPA, 2009). In the state of West Virginia, one narrative standard that is 
particularly relevant to evaluating mountain top removal mining and valley fill impacts is that "No significant adverse impact to the chemical, physical, hydraulic, or biological components of aquatic ecosystems shall be allowed (WV § 47-2-3)". "Adversely affect" or "adversely change" means to alter or change the community structure or function, to reduce the number or proportion of sensitive species, or to increase the number or proportion of pollution tolerant aquatic species so that aquatic life use support or aquatic habitat is impaired (401 KAR 10:001, Section 1(5)) (U.S. EPA, 2009). The watershed approach has made it relevant to examine permits not only at the local level but cumulatively throughout the watershed. The need exists to examine watersheds cumulatively and integrate both landscape and policy analysis to aid in evaluating prospective permits.

The Surface Mining Control and Reclamation Act of 1977 (SMCRA) is the primary federal law that regulates the environmental effects of coal mining in the United States. This act was enacted due to concern about the environmental effects of strip mining (Green, 1997). SMCRA spawned the creation of two different programs: one for regulating active coal mines and another for regulating the reclamation of abandoned mine lands. As a result of SMCRA, the Office of Surface Mining was created to enforce regulations, as well as to fund state regulatory and reclamation efforts (Green, 1997). The regulatory program of SMCRA contains five major components: Standards of Performance, Permitting, Bonding, Inspection and Enforcement, and Land Restrictions. The reclamation program of SMCRA created an Abandoned Mine Land (AML) fund for the cleanup of mine lands abandoned before 1977. The law was amended in 1990 to allow for funds to be utilized to reclaim mines abandoned after 1977 . The fund is financed by a 
tax of 31.5 cents per ton for surface mined coal, 15 cents per ton for coal mined underground, and 10 cents per ton for lignite (Green, 1997). 


\section{Chapter 3. Methodology}

\section{1 - Overview}

This section provides a discussion of the general procedure for creating, analyzing, and interpreting the spatial data within the Coal River Watershed. This study incorporated true color and color infrared imagery from 2007 and 2009 at a 1:10,000 scale (1 meter nominal pixel resolution) to classify the Coal River Watershed landscape in response to disturbance from mining, forestry, and construction. In addition, the quantity of disturbance that has occurred within each permitted mine site was calculated, as well as the forested areas that were important for water quality. With the mapped landscape features, additional ecological indicators could be calculated. For example, a bird community index to determine areas that provided neo-tropical bird habitat was incorporated, as well as specific habitat for the Louisianna Waterthrush. The numbers of headwater watersheds were counted, as well as their potential environmental impact from mining. Surface water zones of critical concern were delineated, and ecological landforms were mapped. Each of these landscape features were also analyzed as to their gain or loss from 15 mine permit areas that are currently being held in review by the West Virginia EPA. These specific types of analysis were chosen to represent the landscape vulnerability of the Coal River watershed due to their indicative nature of current landscape health, as well as effects on the sustainability of the watershed if these areas are disturbed or destroyed. The following sections describe these components of the analysis and provide graphic and tabular results, which were executed in order to evaluate both the current condition of the landscape within the Coal River watershed, as well as the potential loss of each 
of the before mentioned ecological landscape variables due to the disturbance of the landscape within the 15 mine permits under review.

\section{2 - Study Area}

The study area for this analysis is the Coal River watershed located in the southern coalfields of West Virginia (figure 3.2.1). The Coal River watershed is a USGS 8 digit watershed, which contains 24 NRCS 12 digit watersheds and 4,229 segment level watersheds of mapped streams at 1:24,000 scale. The Coal River watershed comprises $640,463.18$ Acres of land in southern West Virginia, and includes many past and active mountain top removal surface mining operations. The Coal River watershed is part of the mountain top removal (MTR) region of West Virginia (figure 3.2.2).

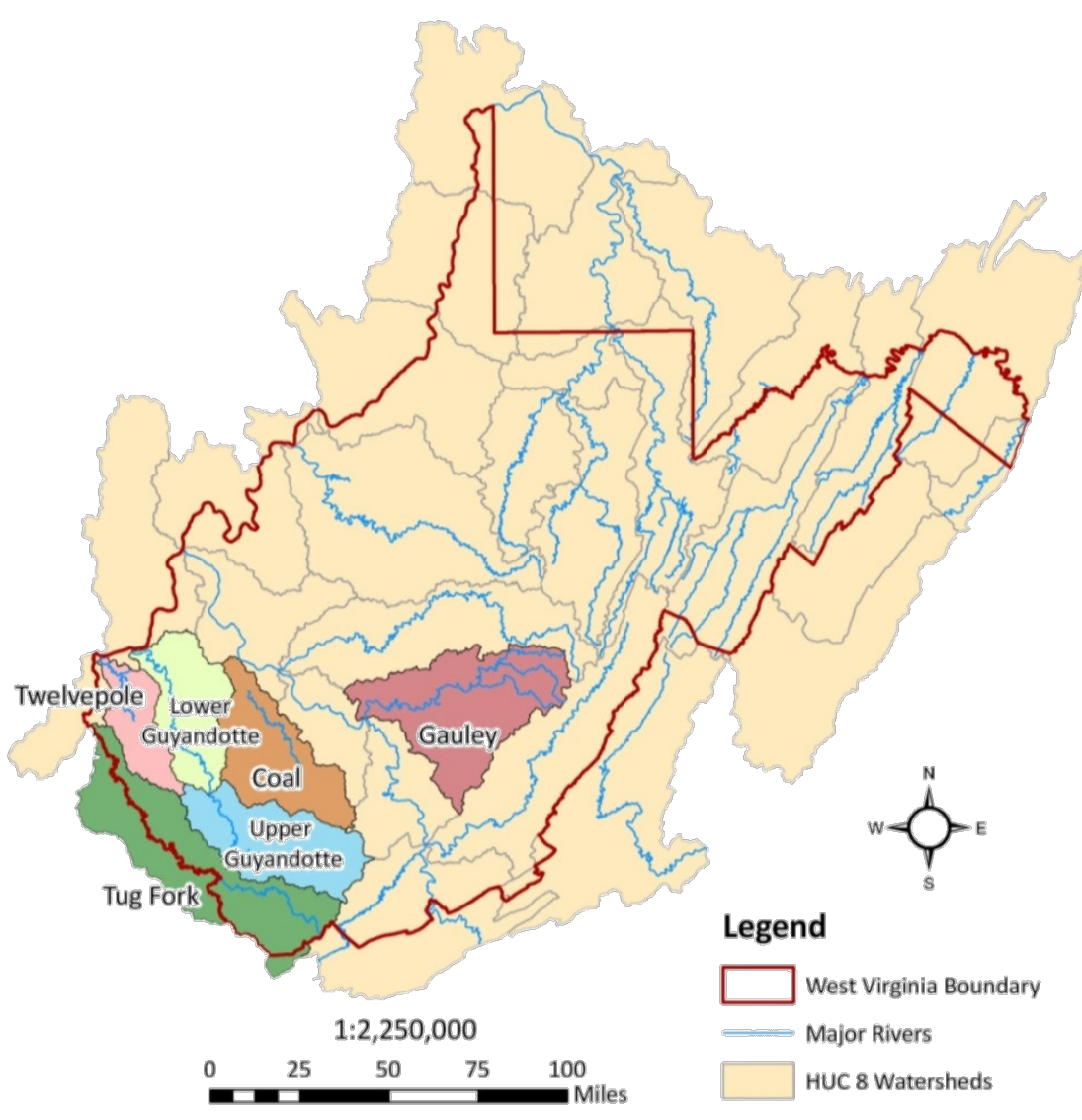

Figure 3.2.1 : 10 Digit Watersheds in Southern Coalfield of West Virginia 


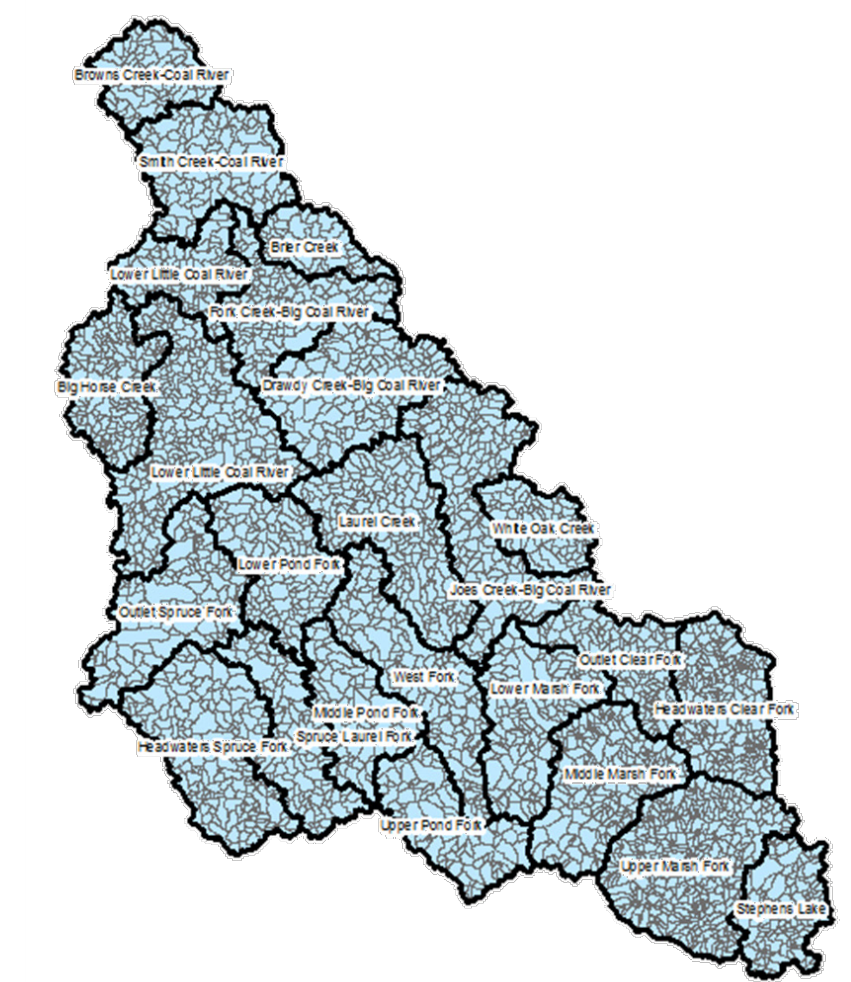

Figure 3.2.2 : 12 Digit Watersheds in Coal River 10 Digit Watershed

\section{3 - Data Collection}

All of the data generated in this study was generated or collected using ArcGIS (ESRI, 2010), the Feature Analyst extension for Erdas Imagine, and JMP statistical software. This study utilized many various geo-processing operations as well as detailed spatial analysis techniques in order to generate a comprehensive landscape analysis dataset for the Coal River watershed. This data was then used to analyze the current and possible future condition of the Coal River watershed based on current and possible future levels of landscape disturbance due to surface coal mining. 


\subsection{1 - Forest Cover}

Forest cover for the Coal River Watershed was created using the Feature Analyst extension for ERDAS Imagine (Overwatch, 2009), as well as through manual digitizing and editing. Two sets of imagery were used for the creation of this layer. The first set was color infrared imagery collected by the USDA's National Agriculture Imagery Program (NAIP) for the entire state of West Virginia. This imagery was collected in late summer, 2007, and was originally published in February of 2008 by the Aerial Photography Field Office of the Farm Service Agency, which is part of the U.S. Department of Agriculture. It was made available from the West Virginia GIS Tech Center in April of 2008. All data was delivered with 1-meter Ground Sample Distance (GSD). The imagery is rectified to a horizontal accuracy of within +/- 5 meters of reference digital ortho quarter quads from the National Digital Ortho Program. The second set of imagery used for the classification came from the National Agriculture Imagery Program (NAIP), which acquires aerial imagery during the agricultural growing seasons in the continental U.S. The primary goal of the NAIP program is to make digital ortho photography available to governmental agencies and the public within a year of acquisition. This imagery was collected in 2009 , and was originally published in October of 2009. It was made available from the West Virginia GIS Tech Center in January of 2010. All data was collected with 1-meter Ground Sample Distance (GSD). The imagery was rectified to a horizontal accuracy of within +/- 5 meters of reference digital ortho quarter quads from the National Digital Ortho Program. The scale of both sets of imagery is $1: 10,000$.

The Feature Analyst extension for ERDAS Imagine requires training data sets to extract desired spectral responses in the imagery. The program finds all areas with the same range of 
spectral response as the training data. The training data sets were created on the $2007 \mathrm{CIR}$ imagery due to the nature of the CIR Imagery and the definitive difference in spectral response between vegetation and bare earth. Both standard-color and color-infrared films are manufactured to have three distinct layers, and each layer is sensitive to different wavelengths (GeoMart, 2011). Standard-color film records the visible wavelengths as red, green, and blue. Color pictures result when the human eye views the varying combinations of the three color layers. Color-infrared film has a yellow filter on top of the three layers to block ultraviolet (UV) and blue wavelengths. The near-infrared wavelengths and the lack of UV and blue wavelengths result in a clear, crisp color-infrared image. Green, healthy vegetation has a high reflection level of near-infrared wavelengths and appears red on the processed image; red objects with very low near-infrared reflection appear green; green objects with very low near-infrared reflection appear blue; and blue objects with very low near-infrared reflection appear black (GeoMart, 2011). The feature extraction was run on this same 2007 CIR imagery, and the resulting raster grid was broken up into two classes, forest and non-forest. From there, the raster grid was converted to a shapefile in ARC Map, and it was overlaid with the 2009 NAIP imagery for the detection of changes in forest cover and disturbance in the two years between the acquisition of the two sets of imagery. From the forested areas, Fragstats was used to create core and fragmented forested areas throughout the Coal River Watershed (Figure 3.3.1). 


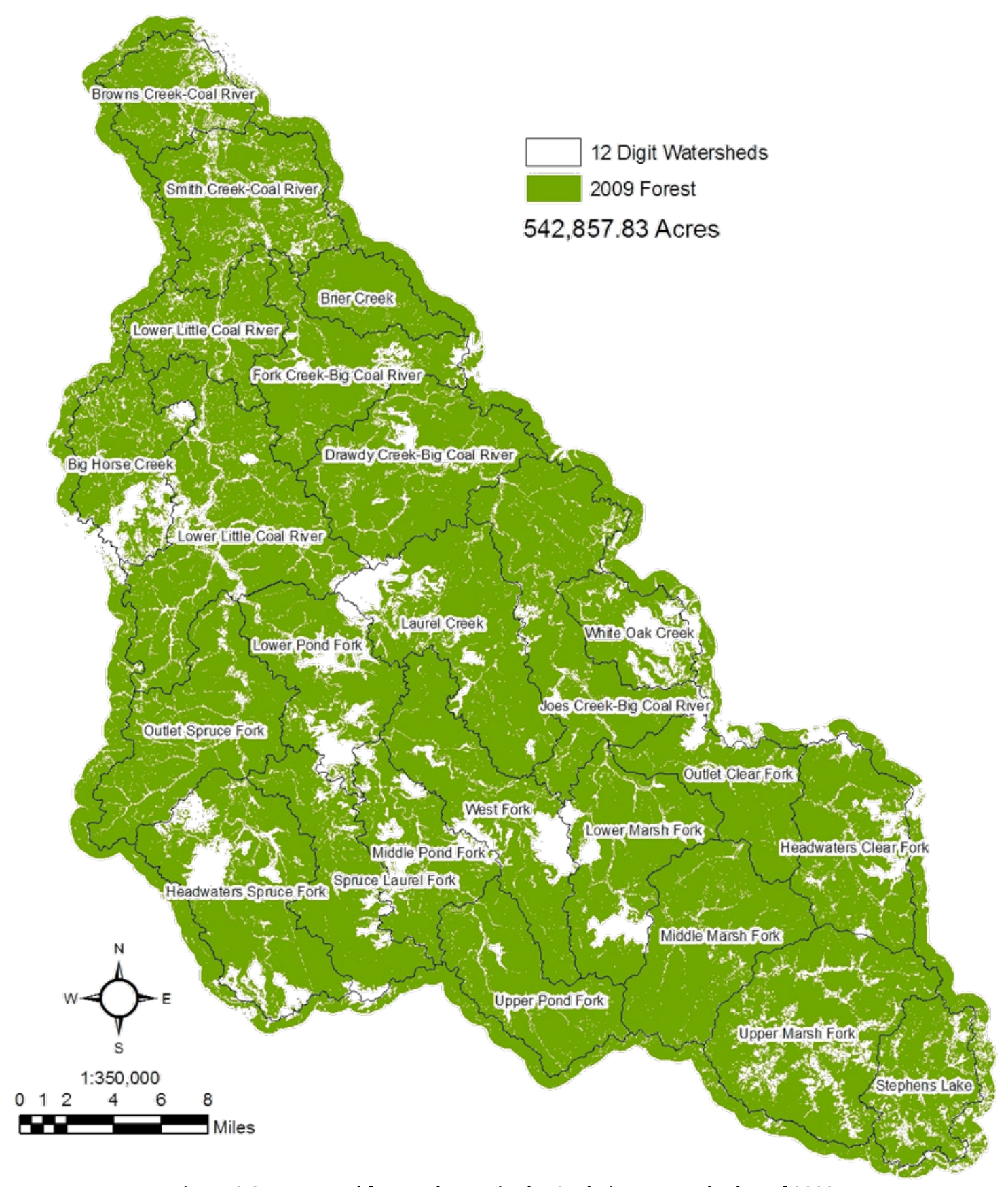

Figure 3.3.1: Mapped forested areas in the Coal River watershed as of 2009

\subsection{2 - Mapping Disturbed Areas}

The non-forested areas became the potential areas for mapping disturbance.

Disturbance is defined as any bare rock and soil area that was not the result of residential or commercial development. The landscape was classified as being disturbed from mining, 
forestry, or highway construction activity. The main area of concern was the mapping of disturbance within the permitted mining areas in the Coal River Watershed. The most recent surface mine permit boundary shapefile from June 2010 was acquired from the WVDEP Division of Mining and Reclamation Data, and was then overlaid on the disturbance map. Using both the 2007 CIR and 2009 NAIP imagery, change detection was conducted manually in and around all of the mining permit boundaries, as well as throughout the non-permitted areas of the Coal River Watershed. Permitted areas were then manually broken down into 3 classes: disturbed, un-disturbed, and reclaimed. This was accomplished through heads-up manual digitizing of each surface mining permit boundary. The use of this multi-temporal data allowed for the identification of new disturbance and new reclamation throughout the Coal River Watershed, and the result was a landscape disturbance map for the entire Coal River Watershed. This disturbance map for the Coal River Watershed is comprised of 7 classifications (figure 3.3.2):

- Disturbed in a Permit Boundary

- Undisturbed in a Permit Boundary

- Reclaimed in a Permit Boundary

- Mining Outside of a Permit Boundary

- Reclaimed Outside of a Permit Boundary

- Forestry Outside of a Permit Boundary

- Construction Outside of a Permit Boundary 


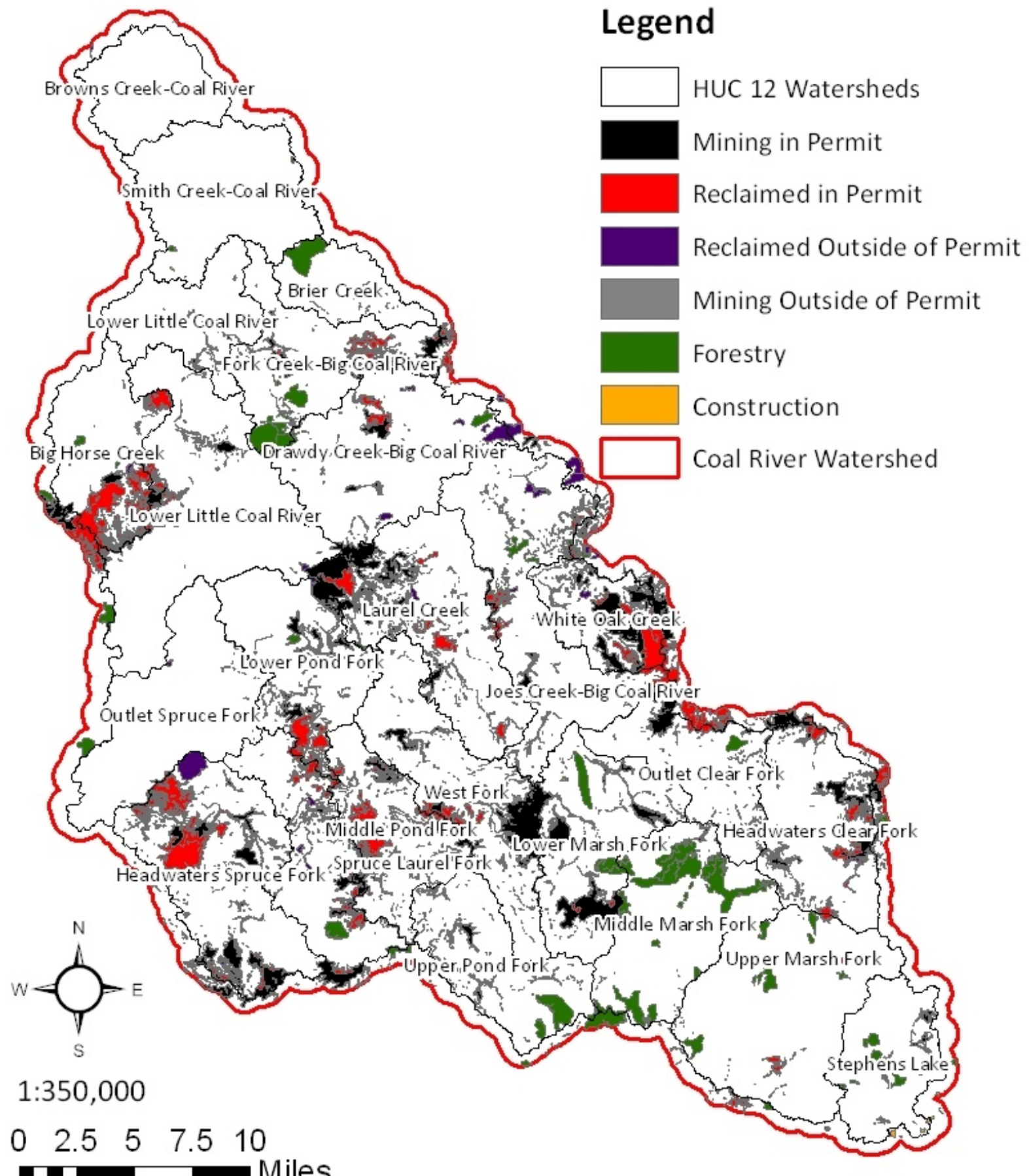

Figure3.3.2: Disturbed areas within the Coal River Watershed

\subsection{3 - Slopes Over 25 Degrees}

Slopes over 25 degrees were mapped for the Coal River Watershed (figure 3.3.3). These slopes are critical to water quality due to the fact that if vegetation is disturbed on slopes over 
25 degrees, a large volume of sedimentation runoff will travel into down-slope waterways. This map was created using the USGS 3-meter DEM from 2003 at a scale of 1:4,800. The DEM consisted of an array of elevations for ground positions at regularly spaced 3-meter intervals. It

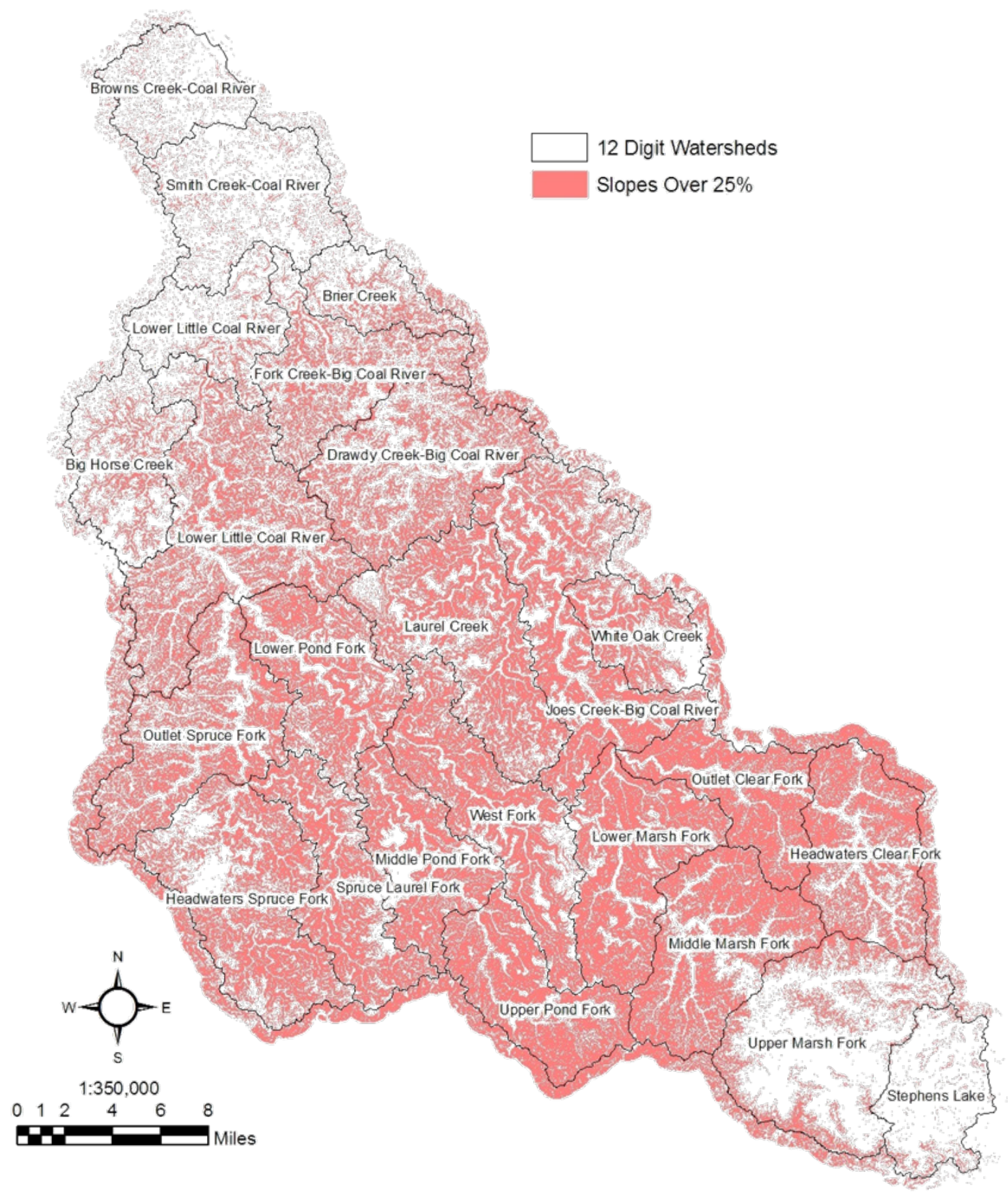

Figure 3.3.3: Slopes over 25 degrees in the Coal River Watershed 
was created from mass points and breaklines collected as part of the Statewide Addressing and Mapping Board's mission. This DEM has been mosaicked by 8-digit watershed boundaries, as defined by the Federal Standard for Delineation of Hydrologic Unit Boundaries.

\subsection{4 - Forested Areas over 25 Degree Slope}

This map depicts the combination of the forested areas and the areas over 25 degree

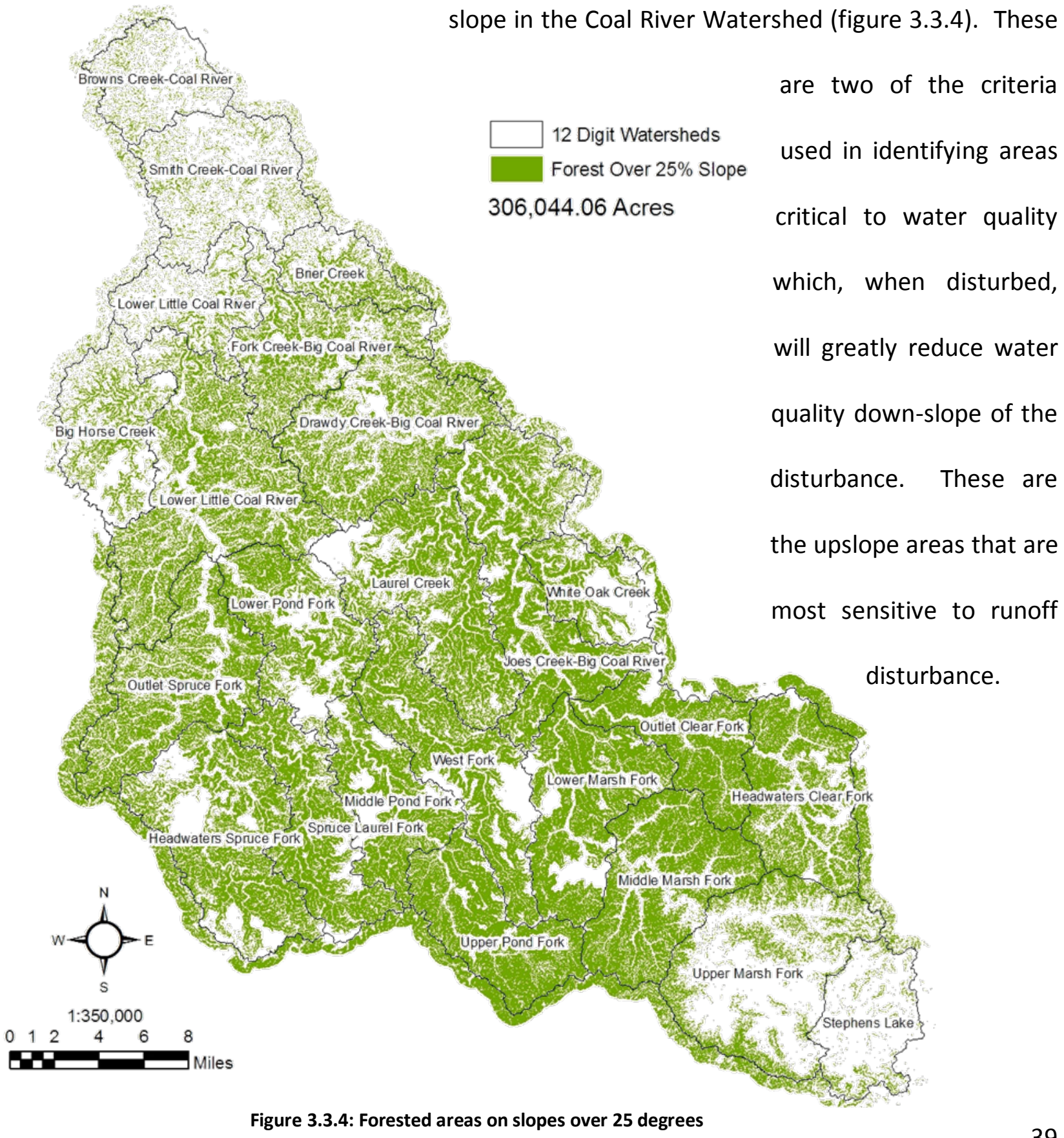




\subsection{5 - Headwater Forested Watersheds}

Headwater forested watersheds are those watersheds that are completely forested in the Coal River Watershed. These areas are a component to identifying forested areas critical to water quality. This map was created by finding all of the headwater segment level watersheds

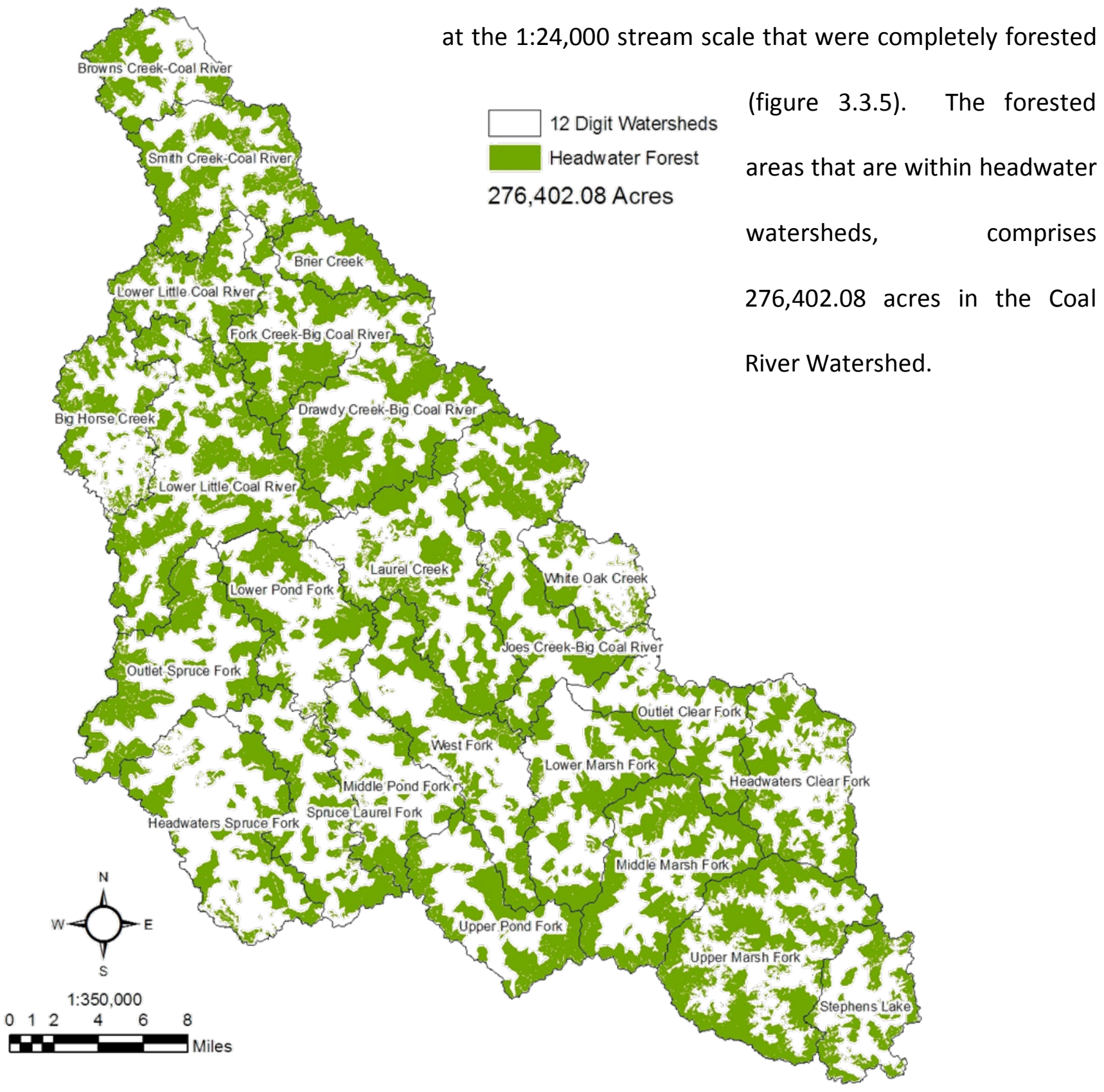

Figure 3.3.5: Location of headwater forested watersheds 


\subsection{6 - Forested Riparian Areas}

This map depicts all of the forested areas that are within riparian areas in the Coal River

Watershed. Riparian areas are defined in this analysis as all areas that are within 100 meters of

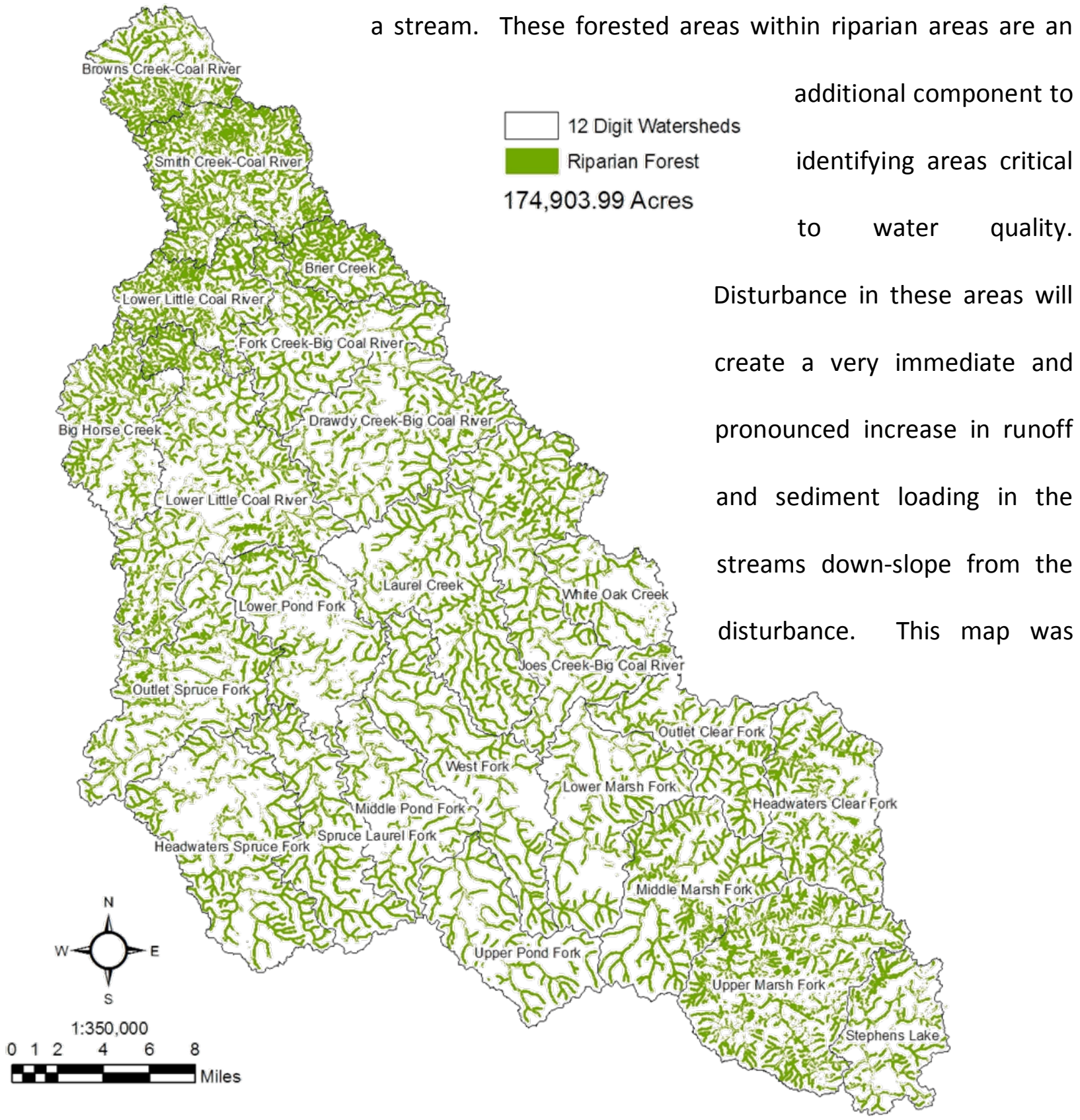

Figure 3.3.6: Forested riparian areas

created by first mapping all of the $1: 4,800$ scale streams from the SAMB hydro layer and then buffering them by a distance of 100 meters. This riparian area shapefile was then used to clip 
the forest cover shapefile, resulting in an area depicting all of the forested areas within riparian areas in the Coal River Watershed (figure 3.3.6). This total is $174,903.99$ acres of the watershed.

\subsection{7 - Forested Areas Critical to Water Quality}

This map depicts all of the forested areas critical to water quality in the

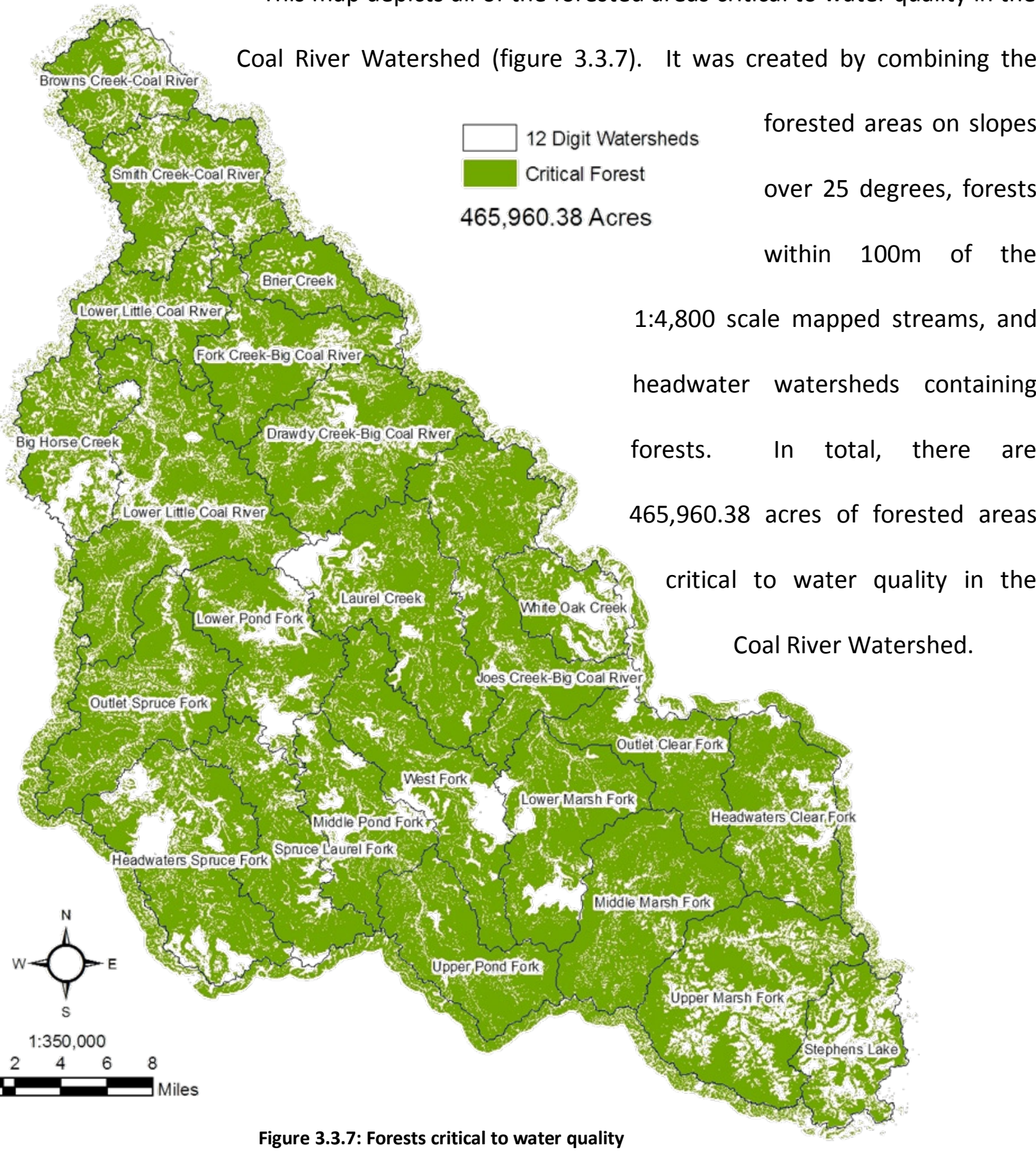




\subsection{8 - Mining Related Disturbance Inside Permits Under Review}

This map was created in order to give a visual representation of how much disturbance has already occurred within the permit boundaries currently being reviewed by the EPA. It was created by merging disturbed and reclaimed land cover classes within a permit boundary shapefiles together to create a shapefile of the overall mining related disturbance. The output was then clipped using the permit boundaries under review, and the resulting shapefile shows all of the areas of mining related disturbance that are within the permit boundaries. The new shapefile was then intersected with the permits under review to calculate a summary for each

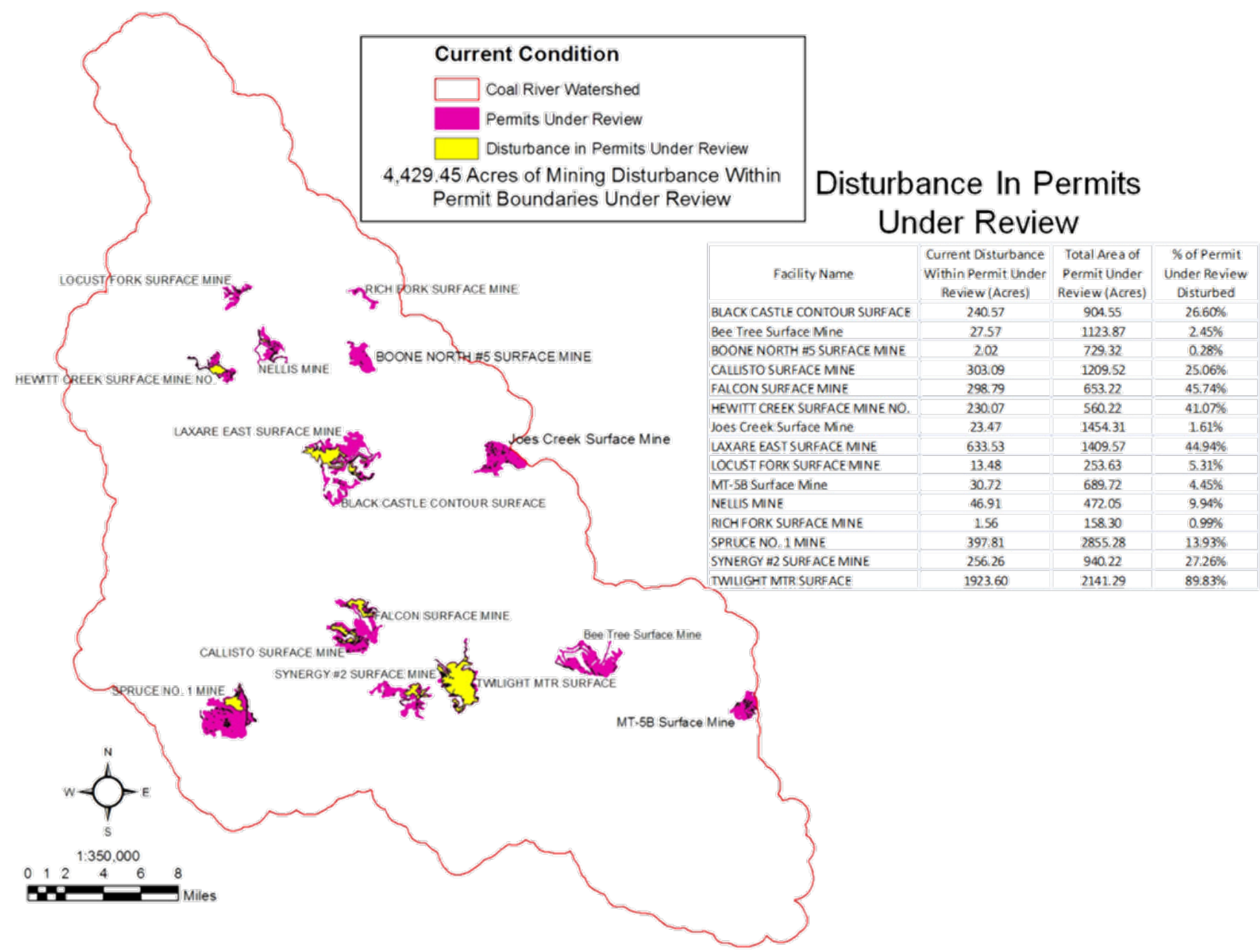

Figure 3.3.8: Mining related disturbance inside permits under review 
permit boundary. The resulting table depicts the total area of mining related disturbance that currently exists within each permit under review, the total area of each permit under review, and the percentage of each permit under review that is currently disturbed (figure 3.3.8). In total, there is currently $4,429.45$ acres of mining disturbance within the permit boundaries under review by the EPA in the Coal River Watershed.

\subsection{9 - Forests Critical to Water Quality Within Surface Mining Permits Under Review}

Forests critical to water quality that are within the surface mining permits currently under review by the EPA in the Coal River Watershed were determined by clipping the forests critical to water quality shapefile created earlier with the permits under review shapefile. The resulting shapefile contained all of the forests critical to water quality that fell within the surface mining permits under review. This result was then intersected with the permits under review in order to summarize an area sum for the forests critical to water quality to each permit under review. The forests critical to water quality were then summarized in each permit boundary under review into the 3 criteria that comprised the forests critical to water quality: riparian forests, headwater forests, and forests over 25 degree slope. Each of these 3 layers were independently clipped with the permits under review, and intersected back to the permits under review to obtain summaries of the area sums for each layer (figure 3.3.9). In total, there are 9,639.21 acres of forest critical to water quality in the Coal River Watershed, which will all be lost assuming a $100 \%$ mine build-out within each permit boundary under review. The proposed scenario of a $100 \%$ mine build-out within each proposed permit boundary is used as a conservative worst case scenario. By using a scenario this conservative, a consistent and 
unbiased comparison can be made between all of the proposed surface mine permit boundaries under review in regard to the impact of additional surface mining.

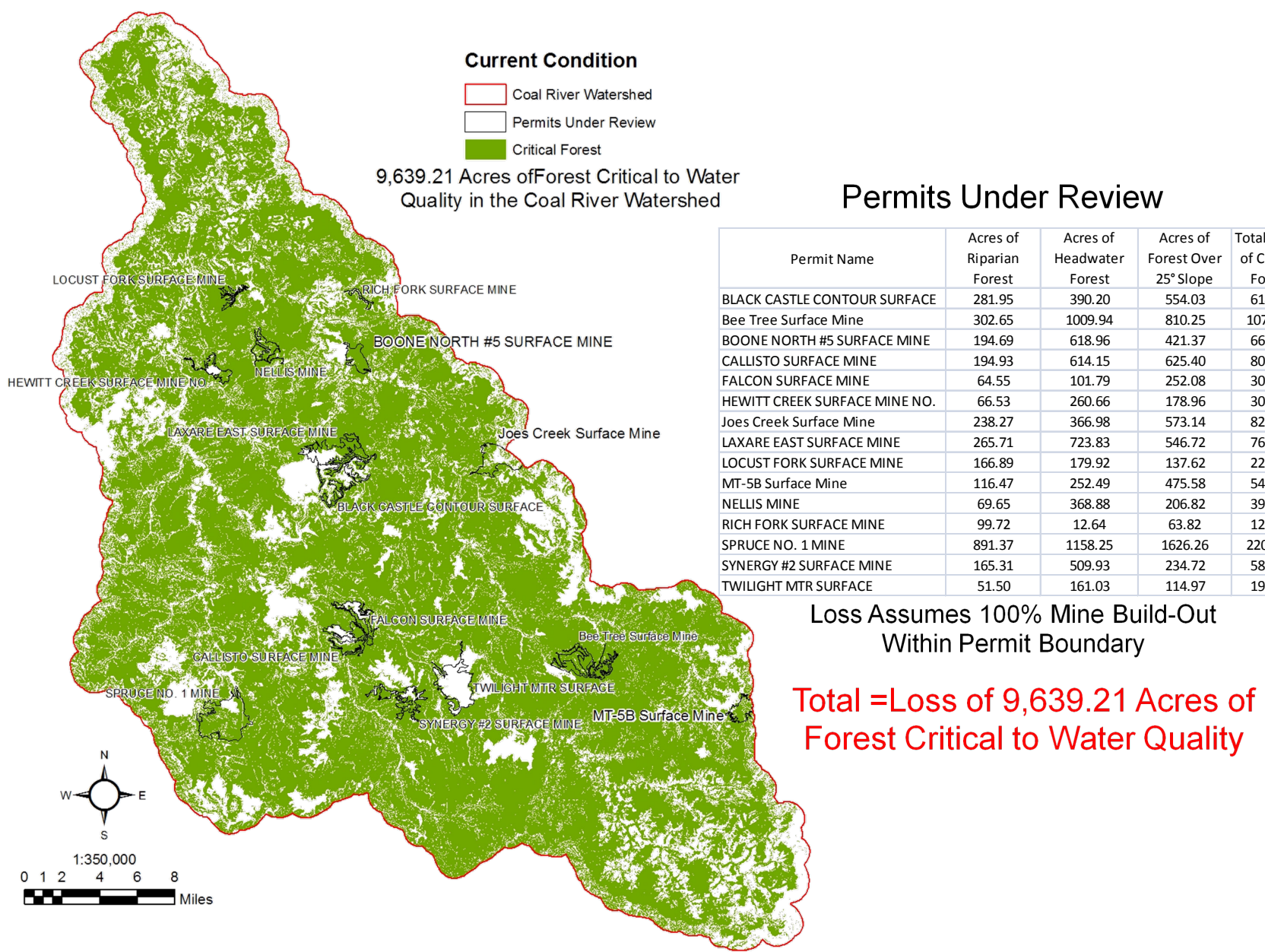

Figure 3.3.9: Forests critical to water quality within the surface mine permits under review

\subsubsection{0 - Mining Related Disturbance Outside of Mining Permit Boundaries}

This map depicts areas of mining related disturbance that were discovered in the manual heads-up digitizing process that are immediately adjacent to a mining permit boundary, but are not contained within the actual permit boundary. These areas were obvious extensions 
of current mining operations taking place at current permit boundaries that extended out past the extents of the permit boundaries. There is a total of 500.7 acres of mining related disturbance outside of permit boundaries in the Coal River Watershed. A table was then created showing the area in acres of each area of disturbance outside of a permit boundary, as well as the Permit ID of the permit immediately adjacent to the area of disturbance outside of the permit boundary (figure 3.3.10).

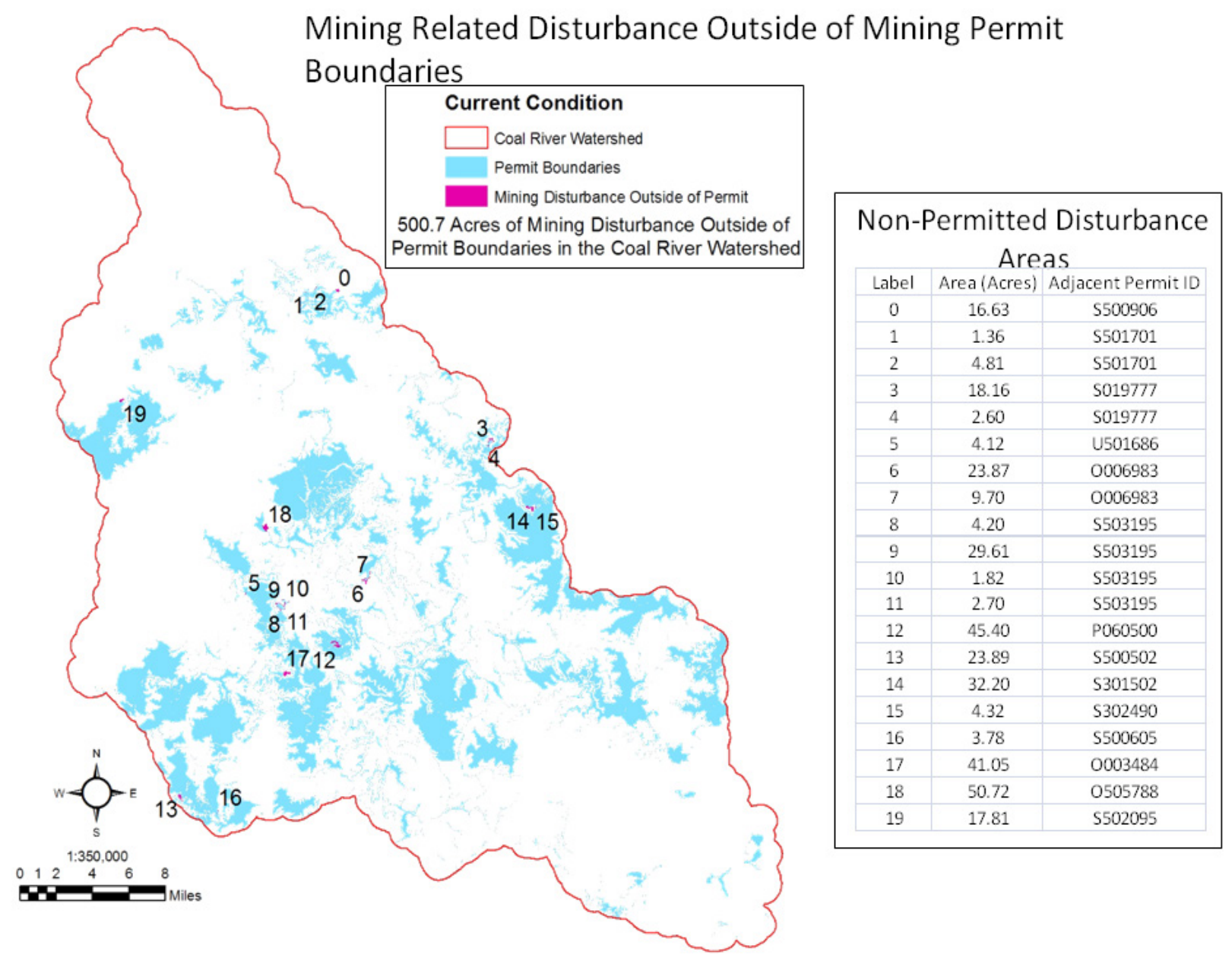

Figure 3.3.10: Mining related disturbance outside of the mine permit boundaries 


\subsubsection{1 - Headwater Watersheds Affected by Surface Mining}

The number of headwater watersheds affected by surface mining in the Coal River Watershed was created by first adding the shapefile of all the headwater watersheds within the Coal River Watershed. Headwater watersheds were delineated based on 1:24K hydrology NHD flowlines. A network table linking each stream segment was also assigned to the watershed boundaries to track the connectivity from one segment level watershed to the next throughout the basin. Using derived methods by Strager et al. (2009), segment level watersheds were identified that were the start of a network link. These were the headwater catchments or areas in which only flow started. It should be noted that all headwater watersheds were delineated based on both perennial and intermittent mapped lines from the 1:24K NHD. These headwater watersheds were then narrowed down to those that are currently affected by surface mining activities in the Coal River Watershed. This was accomplished by using the select by location command in ARC Map and selecting all of the surface mining permit boundaries that intersected a headwater watershed. The next step was to identify all of the permit boundaries under review that will affect head water watersheds in the Coal River Watershed. The resulting headwater watersheds that are affected by the permits under review were then intersected with the permits under review in order to obtain a numerical count for how many headwater watersheds are affected by each permit under review (figure 3.3.14). There were a total of 1135 headwater watersheds affected by surface mining in the Coal River Watershed, and a total of 130 out of those 1135 headwater watersheds are affected by mining in all of the permits under review. This total number of headwater watersheds affected by the mining permits under review assumes a 100\% mine build-out within each permit boundary under 
review.

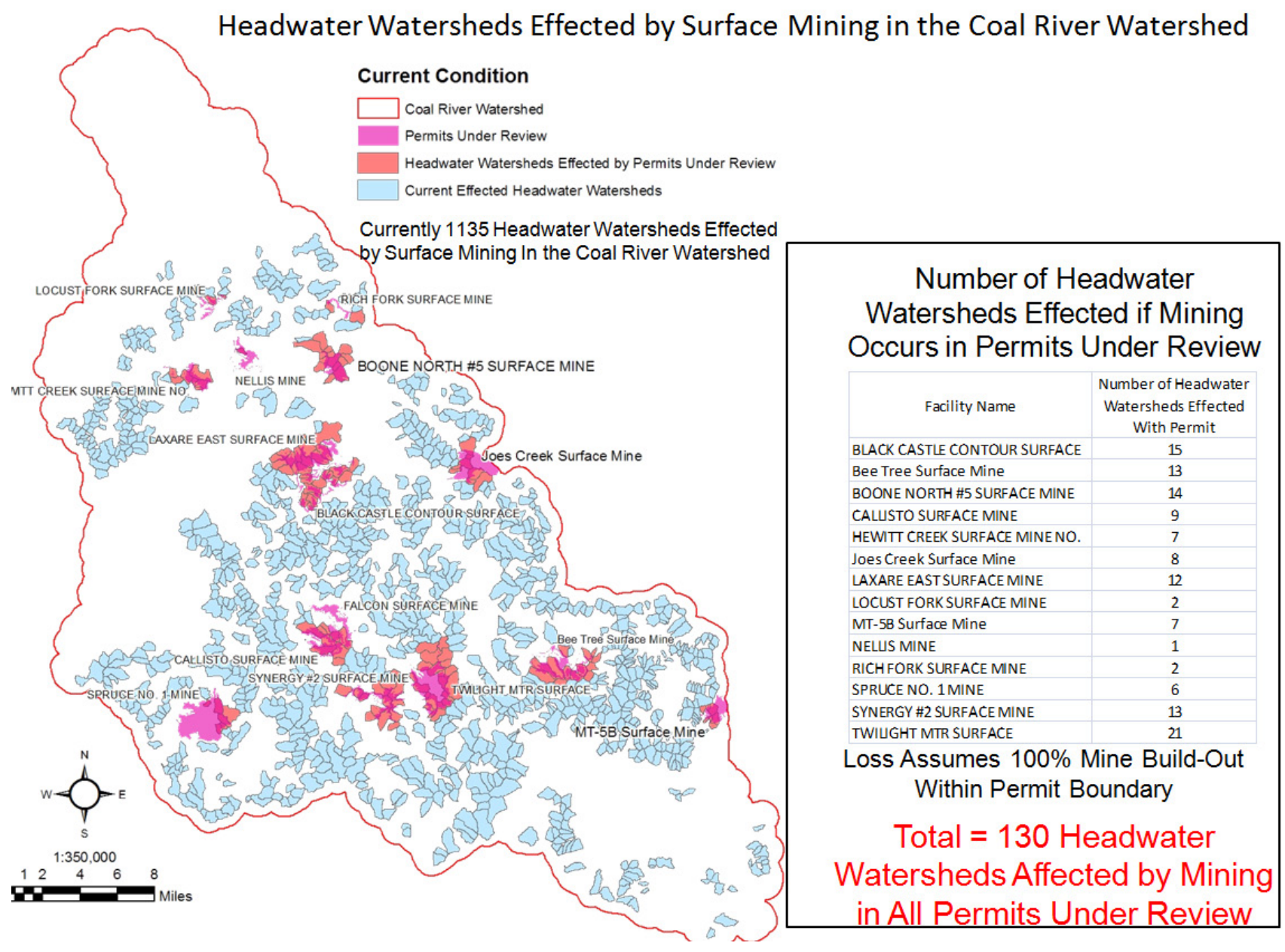

Figure 3.3.11: Impacts of mines in review to headwater watersheds 


\subsubsection{2 - Ecological Land Units}

Classifying the landscape into ecological land units (ELUs) is a means of describing the ecological communities that will be influence by changes to the landscape (TNC, 1997). TNC has developed a method that predicts the general location and extent of a particular ecological community by taking the underlying abiotic ecological features and factors in the coarse land cover data and existing community distribution information to predict the potential extent of a particular community type. ELUs were calculated to explore what landforms would be influence by surface mining and how changing landforms will influence ecological communities. ELUs help to partition the terrain into units of analysis that can be related to vegetation and species habitat preferences.

ELUs were calculated for the Coal River Watershed in a GIS environment using $3 \mathrm{~m}$ spatial resolution digital elevation models (DEMs) produced photogrammatically from 2003 imagery collected by the Statewide Addressing and Mapping Board (SAMB) in West Virginia. The landscape was classified into the following landforms:

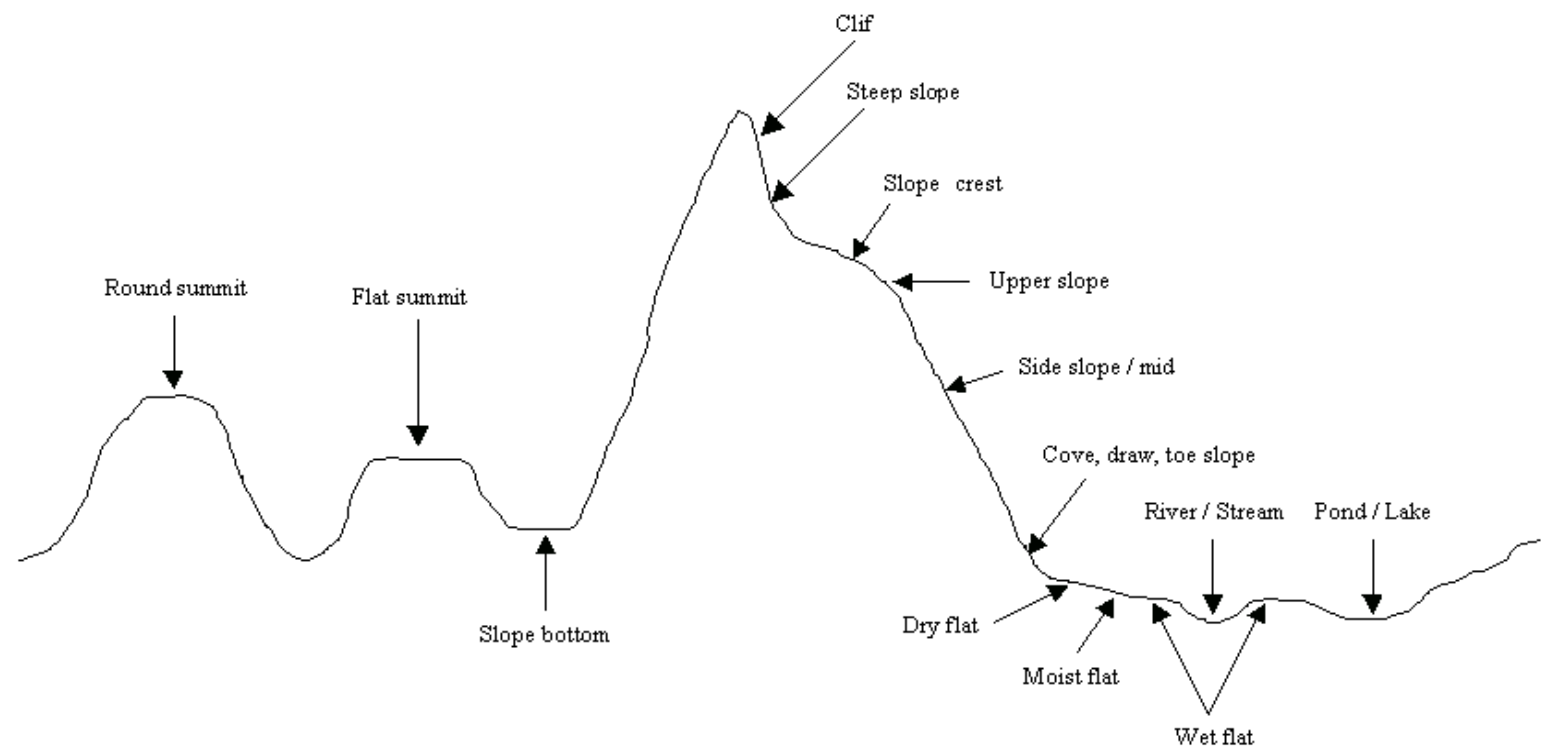

Figure 3.3.12: Ecological land unit definition 
Data was summarized for each of the permits under review (see appendix). The follow surface mines were summarized:

1. Spruce \#1

2. Black Castle Contour Surface

3. Bee Tree Surface Mine

4. Callisto Surface Mine

5. Falcon Surface Mine

6. Hewitt Creek Mine No.

7. Laxare East Surface Mine

8. Locust Fork Surface Mine

9. Nellis Mine

10. Rich Fork Surface Mine

11. Synergy No. 2 Mine

12. Twilight MTR Surface

13. Joes Creek Surface Mine

14. MT-5B Surface Mine

15. Boone North X5 Surface Mine

The tables provide summaries of the following data:

Size: The acreage of the mine

Current Disturbance: Amount of acreage currently disturbed in the mine permit Current \% Disturbance: Percentage of acreage currently disturbed in the mine permit Area of Riparian Forest: Acreage of riparian forest present in mine permit Area of Headwater Forest: Acreage of headwater forest present in mine permit Area of Forest Over $25^{\circ}$ Slope: Acreage of forest over $25^{\circ}$ slope in mine permit Total Acres of Critical Forest: Acreage of critical forest in mine permit Potential Surface water Impact: Describes whether or not a surface water body exists in mine permit

Bird Habitats: Percentage and acreage of bird habitat loss if mining were to take place throughout the entire spatial extent of the mine

Louisiana Waterthrush Habitat Loss: Percentage and acreage of Louisiana Waterthrush Habitat Loss in mine permit if mining were to take place throughout the entire spatial extent of the mine

Headwater Watersheds Affected: Number of headwater watershed that intersect the mine permit area

Landforms: acreage and percentage of ecological landforms in mine permit area

These charts provide a summary of research findings for comparison (See appendix for tables and figures). 


\subsubsection{3 - Stream Conductivity Sampling}

In order to examine the effects of various landscape characteristics on the health and condition of the landscape itself, an indicator or response variable must be used to show the negative effects of differing amounts of these landscape characteristics. The response variable used in this study is stream conductivity, which is water's ability to conduct an electrical current

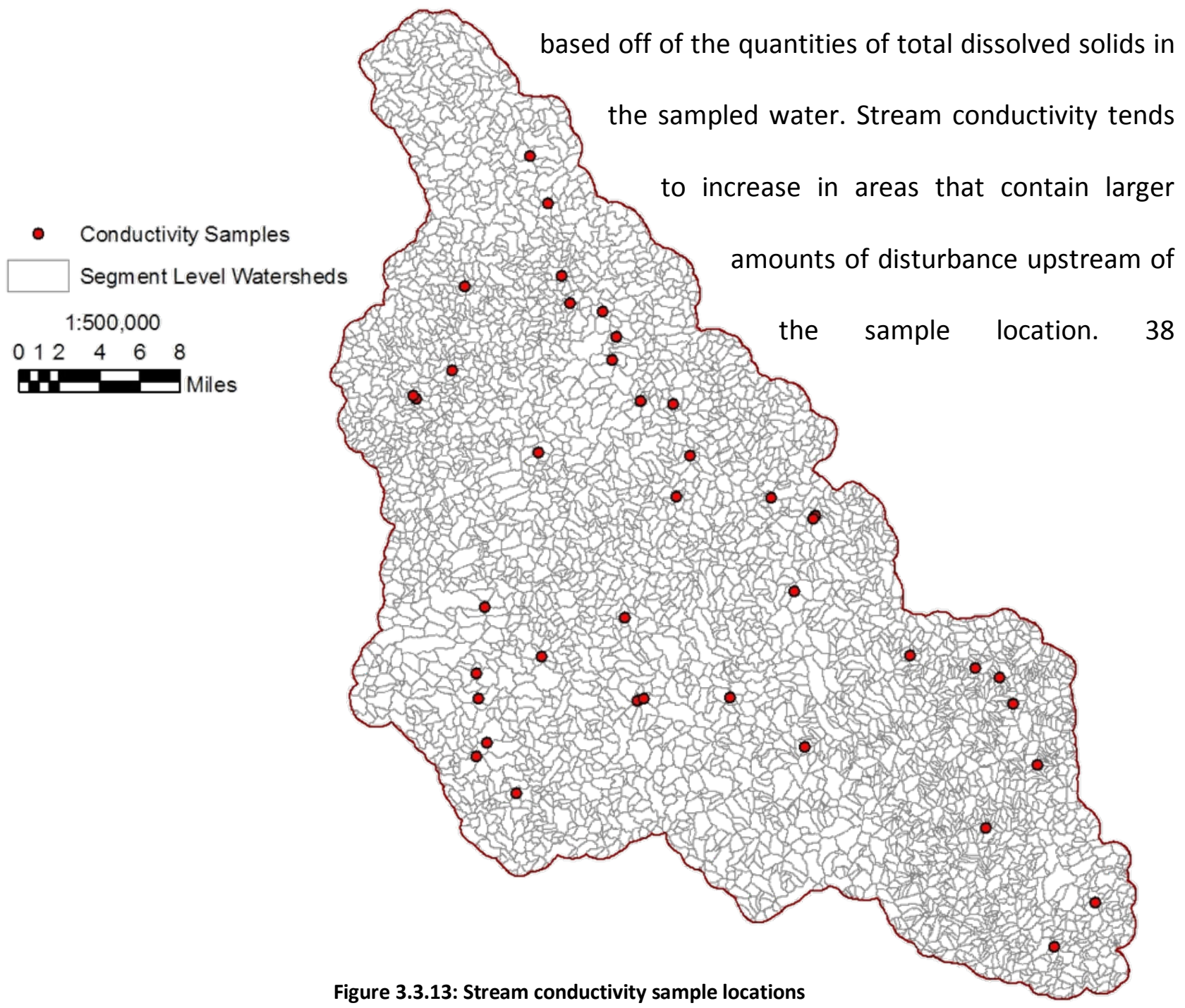

segment-level watersheds were selected as study sites within the Coal River watershed across a range of influence from residential development and mining (figure 3.3.16). Eleven sites made up a distinct residential gradient (structure density: 5-76 structures/km2) and had $<2 \%$ total 
surface mining (Merriam, 2011). Eleven sites were part of a mining gradient (total surface mining: 7 to $64 \%$ ) and a structure density $<2$ structures/km2 (figure 3.3 .16 ). Two sites were included as reference sites because they had minimal mining and development $(<2 \%$ surface mining and $<2$ structures/ $\mathrm{km} 2$, respectively) (figure 5.6). These sites represented the best possible conditions within the study area and served to anchor each gradient (Merriam, 2011). The remaining 14 sites, referred to as combined sites, were affected by a combination of residential development and coal mining (figure 5.6). Drainage areas ranged from 1-36 km2, with similar averages among mined, developed, and combined sites $(12.5,12.9$, and $11.3 \mathrm{~km} 2$, respectively) (Merriam, 2011). All sites were selected to be independent of one another and not linked by flow.

Water samples were taken during the summer of 2010 (August 9-27). Instantaneous measures of temperature $\left({ }^{\circ} \mathrm{C}\right), \mathrm{pH}$, specific conductance $(\mu \mathrm{S} / \mathrm{cm})$, and dissolved $\mathrm{O} 2(\mathrm{mg} / \mathrm{L})$ were obtained with a YSI 650 equipped with a 600XL sonde (Yellow Springs Instruments, Yellow Springs, Ohio). Average current velocity $(\mathrm{m} / \mathrm{s})$ was measured at each site with a digital MarshMcBirney flow meter (Marsh-McBirney Inc., Frederick, Maryland). Two 250-mL filtered samples were collected using a Nalgene filtration unit (mixed cellulose ester membrane filter, $0.45-\mu \mathrm{m}$ pore size). The first was fixed with nitric acid to a $\mathrm{pH}<2$ and analyzed for $\mathrm{Al}, \mathrm{Ca}, \mathrm{Fe}, \mathrm{Mg}, \mathrm{Mn}, \mathrm{Na}$, $\mathrm{Zn}$, and $\mathrm{K}$ (EPA method E200.7), and $\mathrm{Ba}, \mathrm{Cd}, \mathrm{Cr}$, Ni, and Se (EPA method E200.8; mg/L) (Merriam, 2011). The second was fixed with sulfuric acid to a $\mathrm{pH}<2$ and analyzed for NO3 and NO2 (EPA method SM4110B), and total P (EPA method SM4500-P BE; mg/L). A 500-mL unfiltered grab sample was also taken at each site for analysis of total and bicarbonate alkalinity (EPA method SM2320 B; mg/L CaCO3 equivalents), $\mathrm{Cl}$ and SO4 (EPA method E300.0), 
and TDS (EPA method SM2540; mg/L). Samples were stored at $4^{\circ} \mathrm{C}$ until all analyses were completed at Research Environmental \& Industrial Consultants, Inc., Beaver, WV. For quality assurance purposes, the YSI was calibrated prior to each sampling date. DO and $\mathrm{pH}$ probes were checked every 4 hours and at the end of each day. Probes were recalibrated when readings fell outside of acceptable ranges defined by YSI. Duplicate YSI readings and water samples were obtained at $10 \%(n=4)$ of all sites. One field blank was obtained on each sampling date. Instantaneous measures of temperature, $\mathrm{pH}$, specific conductance, and dissolved $\mathrm{O} 2$ were also obtained from 34 sites throughout the Coal River watershed including small tributaries and larger main-stems (drainage areas 3-2292 km2). These sites were used for model validation and extrapolation assessments (Merriam, 2011).

\section{4 - Landscape Feature Mapping}

In order to analyze the impact of landscape disturbance on downstream water quality, the landscape must first be classified in its present state as either disturbed (mining/forestry related) or undisturbed (forested). Disturbance is defined as any bare rock and soil area that was not the result of residential or commercial development, such as being disturbed from mining, forestry, or highway construction activity. Forest cover for the Coal River Watershed was created using the Feature Analyst extension for ERDAS Imagine, as well as through manual digitizing and editing. Two sets of imagery were used for the creation of this layer. The first set was color infrared imagery collected by the USDA's National Agriculture Imagery Program (NAIP) for the entire state of West Virginia. The second set of imagery used for the classification came from the National Agriculture Imagery Program (NAIP), which acquires aerial imagery during the agricultural growing seasons in the continental U.S. The primary goal of the NAIP 
program is to make digital ortho photography available to governmental agencies and the public within a year of acquisition.

The Feature Analyst extension for ERDAS Imagine allows for the creation of training data sets to identify example areas of interest based on spectral response in the imagery, and then to run a feature extraction on larger areas of imagery to identify all areas with the same range of spectral response. The training data sets were created on the $2007 \mathrm{CIR}$ imagery due to the nature of the CIR Imagery and the definitive difference in spectral response between vegetation and bare earth. Both standard-color and color-infrared films are manufactured to have three distinct layers, and each layer is sensitive to different wavelengths (GeoMart, 2011). Standardcolor film records the visible wavelengths as red, green, and blue. Color pictures result when the human eye views the varying combinations of the three color layers. Color-infrared film has a yellow filter on top of the three layers to block ultraviolet (UV) and blue wavelengths. The near-infrared wavelengths and the lack of UV and blue wavelengths result in a clear, crisp colorinfrared image. Green, healthy vegetation has a high reflection level of near-infrared wavelengths and appears red on the processed image; red objects with very low near-infrared reflection appear green; green objects with very low near-infrared reflection appear blue; and blue objects with very low near-infrared reflection appear black (GeoMart, 2011). The feature extraction was then run on this same 2007 CIR imagery, and the resulting raster grid was broken up into two classes, forest and non-forest. From there, the raster grid was converted to a shape file in ARC Map, and it was overlaid with the 2009 NAIP imagery for the detection of changes in forest cover and disturbance in the two years between the acquisitions of the two sets of imagery. 
From this disturbance mapping, additional analysis was conducted on forested areas that also possessed different landscape characteristics that, when disturbed, cause a significantly higher degradation of water quality then areas lacking these characteristics. These forested area characteristics used in this particular part of the study are:

- Forested areas over 25 degree slope

- Forested areas in riparian zones

Slopes over 25 degrees were mapped for the Coal River Watershed. These slopes are critical to water quality since if the vegetation is disturbed on slopes over 25 degrees, a large volume of sedimentation runoff will travel into down-slope waterways. This map was created using the USGS 3-meter DEM Created in 2003 at a scale of 1:4,800. The DEM consisted of an array of elevations for ground positions at regularly spaced 3-meter intervals. It was created from mass points and break-lines collected as part of the Statewide Addressing and Mapping Board's mission. This DEM has been mosaicked by 8-digit watershed boundaries, as defined by the Federal Standard for Delineation of Hydrologic Unit Boundaries. Headwater forested watersheds are those watersheds that are completely forested in the Coal River Watershed. These areas are a component to identifying forested areas critical to water quality. This map was created by finding all of the headwater segment level watersheds at the 1:24,000 stream scale that were completely forested. Riparian areas are defined in this analysis as all areas that are within 100 meters of a stream. These forested areas within riparian areas are a critical component to identifying areas critical to water quality. Disturbance in these areas will create a very immediate and pronounced increase in runoff and sediment loading in the streams downslope from the disturbance. This map was created by first mapping all of the $1: 4,800$ scale 
streams from the SAMB hydro layer and then buffering them by a distance of 100 meters. This riparian area shape file was then used to clip the forest cover shape file, resulting in an area depicting all of the forested areas within riparian areas in the Coal River Watershed. From these grids, a forest critical to water quality map was created by combining the forested areas on slopes over 25 degrees, forests within $100 \mathrm{~m}$ of the 1:4,800 scale mapped streams, and headwater watersheds containing forests (figure 3.4).
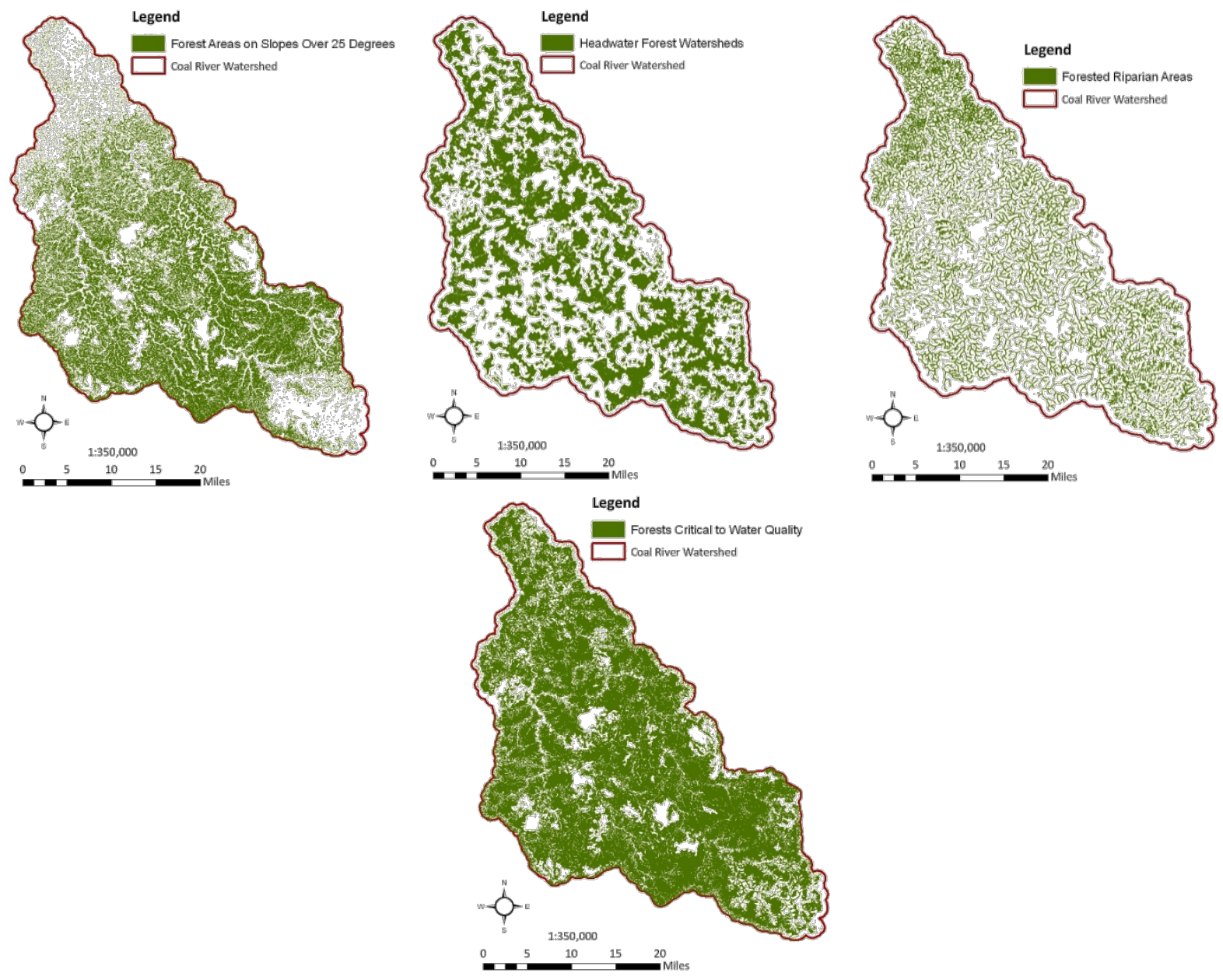

Figure 3.4: Binary inputs and output of forests critical to water quality

\subsection{1 - Fuzzy Membership Functions}

The Boolean result of this combination of forest locations with these three attributes provides a binary output representing the forested areas that are most detrimental to water 
quality if they are disturbed. This grid is strictly a "yes or no" output, but in real life, there are varying levels of how critical these critical forests are to downstream water quality. Instead of using this crisp output of forest characteristics, a fuzzy output better represents the variance in how critical the forests are to water quality. Instead of using this crisp output of forest characteristics, a fuzzy output better represents the variance in how critical the forests are to water quality. Fuzziness refers to vagueness and uncertainty, in particular to the vagueness related to human language and thinking, and provides a way to obtain conclusions from vague, ambiguous or imprecise information. It imitates the human reasoning process of working with non precise data. The fuzzy classification process is an "if than else" statement. The outputs of these expressions are grids of continuous data that increase or decrease in value as a characteristic becomes more or less sever. There are a few key advantages with using fuzzy membership functions to calculate ranges of values pertaining to how critical the lost of forested areas are to down-stream water quality. There is a lot of flexibility in the assignment of fuzzy membership functions due to the fact that exact values are not being calculated, but rather ranges of values that express levels of criticalness. Fuzzy logic outputs are also easy to understand because they resemble logical thought of in-between values between "yes" and "no".

In classical set theory, the membership of a set is defined as true or false, 1 or 0 . Membership of a fuzzy set, however, is expressed on a continuous scale from 1 (full membership) to 0 (full non-membership). Every value of $x$ is associated with a value of $\mu(x)$, and the ordered pairs $(x, \mu(x))$ are known collectively as a fuzzy set. The shape of the function does not need to be linear; it can take on any analytical or arbitrary shape appropriate to the 
problem at hand. Fuzzy membership functions can also be expressed as lists or tables of numbers. Fuzzy membership values must lie in the range $(0,1)$, but there are no practical constraints on the choice of fuzzy membership values. Values are simply chosen to reflect the degree of membership of a set, based on subjective judgment. Crisp set boundaries fall at the value of 0.5 on the membership scale. This allows for a stretched suitability classification on either side of the crisp set boundary (Bonham-Carter, 1991). Based on a lack of field data to prove a non-linearity of each fuzzy membership function, a linear membership will be assumed in this study.

The two membership functions being utilized in this study are based on the crisp sets used in the binary output mapping of forests critical to water quality. In order to adapt these crisp set parameters for use in a fuzzy membership function, the $\mathrm{max} / \mathrm{min}$ value of the crisp set is doubled and the original crisp set boundary value is placed at the 0.5 value on the membership scale (figure 3.4.1).
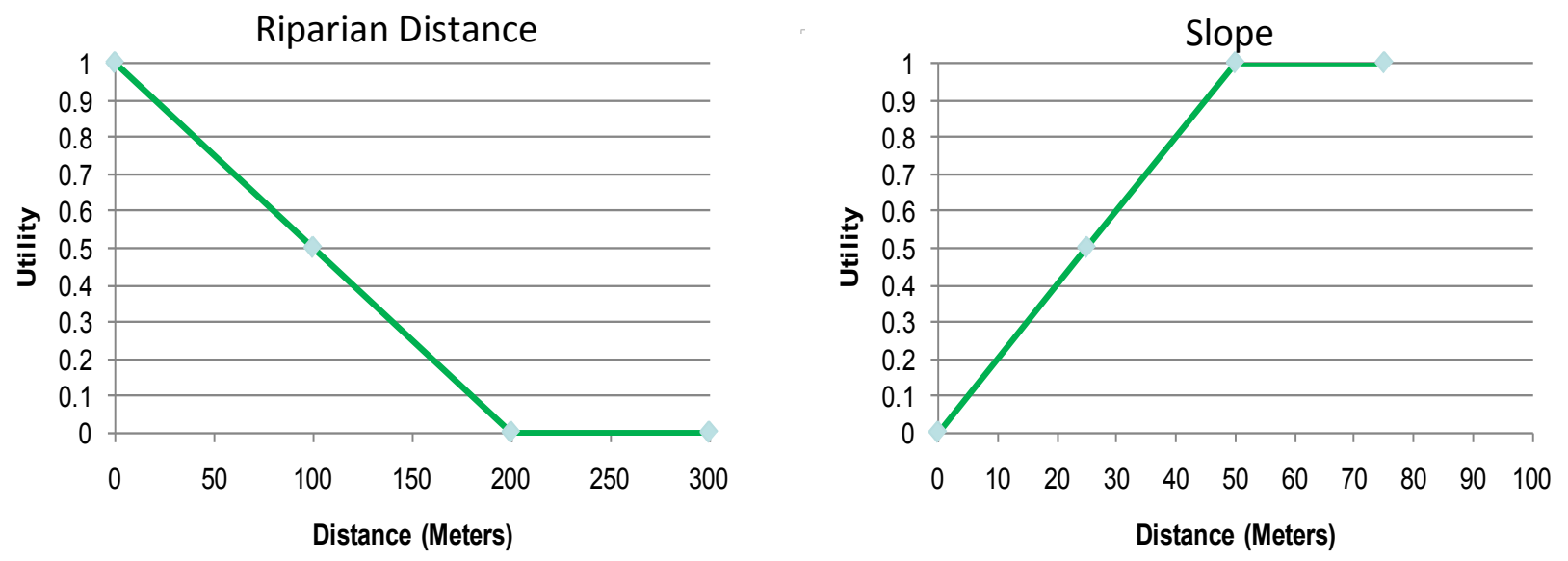

Figure 3.4.1: Fuzzy membership functions of critical forest input parameters

This doubling of the crisp value allows for an increased range of values on either side of the crisp set boundary that can be classified as various ranges of critical forest that were 
perhaps not even classified in the binary output. These resulting fuzzy logic grids will contain continuous data values rather than a binary "yes or no" output. Areas that have a higher resulting grid cell value are more critical to water quality than those with lower values. When all of the fuzzy membership functions are implemented and the new fuzzy map grids are created, these grids are multiplied together to create the fuzzy representation of forests critical to water quality as follows:

$$
\operatorname{int}(([\text { fuzzy_slope }]+[\text { fuzzy_dist }]) * 100)
$$

\subsection{2 - Riparian Distance}

In order to calculate a continuous fuzzy logic grid for the distance to streams parameter of the critical forest calculation, I first calculated a straight line distance raster grid using the distance function in the spatial analyst extension of ArcMap. This function uses the 1:24,000 streams vector dataset as the input and calculates a continuous raster grid of distance values (in meters) from a stream (figure 3.4.2). Using this resulting distance to streams grid, the conditional function is utilized to calculate a fuzzy logic distance to streams grid with values ranging from 0 to 1,0 meaning least critical and 1 meaning most critical (figure 3.4.2). As mentioned before, the crisp set boundary, in this case 100 meters from a stream, has a fuzzy membership value of 0.5 . 


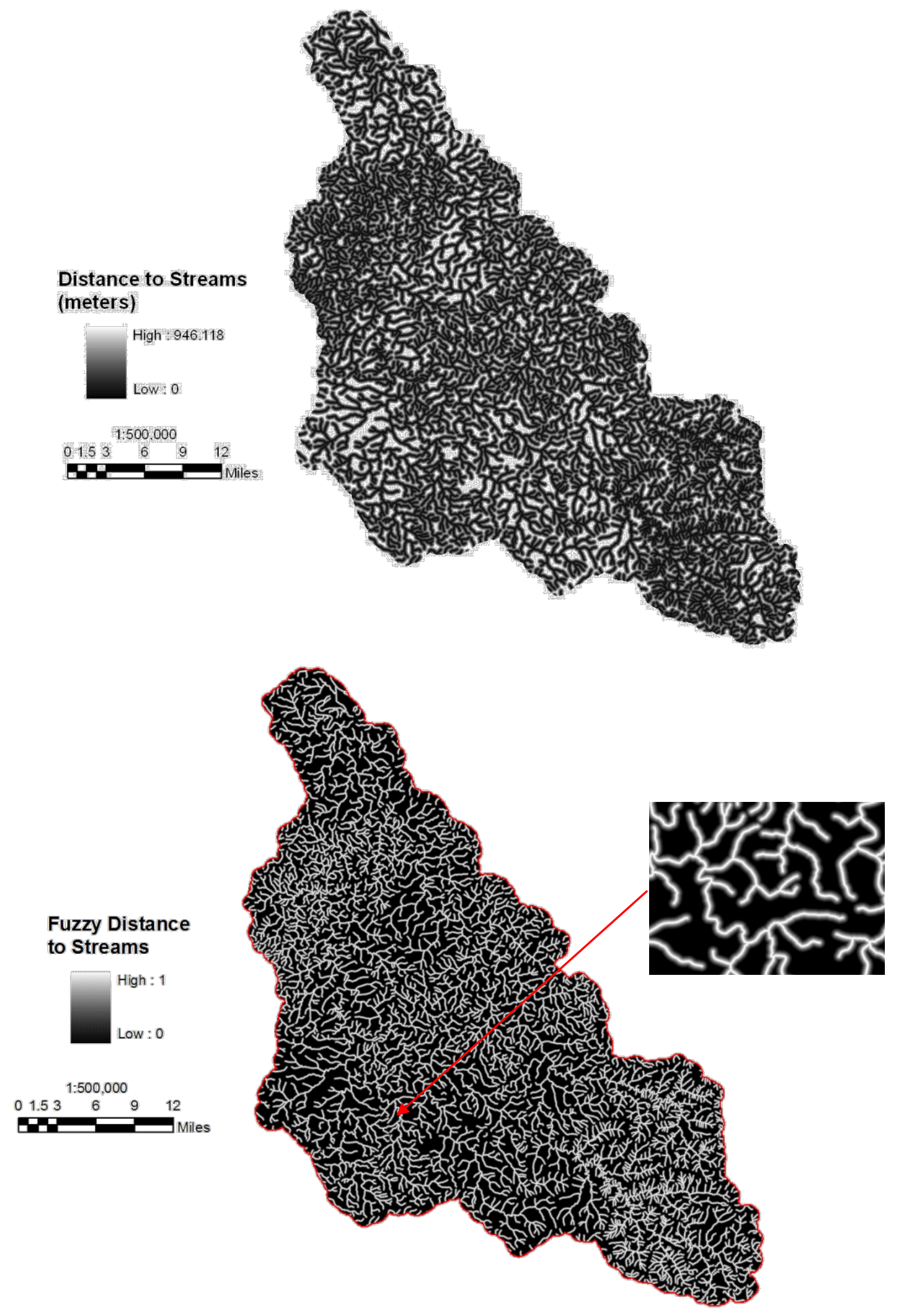

Figure 3.4.2: Creation of fuzzy distance to streams grid 


\subsection{3 - Slope}

The slope grid used of the study area was created using the USGS 3-meter DEM Created

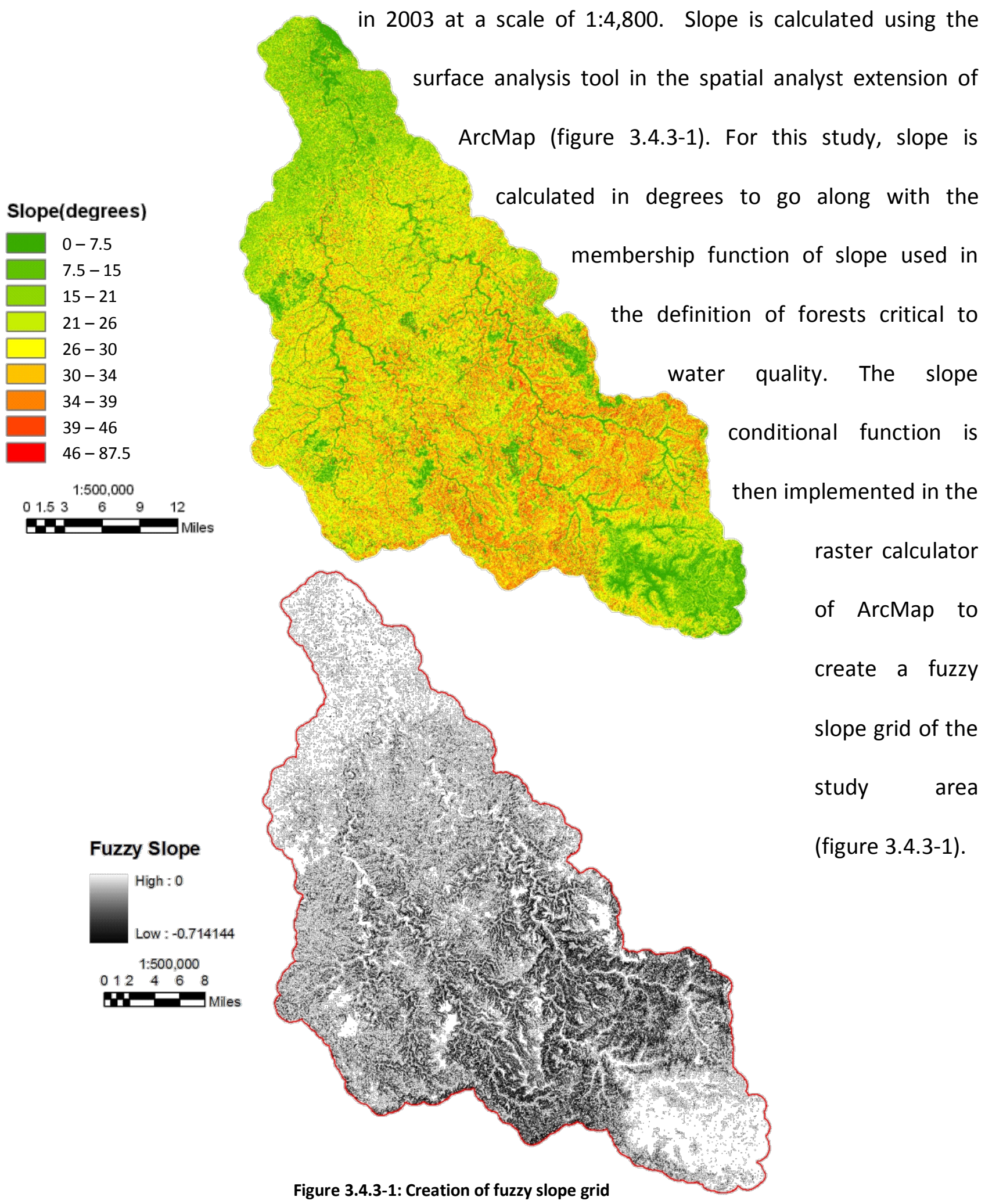


The range of values falls on the negative side of zero, ranging from 0 to -0.714 . This needs to be corrected before the aggregation of fuzzy input parameters can take place. To

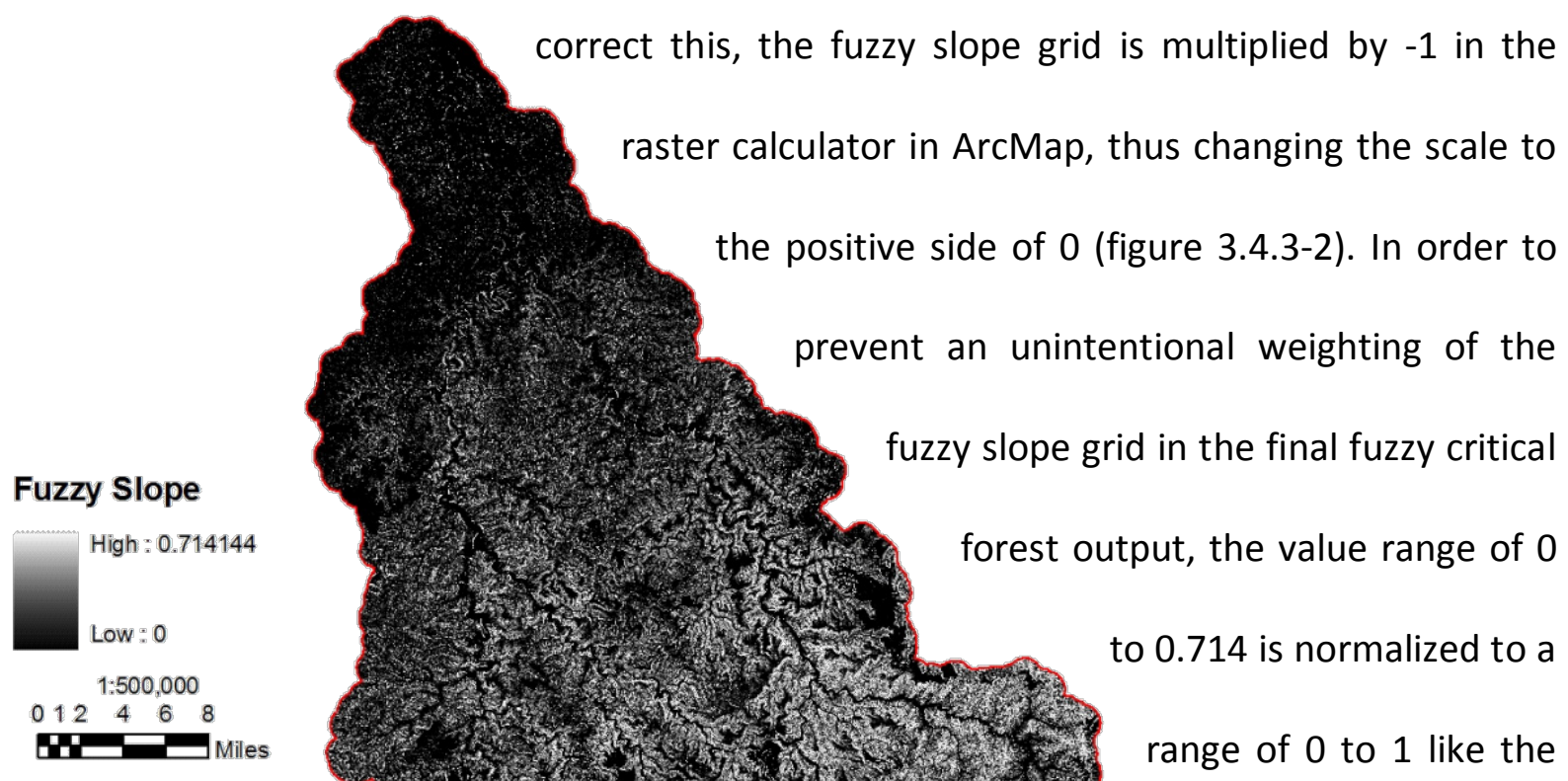

Fuzzy Slope Normalized

High: 1

Low: 0

1:500,000

$012 \quad 4 \quad 6 \quad 8$

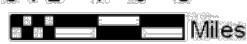

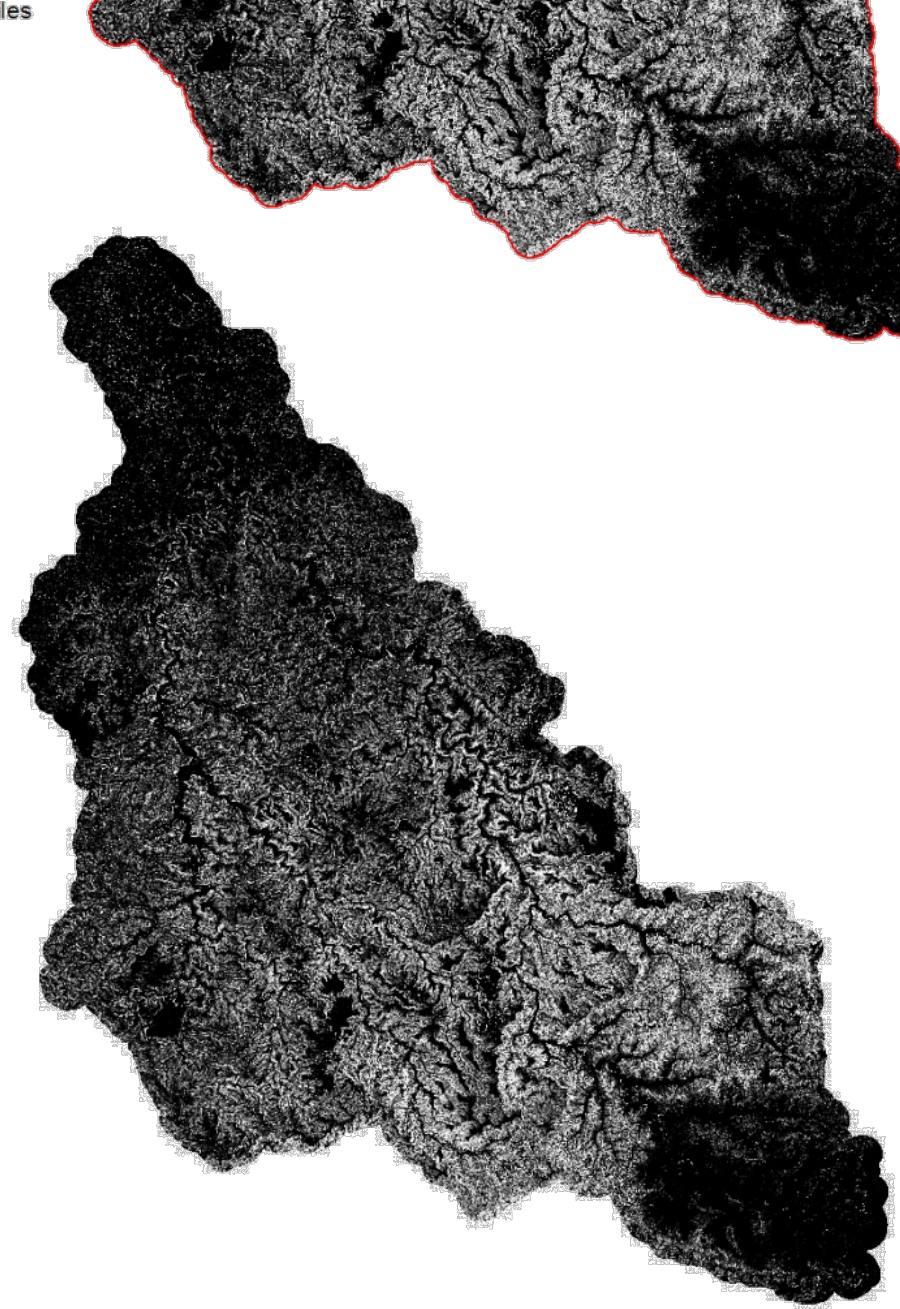

Figure 3.4.3-2: Normalization of fuzzy slope grid like the

fuzzy distance to

streams grid. This is done by using a multiplicative scalar of 1.401 in the raster calculator (figure 3.4.3-2). 


\subsection{4 - Combined Fuzzy Memberships}

By combining the two calculated fuzzy logic input grids in the raster calculator using the equation "int(([fuzzy_slope] + [fuzzy_dist] $) * 100)$ ", a combined fuzzy logic output is created that takes into account both the slope and distance to streams critical to water quality. The multiplier of 100 in the equation is used to create whole integer values in the grid, rather than decimal values that are harder to interpret in a histogram. The resulting combined fuzzy logic grid is then classified into 5 classes ranging from 1 to 5 , one being least critical to water quality and 5 being most critical (figure 3.4.4-1). These classes are defined by a 5 class quantile break of the grid values, which places an even number of grid cells into each class. A quantile classification is well suited to linearly distributed data, which is assumed in this study (ArcGIS desktop help, 2007). Because features are grouped by the number in each class, the resulting map can be misleading. Similar features can be placed in adjacent classes, or features with widely different values can be put in the same class. This distortion is minimized by increasing the number of classes displayed to 5.

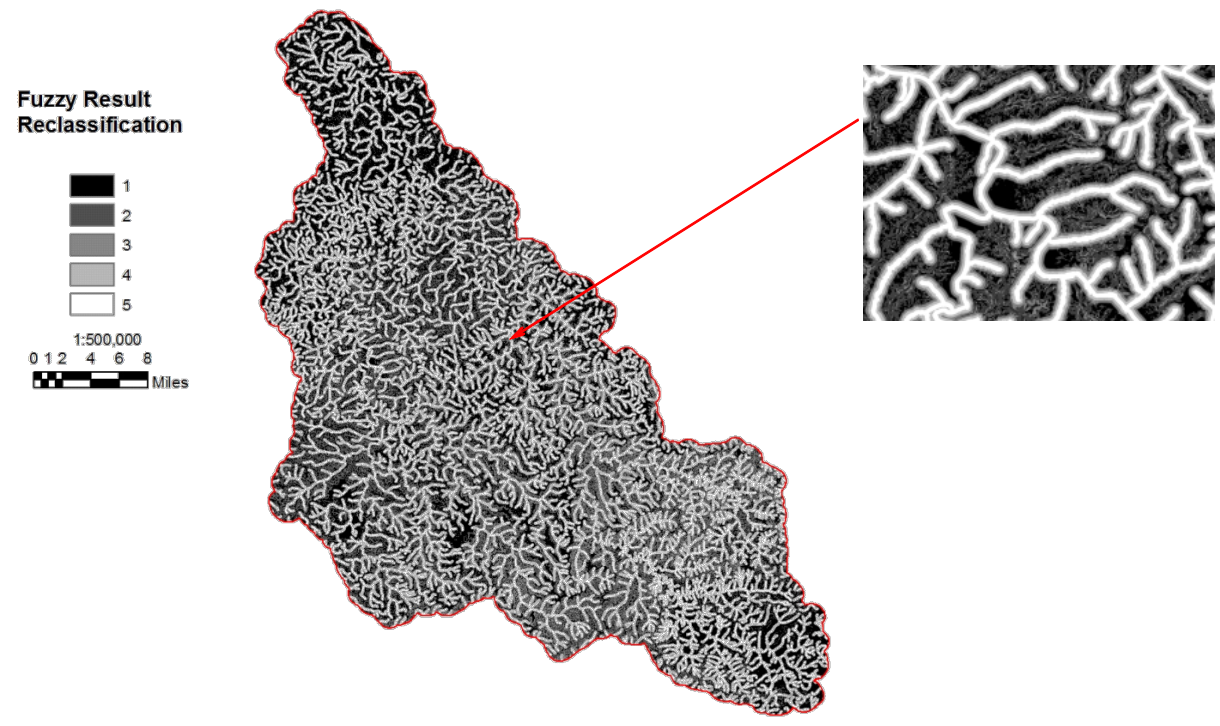

Figure 3.4.4-1: Fuzzy logic critical forest reclassification 
This new critical forest grid represents the Coal River watershed if it was completely forested, but there is existing disturbance within the watershed. As mentioned earlier, a disturbance map was created from 2009 NAIP true color aerial imagery for the study area, which is used to extract just the forested areas from the critical forest grid in figure 3.4.4-2. This is done using the raster calculator and multiplying the critical forest grid together with the forested cover grid created earlier. All forested cells have a value of 1 in the forest cover grid, and all non-forested cells have a value of "NoData", which will completely eliminate any cells that are non-forested in the study area after multiplication. The resulting grid is the final output of forests critical to water quality based on the fuzzy logic membership functions (figure 3.4.43).
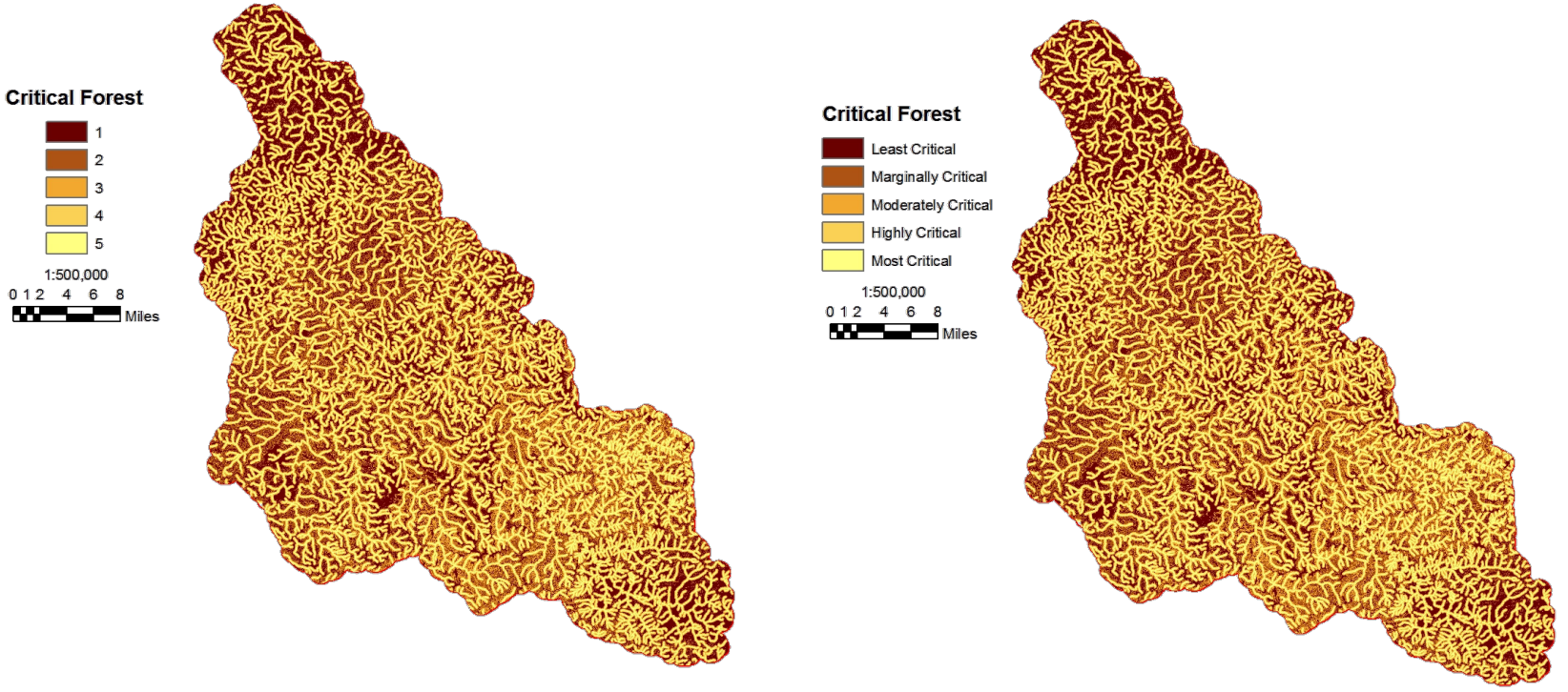

Figure 3.4.4-2: Reclassification of critical forests 

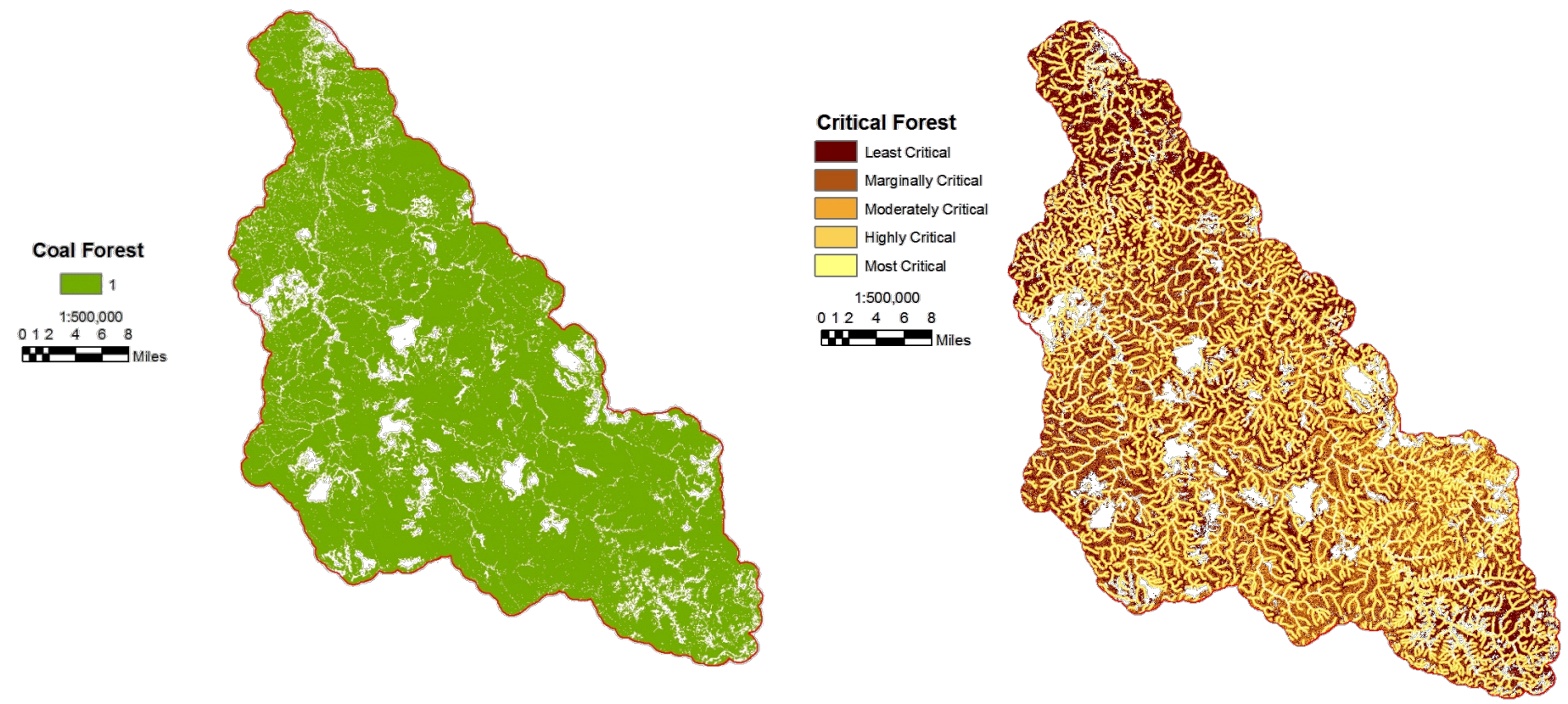

Figure 3.4.4-3: Extracting forested areas from critical forest grid to create final critical forest grid

\subsection{5 - Hydrologic Catchment Study Area Selection}

In order to use the stream conductivity sample values as a response variable to varying landscape characteristics, study areas were interpreted for each conductivity sample location based on the total area of the Coal River watershed that flowed into each sample location. This was conducted on the segment level watershed scale, finding all of the segment level watersheds upstream from each of the 38 sample locations flowing into the sample locations. This was accomplished using the Mass Balance Accumulator toolbar, which is a spatial decision support system created to help decision makers more effective in their ability to solve different water quality issues (Strager et. al. 2008). The Mass Balance Accumulator toolbar works off of a set of shape files and flow tables for the study area being examined in order to conduct a wide variety of water quality calculations and alternative scenario analysis. The setup of the Mass Balance Accumulator toolbar involves the input of a segment level watershed shapefile, NHD 
stream shapefile, and a flow table for the study area, as well as identifying where the Mass Balance Accumulator should look for reach shed codes, NHD shed codes, and segment length fields (in meters) in the attribute tables on the before mentioned shape files. Once this initial setup is completed, study areas could be interpreted for each stream conductivity sample

\section{Study Areas}

- Conductivity Samples

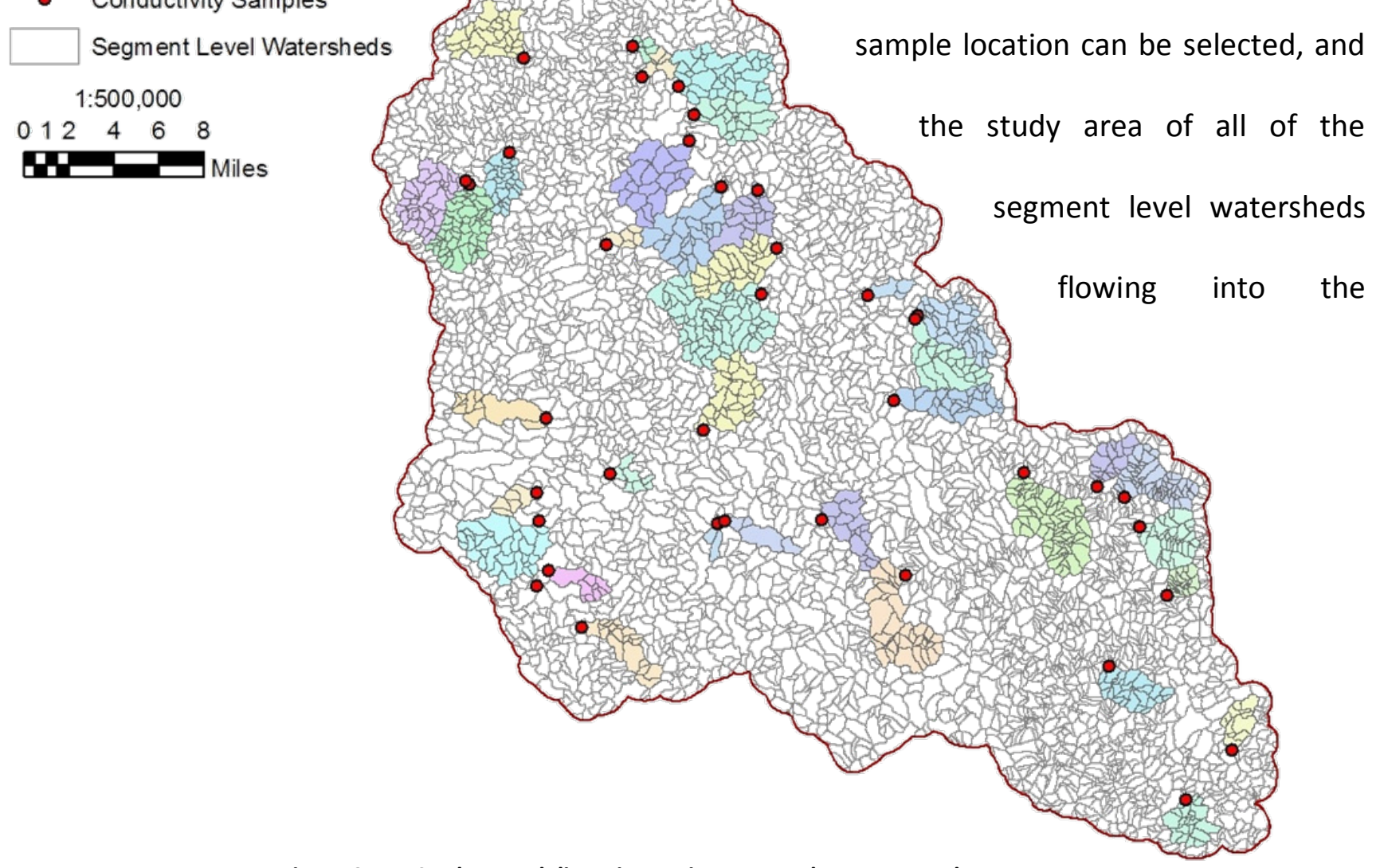

Figure 3.4.5: Study area delineations using Mass Balance Accumulator

conductivity sample location area selected. This selection of segment level watersheds is then exported as a new shape file, and this process is repeated for all 38 sample locations. This process also verifies that none of the sample locations are nested within larger flow areas, and 
each study area is completely independent of all other study areas in terms of flow (figure 3.4.5).

\subsection{6 - Landscape Characteristic Variables}

Using the landscape disturbance mapping outlined earlier based off of the 2009 NAIP true color aerial imagery, six of the disturbance classifications were chosen for use as

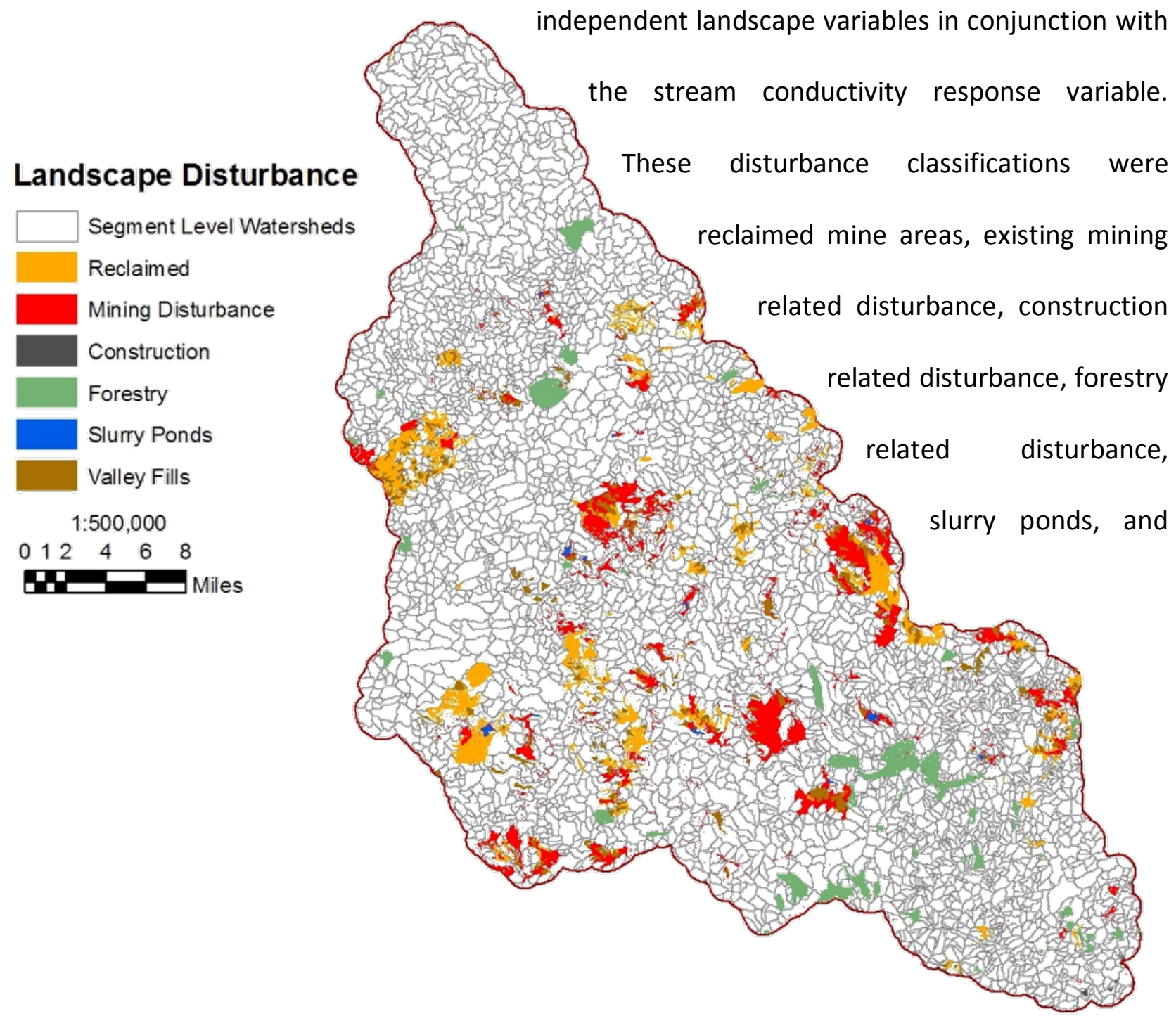

Figure 3.4.6-1: Landscape disturbance within delineated study areas

valley fills (figure 3.4.6-1). In order to statistically examine the effects of these independent landscape disturbance variables on stream conductivity in each study area, each one of these 
independent landscape disturbance variables had to be clipped to each individual delineated hydrological study area containing a stream conductivity sample location at its outflow point.

These independent landscape disturbance variables were then summarized by each individual study area to calculate a percentage of the total area of each study area that was comprised of each one of these six independent variables (table 3.4.6-1), and these values are expressed in square meters. These percentages of the total study area will comprise part of the multivariate linear regression analysis with the summer stream conductivity readings as the response variable. The remaining independent landscape variables to be used in the multivariate linear regression analysis are the fuzzy membership function values for forests critical to water quality (figure $3.4 .4-3$ ). In the same way that the independent landscape disturbance variables were clipped to each individual hydrological study area, the classified fuzzy membership grid was clipped to each individual hydrological study area. These clipped critical forest grids were then summarized to show the percentage of each hydrological study area that is comprised of each individual value of critical forest, ranging from 1(least critical to water quality) to 5 (most critical to water quality) (table 3.4.6-2). 


\begin{tabular}{|c|c|c|c|c|c|c|c|c|c|c|c|c|c|}
\hline Study Area & total_area & rec_total & $\%$ total & dist_total & $\%$ total & construction & $\%$ total & forestry & $\%$ total & slurry & $\%$ total & v_fills & $\%$ total \\
\hline Beaver Pond BR & 2610121.03 & 1105772.94 & 42.36 & 25013.06 & 0.96 & 0.00 & 0.00 & 0.00 & 0.00 & 0.00 & 0.00 & 119512.62 & 4.58 \\
\hline Millers Camp BR & 6722724.67 & 0.00 & 0.00 & 485007.68 & 7.21 & 0.00 & 0.00 & 0.00 & 0.00 & 0.00 & 0.00 & 0.00 & 0.00 \\
\hline Pigeonroost BR & 5969159.24 & 0.00 & 0.00 & 433503.73 & 7.26 & 0.00 & 0.00 & 0.00 & 0.00 & 0.00 & 0.00 & 669380.74 & 11.21 \\
\hline Jarrells BR & 6545852.23 & 874265.02 & 13.36 & 1210308.39 & 18.49 & 0.00 & 0.00 & 0.00 & 0.00 & 228223.09 & 3.49 & 243057.73 & 3.71 \\
\hline Little Horse CR & 9256787.43 & 1034907.64 & 11.18 & 182887.38 & 1.98 & 0.00 & 0.00 & 0.00 & 0.00 & 0.00 & 0.00 & 0.00 & 0.00 \\
\hline Toney FK & 14069295.23 & 2693254.77 & 19.14 & 1903658.48 & 13.53 & 0.00 & 0.00 & 0.00 & 0.00 & 0.00 & 0.00 & 1723196.93 & 12.25 \\
\hline Seng Creek & 14293394.95 & 1521950.26 & 10.65 & 1195135.32 & 8.36 & 0.00 & 0.00 & 0.00 & 0.00 & 0.00 & 0.00 & 393405.62 & 2.75 \\
\hline White Oak BR CF & 15759472.68 & 777960.17 & 4.94 & 1000353.00 & 6.35 & 0.00 & 0.00 & 0.00 & 0.00 & 0.00 & 0.00 & 613202.93 & 3.89 \\
\hline Sandlick CR & 16179391.38 & 137083.02 & 0.85 & 2931551.43 & 18.12 & 0.00 & 0.00 & 0.00 & 0.00 & 0.00 & 0.00 & 297569.50 & 1.84 \\
\hline LF White Oak & 16354888.78 & 3253376.85 & 19.89 & 7083338.95 & 43.31 & 0.00 & 0.00 & 0.00 & 0.00 & 143544.84 & 0.88 & 1643430.42 & 10.05 \\
\hline Dodson FK & 17064835.27 & 1338737.08 & 7.85 & 258209.35 & 1.51 & 15312.67 & 0.09 & 487724.76 & 2.86 & 0.00 & 0.00 & 251020.10 & 1.47 \\
\hline Big Horse CR & 19587616.84 & 9762831.22 & 49.84 & 982315.82 & 5.01 & 0.00 & 0.00 & 0.00 & 0.00 & 0.00 & 0.00 & 2707135.64 & 13.82 \\
\hline Drawdy CR & 22253739.39 & 5960.57 & 0.03 & 1283797.53 & 5.77 & 0.00 & 0.00 & 0.00 & 0.00 & 73678.93 & 0.33 & 179747.90 & 0.81 \\
\hline Little Alum CR & 2212557.61 & 0.00 & 0.00 & 0.00 & 0.00 & 0.00 & 0.00 & 0.00 & 0.00 & 0.00 & 0.00 & 0.00 & 0.00 \\
\hline Crooked CR & 4631963.62 & 0.00 & 0.00 & 0.00 & 0.00 & 5175.37 & 0.11 & 0.00 & 0.00 & 0.00 & 0.00 & 0.00 & 0.00 \\
\hline Surveyor CR & 9626550.90 & 0.00 & 0.00 & 83973.27 & 0.87 & 1920.43 & 0.02 & 0.00 & 0.00 & 0.00 & 0.00 & 0.00 & 0.00 \\
\hline RF Sandlick CR & 11552858.57 & 0.00 & 0.00 & 0.00 & 0.00 & 0.00 & 0.00 & 12831.34 & 0.11 & 0.00 & 0.00 & 0.00 & 0.00 \\
\hline Sixmile CR & 11846092.99 & 0.00 & 0.00 & 0.00 & 0.00 & 0.00 & 0.00 & 0.00 & 0.00 & 0.00 & 0.00 & 0.00 & 0.00 \\
\hline Lick $\mathrm{Cr}$ & 14287023.50 & 230034.12 & 1.61 & 1914.91 & 0.01 & 0.00 & 0.00 & 0.00 & 0.00 & 0.00 & 0.00 & 0.00 & 0.00 \\
\hline Cobb CR & 15943587.69 & 0.00 & 0.00 & 0.00 & 0.00 & 6175.54 & 0.04 & 0.00 & 0.00 & 0.00 & 0.00 & 0.00 & 0.00 \\
\hline Whites BR & 17184376.63 & 0.00 & 0.00 & 64271.62 & 0.37 & 0.00 & 0.00 & 0.00 & 0.00 & 0.00 & 0.00 & 62680.81 & 0.36 \\
\hline Brush CR & 22391424.93 & 0.00 & 0.00 & 114154.17 & 0.51 & 0.00 & 0.00 & 363826.52 & 1.62 & 0.00 & 0.00 & 24.39 & 0.00 \\
\hline Sycamore CR & 27140976.28 & 0.00 & 0.00 & 190495.50 & 0.70 & 0.00 & 0.00 & 0.00 & 0.00 & 0.00 & 0.00 & 0.00 & 0.00 \\
\hline Little White Oak & 3452746.89 & 111250.59 & 3.22 & 110731.18 & 3.21 & 0.00 & 0.00 & 0.00 & 0.00 & 0.00 & 0.00 & 32968.68 & 0.95 \\
\hline Trace BR SLF & 4105700.73 & 1133008.18 & 27.60 & 15037.42 & 0.37 & 0.00 & 0.00 & 0.00 & 0.00 & 0.00 & 0.00 & 265123.77 & 6.46 \\
\hline Lick Run & 4599382.00 & 500906.32 & 10.89 & 368160.26 & 8.00 & 0.00 & 0.00 & 0.00 & 0.00 & 0.00 & 0.00 & 0.00 & 0.00 \\
\hline Rockhouse CR & 4688742.57 & 2847045.95 & 60.72 & 15286.12 & 0.33 & 0.00 & 0.00 & 0.00 & 0.00 & 0.00 & 0.00 & 406368.72 & 8.67 \\
\hline Laurel FK & 11183439.60 & 0.00 & 0.00 & 314681.77 & 2.81 & 0.00 & 0.00 & 0.00 & 0.00 & 0.00 & 0.00 & 265368.28 & 2.37 \\
\hline James CR & 12092343.19 & 0.00 & 0.00 & 7547027.45 & 62.41 & 0.00 & 0.00 & 0.00 & 0.00 & 0.00 & 0.00 & 437022.45 & 3.61 \\
\hline Hazy CR & 24463424.81 & 63376.27 & 0.26 & 2627230.30 & 10.74 & 0.00 & 0.00 & 0.00 & 0.00 & 0.00 & 0.00 & 26851.75 & 0.11 \\
\hline Beech CR & 23182270.60 & 7154081.88 & 30.86 & 1797116.29 & 7.75 & 0.00 & 0.00 & 0.00 & 0.00 & 480533.44 & 2.07 & 404908.77 & 1.75 \\
\hline Laurel CR Upper & 36758418.20 & 2700425.02 & 7.35 & 9998391.12 & 27.20 & 0.00 & 0.00 & 164849.06 & 0.45 & 0.00 & 0.00 & 4013860.94 & 10.92 \\
\hline Lick BR BC & 2105479.83 & 0.00 & 0.00 & 1906.93 & 0.09 & 0.00 & 0.00 & 0.00 & 0.00 & 0.00 & 0.00 & 0.00 & 0.00 \\
\hline Cane BR & 3255870.23 & 0.00 & 0.00 & 2964.55 & 0.09 & 0.00 & 0.00 & 0.00 & 0.00 & 0.00 & 0.00 & 17753.40 & 0.55 \\
\hline Indian $\mathrm{Cr}$ & 12400362.20 & 330469.93 & 2.67 & 3814.27 & 0.03 & 0.00 & 0.00 & 0.00 & 0.00 & 0.00 & 0.00 & 0.00 & 0.00 \\
\hline
\end{tabular}

Table 3.4.6-1: Landscape disturbance within delineated study areas 


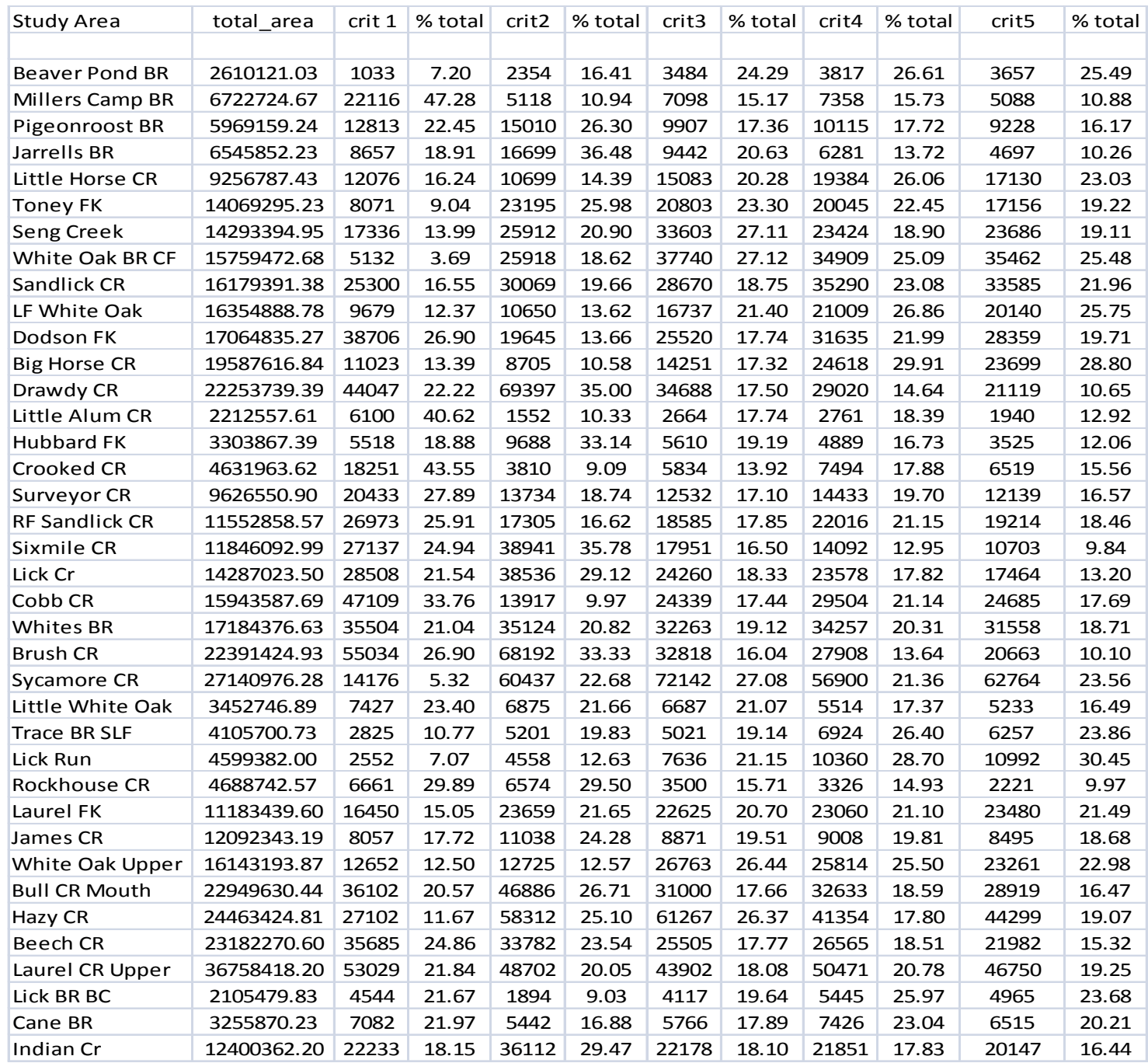

Table 3.4.6-2: Critical forest classifications within delineated study areas

\section{5 - Multivariate Linear Regression}

In order to explore the relationship between these independent landscape related

variables and the response variable of summer stream conductivity within each study area,

multivariate linear regression analysis was used to statistically examine the effects and

significance of each landscape variable on stream conductivity. The main purpose of multiple

regression is to learn more about the relationship between several independent or predictor

variables and a dependent or criterion variable (StatSoft, 2010). The combined effects of 
multiple variables can also be examined in order to determine which landscape variables or combinations of landscape variables have the greatest influence over summer stream conductivity levels in waterways downstream of mining related landscape disturbance.

\subsection{1 - Data Distributions}

Using JMP statistical software, a regression analysis was performed on the various independent variables described above plotted against the dependent variable of the summer stream conductivity. The first step to conducting the regression analysis is to explore the nature of the data value distributions for all of the dependent variables being analyzed (figure 3.5.1). These distributions display a variety of patterns. The critical forest values 1 through 5 distributions display a normal "bell-curve" distribution, showing that these five independent variables are fairly evenly distributed throughout the study area. The landscape disturbance variables (reclaimed mine areas, existing mining related disturbance, construction related disturbance, forestry related disturbance, slurry ponds, valley fills) distributions are skewed showing that there is an uneven distribution of these independent variables throughout the study area. All of these independent landscape variables display a fairly evident uni-modal distribution, displaying 1 distinct peak in each distribution. This shows that there is one dominant trend of each variable in the study areas. The summer stream conductivity distribution is uni-modal and skewed, which shows that there is a very concentrated clustering of conductivity values somewhere in the study area, and they are not evenly distributed. 


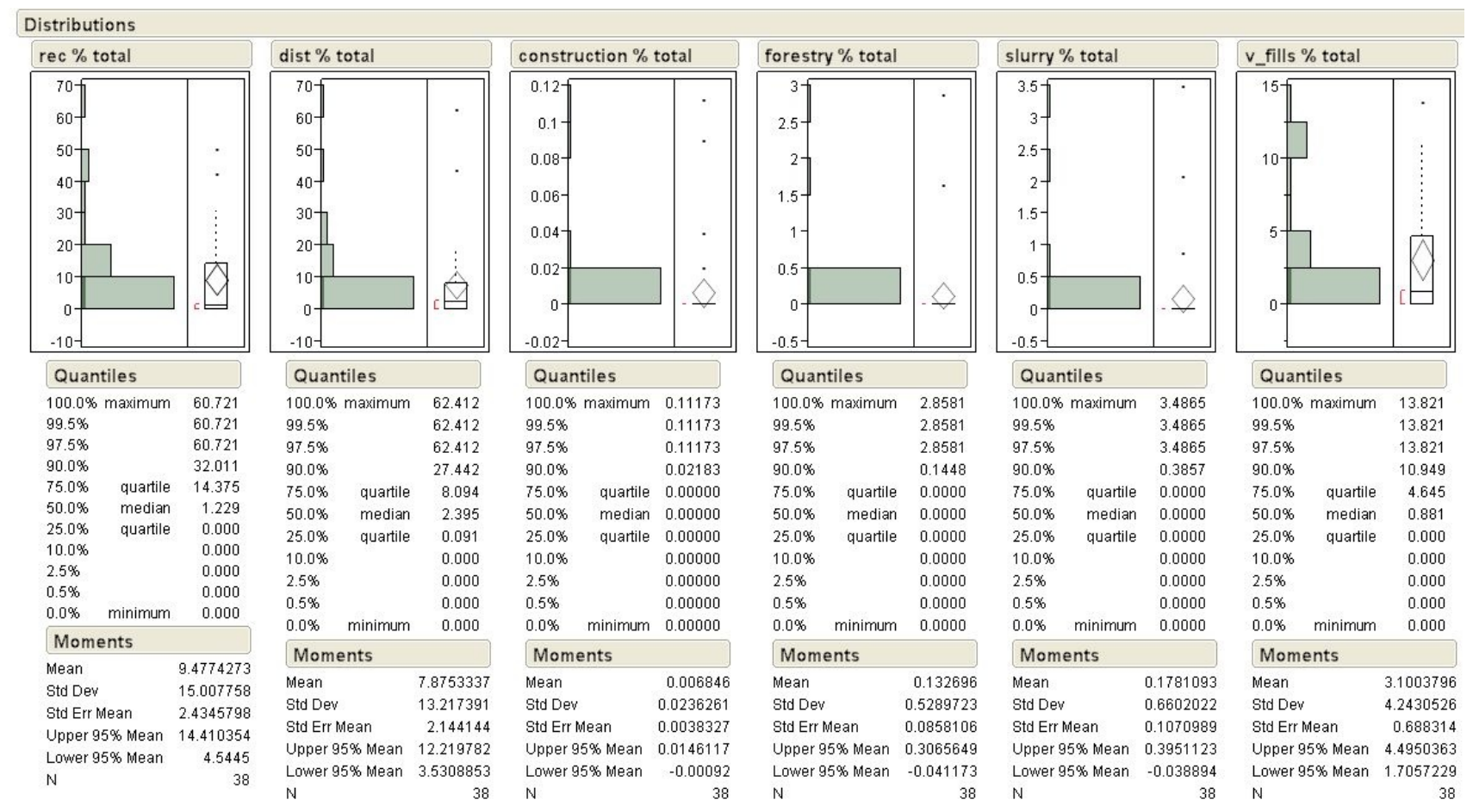

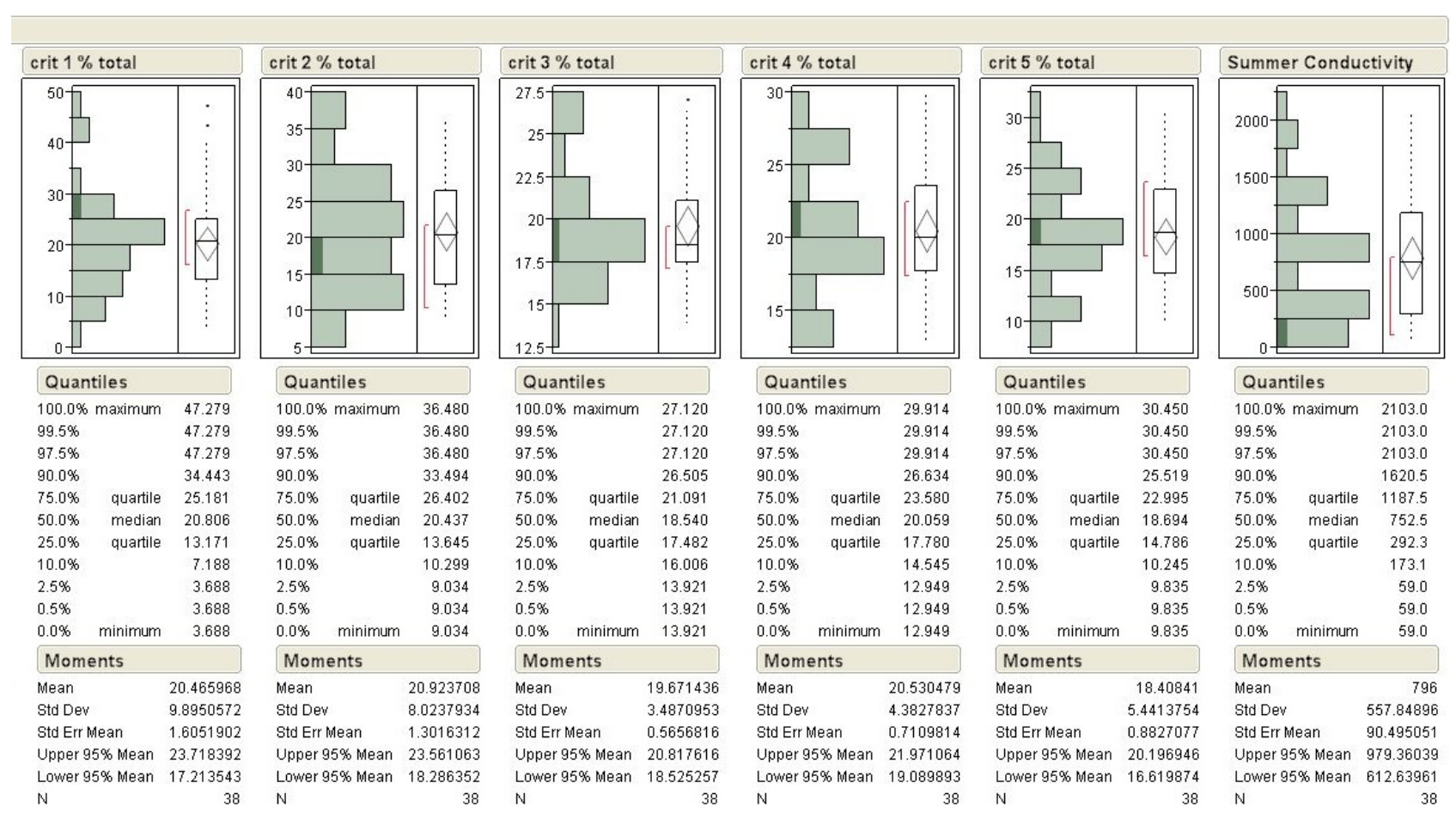

Figure 3.5.1: Independent landscape variable data distributions 


\subsection{2 - Co-variation and Pairwise Correlations}

Examining for co-variation among the independent variables by using percentages of each study area composed of each independent landscape variable reveals the similarity of the different types of landscape variables. Co-variation is a measure of how much two variables change together, and is sometimes called a measure of linear dependence between two random variables. Using the JMP statistical software, a "multivariate" regression is conducted using the 11 main landscape characteristic independent variables. From this, scatterplots are generated showing the relationships among the independent variables (figure 3.5.2-1). The significance of the correlations is also tested in a pairwise fashion. By squaring the " $r$ " correlation coefficient, an $\mathrm{R}^{2}$ statistic is calculated, which is an approximate measure of the percentage of shared variance among the independent variables. 


\begin{tabular}{|c|c|c|c|c|c|c|c|c|c|c|c|}
\hline \multicolumn{12}{|l|}{ Multivariate } \\
\hline \multicolumn{12}{|l|}{ Correlations } \\
\hline & rec $\%$ total o & ist $\%$ totalc & on $\%$ totalf & try $\%$ total s & Irry $\%$ totalv & fills $\%$ totalcri & $11 \%$ total $c$ & it $2 \%$ total cri & it $3 \%$ total $\mathrm{cr}$ & it $4 \%$ total $c$ & rit $5 \%$ total \\
\hline rec $\%$ total & 1.0000 & 0.0255 & -0.1343 & -0.0751 & 0.1742 & 0.6056 & -0.2359 & -0.0495 & 0.0387 & 0.3114 & 0.2263 \\
\hline dist $\%$ total & 0.0255 & 1.0000 & -0.1641 & -0.0864 & 0.2080 & 0.4282 & -0.2352 & -0.0115 & 0.2190 & 0.1488 & 0.1845 \\
\hline construction $\%$ total & -0.1343 & -0.1641 & 1.0000 & 0,4800 & -0.0803 & -0.1819 & 0.4416 & -0.3481 & -0.3128 & -0.0412 & -0.0560 \\
\hline forestry $\%$ total & -0.0751 & -0.0864 & 0.4800 & 1.0000 & -0.0695 & -0.0787 & 0.1553 & -0.0095 & -0.1808 & -0.0798 & -0.0882 \\
\hline slurry $\%$ total & 0.1742 & 0.2080 & -0.0803 & -0.0695 & 1.0000 & 0.0451 & -0.0117 & 0.2954 & 0.0022 & -0.2272 & -0.2328 \\
\hline$v_{\text {fillls }} \%$ total & 0.6056 & 0.4282 & -0.1819 & -0.0787 & 0.0451 & 1.0000 & -0.3261 & -0.0437 & 0.1445 & 0.3386 & 0.2922 \\
\hline crit $1 \%$ total & -0.2359 & -0.2352 & 0.4416 & 0.1553 & -0.0117 & -0.3261 & 1.0000 & -0.1595 & -0.7613 & -0.5410 & -0.6597 \\
\hline crit $2 \%$ total & -0.0495 & -0.0115 & -0.3481 & -0.0095 & 0.2954 & -0.0437 & -0.1595 & 1.0000 & -0.0423 & -0.6844 & -0.6062 \\
\hline crit $3 \%$ total & 0.0387 & 0.2190 & -0.3128 & -0.1808 & 0.0022 & 0.1445 & -0.7613 & -0.0423 & 1.0000 & 0.3677 & 0.5099 \\
\hline crit $4 \%$ total & 0.3114 & 0.1488 & -0.0412 & -0.0798 & -0.2272 & 0.3386 & -0.5410 & -0.6844 & 0.3677 & 1,0000 & 0.9520 \\
\hline crit $5 \%$ total & 0.2263 & 0.1845 & -0.0560 & -0.0882 & -0.2328 & 0.2922 & -0.6597 & -0.6062 & 0.5099 & 0.9520 & 1.0000 \\
\hline
\end{tabular}

The correlations are estimated by REML method.

Scatterplot Matrix

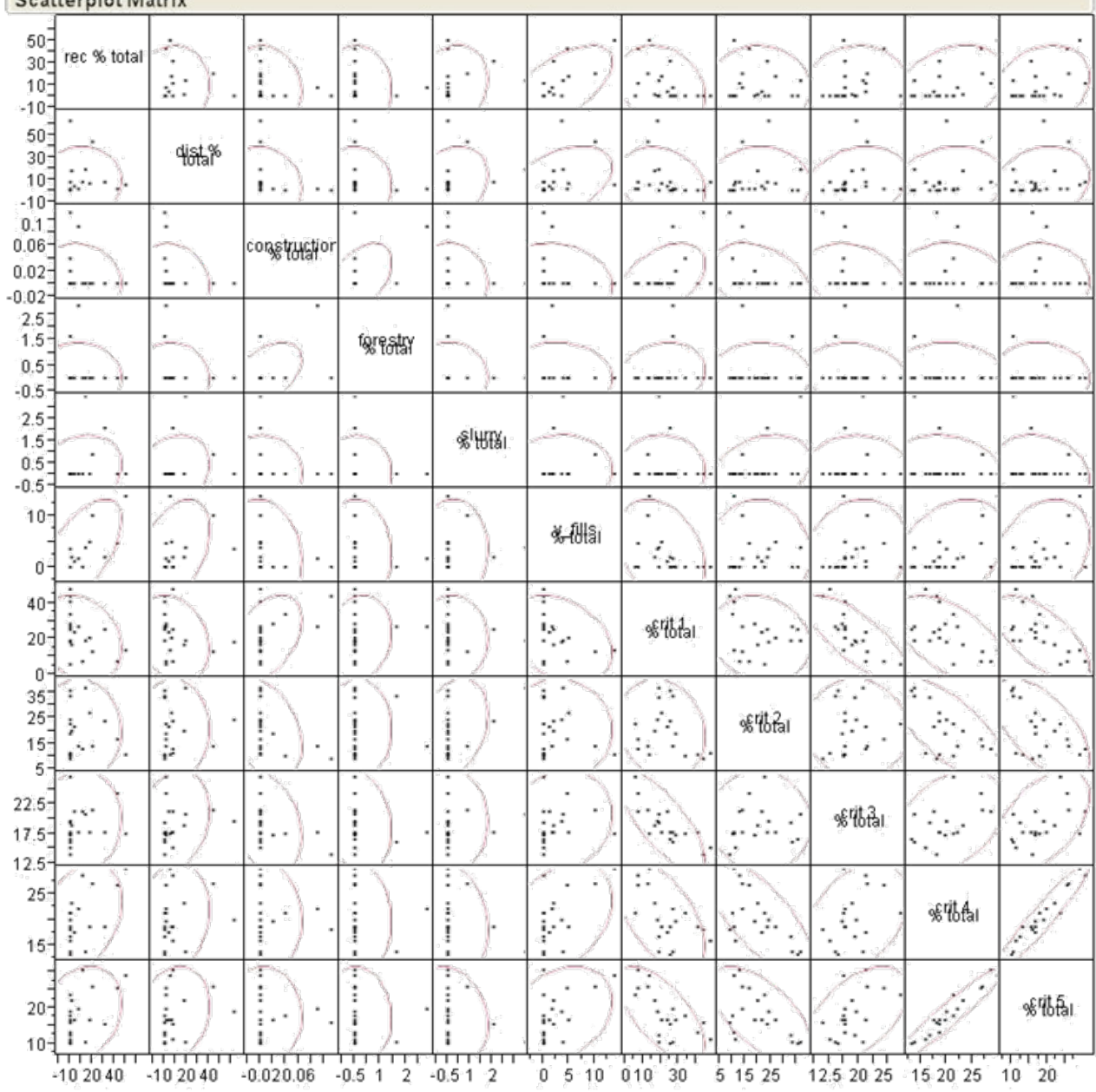

Figure 3.5.2-1: Co-variation among independent landscape variables

These full pairwise correlation comparisons show the extent that each independent landscape variable interacts with every other independent landscape variable. Positive correlations closer to a value of 1 show strong positive correlations, while negative correlations closer to a value of -1 show strong negative correlations. Correlations around a value of 0 show no correlation between variables. In this pairwise correlation comparison, the strongest 
relationship is between critical forest values of 1 and 3 , with a correlation value of -0.7613 , showing a strong negative correlation (figure 3.5.2-2). The highest positive correlation between independent variables exists between valley fills and total reclaimed area, with a correlation value of 0.6056 (figure 3.5.2-2). The remaining pairwise correlations between the independent landscape variables can be seen in figure 3.5.2-2. 


\begin{tabular}{|c|c|c|c|c|c|c|c|c|c|}
\hline \multicolumn{10}{|c|}{ Pairwise Correlations } \\
\hline Variable & by Variable & Correlation & Count & Lower $95 \%$ & Upper $95 \%$ & Signif Prob & $-.8-.6-.4-.2$ & 0.2 .4$. & .6 .8 \\
\hline dist $\%$ total & rec $\%$ total & 0.0255 & 38 & -0.2966 & 0.3424 & 0.8794 & & & \\
\hline \multicolumn{2}{|c|}{ construction $\%$ total rec $\%$ total } & -0.1343 & 38 & -0.4353 & 0.1937 & 0.4216 & & & \\
\hline \multicolumn{2}{|c|}{ construction $\%$ total dist $\%$ total } & -0.1641 & 38 & -0.4596 & 0.1642 & 0.3250 & & & \\
\hline forestry $\%$ total & rec $\%$ total & -0.0751 & 38 & -0.3856 & 0.2506 & 0.6539 & & & \\
\hline forestry $\%$ total & dist $\%$ total & -0.0864 & 38 & -0.3952 & 0.2399 & 0.6059 & & & \\
\hline forestry $\%$ total & construction $\%$ total & 0.4800 & 38 & 0.1893 & 0.6933 & $0.0023^{*}$ & & & \\
\hline slurry $\%$ total & rec $\%$ total & 0.1742 & 38 & -0.1541 & 0.4678 & 0.2956 & & & \\
\hline slurry $\%$ total & dist $\%$ total & 0.2080 & 38 & -0.1196 & 0.4948 & 0.2102 & & & \\
\hline slurry $\%$ total & construction $\%$ total & -0.0803 & 38 & -0.3900 & 0.2457 & 0.6318 & & & \\
\hline slurny $\%$ total & forestry $\%$ total & -0.0695 & 38 & -0.3807 & 0.2559 & 0.6784 & & & \\
\hline V_fills $\%$ total & rec $\%$ total & 0.6056 & 38 & 0.3546 & 0.7752 & $<.0001^{*}$ & & & \\
\hline V_fills $\%$ total & dist $\%$ total & 0.4282 & 38 & 0.1257 & 0.6578 & $0.0073^{*}$ & & & \\
\hline V_fills $\%$ total & construction $\%$ total & -0.1819 & 38 & -0.4740 & 0.1463 & 0.2745 & & & \\
\hline V_fills $\%$ total & forestry $\%$ total & -0.0787 & 38 & -0.3886 & 0.2472 & 0.6388 & & & \\
\hline V_fills $\%$ total & slurry $\%$ total & 0.0451 & 38 & -0.2786 & 0.3596 & 0.7882 & & & \\
\hline crit $1 \%$ total & rec $\%$ total & -0.2359 & 38 & -0.5166 & 0.0906 & 0.1539 & & & \\
\hline crit $1 \%$ total & dist $\%$ total & -0.2352 & 38 & -0.5161 & 0.0914 & 0.1552 & & & \\
\hline crit $1 \%$ total & construction $\%$ total & 0.4416 & 38 & 0.1420 & 0.6671 & $0.0055^{*}$ & & & \\
\hline crit $1 \%$ total & forestry $\%$ total & 0.1553 & 38 & -0.1730 & 0.4525 & 0.3520 & & & \\
\hline crit $1 \%$ total & slurry $\%$ total & -0.0117 & 38 & -0.3301 & 0.3092 & 0.9445 & & & \\
\hline crit $1 \%$ total & $v_{\text {_fills }} \%$ total & -0.3261 & 38 & -0.5848 & -0.0072 & $0.0457^{*}$ & & & \\
\hline crit $2 \%$ total & rec $\%$ total & -0.0495 & 38 & -0.3634 & 0.2746 & 0.7680 & & & \\
\hline crit $2 \%$ total & dist $\%$ total & -0.0115 & 38 & -0.3300 & 0.3093 & 0.9452 & & & \\
\hline crit $2 \%$ total & construction $\%$ total & -0.3481 & 38 & -0.6009 & -0.0320 & $0.0322^{*}$ & & & \\
\hline crit $2 \%$ total & forestry $\%$ total & -0.0095 & 38 & -0.3282 & 0.3112 & 0.9550 & & & \\
\hline crit $2 \%$ total & slurry $\%$ total & 0.2954 & 38 & -0.0268 & 0.5620 & 0.0717 & & & \\
\hline crit $2 \%$ total & $v_{\text {_fills }} \%$ total & -0.0437 & 38 & -0.3584 & 0.2799 & 0.7945 & & & \\
\hline crit $2 \%$ total & crit $1 \%$ total & -0.1595 & 38 & -0.4559 & 0.1688 & 0.3389 & & & \\
\hline crit $3 \%$ total & rec $\%$ total & 0.0387 & 38 & -0.2845 & 0.3540 & 0.8175 & & & \\
\hline crit $3 \%$ total & dist $\%$ total & 0.2190 & 38 & -0.1082 & 0.5035 & 0.1864 & & & \\
\hline crit $3 \%$ total & construction $\%$ total & -0.3128 & 38 & -0.5750 & 0.0076 & 0.0558 & & & \\
\hline crit $3 \%$ total & forestry $\%$ total & -0.1808 & 38 & -0.4732 & 0.1474 & 0.2772 & & & \\
\hline crit $3 \%$ total & slurry $\%$ total & 0.0022 & 38 & -0.3177 & 0.3216 & 0.9896 & & & \\
\hline crit $3 \%$ total & $v_{\text {fillls }} \%$ total & 0.1445 & 38 & -0.1837 & 0.4436 & 0.3869 & & & \\
\hline crit $3 \%$ total & crit $1 \%$ total & -0.7613 & 38 & -0.8694 & -0.5837 & $<.0001^{*}$ & & & \\
\hline crit $3 \%$ total & crit $2 \%$ total & -0.0423 & 38 & -0.3572 & 0.2811 & 0.8007 & & & \\
\hline crit $4 \%$ total & rec $\%$ total & 0.3114 & 38 & -0.0092 & 0.5740 & 0.0570 & & & \\
\hline crit $4 \%$ total & dist $\%$ total & 0.1488 & 38 & -0.1795 & 0.4472 & 0.3727 & & & \\
\hline crit $4 \%$ total & construction $\%$ total & -0.0412 & 38 & -0.3562 & 0.2822 & 0.8059 & & & \\
\hline crit $4 \%$ total & forestry $\%$ total & -0.0798 & 38 & -0.3896 & 0.2462 & 0.6339 & & & \\
\hline crit $4 \%$ total & slurry $\%$ total & -0.2272 & 38 & -0.5099 & 0.0997 & 0.1701 & & & \\
\hline crit $4 \%$ total & V_fills $\%$ total & 0.3386 & 38 & 0.0212 & 0.5940 & $0.037 \sigma^{*}$ & & & \\
\hline crit $4 \%$ total & crit $1 \%$ total & -0.5410 & 38 & -0.7338 & -0.2676 & $0.0005^{*}$ & & & \\
\hline crit $4 \%$ total & crit $2 \%$ total & -0.6844 & 38 & -0.8239 & -0.4669 & $<.0001^{*}$ & & & \\
\hline crit $4 \%$ total & crit $3 \%$ total & 0.3677 & 38 & 0.0544 & 0.6151 & $0.0231^{*}$ & & & \\
\hline crit $5 \%$ total & rec $\%$ total & 0.2263 & 38 & -0.1007 & 0.5092 & 0.1719 & & & \\
\hline crit $5 \%$ total & dist $\%$ total & 0.1845 & 38 & -0.1436 & 0.4761 & 0.2674 & & & \\
\hline crit $5 \%$ total & construction $\%$ total & -0.0560 & 38 & -0.3691 & 0.2685 & 0.7384 & & & \\
\hline crit $5 \%$ total & forestry $\%$ total & -0.0882 & 38 & -0.3967 & 0.2382 & 0.5985 & & & \\
\hline crit $5 \%$ total & slurry $\%$ total & -0.2328 & 38 & -0.5142 & 0.0939 & 0.1596 & & & \\
\hline crit $5 \%$ total & $v_{\text {ffills }} \%$ total & 0.2922 & 38 & -0.0303 & 0.5596 & 0.0751 & & & \\
\hline crit $5 \%$ total & crit $1 \%$ total & -0.6597 & 38 & -0.8088 & -0.4309 & $<.0001^{*}$ & & & \\
\hline crit $5 \%$ total & crit $2 \%$ total & -0.6062 & 38 & -0.7756 & -0.3553 & $<.0001^{*}$ & & & \\
\hline crit $5 \%$ total & crit $3 \%$ total & 0.5099 & 38 & 0.2272 & 0.7133 & $0.0011^{*}$ & & & \\
\hline
\end{tabular}

Figure 3.5.2-2: Full pairwise correlations among independent landscape variables 


\subsection{3 - Uni-variate Regression Analysis}

Next a uni-variate regression analysis was performed by setting the summer stream conductivity as the response variable, and adding all of the independent landscape variables as the driving variables. I then fit regression lines through all the derived scatter plots to examine the correlations between the driving and response variables (figure 3.5.3). This regression also provides probability values to show the statistical significance of the relationships between the independent landscape variables and the summer stream conductivity levels. Additionally, an R-squared value is given to show the strength of the correlation between the independent landscape variables and the summer stream conductivity levels.

\subsection{4 - Stepwise Multiple Regression}

With the presence of multiple independent variables, it is possible that the combination of two independent variables can explain additional variance in the response variable (Townsend et al. 2004). Using a stepwise multiple regression using the summer stream conductivity levels as the response variable and the independent landscape data types as "model effects" in JMP, these combinations of independent variables can be found that explain additional variance in the nitrate export levels (figure 3.5.4). Once these multiple independent variables are found, a model is run that shows leverage plots of each independent variable that explains additional variance in summer stream conductivity from the study areas. Additionally, a whole model plot is provided that shows the variance provided by the combination of these two independent variables.

Using the stepwise regression control panel in JMP, significant variables can be separated from insignificant variables for addition into a multivariate linear model. The 
stepwise regression control panel has editable areas, buttons and popup menus. You use these dialog features to limit regressor effect probabilities, determine the method of selecting effects, begin or stop the selection process, and create a model (SAS Institute Inc. 2009). The Pvalue threshold uses p-values (significance levels) to enter and remove effects from the model. Two other options appear when P-value Threshold is chosen: Prob to Enter is the maximum $p$ value that an effect must have to be entered into the model during a forward step. Prob to Leave is the minimum $\mathrm{p}$-value that an effect must have to be removed from the model during a backward step. In this analysis, the prob to enter is set to 0.250 , and the prob to leave is set to 0.100 (figure 3.5.4). The current estimates table lets you enter, remove, and lock in model effects. The platform begins with no terms in the model except for the intercept. The intercept is permanently locked into the model (SAS Institute Inc. 2009).

From this stepwise regression, it can be seen that out of the 11 independent landscape variables driving summer stream conductivity levels, only 6 of these independent landscape variables are significant, as seen in the step history section of figure 3.5.4. These 6 independent landscape variables are valley fills, existing mining related disturbance, reclaimed surface mine area, slurry ponds, critical forest value 4, and forestry related disturbance. These 6 independent landscape variables were then used in a multivariate linear regression in JMP. 


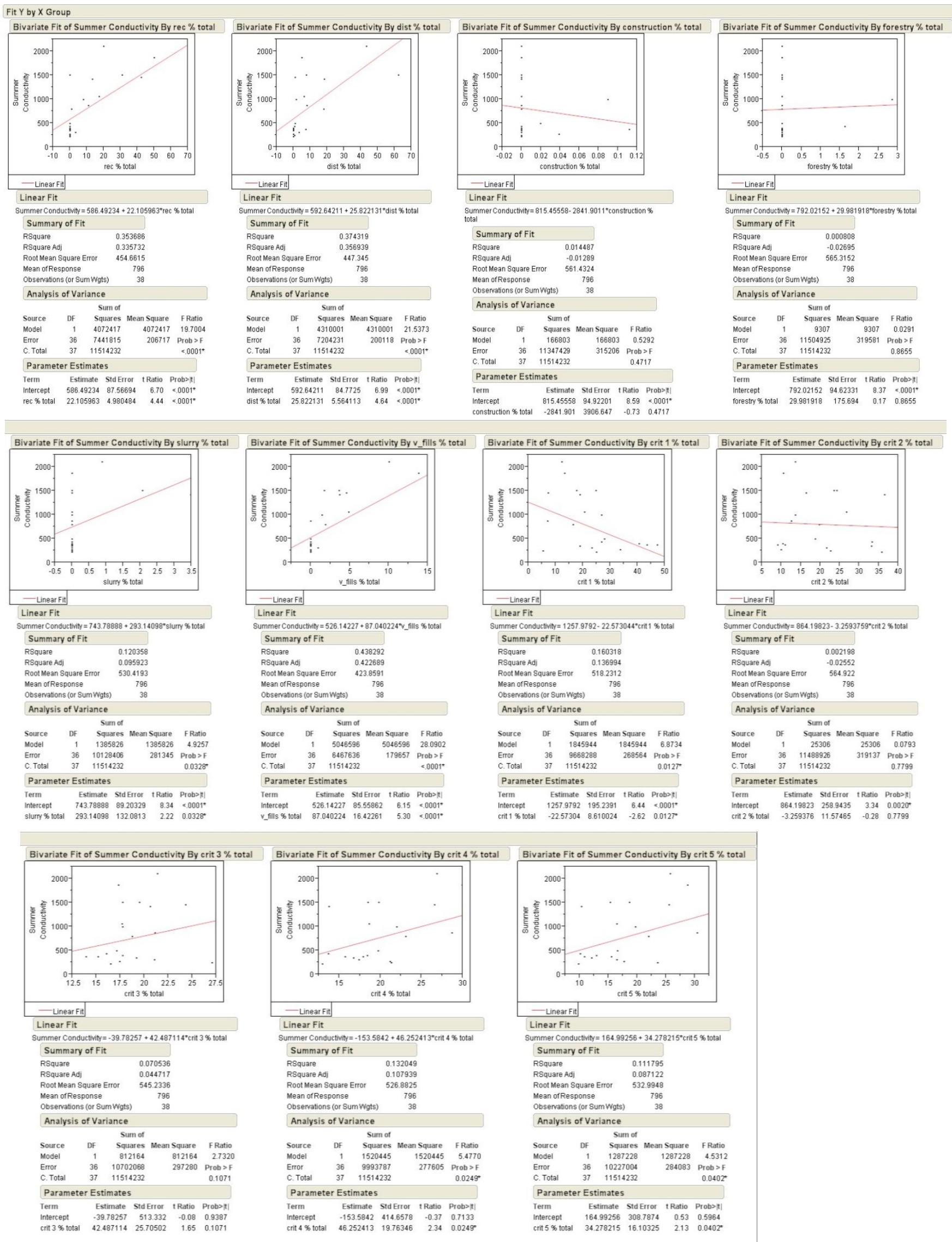

Figure 3.5.3: Uni-variate regression analysis for independent landscape variables 


\section{Stepwise Fit}

\begin{tabular}{|c|c|c|c|c|c|c|}
\hline \multicolumn{3}{|c|}{ ResponseSummer Conductivity } & & & & \\
\hline \multicolumn{7}{|c|}{ Stepwise Regression Control } \\
\hline \multirow{2}{*}{$\begin{array}{l}\text { Prob to Enter } \\
\text { Prob to Leave }\end{array}$} & 0250 & & & & & \\
\hline & 0.100 & & & & & \\
\hline \multicolumn{7}{|c|}{ Direction: Forward } \\
\hline \multicolumn{7}{|c|}{ Current Estimates } \\
\hline SSE & MSE & RSquare. & RSqual & Ire Adj & Cp & AiCc \\
\hline 2543707.5 & $31 \quad 82055079$ & 07791 & & $0.7363 \cdot 4.89$ & $912029 \quad 55$ & 51.0436 \\
\hline \multicolumn{2}{|c|}{ LockEntered Parameter } & Estimate & $\mathbf{n D F}$ & SS & "Fratio" & "Prob>F" \\
\hline \multicolumn{2}{|c|}{ Intercept } & $\therefore-78.071163$ & 1 & 0 & 0.000 & 1 \\
\hline \multicolumn{2}{|c|}{ rec $\%$ total } & 151600912 & 1 & 944249.6 & 11.508 & 0.00191 \\
\hline \multicolumn{2}{|c|}{ dist $\%$ total } & 20.1101514 & 1 & 1704845 & 20777 & $759 e-5$ \\
\hline \multicolumn{2}{|c|}{ construction $\%$ total } & 0 & 1 & 112.0836 & 0.001 & 0.97124 \\
\hline \multicolumn{2}{|c|}{ forestry \& total } & 149.230061 & 1 & 2262446 & 2.757 & 0.1069 \\
\hline \multicolumn{2}{|c|}{ slurry \% tọtal } & 185414395 & 1 & 4372129 & 5328 & 0.02782 \\
\hline \multicolumn{2}{|c|}{ Vi fils \% total } & 20.1242274 & 1 & 1181058 & 1.439 & 0.23933 \\
\hline \multicolumn{2}{|c|}{ crit $1 \%$ total } & 0 & 1 & 78973.52 & 0.961 & 0.33472 \\
\hline \multicolumn{2}{|c|}{ crit $2 \%$ total } & 0 & 1 & 42161.94 & 0.506 & 0.48253 \\
\hline \multicolumn{2}{|c|}{ crit $3 \%$ total } & 0 & 1 & 101108.9 & $1: 242$ & 0.27397 \\
\hline \multicolumn{2}{|c|}{ crit 4 \% totala } & 22.2498149 & 1 & 271595.1 & $3.310^{\circ}$ & 0.07853 \\
\hline \multicolumn{2}{|c|}{ crit $5 \%$ total } & 0 & 1 & 5746.967 & 0.068 & 0.79615 \\
\hline
\end{tabular}

\begin{tabular}{|rlllllll|}
\hline \multicolumn{2}{|l}{ Step History } \\
\hline Step & Parameter & Action & "Sig Prob" & Seq SS & RSquare & Cp & p \\
1 & Y fills $\%$ total & Entered & 0.0000 & 5046596 & 0.4383 & 39.459 & 2 \\
2 & dist $\%$ total & Entered & 0.0024 & 1520096 & 0.5703 & 24.194 & 3 \\
3 & rec $\%$ total & Entered & 0.0002 & 1684118 & 0.7166 & 70657 & 4 \\
4 & slurry $\%$ total & Entered & 0.1058 & 2522973 & 0.7385 & 6.2001 & 5 \\
5 & crit $4 \%$ total & Entered & 0.1048 & 241172.9 & 0.7594 & 5.4609 & 6 \\
6 & forestry $\%$ total Entered & 0.1069 & 2262446 & 0.7791 & 4.8912 & 7
\end{tabular}

Figure 3.5.4: Stepwise multiple regression for independent landscape variables 


\section{6 - Application of Multivariate Linear Conductivity Model to Surface Mine Permits Under Review}

The following sub-sections outline the application of the second iteration of the multivariate linear conductivity model to evaluate the summer stream conductivity levels at the outflow point of hydrologic catchment areas delineated for each mine permit boundary under review. The results from the conductivity calculations for each hydrologic catchment area can be used to determine the current health of waterways downstream of proposed and current surface mine permit boundaries in order to allow environmental agencies to make decisions regarding the granting, refusal, or re-evaluation of surface mine permit boundary proposals.

\subsection{1 - Delineating Hydrologic Catchment Areas for Permits Under Review}

In order to predict the downstream summer conductivity levels for each of the surface mine permits currently being held under review by the West Virginia EPA (figure 3.3.9), study areas were first delineated on the segment level watershed scale to determine the total area possibly affected by each permit under review. These study areas include all segment level watersheds within the hydrological catchment area of each of the permits under review, as well as an aggregate outflow point for all of the segment level watersheds delineated as the catchment area for each permit. The aggregate outflow point for each study area serves as the location where summer stream conductivity was calculated using the second iteration of the multivariate linear conductivity model outlined previously. The study areas for each permit under review were delineated using the Mass Balance Accumulator toolbar for ArcMap. This toolbar allows for the selection of a single segment level watershed, and then automatically delineated each segment level watershed that flows into the selected watershed. By 
systematically selecting segment level watersheds at the location most downstream in the permit boundary, and then working outward from the permit boundary in the downstream direction, a hydrological catchment area can be delineated that includes either part of a permit boundary, and whole permit boundary, or multiple permit boundaries nested in the same catchment area (figure 3.6.1). In total, 15 different hydrological catchment areas were delineated (figure 3.6.1).

\section{Water Quality Study Areas: Permits Under Review}

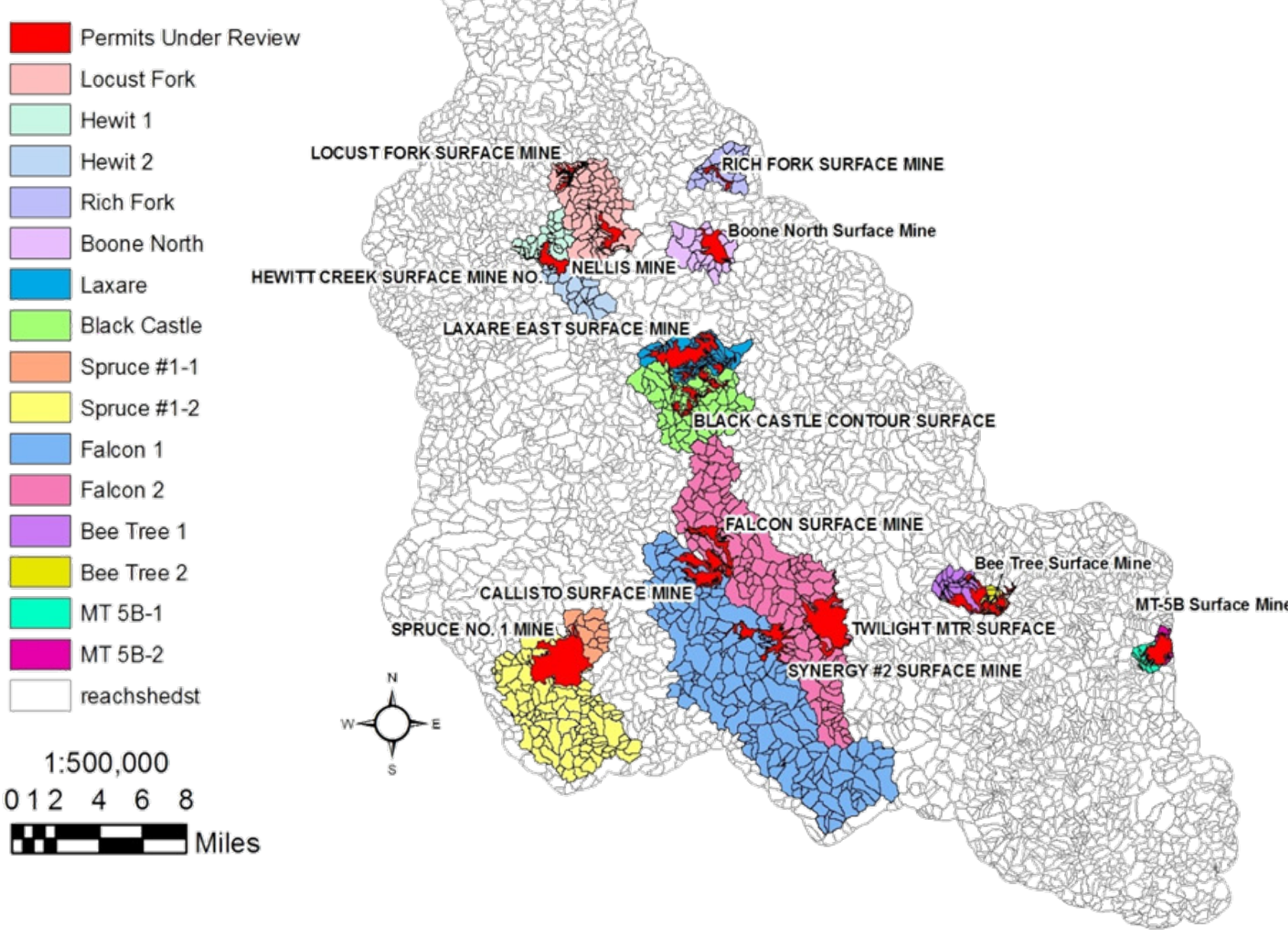

Figure 3.6.1: Water quality study area delineation for surface mine permits under review 


\subsection{2 - Predicting Summer Stream Conductivity Using Multivariate Linear Conductivity Model}

Each of the independent landscape variables used in the final multivariate linear conductivity model were then summarized for each of the hydrological catchment areas to calculate percentages of the total area of each catchment area comprised of each independent landscape variable (table 3.6.2-1). These percentages of the total hydrological catchment areas were then incorporated into the final multivariate linear conductivity model to calculate the current summer stream conductivity levels at the outflow point of each catchment area based on the current landscape disturbance present in each catchment area (table 3.6.2-2). These summer conductivity levels are the basis for determining the current health of each catchment area that include the surface mine permits currently under review, and are an indicator as to how much, if any, additional mining can take place within these permits before summer stream conductivity levels become too high. Based on macro-invertebrate change point analysis based on summer stream conductivity levels (Petty, 2010), stream health thresholds were calculated for use as an indicator of current stream health and additional mine carrying capacity in the landscape. These thresholds are as follows (Petty, 2010):

\section{EXCELLENT CONDITIONS}

- mining threshold needed to ensure that stream conductivities are below $300 \mu \mathrm{S} / \mathrm{cm}$

GOOD CONDITIONS

- \% mining range that correlates to variable stream conditions but generally relates to conductivities that transition from $300-500 \mu \mathrm{S} / \mathrm{cm}$.

FAIR CONDITIONS

- \% mining range that correlates to variable stream conditions but generally relates to conductivities that range from $500-750 \mu \mathrm{S} / \mathrm{cm}$.

POOR CONDITIONS

- $\%$ mining range that relates to conductivities that transition from $750-1000 \mu \mathrm{S} / \mathrm{cm}$. 
- This is a range of mining that very likely results in unacceptable conditions in larger rivers (e.g., at the outflow of 12-Digit HUCs).

\section{VERY POOR CONDITIONS}

- Mining threshold that results in conductivities that almost certainly will exceed 1000 $\mu \mathrm{S} / \mathrm{cm}$.

\begin{tabular}{|c|c|c|c|c|c|c|c|c|c|c|c|c|c|}
\hline Study Area & total_area & rec_total & $\%$ total & dist_total & $\%$ total & forestry & $\%$ total & slurry & $\%$ total & v_fills & $\%$ total & crit4 count & $\%$ total \\
\hline Locust Fork & 34547195.16 & 89078.74 & 0.26 & 1435601.27 & 4.16 & 7062806.64 & 20.44 & 0.00 & 0.00 & 445960.42 & 1.29 & 68472.00 & 1.98 \\
\hline Hewit_1 & 10128943.40 & 0.00 & 0.00 & 752690.02 & 7.43 & 0.00 & 0.00 & 0.00 & 0.00 & 578393.83 & 5.71 & 19522.00 & 1.93 \\
\hline Hewit_2 & 14007817.59 & 0.00 & 0.00 & 308682.58 & 2.20 & 172808.37 & 1.23 & 0.00 & 0.00 & 385671.81 & 2.75 & 24520.00 & 1.75 \\
\hline Rich Fork & 11156504.14 & 1006354.99 & 9.02 & 1090548.66 & 9.78 & 0.00 & 0.00 & 0.00 & 0.00 & 475931.92 & 4.27 & 18180.00 & 1.63 \\
\hline Boone North & 15472944.69 & 909137.54 & 5.88 & 1444086.37 & 9.33 & 0.00 & 0.00 & 0.00 & 0.00 & 110872.88 & 0.72 & 23800.00 & 1.54 \\
\hline Laxare & 18163765.01 & 137551.94 & 0.76 & 3972246.74 & 1.87 & 0.00 & & & .00 & 454282.15 & 2.50 & & 1.93 \\
\hline Spruce 1_1 & 69519366.84 & 3027333.64 & 4.35 & 7626743.39 & 10.97 & 0.00 & 0.00 & 0.00 & 0.00 & 3050858.91 & 4.39 & 118523.00 & 1.70 \\
\hline Spruce 1_2 & 10738308.80 & 0.00 & 0.00 & 1800736.92 & 16.77 & 43773.23 & 0.41 & 0.00 & 0.00 & 259874.52 & 2.42 & 18556.00 & 1.73 \\
\hline Falcon_1 & 153671444.44 & 7515198.74 & 4.89 & 7433802.77 & 4.84 & 4017912.37 & 2.61 & 228223.09 & 0.15 & 2557439.04 & 1.66 & 222742.00 & 1.45 \\
\hline Falcon_2 & 109096065.59 & 2642997.76 & 2.42 & 13652166.73 & 12.51 & 0.00 & 0.00 & 34790.03 & 0.03 & 2390280.74 & 2.19 & 180687.00 & 1.66 \\
\hline Bee Tree_1 & 8811540.70 & 0.00 & 0.00 & 120187.36 & 1.36 & 0.00 & 0.00 & 0.00 & 0.00 & 0.00 & 0.00 & 17707.00 & 2.01 \\
\hline Bee Tree_2 & 3360578.01 & 0.00 & 0.00 & 20716.96 & 0.62 & 0.00 & 0.00 & 0.00 & 0.00 & 0.00 & 0.00 & 5557.00 & 1.65 \\
\hline MT 5B_1 & 3693987.76 & 398597.05 & 10.79 & 366698.39 & 9.93 & 0.00 & 0.00 & 0.00 & 0.00 & 0.00 & 0.00 & 7636.00 & 2.07 \\
\hline
\end{tabular}

Table 3.6.2-1: Independent landscape variable summary for each hydrological catchment area

\begin{tabular}{|l|c|}
\hline Study Area & Summer Stream Conductivity \\
\hline Locust Fork & 2862.59 \\
\hline Hewit_1 & 427.73 \\
\hline Hewit_2 & 415.62 \\
\hline Rich Fork & 640.62 \\
\hline Boone North & 481.53 \\
\hline Laxare & 651.91 \\
\hline Black Castle & 1142.01 \\
\hline Spruce 1_1 & 562.33 \\
\hline Spruce 1_2 & 584.45 \\
\hline Falcon_1 & 744.22 \\
\hline Falcon_2 & 503.61 \\
\hline Bee Tree_1 & 184.17 \\
\hline Bee Tree_2 & 166.44 \\
\hline MT 5B_1 & 592.33 \\
\hline MT 5B_2 & 310.88 \\
\hline
\end{tabular}

Table 3.6.2-2: Summer stream conductivity calculations for each hydrological catchment area 


\section{Chapter 4. Discussion and Results}

\section{1 - Current Landscape Condition}

As a result of the numerous spatial analysis and geoprocessing operations conducted on the Coal River watershed, a detailed landscape analysis pertaining to the current ecological condition of the watershed was achieved. This landscape analysis gives important feedback as to the category and quantity of ecological damage that will occur if the 15 surface mine permits are granted and a complete mine-out scenario is realized. Based on the 2009 forest cover analysis based off of the 2009 NAIP true color aerial imagery, there is currently $542,857.83$ acres of forested, undisturbed land in the Coal River watershed. When this 2009 forest cover is combined with slopes over 25 degree slope, there is a total of 306,044.06 acres of forested area that is over a 25 degree slope. A total of $276,402.08$ acres of the forest cover in the Coal River watershed lies within headwater watersheds, which are the most sensitive watersheds to downstream water quality if disturbed. Out of the forested area of the Coal River watershed, 174,903.99 acres lie within riparian areas. When these forested areas are combined (forested areas over 25 degree slope, headwater forest, and riparian forest), a forested area critical to water quality is calculated, which composes $465,960.38$ acres of the Coal River watershed. This critical forest is highly sensitive to disturbance in terms of downstream water quality. In the event of a complete mine build out of the 15 mine permits currently under review by the WV EPA, a total of 9,639.21 acres of forest critical to water quality would be lost (figure 3.3.9), causing a significant degradation of downstream water quality.

In total, the zones of critical concern comprised $11,721.33$ acres of the Coal River Watershed. Surface mining permit boundaries in the Coal River Watershed were found that 
either intersected or were within 500 meters of a zone of critical concern. A table was then created depicting all of the facility names of the permit boundaries that could potentially affect the zones of critical concern with the activity status of each of the permits appended to their respective facility names (figure 3.3.11). In total, there were 44 permits that either intersected or were within 500 meters of a zone of critical concern in the Coal River Watershed. Of these 44 permits, 31 were still current, 11 were expired, and 2 were under review by the EPA. In addition to this loss of area related to the zones of critical concern, In the scenario that every one of the permits under review were completely mined out, there would be a loss of 9,084.11 acres of migratory bird habitat in the coal river watershed. There is a total of $104,878.27$ acres of Louisiana Waterthrush habitat in the Coal River Watershed, and a total of 2,347.75 acres of that habitat could also be lost with a total build-out of all of the surface mining permits currently under review by the EPA.

With the realization of a complete mine build-out scenario in all 15 surface mine permit boundaries currently under review by the EPA, the Coal River watershed would experience a great loss of wildlife habitat as well as the water quality necessary to sustain the lives of many different types of wildlife. There would be a great loss of macro-invertebrate species richness in waterways downstream of mining disturbance, as well as a massive decline in both neotropical and Louisiana Waterthrush populations residing in the Coal River Watershed. These species richness and distribution statistics are a very strong indicator of the overall health of the watershed as a whole. 


\title{
4.1.1 - Multivariate Linear Regression (First Iteration)
}

The first iteration of the multivariate linear regression was conducted using all 38 study areas in the Coal River watershed (figure 4.1.1). This iteration produced an r-squared value of 0.779 (a value of 1 being the highest). R-squared is used in the context of statistical models whose main purpose is the prediction of future outcomes on the basis of other related information. It is the proportion of variability in a data set that is accounted for by the statistical model, and it provides a measure of how well future outcomes are likely to be predicted by the model. This iteration also produced a root mean square error (RMSE) of 286.45. The RMSE is a frequently used measure of the differences between values predicted by a model or an estimator and the values actually observed from the thing being modeled or estimated, and is a good measure of precision. These individual differences are also called residuals, and the RMSE serves to aggregate them into a single measure of predictive power. This iteration does not take into account outliers in the data, and by examining the whole model predicted plot in figure 4.1.1, there are a number of points falling outside of the confidence curves (figure 4.1.1). The confidence curves indicate whether the test is significant at the $5 \%$ level by showing a confidence region for the line of fit. If the confidence region between the curves contains the horizontal line, then the effect is not significant. If the curves cross the line, the effect is significant (SAS Institute Inc. 2009). The multivariate linear model generated by this first iteration using all 38 study areas is:

\author{
Summer Conductivity $=$ \\ 15.16(reclaimed)+20.11(disturbed)+149.23(forestry)+185.41(slurry)+20.12(valley \\ fills)+22.25(critical forest 4)- 78.07
}


*Coefficients represent percent of total study area composed of given landscape variable.

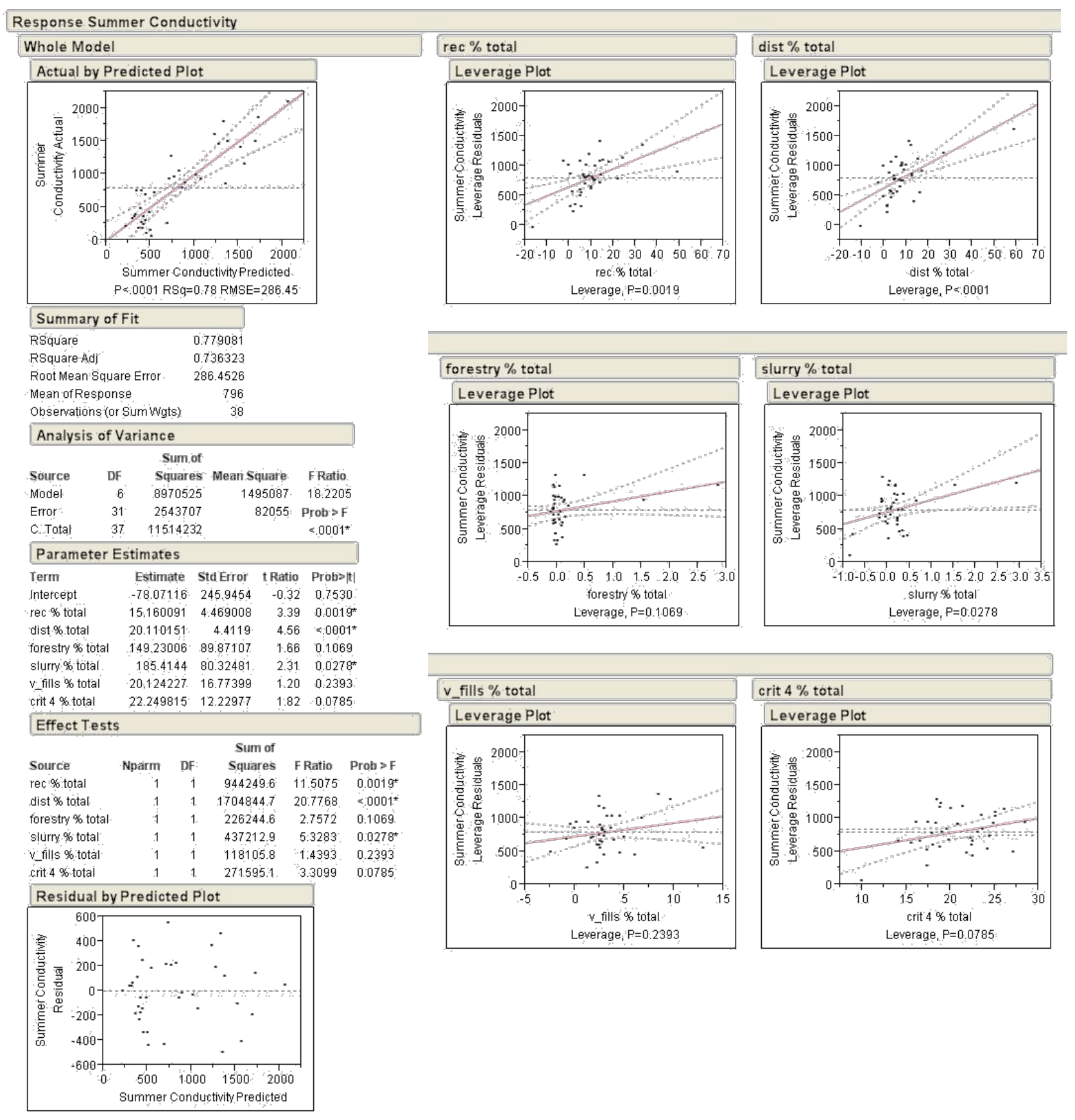

Figure 4.1.1: Multivariate linear regression (first iteration) 


\title{
4.1.2 - Multivariate Linear Regression (Second Iteration)
}

The second iteration of the multivariate linear regression removes some of the outlier study areas that fall far outside of the confidence curves. Possible sources of outliers are: recording and measurement errors, incorrect distribution assumption, unknown data structure, or novel phenomenon (Iglewicz, 1993). Recording and measurement errors are often the first suspected source of outliers. Incorrect assumption about the data distribution can lead to mislabeling data as outliers. The data which does not fit well into the assumed distribution may fit well into a different distribution (Iglewicz, 1993). Outliers can sometimes be accommodated in the data analysis. This process prevents the outliers from biasing the estimated population parameters. Some ways of accommodating outliers are the use of trimmed means, scale estimators, or confidence intervals. In calculations of a trimmed mean a fixed percentage of data is dropped from each end of an ordered data (Iglewicz, 1993). In total, 14 study areas were removed from the regression, leaving 24 study areas that fall within the confidence curves in the leverage plot (figure 4.1.2). With these outliers removed, much higher $r$-squared and RMSE values are achieved. The new $r$-squared value is 0.96 , and the new RMSE is 132.35 . These new values show much strong relationships in the data, and much more accurate prediction of summer stream conductivity based on the 6 remaining independent landscape variables. The multivariate linear model generated by this first iteration using these 24 remaining study areas is:

\author{
Summer Conductivity $=$ \\ 22.46 (reclaimed)+19.30(disturbed)+126.70(forestry)+134.83(slurry)+22.28(valley \\ fills)+9.29(critical forest 4$)+139.18$
}




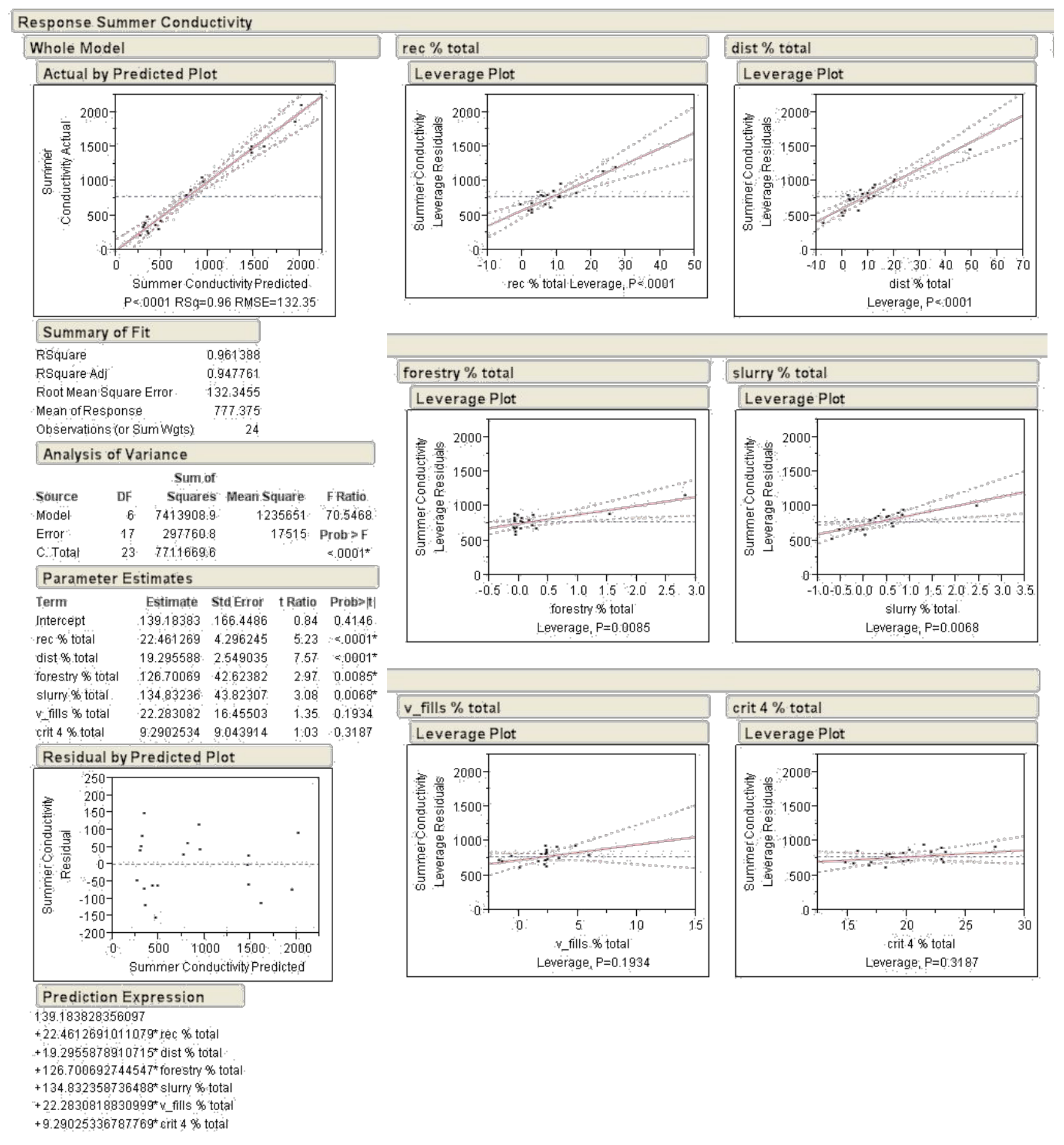

Figure 4.1.2: Multivariate linear regression (second iteration) 


\section{2 - Multivariate Linear Conductivity Model}

Based on the summer stream conductivity thresholds outlined earlier, additional carrying capacity can be examined for each hydrological catchment area, and in turn, each surface mine permit under review. Out of these 15 hydrologic catchment areas, based on current summer stream conductivity calculations, 2 are considered to be in excellent condition, 4 in good condition, 7 in fair condition, and 2 in very poor condition (table 4.2.1). No additional mining should occur in the 2 catchment areas listed as very poor condition, which are the Locust Fork (containing the Locust Fork and Nellis Mine permits) and Black Castle (containing the Black Castle Contour Surface) study areas (figure 3.6.2). The 13 catchment areas listed as excellent, good, and fair condition can sustain additional mining until the absolute cutoff summer conductivity level of $750 \mu \mathrm{S} / \mathrm{cm}$ is reached. Just how much disturbance can take place in each catchment area can then be explored before the summer conductivity level cutoff is reached.

\begin{tabular}{|l|c|c|}
\hline Study Area & Summer Stream Conductivity & Condition \\
\hline Locust Fork & 2862.59 & Very Poor \\
Hewit_1 & 427.73 & Good \\
Good \\
Hewit_2 & 415.62 & Fair \\
\hline Rich Fork & 640.62 & Good \\
\hline Boone North & 481.53 & Fair \\
\hline Laxare & 651.91 & Very Poor \\
\hline Black Castle & 1142.01 & Fair \\
\hline Spruce 1_1 & 562.33 & Fair \\
\hline Spruce 1_2 & 584.45 & Fair \\
\hline Falcon_1 & 744.22 & Fair \\
\hline Falcon_2 & 503.61 & Excellent \\
\hline Bee Tree_1 & 184.17 & Excellent \\
\hline Bee Tree_2 & 166.44 & Fair \\
\hline MT 5B_1 & 592.33 & Good \\
\hline MT 5B_2 & 310.88 & \\
\hline
\end{tabular}

Table 4.2.1: Stream health conditions for each hydrological catchment area 
By altering the percentages of disturbance, slurry ponds, and valley fills in each of the hydrologic catchment areas, an additional surface mining carrying capacity for each catchment area was calculated. Based off of the trends of previous surface mining operations in the Coal River Watershed, every 5 percent increase in surface mining disturbance yields approximately a 1 percent increase in total valley fill area, and a 0.1 percent increase in slurry ponds in the respective mining permit area. Using this ratio of 5(disturbance): 1 (valley fills): 0.5 (slurry ponds), maximum increases in mining related disturbance, valley fills, and slurry ponds in each hydrologic catchment area were calculated that result in a maximum cutoff summer stream conductivity reading at the outflow point of each catchment area of approximately $750 \mu \mathrm{S} / \mathrm{cm}$ (table 4.2.2).

\begin{tabular}{|c|c|c|c|c|c|c|c|c|c|c|}
\hline Study Area & $\begin{array}{c}\text { dist } \\
\% \text { total }\end{array}$ & $\begin{array}{l}\text { new dist } \\
\% \text { total }\end{array}$ & Difference & $\begin{array}{l}\text { slurry } \\
\% \text { total }\end{array}$ & $\begin{array}{c}\text { New slurry } \\
\% \text { total }\end{array}$ & Difference & $\begin{array}{l}\text { v_fills } \\
\% \text { total }\end{array}$ & $\begin{array}{c}\text { New v_fills } \\
\% \text { total }\end{array}$ & Difference & $\begin{array}{c}\text { Summer Stream } \\
\text { Conductivity }\end{array}$ \\
\hline Locust Fork & 4.16 & 4.16 & 0.00 & 0.00 & 0.00 & 0.00 & 1.29 & 1.29 & 0.00 & 2862.59 \\
\hline Hewit_1 & 7.43 & 19.93 & 12.50 & 0.00 & 0.25 & 0.25 & 5.71 & 8.21 & 2.50 & 758.36 \\
\hline Hewit_2 & 2.20 & 13.75 & 11.55 & 0.00 & 0.28 & 0.28 & 2.75 & 5.50 & 2.75 & 736.74 \\
\hline Rich Fork & 9.78 & 13.55 & 3.77 & 0.00 & 0.08 & 0.08 & 4.27 & 5.02 & 0.75 & 740.39 \\
\hline Boone North & 9.33 & 19.33 & 10.00 & 0.00 & 0.20 & 0.20 & 0.72 & 2.72 & 2.00 & 746.07 \\
\hline Laxare & 21.87 & 25.62 & 3.75 & 0.00 & 0.08 & 0.08 & 2.50 & 3.25 & 0.75 & 751.10 \\
\hline Black Castle & 27.20 & 27.20 & 0.00 & 0.00 & 0.00 & 0.00 & 10.92 & 10.92 & 0.00 & 1142.01 \\
\hline Spruce 1_1 & 10.97 & 17.97 & 7.00 & 0.00 & 0.14 & 0.14 & 4.39 & 5.79 & 1.40 & 747.52 \\
\hline Spruce 1_2 & 16.77 & 22.77 & 6.00 & 0.00 & 0.12 & 0.12 & 2.42 & 3.62 & 1.20 & 743.17 \\
\hline Falcon_1 & 4.84 & 4.84 & 0.00 & 0.15 & 0.15 & 0.00 & 1.66 & 1.66 & 0.00 & 744.22 \\
\hline Falcon_2 & 12.51 & 21.76 & 9.25 & 0.03 & 0.19 & 0.16 & 2.19 & 4.04 & 1.85 & 744.31 \\
\hline Bee Tree_1 & 1.36 & 22.61 & 21.25 & 0.00 & 0.43 & 0.43 & 0.00 & 4.25 & 4.25 & 746.21 \\
\hline Bee Tree_2 & 0.62 & 22.62 & 22.00 & 0.00 & 0.44 & 0.44 & 0.00 & 4.40 & 4.40 & 748.47 \\
\hline MT 5B_1 & 9.93 & 15.93 & 6.00 & 0.00 & 0.12 & 0.12 & 0.00 & 1.20 & 1.20 & 751.10 \\
\hline MT 5B_2 & 3.71 & 20.21 & 16.50 & 0.00 & 0.33 & 0.33 & 0.00 & 3.30 & 3.30 & 747.34 \\
\hline
\end{tabular}

Table 4.2.2: Maximum increases in disturbance for each hydrological catchment area 
The Locust Fork and Black Castle catchment areas are already well into the "very poor" condition classification, meaning there shall be no additional mining allowed in these areas. The Falcon 1 catchment area allowed for no additional mining related disturbance, due to the fact that its current summer stream conductivity level already sits at $744.22 \mu \mathrm{S} / \mathrm{cm}$. The remaining 12 catchment areas all allowed for additional surface mine carrying capacity of varying levels. The Bee Tree 2 catchment area allowed for the highest additional mining related disturbance before the maximum summer conductivity threshold was reached, with a $22 \%$ increase in disturbance, a $0.44 \%$ increase in slurry ponds, and a $4.40 \%$ increase in valley fills. This was immediately followed by the Bee Tree 1 catchment area, which allowed for a $21.25 \%$ increase in disturbance, a $0.43 \%$ increase in slurry ponds, and a $4.25 \%$ increase in valley fills. The Laxare catchment area allowed for the lowest additional mining related disturbance before the maximum summer conductivity threshold was reached, with a $3.75 \%$ increase in disturbance, a $0.08 \%$ increase in slurry ponds, and a $0.75 \%$ increase in valley fills.

These calculations of the maximum additional mining capacity of each study area should be used by state and federal environmental agencies in order to grant or deny additional surface mining permit boundaries. By broadening the focal area from just a permit boundary to an entire catchment area that the permit boundary falls within, the permit boundary itself becomes slightly less relevant due to the fact that if the study area has a current summer stream conductivity level that is close to or past the maximum threshold, the permit boundary should be denied. If the study area has a current summer stream conductivity level that is far below the maximum threshold, other factors would come into play regarding the granting or denial of the permit boundary, such as species habitat loss, ecological land unit loss, and zones 
of critical concern. Just because a hydrologic catchment area has not reached the maximum summer stream conductivity threshold at its outflow point does not mean that mining activity disturbance should be allowed until that threshold is reached, healthy hydrologic catchment areas should be preserved as much as possible.

\section{3 - Potential for Economic and Environmental Policy in West Virginia's Coal Industry}

In order to ensure the ecological future of regions such as the Appalachian region where mining operations are such an essential part of the economy, both economic and environmental policy must be both enforced and revised. This could be achieved through the implementation of taxes on the production of negative environmental externalities and economic incentives to reduce the output of these negative externalities. Research on this issue is of great importance, as it could lead to much more sustainable mining practices to ensure the future of the mining industry, as well as the future of our environment. This research can spawn new policies and regulations that can steer the mineral extraction industry in the right direction; directions that will minimize environmental damage, as well as reclaim land that has already been damaged. Economic incentives can be instituted in order to reward mining companies who choose to do the research and follow sustainability guidelines in order to both minimize the current environmental impacts, as well as ensure the future of the industry and those who need it. There is a great need for environmental and economic policy reform in the West Virginia and the U.S. mineral extraction industries. If these changes do not occur, we have no way of ensuring the future health of the environment we live in, or the natural resources we need. 


\subsection{1 - Pigouvian Tax}

One policy that could potentially reduce the damage on watersheds associated with mountain top removal activities would be the implementation of a Pigouvian tax. A Pigouvian tax, sometimes referred to as a "Green Tax" or a "Pollution Tax", is a tax targeted on a market activity that generates negative externalities. The implementation of this Pigouvian tax is intended to correct the outcome of a targeted market by reducing or eliminating the negative externality or externalities being focused upon. When there is a negative externality present in the targeted market, the social cost of that market's activities is not covered by the private cost of the activities. In turn, the resulting market outcome is inefficient, and over-consumption of the market product can occur. By implementing a Pigouvian tax that is equal in magnitude to the negative externality, a state of efficiency can be achieved in the outcome of the target market. If there is no means to reduce the level of the negative externality without reducing the market output, then the tax must be placed on the units of market output, which will discourage excessive levels of production. If the level of the negative externality can be reduced without reducing the total market production level, such as through the use of pollution abatement equipment or precautionary measures, then the tax must be placed on units of the negative externality being created by the market activity, rather than on the units of market output.

In the case of the coal industry in West Virginia, there are measures that can be taken to ensure reduced levels of negative externalities resulting from mountaintop mining activities. Through appropriate landscape vulnerability analysis of potential mining areas, mining activities can be focused on areas that are less likely to cause increased levels of runoff and the 
sedimentation of waterways. In this case, the Pigouvian tax will be implemented on units of sedimentation measured in terms of the volume of total dissolved solids seen in waterways in the flow path of the mining activities. The producers in this instance are the mining companies producing the externality, and the consumers are people who value water quality in the watersheds containing mining activities. The instatement of a Pigouvian tax on the volume of total dissolved solids equal to $\mathrm{p}_{1}-\mathrm{p}_{2}$ (Figure 4.3.1) will in turn reduce the volume of total dissolved solids created as a result of the mining activities from $q_{0}-q_{1}$ (Figure 4.3.1). This will also lead to a change in the price of the market output good seen by consumers from $p_{0}$ up to $\mathrm{p}_{1}$ (Figure 4.3.1). The implementation of the Pigouvian tax results in various welfare effects. In this study, these areas are being measured using the actual area in square units of the areas lost and gained by producers, consumers, and taxpayers. These areas are not exact in terms of costs associated with the mining industry, due to the fact that information has not been acquired about these costs. These areas, however, are an accurate measurement of the relative losses or gains seen by producers and consumers after the implementation of the tax. 
After the implementation of the tax on the volume of total dissolved solids created by mining activities, the producers (mining companies) will lose areas $d+e+f$ in producer surplus (Figure 4.3.1), equal to 0.7311 square units. The consumers will lose areas $a+b+c$ in consumer surplus, equal to 0.7311 square units. Consumers will also gain area $h$, which is equal to areas $f$ $+c+m$, equal to 0.9038 square units. Tax payers will gain areas $a+b+d+e$ in the form of

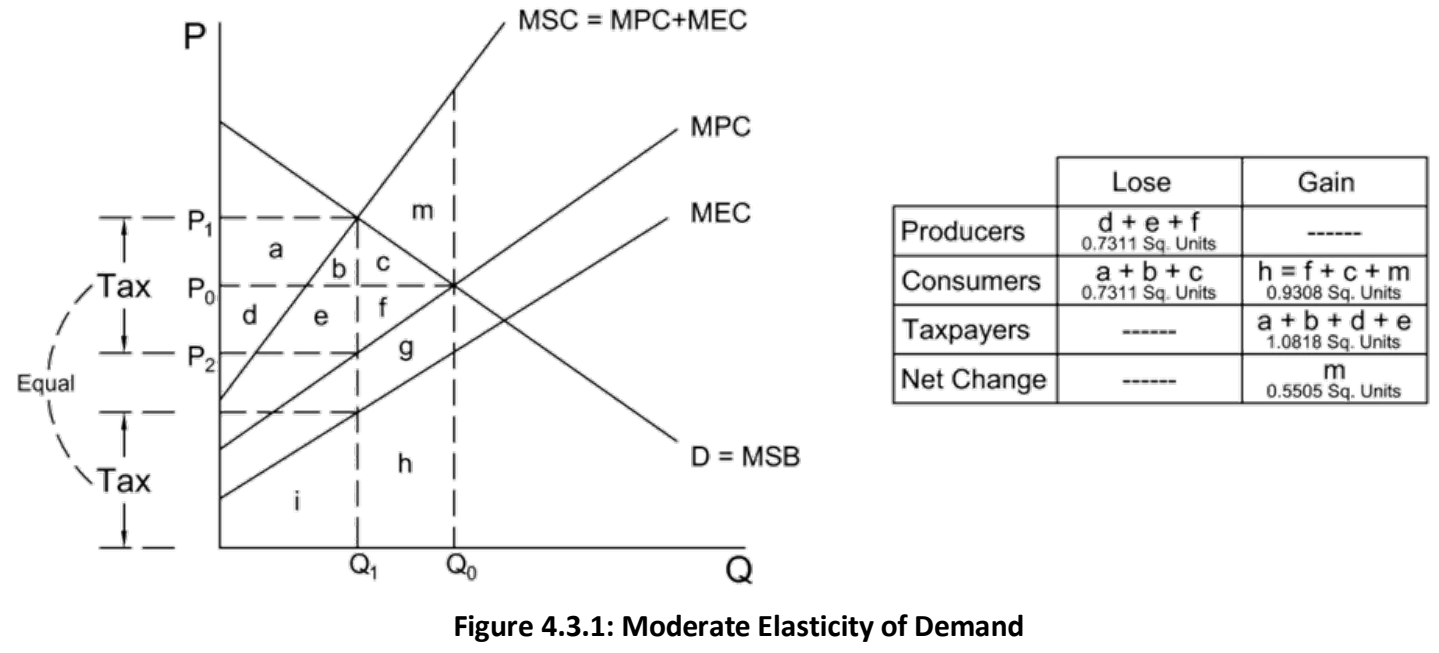

government revenue, equal to 1.0818 square units. The net effect of the implementation of the Pigouvian tax on the volume of total dissolved solids created is equal to area $m$, equal to 0.5505 square units. In this diagram (Figure 4.3.1), the elasticity of demand is relatively moderate, which is proven by the fact that the area of consumer surplus lost by consumers is equal to the area of producer surplus lost by producers. This shows an even split in who (producers and consumers) bears the burden of the Pigouvian tax.

Since the elasticity of demand cannot be accurately calculated in this study due to a lack of survey data, the effects of the implementation of the Pigouvian tax must also be examined with varying elasticities of demand. This shows who will bear more of the burden of the Pigouvian tax in reference to the potential elasticity of demand for the volume of total 
dissolved solids resulting from mountaintop removal mining activities. While varying the elasticities of demand, which is the marginal social benefit (MSB) for the volume of total dissolved solids resulting from mountaintop removal activities, the marginal external cost (MEC), marginal private cost (MPC), and the marginal social cost (MSC) are held constant. Figure 4.3.2 shows the effects of the implementation of the Pigouvian tax on the volume of total dissolved solids when the elasticity of demand for the volume of total dissolved solids is lower than that of Figure 4.3.1.

With this lower elasticity of demand, producers still lose areas $d+e+f$ in producer surplus (Figure 4.3.2), but this areas is now equal to 0.3023 square units (decrease of 0.4288 square units). The consumers will still lose areas $a+b+c$ (Figure 4.3.2) in consumer surplus, but this area is now equal to 0.5799 square units (decrease of 0.1512 square units). Consumers will still gain area $h$, which is equal to areas $f+c+m$ (Figure 4.3.2), but this area is now equal to 0.4310 square units (decrease of 0.4998 square units). Tax payers will still gain areas $a+b+d+$ $e$ (Figure 4.3.2) in the form of government revenue, which is now equal to 0.6954 square units (decrease of 0.3864 square units). The net effect of the implementation of the Pigouvian tax on the volume of total dissolved solids created is still equal to area $m$ (Figure 4.3.2), which is now

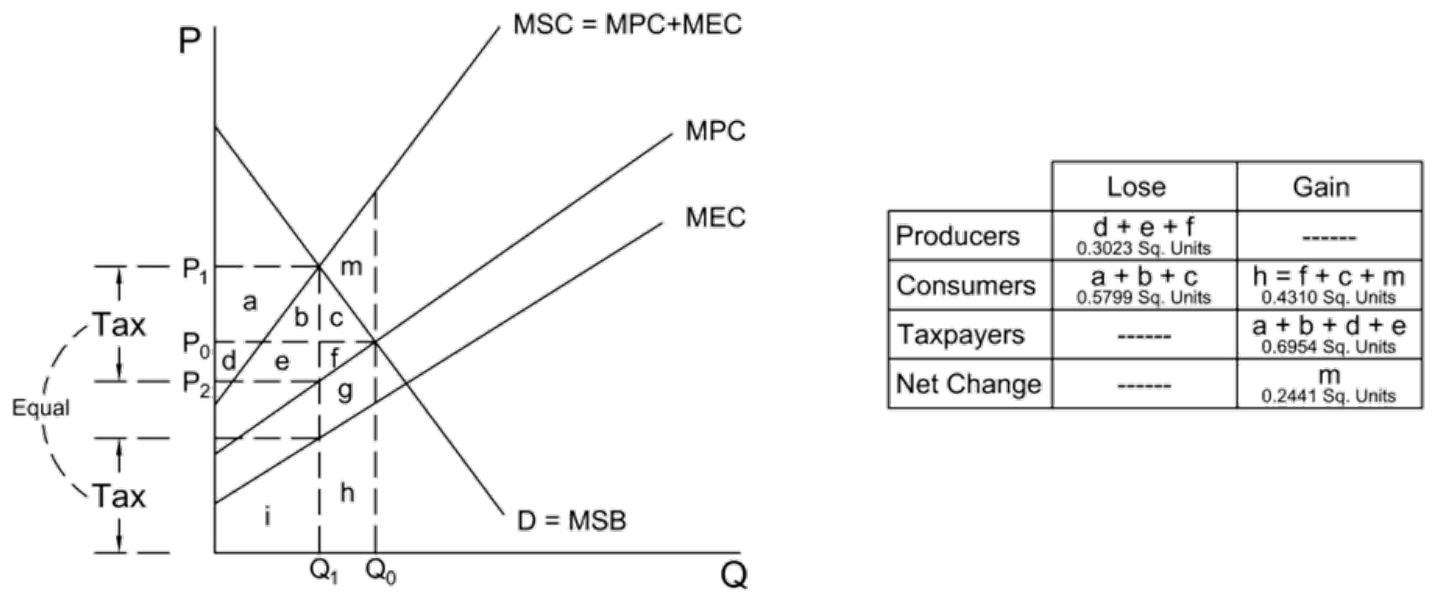


equal to 0.2441 square units (decrease of 0.3064 square units). These results show that when the elasticity of demand for the volume of total dissolved solids resulting from mountaintop mining activities is relatively low, the consumers will bear more of the burden of the tax then the producers. Additionally, there will be less tax revenue raised by the implementation of the tax when the elasticity of demand is lower, as well as a smaller net gain in social welfare.

Figure 4.3.3 shows the effects of the implementation of the Pigouvian tax on the volume of total dissolved solids when the elasticity of demand for the volume of total dissolved solids is higher than that of Figure 4.3.1. With this higher elasticity of demand, producers still lose areas $d+e+f$ in producer surplus (Figure 4.3.3), but this area is now equal to 1.3861 square units (increase of 0.6550 square units). The consumers will still lose areas $a+b+c$ (Figure 4.3 .3 ) in consumer surplus, but this area is now equal to 0.7160 square units (decrease of 0.0151 square units). Consumers will still gain area $h$, which is equal to areas $f+c+m$ (Figure 4.3.3), but this area is now equal to 1.6518 square units (increase of 0.7210 square units). Tax payers will still gain areas $a+b+d+e$ (Figure 4.3.3) in the form of government revenue, which is now equal to 1.4644 square units (increase of 0.3826 square units). The net effect of the implementation of the Pigouvian tax on the volume of total dissolved solids created is still equal to area $m$ (Figure 4.3.3), which is now equal to 1.0141 square units (increase of 0.4636 square units). These results show that when the elasticity of demand for the volume of total dissolved solids resulting from mountaintop mining activities is relatively high, the producers will bear more of the burden of the tax then the consumers. Additionally, there will be more tax revenue raised by the implementation of the tax when the elasticity of demand is higher, as well as a larger net gain in social welfare. 


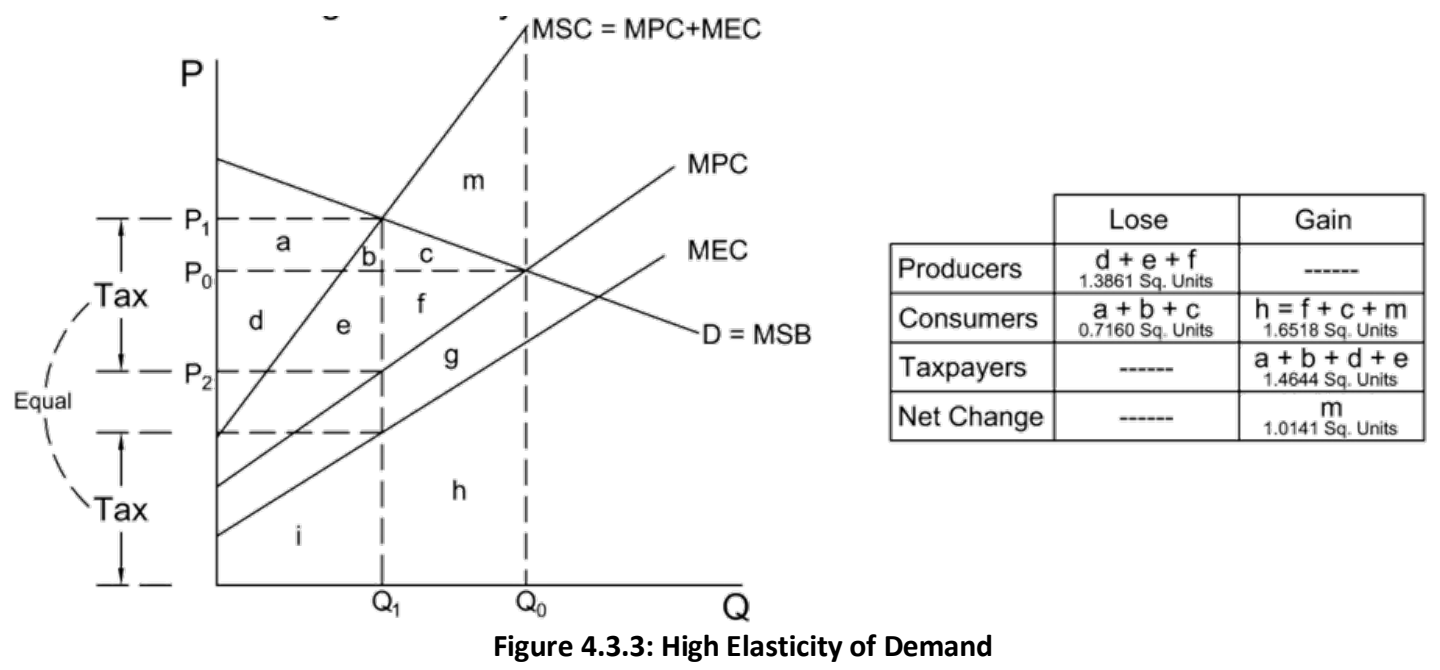

These variations in the effects of the Pigouvian tax on social welfare can also be examined from the supply side of the market by changing the elasticity of supply while holding the elasticity of demand constant. Changing the elasticity of supply results in a pivot of the marginal external cost (MEC), marginal private cost (MPC), and the marginal social cost (MSC). The fact that all three of these lines pivot is due to the correlation between them, as the marginal social cost (MSC) is equal to the marginal private cost (MPC) plus the marginal external cost (MEC). Figure 4.3.2 demonstrates the effects of the Pigouvian tax on social welfare with a relatively moderate elasticity of supply. Figure 4.3 .4 is the same as Figure 4.3.1, serving as a baseline for comparison for the effects of relatively higher and lower elasticities of supply on social welfare after the implementation of the Pigouvian tax. 


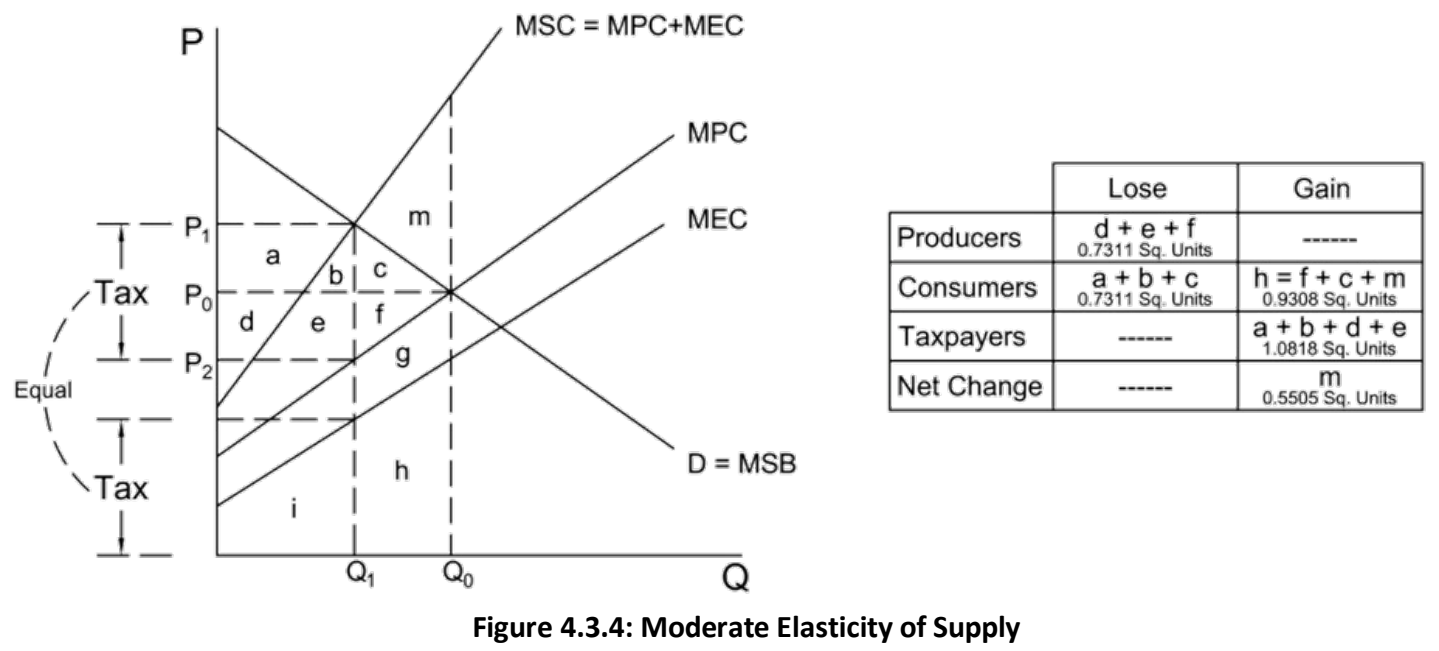

Figure 4.3.5 shows the effects on social welfare after the implementation of the Pigouvian tax on the volume of total dissolved solids with a relatively low elasticity of supply compared to that of Figure 4.3.4. Supply in this instance refers to the cost of abatement to producers. With this lower elasticity of supply, producers still lose areas $d+e+f$ in producer surplus (Figure 4.3.5), but this areas is now equal to 0.7330 square units (increase of 0.0019 square units). The consumers will still lose areas $a+b+c$ (Figure 4.3.5) in consumer surplus, but this area is now equal to 0.5336 square units (decrease of 0.1975 square units). Consumers will still gain area $h$, which is equal to areas $f+c+m$ (Figure 4.3.5), but this area is now equal to 0.9060 square units (decrease of 0.0248 square units). Tax payers will still gain areas $a+b+d+$ $e$ (Figure 4.3.5) in the form of government revenue, which is now equal to 0.8944 square units (decrease of .1874 square units). The net effect of the implementation of the Pigouvian tax on the volume of total dissolved solids created is still equal to area $m$ (Figure 4.3.5), which is now equal to 0.5338 square units (decrease of 0.0167 square units). These results show that when the elasticity of supply for the cost of abatement to reduce the volume of total dissolved solids resulting from mountaintop mining activities is relatively low, the consumers will bear more of the burden of the tax then the producers. Additionally, there will be less tax revenue raised by 
the implementation of the tax when the elasticity of supply is lower, as well as a smaller net gain in social welfare.

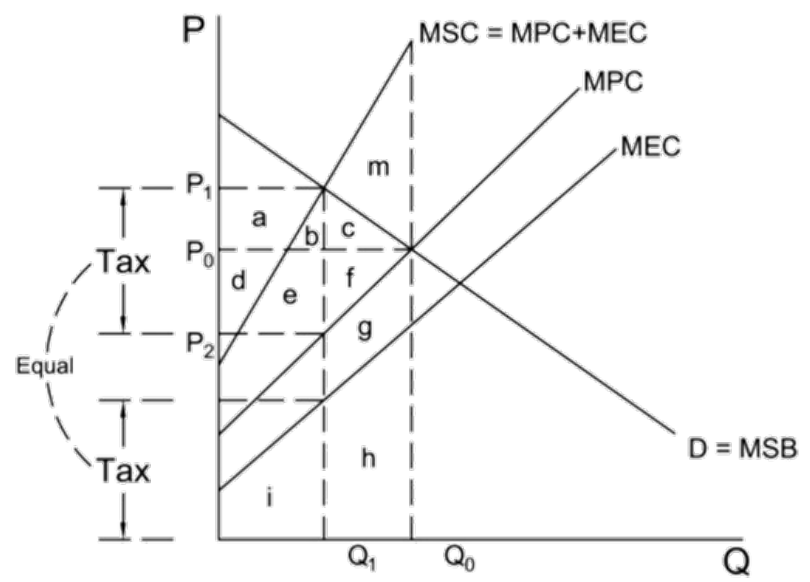

\begin{tabular}{|c|c|c|}
\hline & Lose & Gain \\
\hline Producers & $\begin{array}{c}d+e+f \\
0.7330 \text { Sq. Units }\end{array}$ & - \\
\hline Consumers & $\begin{array}{c}a+b+c \\
0.5336 \text { Sq. Units }\end{array}$ & $\begin{array}{c}h=f+c+m \\
0.9060 \text { Sq. Units }\end{array}$ \\
\hline Taxpayers & ...... & $\begin{array}{l}a+b+d+e \\
0.8944 \text { Sq. Units }\end{array}$ \\
\hline Net Change & -.+- & $\mathrm{m}_{0.5338 \mathrm{Sq} \text {. Units }}^{\mathrm{m}}$ \\
\hline
\end{tabular}

Figure 4.3.5: Low Elasticity of Supply

Figure 4.3.6 shows the effects on social welfare after the implementation of the Pigouvian tax on the volume of total dissolved solids with a relatively high elasticity of supply compared to that of Figure 4.3.4. With this higher elasticity of demand, producers still lose areas $d+e+f$ in producer surplus (Figure 4.3.6), but this area is now equal to 0.6520 square units (decrease of 0.0791 square units). The consumers will still lose areas $a+b+c$ (Figure 4.3.6) in consumer surplus, but this area is now equal to 0.9481 square units (increase of 0.2170 square units). Consumers will still gain area $h$, which is equal to areas $f+c+m$ (Figure 4.3.6), but this area is now equal to 0.9164 square units (decrease of 0.0144 square units). Tax payers will still gain areas $a+b+d+e$ (Figure 4.3.6) in the form of government revenue, which is now equal to 1.2185 square units (increase of 0.1367 square units). The net effect of the implementation of the Pigouvian tax on the volume of total dissolved solids created is still equal to area $m$ (Figure 4.3.6), which is now equal to 0.5349 square units (decrease of 0.0156 square units). These results show that when the elasticity of supply for the cost of abatement to 
reduce the volume of total dissolved solids resulting from mountaintop mining activities is relatively high, the consumers will bear more of the burden of the tax then the consumers. Additionally, there will be more tax revenue raised by the implementation of the tax when the elasticity of supply is higher, but at the cost of a smaller net gain in social welfare. This graphical analysis shows that changes in the elasticity of supply have less drastic effects on social welfare as changes in the elasticity of demand.

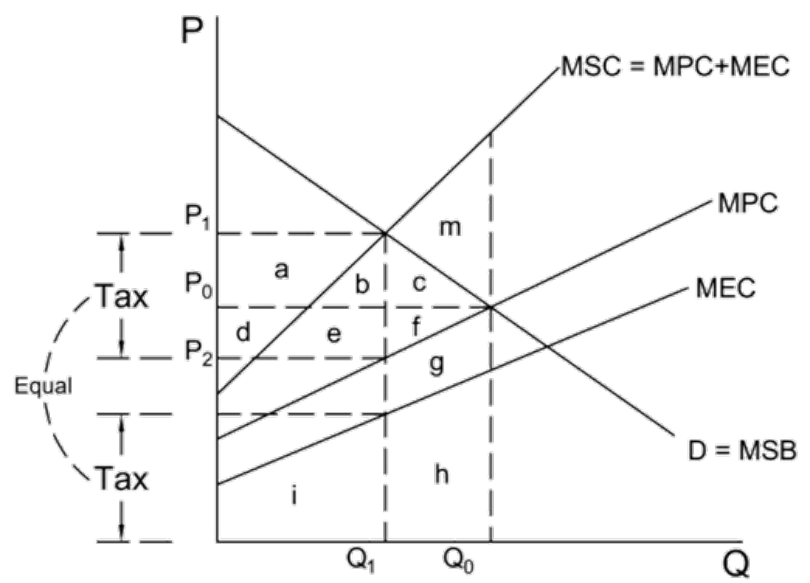

\begin{tabular}{|l|c|c|}
\cline { 2 - 3 } \multicolumn{1}{c|}{} & Lose & Gain \\
\hline Producers & $\begin{array}{c}\mathrm{d}+\mathrm{e}+\mathrm{f} \\
0.6520 \mathrm{Sq} \text {.Units }\end{array}$ & --- \\
\hline Consumers & $\begin{array}{c}\mathrm{a}+\mathrm{b}+\mathrm{c} \\
0.9481 \mathrm{Sq} \text {. Units }\end{array}$ & $\begin{array}{c}\mathrm{h}=\mathrm{f}+\mathrm{c}+\mathrm{m} \\
0.9164 \mathrm{Sq} \text {. Units }\end{array}$ \\
\hline Taxpayers & $-\cdots$ & $\begin{array}{c}\mathrm{a}+\mathrm{b}+\mathrm{d}+\mathrm{e} \\
1.2185 \mathrm{Sq} \text {. Units }\end{array}$ \\
\hline Net Change & --- & $\begin{array}{c}m \\
0.5349 \text { Sq. Units }\end{array}$ \\
\hline
\end{tabular}

Figure 4.3.6: High Elasticity of Supply

\subsection{2 - Double Dividend Tax}

Instead of pollution tax revenue going to the government to be redistributed to consumers through various civil service government expenditures, wouldn't the tax placed on pollution be accepted faster by producers and consumers if all consumers saw more immediate results from the allocation of the tax revenue? This is the theory behind a double dividend tax. This type of taxation is used to take revenues from environmental taxation on emissions and use these revenues to reduce income taxes for all consumers in a revenue-neutral fashion (Just, Hueth, and Schmitz, 2004). The swap of tax revenues result in a double dividend, meaning that 
there are two positive results obtained from the implementation of a single policy. The first dividend would be the reduction of the negative environmental externality. If a Pigouvian tax is placed on units of pollution created by a firm, like the volume of total dissolved solids in a stream resulting from mountaintop removal mining operations, the firm will have to take measures to reduce this externality or pay the tax on each unit of the negative externality. Whatever tax revenue is acquired from the mining companies as a result of this Pigouvian tax can then be used to reduce the income tax for the entire population of consumers, like the citizens living in the state of West Virginia, creating the second dividend.

With one policy, the economic distortions created by both the environmental externality and the state income tax have been reduced. This would mean that the optimal second-best tax on the volume of total dissolved solids created by mountaintop mining operations in the state of West Virginia would be greater than the marginal environmental damages that result from these mining operations. This type of policy makes the task of proving the benefits of pollution reduction much less challenging, due to the fact that acceptance is much easier to obtain from everyone that will benefit from the reduction of income tax. This type of taxation has a lot of potential for success in the state of West Virginia for a few reasons. First, coal mining is a way of life for many people in the state of West Virginia, it is what their families have been doing for generations and it is their livelihood. To reduce coal production, rather than reducing pollution through methods of abatement, would mean a loss of jobs in the coal mining industry throughout the state. In West Virginia, that is not really an option. Second, through the implementation of the double dividend tax, the tax revenue raised by taxing the volume of total dissolved solids resulting from mountaintop removal activities would go directly 
to reducing the income tax for everyone paying income tax throughout the state, and a lot of these people would benefit from not having to pay as high of an income tax.

To put the effects on social welfare of this double dividend tax into perspective, refer to Figure 4.3.7 and Figure 4.3.8. Figure 4.3.7 represents the labor market in the state of West Virginia, and Figure 4.3.8 represents the coal production market. It will be assumed that the demand for labor $\left(D_{L}\right)$ is perfectly elastic for purposes of simplicity. The supply for labor is represented by line $S\left(p_{1}\right)$, and the quantity of labor supplied is represented by $L_{1}$ at the wage rate of $w_{1}$. This wage rate of $w 1$ represents the wage rate before income taxes are charged, and the wage rate of $w_{1}-t_{L}$ represents the wage rate after income taxes are charged. Government revenues from income tax in Figure 4.3.7 are represented by areas $a+b$, and the income tax results in a dead weight loss of area c. Before the implementation of any tax on the coal market (Figure 4.3.8), the coal production firms will ignore marginal external costs (MEC), and will produce coal at an output level of $q_{1}$ at price $p_{1}$ at the level of demand represented by $D_{q}\left(w_{1}-\right.$ $\left.t_{\mathrm{L}}\right)$. Producing under these parameters results in a dead weight loss of area $z$.

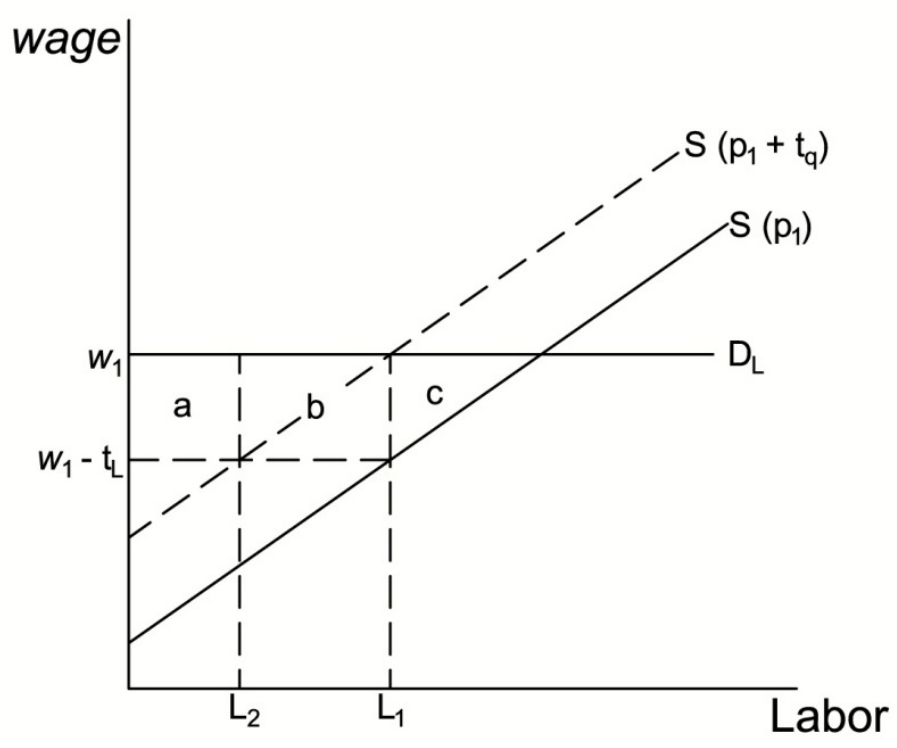

Figure 4.3.7: Labor Market of West Virginia 


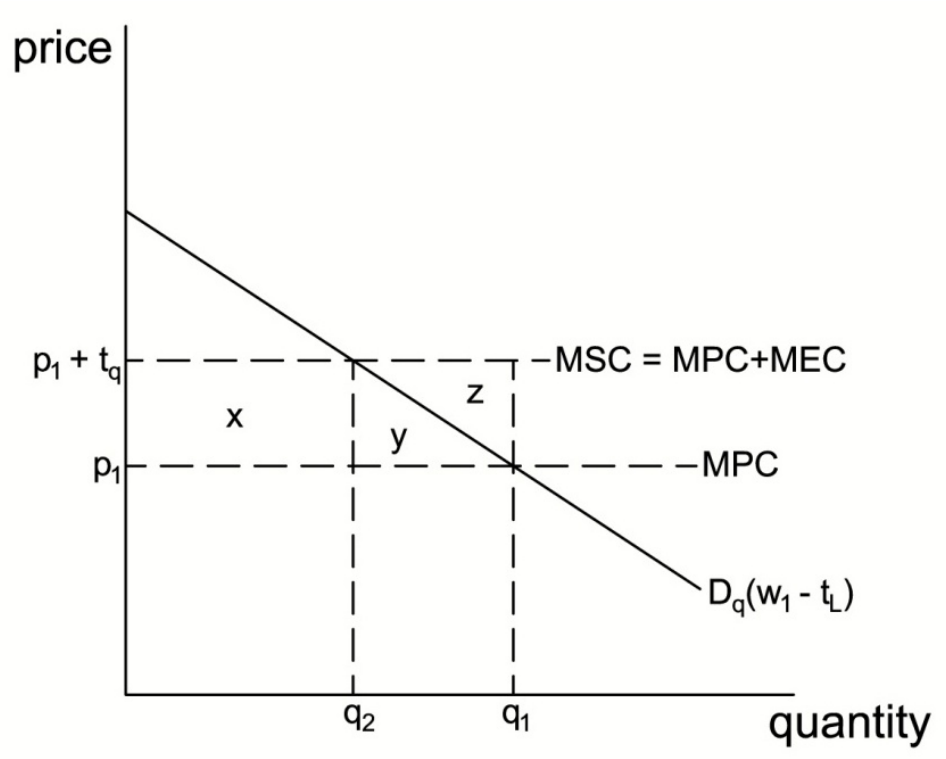

Figure 4.3.8: Market for Units of Volume of Total Dissolved Solids

Through the implementation of a double dividend tax, a portion of the income taxes seen by those in the labor market could be replaced with environmental taxes imposed on firms in the coal market who are creating too high of a volume of total dissolved solids downstream from their mining activities. If a Pigouvian tax was imposed on coal producing firms, area $z$ (Figure 4.3.8) would represent a net social gain, and this value of area $z$ would be redistributed to consumers through various public government expenditures. Through the implementation of a double dividend tax, the tax revenue represented by area $z$ would instead be used to reduce income tax seen in the labor market. This means that the amount of tax revenue generated by the implementation of a pollution tax on coal producing firms is directly proportional to the reduction level of income tax seen in the labor market. This becomes a winwin situation, because not only are income taxes being reduced in the labor market, but the volume of total dissolved solids created by coal producing firms is also being reduced. This is a much more efficient allocation of tax revenue then the lump-sum redistribution to consumers through various public government expenditures. 


\section{Chapter 5. Summary and Conclusions}

\section{1 - Summary of Study}

With the rapid and constant pace at which the coal industry in the Appalachian region of the United States operates, the approval process for new surface mining permits is expedited without thorough regard for the health and future of the landscape (Appalachian Voices, 2000). In such states such as West Virginia where coal mining is an essential element of the state's economy, the condition of the landscape usually takes a back seat to the constant pressure of the mineral extraction industry to remove material as rapidly and efficiently as they see possible. In order to preserve the future of the landscape in this region, and in particular, the health of the waterways downstream from mining related activities, more careful consideration needs to be given to the approval process of new mine permits based on the potential impact on downstream water quality measured in terms of stream conductivity. The results of this consideration can be used not only to limit the approval of new mine permits, but also to steer mining activities to areas of a landscape that are less vulnerable to mining related disturbance, causing less of a negative impact on downstream water quality.

The process of evaluating the location where and extent to which mining related disturbance should take place involves first and foremost identifying the current condition of the landscape. This means that all disturbance in the landscape needs to be spatially identified and quantified in order to determine how much disturbance has already occurred in the landscape being studied. This disturbance then needs to be summarized within the mining permits requesting approval from the state environmental agency in jurisdiction. Using summer stream conductivity field samples, study areas can be delineated based off of segment level 
watershed based upstream catchment areas flowing to the location of the conductivity sample location. Landscape disturbance variables are then summarized within each study area, and this data is used to run multivariate linear regression models in order to calculate the relationships between the independent landscape disturbance variables and the response variable of summer stream conductivity. After removing outlier data and creating a strongly correlated multivariate linear conductivity model, this model can be used to predict summer stream conductivity levels for the outflow point location of any study area of similar physical composition. The coefficients of each of the independent variables used in the multivariate linear conductivity model can then be altered to simulate what would happen in that study area if additional mining related disturbance was to take place, and in turn, show approximately how much disturbance can take place before summer stream conductivity levels reach a level that is too high for the overall health of the downstream waterway.

By being able to calculate approximately how much mining related disturbance can take place in a study area and where the disturbance should be focused based on the vulnerability of the landscape, state environmental agencies can be better prepared to make responsible decisions regarding the approval of mining permits based on the current and possible future conditions of a landscape. Surface coal mining is an inevitable reality in the Appalachian region of the United States, and in the state of West Virginia in particular. This reality, however, does not mean that surface coal mining should take place without question or consideration for the landscape, and with careful spatial analysis and planning, negative environmental impacts can be reduced to a point where at least the overall health of downstream waterways do no reach a threshold boundary where their ability to sustain life is compromised. 


\section{2 - Economic and Environmental Policy}

Due to the high levels of negative externalities created by the coal mining industry in the state of West Virginia, and in particular mountaintop removal mining activities, widespread environmental damage has been occurring throughout the state. These negative externalities related to mountaintop removal mining activities include increased storm water discharge due to clear cutting forests, increased sedimentation of waterways downstream of mining activities, and increased loading of various minerals and total dissolved solids of these waterways. This leaves a lot of potential throughout the state for environmental policy implementation. The creation and implementation of environmental policies can drastically reduce the negative environmental externalities created by mountaintop removal mining activities without reducing the overall coal production in the state of West Virginia. These environmental policies can also, at the same time, increase social welfare for the people of West Virginia.

Due to the nature of the coal industry in West Virginia, being that it provides so many crucial jobs to people throughout the state, as well as the fact that coal is needed to produce electricity throughout the region, the overall reduction in coal output to reduce negative environmental externalities is not feasible. Because of this, the implementation of any tax on the coal industry targeting the reduction of negative environmental externalities cannot be placed on units of coal output. Taxation on coal output will raise prices of coal production, and in turn, reduce the total output of coal. This will lead to a reduction in the size of the coal industry, eliminating coal mining related jobs throughout the state and increase the level of unemployment. Instead, taxation needs to be targeted on the units of the negative externality being created as a result of the mountaintop removal mining activities. This taxation on the 
units of the negative externalities will provide a need for coal producers to reduce the amount of the negative externality being created, while leaving the overall coal output the same.

Focusing this Pigouvian tax on the units of negative environmental externalities rather than on the output level of coal would have to mean that there is some kind of possible abatement available to reduce these externalities without reducing output. Traditional methods of abatement, which directly treat the negative externality after the externality has already been created, will not work in this instance. For this reason, consideration of landscape vulnerability must be taken when planning and permitting new mountaintop removal mining locations. By treating landscape vulnerability analysis as a form of abatement, mountaintop removal mining activities can be directed to geographical areas that are less vulnerable to mining activities. Vulnerability in this instance would be how much the mining of a given unit of land would degrade downstream water quality in terms of the volume of total dissolved solids present and the overall mineral loading present in the downstream waterway. By taxing the volume of materials discharged into waterways downstream of mountaintop removal mining activities, incentive is given to mining firms to focus their efforts on less vulnerable parts of the landscape.

The overall social welfare impacts due to the implementation of these pollution taxes are highly dependent on the elasticities of supply and demand in the given market. Supply in this instance is the cost of abatement to producers, and demand refers to the demand for clean water by consumers. As the elasticity of demand decreases, consumers will bear more of the burden of the tax then the producers. Additionally, there will be less tax revenue raised by the implementation of the tax when the elasticity of demand is lower, as well as a smaller net gain 
in social welfare. As the elasticity of demand increases, the producers will bear more of the burden of the tax then the consumers. Additionally, there will be more tax revenue raised by the implementation of the tax when the elasticity of demand is higher, as well as a larger net gain in social welfare. When the elasticity of supply decreases, the consumers will bear more of the burden of the tax then the producers. Additionally, there will be less tax revenue raised by the implementation of the tax when the elasticity of supply is lower, as well as a smaller net gain in social welfare. When the elasticity of supply increases, the consumers will bear more of the burden of the tax then the consumers. Additionally, there will be more tax revenue raised by the implementation of the tax when the elasticity of supply is higher, but at the cost of a smaller net gain in social welfare.

Through the implementation of a double dividend tax, both environmental quality and social welfare can be increased through one policy implementation. The revenue gained from the taxation on the units of the negative environmental externality produced as a result of mountaintop removal mining activities will be directly applied to the reduction of the state income tax seen by all consumers in the state of West Virginia. This type of taxation reduces market distortions in the form of dead weight losses resulting from income taxes and pollution taxes, and results in a much more efficient overall market condition. This type of taxation makes gaining the acceptance of everyone affected by the tax much easier, due to the fact that all consumers will see immediate beneficial results of the taxation that will increase their overall social welfare. This potential gain in social welfare, coupled with the potential reductions in environmental externalities resulting from mountaintop removal mining activities, shows the enormous potential for environmental policy implementation in the coal industry in 
West Virginia. If environmental and economic policies are not implemented on the coal industry in West Virginia, the health of the landscape and its ability to sustain life will drastically decrease in future, and there will be no way of getting it back.

\section{3 - Limitations of Study}

Some of the limitations of this study were the result of the lack of a current, multispectral aerial imagery set. This study incorporates true color and color infrared imagery from 2007 and 2009 at a 1:10,000 scale (1 meter nominal pixel resolution) to classify the Coal River Watershed landscape in response to disturbance from mining, forestry, and construction. The first set was color infrared imagery collected by the USDA's National Agriculture Imagery Program (NAIP) for the entire state of West Virginia. This imagery was collected in late summer, 2007, and was originally published in February of 2008 by the Aerial Photography Field Office of the Farm Service Agency, which is part of the U.S. Department of Agriculture. The second set of imagery used for the classification came from the National Agriculture Imagery Program (NAIP), which acquires aerial imagery during the agricultural growing seasons in the continental U.S. This imagery was collected in 2009, and was originally published in October of 2009, and is true color. The training data sets were created on the 2007 CIR imagery due to the nature of the CIR Imagery and the definitive difference in spectral response between vegetation and bare earth.

Despite the fact that the 2007 color infra-red imagery resulted in a very crisp disturbance mapping of the Coal River watershed, a lot of disturbance had occurred within the watershed between the acquisition of the 2007 and 2009 aerial imagery. Manual heads-up digitizing accounted for the differences in disturbance between the dates of acquisition of these 
two sets of imagery, but there is no way of precisely knowing how much disturbance has taken place in the Coal River watershed between the acquisition of the 2009 imagery and the current date. This analysis is based off of a snapshot of the landscape of the Coal River watershed at the time the 2009 imagery was acquired, and given that this imagery was the most recent available for use, it is the imagery the study was based.

Another limitation of this study was the data sources used to conduct additional landscape analysis and statistical regression. The stream conductivity samples used in this study have their own set of possible limitations, such as inaccuracies in the field sampling process. The elevation data used in this analysis is also a possible source of error. The temporal formation of the elevation data set does not perfectly match the temporal acquisition of the aerial imagery used, which can cause possible discrepancies in the resulting analysis. An ideal data set for this analysis would include presently acquired LiDAR elevation data for the Coal River watershed, as well as presently acquired hyper-spectral aerial imagery for ease of separating vegetation, bare earth, water, rock, reclaimed areas, and numerous other categories of landscape characteristics that cannot be extracted through automated techniques with the currently available imagery.

Underground mining was not taken into account in this study due to the lack of accurate underground mine permit boundaries available for the analysis. This study only takes surface mining operations into account for downstream conductivity calculations. This is a major limitation to this study due to the large effects underground mining discharge can have on downstream conductivity levels. Due to the dip directions of underground coal seems it is very difficult to associate underground disturbance with surface flow directions. 


\section{4 - Directions for Future Research}

Future research pertaining to the evaluation of proposed and current surface coal mine permits can be conducted using more current imagery to map the most recent landscape disturbance in the Coal River watershed and the entire EPA MTR region. By regularly updating disturbance mapping for this region, better information can be collected on mining activities to be sure that mining is only occurring in permit boundaries, as well as to continuously conduct calculations as to what effects on stream conductivity additional mining will comprise. Regular field sampling of stream conductivity levels would provide a good "truth" to verify multivariate linear conductivity models used to estimate stream conductivity where field samples are not available. Underground mining activity can also be incorporated into future research to investigate the effects on downstream conductivity in addition to the effects of surface mining operations. 


\section{Literature Cited}

Appalachian Voices. 1999. Mountaintop Removal Coal Mining. Web. 20 September. 2000.

ASPRS, 2009. Guidelines for Procurement of Professional Aerial Imagery, Photogrammetry, Lidar and Related Remote Sensor-based Geospatial Mapping Services. American Society for Pthogrammetry and Remote Sensing. August 2009.

Chakrabarti,T., Patil, MP, Subramani, T, Patil, SA, 2001. Multi-level screening of a proposed hazardous waste treatment and disposal facility site - A case study. Environmental Monitoring and Assessment. 76.3 (2002): 299-309.

Copeland, B.R. and M.S. Taylor, 2003. "Trade and the environment". Princeton University Press: Princeton and Oxford.

Deng, J.S., Wang, K., Hong, Y., \& Qi, J.G. 2009. Spatio-temporal dynamics and evolution of land use change and landscape pattern in response to rapid urbanization. Landscape and Urban Planning, 92, 187-198

Dengiz O. Bayramin I. Yuksel,M. 2003. Geographic information system and remote sensing based land evaluation of Beypazari area soils by ILSEN model. Turkish Journal of Agriculture and Forestry, 27, 145-153

Dooley, G., \& Leddin, A. 2005. Perspectives on Mineral Policy in Ireland. Resources Policy. v30(n3): 194-202.

Eggleston Jane R. History of West Virginia Mineral Industries - Coal. West Virginia Geological and Economic Survey. September 1996. Web. 16 July. 2004.

Environmental Systems Research Institute (ESRI), 2010. ArcGIS ArcMap Version 10, Redlands CA.

Flood, Martin. 2001. Laser Altimetry: From Science to Commercial Lidar Mapping. PE\&RS. Journal of the American Society for Photogrammetry and Remote Sensing. November 2001. Vol. 67, Num. 11.

Flood, Martin. 2002. Product Definitions and Guidelines for use in Specifying Lidar Deliverables. PE\&RS. Journal of the American Society for Photogrammetry and Remote Sensing. December 2002. Vol. 68, Num. 12.

Freund, J. G. and J. T. Petty. 2007. Response of fish and macroinvertebrate bioindices to specific stressor levels in a mined Appalachian watershed. Environmental Management 39:707-720. 
Funk, Robert E. 1993. Identifying a Cost-Effective Solution for Treating Acid Mine Drainage in the Middle Fork River Watershed.

GeoMart. 2011. Understanding Color Infrared (CIR) Aerial Photography. Ft. Collins, CO: GeoMart. WEB: http://www.geomart.com/products/aerial/cir.htm

Green, Edward, 1997. State and Federal Roles Under the Surface Mining Control and Reclamation Act of 1977, 21 S. III. U. L.J. 531 (1997)

Hartman K.J., Kaller M.D., Howell J.W., \& Sweka J.A. 2005. How much do valley fills influence headwater streams? Hydrobiologia. 532(1), 91-102.

Lahiri-Dutt, K. 2007. Coal mining industry at the crossroads: Towards a Coal policy for liberalising India. Australian National University, Australia South Asia Research Centre, ASARC Working Papers.

Marconi, D. 2009. Trade, Technical Progress and the Environment: The Role of a Unilateral Green Tax on Consumption. Asia-Pacific Journal of Accounting and Economics. v16(n3): 297-316.

Mtegha, H. D., Cawood, F. T., \& Minnitt, R. C. A. 2006. National Minerals Policies and Stakeholder Participation for Broad-Based Development in the Southern African Development Community (SADC). Resources Policy. v31(n4), 231-38.

NOAA, 2002. About LIDAR Data. National Oceanic and Atmospheric Administration.

O'Connell, T.J., Jackson, L.E., Brooks, R.P. 1998. A Bird Community Index of Biotic Integrity for the Mid-Atlantic Highlands. Environmental Monitoring and Assessment. 1998-06-01.

Peretto, P., 2008. Effluent Taxes, Market Structure, and the Rate and Direction of Endogenous Technological Change. Journal of Environmental Economics and Management 39: 113138.

Petty, J. T., and D. Thorne. 2005. An ecologically based approach for identifying restoration priorities in acid impacted watersheds. Restoration Ecology. 13:348-357.

Pond G.J., Passmore M.E., Borsuk F.A., Reynolds L., \& Rose C.J. 2008. Downstream Effects of Mountaintop Coal Mining: Comparing Biological Conditions Using Family and Genus Level Macroinvertebrate Bioassessment Tools. Journal of the North American Benthological Society. 27(3), 717-737.

Ricci, F., 2007. Environmental Policy and Growth When Input are Differentiated in Pollution Intensity. Journal of Environmental Economics and Management 38: 285-310. 
SAS Institute Inc. 2009. JMP ${ }^{\circledR} 9$ Modeling and Multivariate Methods. Cary, NC: SAS Institute Inc.

Shank, Michael, 1998. Automated Detection of Mining Valley Fills From Multi-Date Elevation Data. TAGIS, West Virginia Department of Environmental Protection. 2003

Shen, L., Dai, T., and Gunson, A. J. 2009. Small-Scale Mining in China: Assessing Recent Advances in the Policy and Regulatory Framework. Resources Policy. v34(n3), 150-57.

StatSoft, Inc. 2010. Electronic Statistics Textbook. Tulsa, OK: StatSoft. WEB: http://www.statsoft.com/textbook/.

Strager, M. P., V. Maskey, B. Gutta, R. Herd, J. Fulton, J. T. Petty, J. Stiles, J. Svetlik, P. Ziemkiewicz. 2008. A Hydrologically networked watershed model for evaluating AMD treatment scenarios. American Society of Mining and Reclamation, Proceedings.

Strager, Michael P. 1995. Prioritizing Acid Mine Drainage Affected Watersheds : a Compromise Programming Approach.

Taylor, M., 1998. Governing natural resources. Society of Natural Resources, 11:251-258.

U.S. EPA (Environmental Protection Agency). 2000. Mountaintop Mining/Valley Fill Environmental Impact Statement. EPA Region 3, Philadelphia, PA. EPA/903/R-00/013. October, 2000.

U.S. EPA (Environmental Protection Agency). 2009. The Effects of Mountaintop Mines and Valley Fills on Aquatic Ecosystems of the Central Appalachian Coalfields. Office of Research and Development, National Center for Environmental Assessment, Washington, DC. EPA/600/R-09/138A.

West Virginia Department of Environmental Protection. 2007. Water Quality Standards Program Update. West Virginia Department of Environmental Protection. November 29, 2007.

West Virginia Office of Miners' Health Safety and Training. 2002. A Brief History of Coal and Safety Enforcement in West Virginia. Web. 17 Aug. 2009.

Zucker, David A. 1992. Costs of Alternative Methods of Abating Acid Mine Drainage from Abandoned Mine Lands: A Case Study of the Sovern Run Watershed. 


\section{Appendix}

\section{A.1 - Zones of Critical Concern}

Zones of critical concern are the five hour travel times upstream of surface water intakes used for public drinking water (WV DEP, 2007). These zones are very sensitive to landscape disturbance. Delineations were performed by using an interim fixed radius for all Non-Community Non-Transient and Transient Public Water Systems. The radius was determined based on a sliding scale (see below) based on pumping or estimated pumping capacity and other relevant information available. The following is a scale that was used to determine the distance of the radius:

\begin{tabular}{|c|c|}
\hline $\begin{array}{c}\text { Pumping Capacity } \\
\text { (gallons per day) }\end{array}$ & $\begin{array}{c}\text { Fixed Radius } \\
\text { (feet) }\end{array}$ \\
\hline $500>$ and $<=2,500$ & 250 \\
\hline $2,500>$ and $<=5,000$ & 500 \\
\hline $5,000>$ and $<=10,000$ & 750 \\
\hline $10,000>$ and $<=25,000$ & 1000 \\
\hline
\end{tabular}

Table A.1 - ZCC Pumping Capacity, WV DEP (2007)

Susceptibility has been defined as the potential (likelihood) for a PWSS's to draw water contaminated at concentrations that would pose concern. However due to their inherent nature (open system with no confining layer, easy access for contaminant movement and relatively short time of travel) of all surface water sources of public drinking water are susceptible to contamination. This analysis should provide for an indicator directing PWSS to take further action to define and reduce susceptibility and increase source management practices. The susceptibility of a surface source to contamination is determined by the following four critical factors: (1) assessing the construction and capability of the source water intake, and raw water transmission mains to the treatment plant; (2) assessing the sensitivity of 
the hydrologic settings between the intake and the boundary of the delineated area; (3) identifying and evaluating the potential contamination sources located between the intake and the boundary of the delineated area; and (4) assessing the relationships among the factors to estimate the sensitivity or susceptibility to the system (figure A.1).

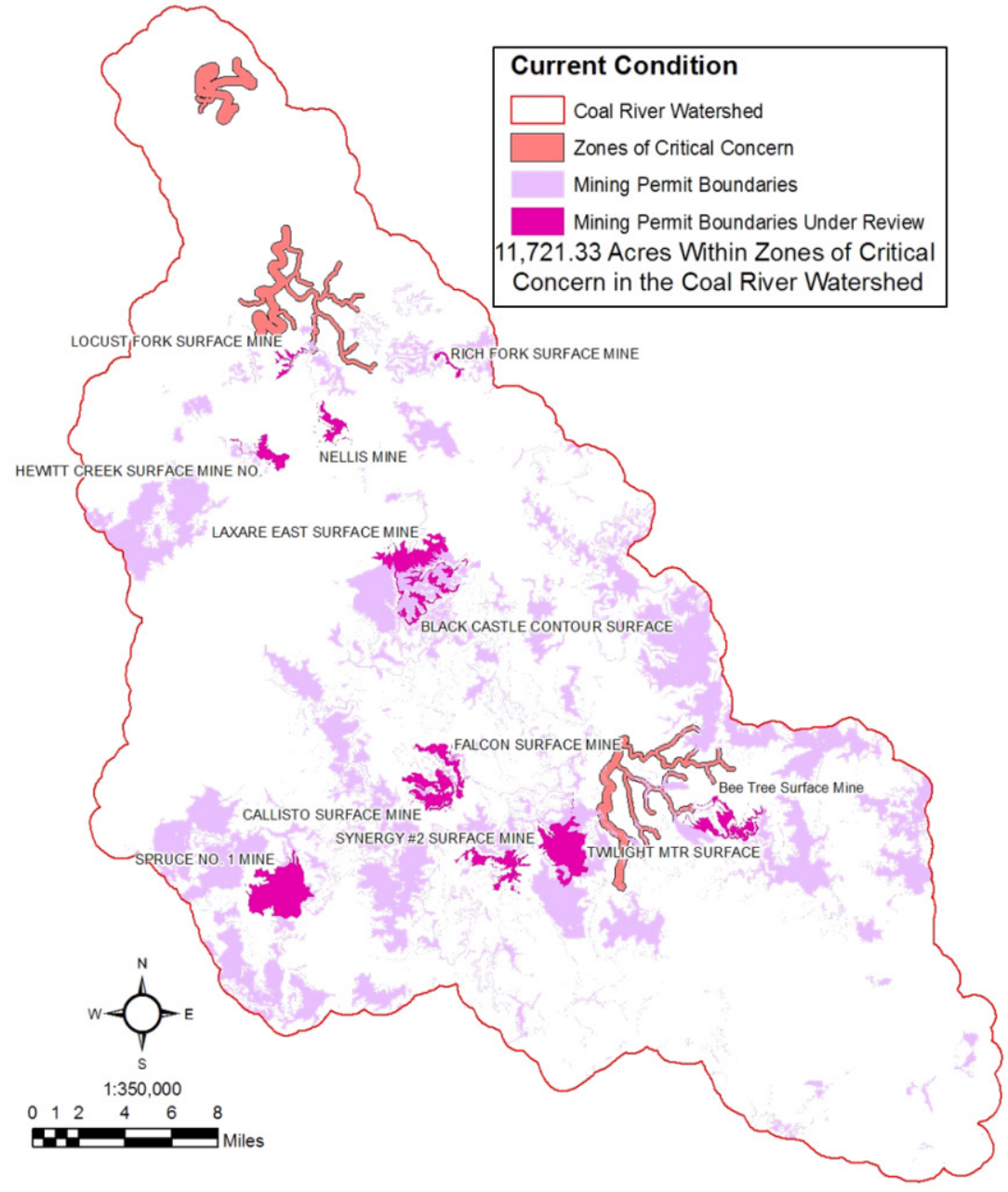

\begin{tabular}{|c|c|}
\hline Facility Name & Activity Status of Mining Permit \\
\hline 5602487 (No Facility Name) & Expired \\
\hline 10A \& $10 B$ MNE & Expired \\
\hline BEETREE POWEUTON & Current \\
\hline BRADLEY BR LWR CEDAR GROVE DEE & Current \\
\hline BRUSHY EAGLE\#1 MINE & Current \\
\hline BRUSHY FORK SLURRYIMPOUNDMENT & Current \\
\hline Bee Tree Surface Mne & Under Review \\
\hline CHERRY TREE HOLLOW REFUSE & Current \\
\hline COONHOLLOWNO 1 & Expired \\
\hline COONHOLLOWNO 2 & Expired \\
\hline COONHOLLOWNO.3 & Current \\
\hline Catenary Haulroad & Current \\
\hline Coon-Cedar Grove Deep Mine & Current \\
\hline EUS CK COAL REFUSE DISPOSAL & Current \\
\hline EUNICE EAGLE MINE & Current \\
\hline FORK CREEK HAULROAD & Current \\
\hline FORK CREEK HAULROAD NO.2 & Current \\
\hline FORK CREEK MINENO. 1 & Current \\
\hline FORK CREEK PREPARATION PLANT & Current \\
\hline Fork Creek No. 10Mine & Current \\
\hline Fork Creek No. 3 Mine & Current \\
\hline ISLAND 5 RESERVE & Current \\
\hline Kayford South Surface Mine & Current \\
\hline LAUREL BRANCH ALMA MINE & Expired \\
\hline LAUREL EAGLE MINE & Current \\
\hline LAUREL POWEUTON MINE & Current \\
\hline LOCUST FORK SURFACE MINE & Under Review \\
\hline LOW GAP BR POWELLTON \#1 & Expired \\
\hline LOW GAP BR POWELLTON \#2 & Expired \\
\hline LOWER CEDAR GROVE MINE\#1 & Current \\
\hline MARFORK PROCESSING & Current \\
\hline MONTCOALEAGLE MINE & Current \\
\hline MONTCOAL MOUNTAIN HAULROAD & Current \\
\hline N-Extension & Current \\
\hline NO. 1 MINE (NAOMA COALCO.) & Current \\
\hline NO.7 MINE IRENE PORTAL & Current \\
\hline NOTOMINE SURFACE MINE & Expired \\
\hline PANTHER EAGLE DEEP MINE & Current \\
\hline Patriot Chilton Mine & Current \\
\hline REFUSE CONVEYOR & Current \\
\hline REFUSE DISPOSALAREA NO. 2 & Expired \\
\hline RIVER FORK REFUSE IMPOUNDMENT & Expired \\
\hline RTFK LOW GAP BR. COALREF. DIS & Current \\
\hline River Fork Powell ton Deep Mine & Expired \\
\hline
\end{tabular}

Figure A.1: Mining permits in relation to source water protection zones 


\section{A.2 - Bird Community Index}

The bird community index $(\mathrm{BCl})$ provides a good indication as to the overall ecological condition of the watershed, which is broken down into categories pertaining to the suitability for bird habitat in the lane (O'Connell et. al. 1998). The $\mathrm{BCl}$ makes the assumption that the watershed's ecological condition correlates with the existing land cover. From the $\mathrm{BCl}$ calculations, a $\mathrm{BCl}$ score is obtained, which is based on the amount of forested land cover within a 200 acre extent throughout the study area, and also takes into consideration the forest edge effects from landscape disturbance. The quantities and types of birds in a landscape are a good indicator of the given region's overall ecological landscape condition. Birds are generally fairly sensitive to changes in the landscapes condition, whether the change is physical, chemical, or biological in nature (O'Connell et. al. 1998).

The $\mathrm{BCl}$ was calculated by starting with the buffered boundary for the Coal River Watershed. The same 1000 meter buffer was used for this step as was used for the rest of the analysis in the Coal River Watershed. The forest cover grid calculated earlier on in the analysis was then used to identify all of the forested areas in the Coal River Watershed. Using this forest cover grid, all of the areas that were not classified as "forest" were then reclassified as "human cover", or disturbance in the landscape. The result was two separate grids, one for "forest" and one for "human cover". The next step was to create a new grid that identified all human cover areas that were greater than or equal to 5 acres using the majority filter command in ARC Map. The 5 acre human cover areas were then expanded outward by a distance of 3 cells in order to create an area of forest edge. By querying to find the grid cells that were forested in the expanded areas, a grid was created of forest edge area. A new grid was then created that 
combined the forest buffer and all the other areas of human cover, which was then reclassified to inverse the grid values for multiplication with the next grid. All of the forested cells were then found within the expanded area by multiplying the previous grid with the queried grid that found the forested cells in the expanded area. This new grid contains values of 0,1 , and 2 . A value of 0 indicates all of the non buffered human land cover tracts under 5 acres in area. A value of 1 indicates all forested buffers surrounding human cover tracts over 5 acres in area. A value of 2 indicates all of the remaining forested areas (O'Connell et. al. 1998).

The areas identified with a low index score, such as 0 and 1 , contain a greater amount of non forest land uses, such as mining, timbering, and urban/residential development. These areas are suitable habitat for generalist bird species such as European Starlings, American Crows, and Blue Jays. Areas with a higher index score, mainly the areas with a score of 2, are primarily forested and provide suitable habitat for many neo-tropical migratory birds, such as Cerulean Warbler, Scarlet Tanager, and Louisiana Waterthrush (O'Connell et. al. 1998). The map created from this analysis shows all of the areas of un-preferred bird habitat (value of 0 ), generalist bird habitat (value of 1), and migratory bird habitat (value of 2) (figure A.2). These areas were then summarized by each of the surface mine permits that are currently under review by the EPA, and a total area of migratory bird habitat (in acres) was calculated within each surface mine permit boundary. These area calculations were used to calculate a total loss of migratory bird habitat in the Coal River Watershed under the assumption that there was to be a $100 \%$ mine build-out within each permit boundary under review. 


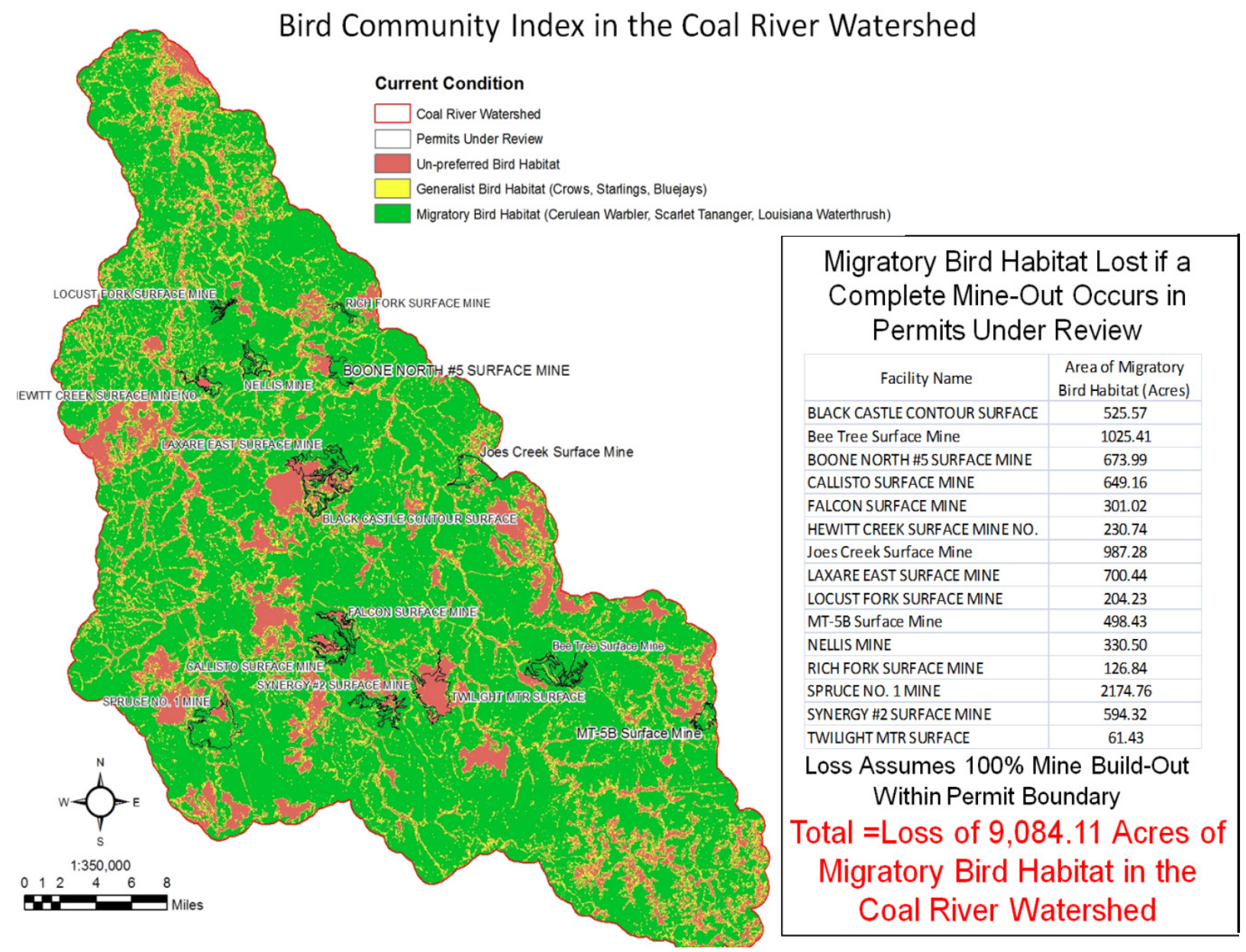

Figure A.2: Bird Community Index for the Coal River watershed 


\section{A.3 - Louisiana Waterthrush Habitat Modeling}

The Louisiana Waterthrush habitat model for the Coal River Watershed was chosen since the species prefers high elevation forested headwater streams. The goal was to find the potential amount of this habitat that could be lost to the mine permits. This map was created by clipping the riparian forests in the Coal River Watershed created earlier in the analysis with the headwater forest areas also created earlier. The result was a shapefile of all suitable habitat for Louisiana Waterthrush in the Coal River Watershed. The permits under review were then overlaid onto the habitat, and the two layers were intersected in ARC Map. A summary table was then created that shows how much Louisiana Waterthrush habitat would be lost in each permit under review if there was to be a complete mine build-out in each of the permit boundaries under review (figure A.3). 


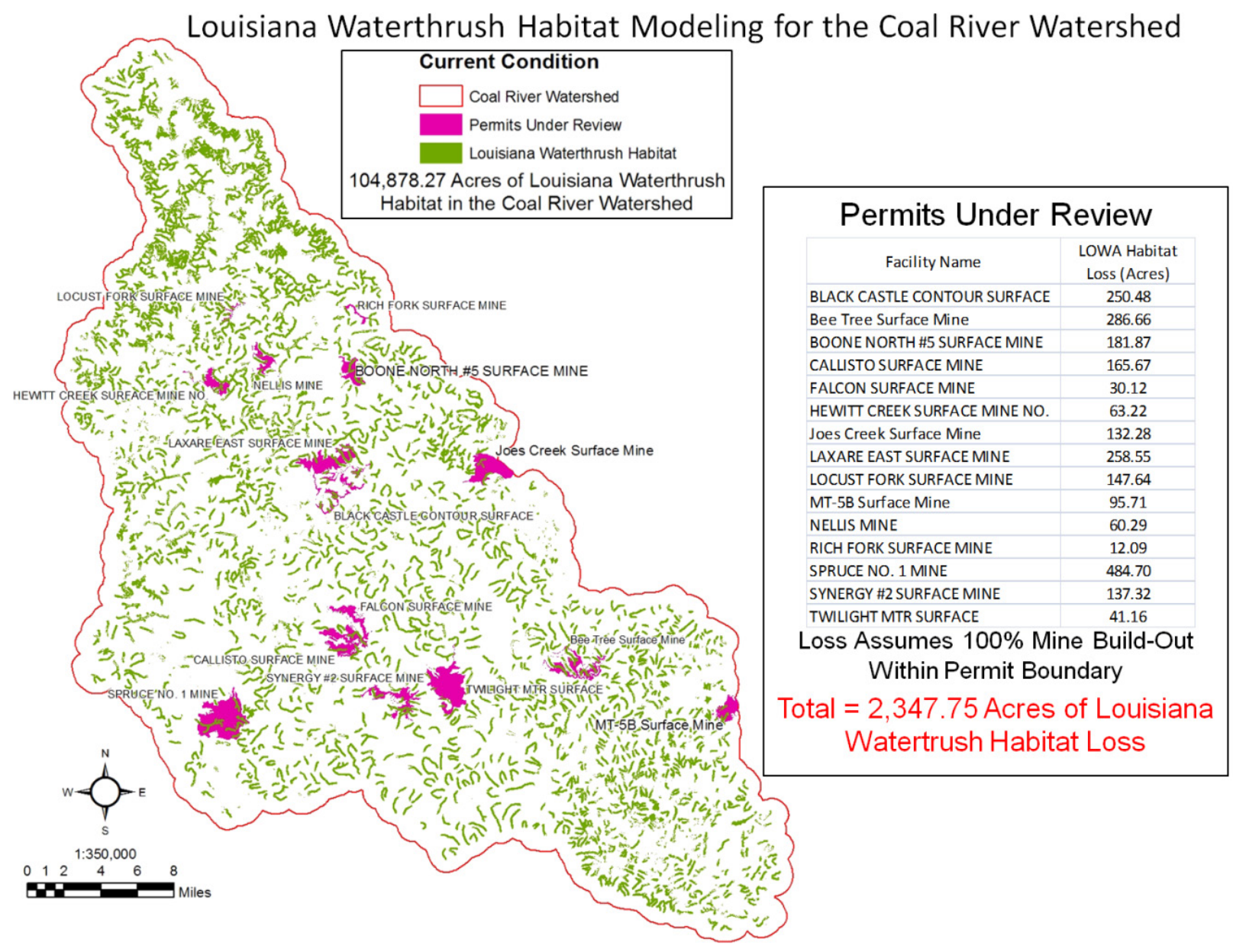

Figure A.3: Louisiana Waterthrush habitat impacts from mine permits under review 


\section{A.4 - Surface Mine Permits Under Review : Descriptions}

Spruce No. 1 Surface Mine Ecological Landscape Unit Coverage

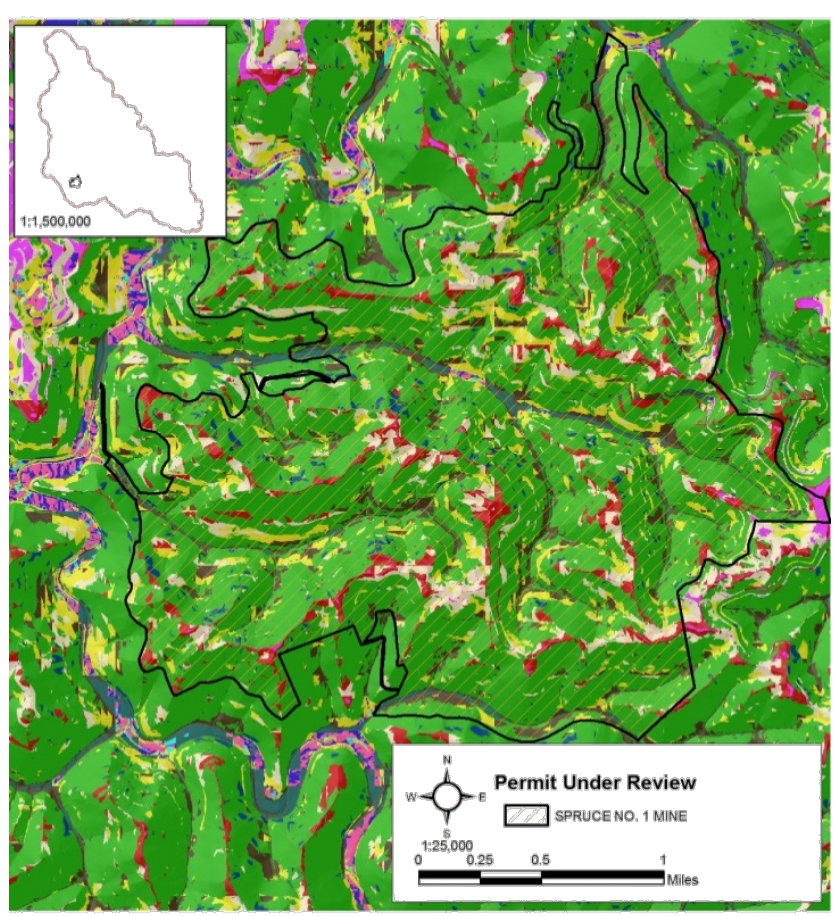

Ecological Landscape Unit Distribution

$\%$ of Total Permit Boundary Under Review

Covered by Each Ecological Landscape Unit

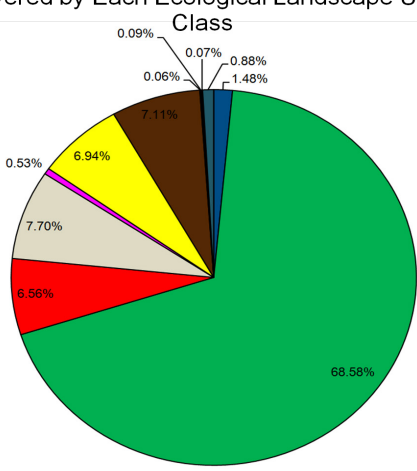

Ecological Landscape Units

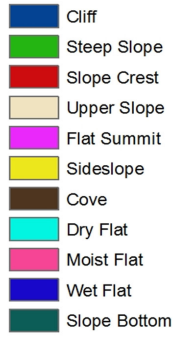

\begin{tabular}{|c|c|}
\hline \multicolumn{2}{|c|}{ Spruce \#1 Mine } \\
\hline Size & 2855.28 Acres \\
\hline Current Disturbance & 397.81 Acres \\
\hline Current \% Disturbance & $13.93 \%$ \\
\hline Area of Riparian Forest & 891.37 Acres \\
\hline Area of Headwater Forest & 1158.25 Acres \\
\hline $\begin{array}{c}\text { Area of Forest over } 25^{\circ} \\
\text { Slope }\end{array}$ & 1626.26 Acres \\
\hline $\begin{array}{l}\text { Total Acres of Critical } \\
\text { Forest Present }\end{array}$ & 2209.54 Acres \\
\hline $\begin{array}{c}\text { Potential Surface Water } \\
\text { Impact }\end{array}$ & None in Viainity \\
\hline Un-Preferred Bird Habitat & $\begin{array}{l}\text { 411.13 Acres } \\
\text { (14.40\%) }\end{array}$ \\
\hline Generalist Bird Habitat & $\begin{array}{l}\text { 275.99 Acres } \\
(9.67 \%)\end{array}$ \\
\hline Migratory Bird Habitat & $\begin{array}{c}2168.15 \text { Acres } \\
\text { (75.94\%) }\end{array}$ \\
\hline $\begin{array}{c}\text { Louisiana Waterthrush } \\
\text { Habitat Loss }\end{array}$ & $\begin{array}{l}\text { 484.70 Acres } \\
\text { (16.98\%) }\end{array}$ \\
\hline $\begin{array}{l}\text { Headwater Watersheds } \\
\text { Affected }\end{array}$ & 6 \\
\hline
\end{tabular}

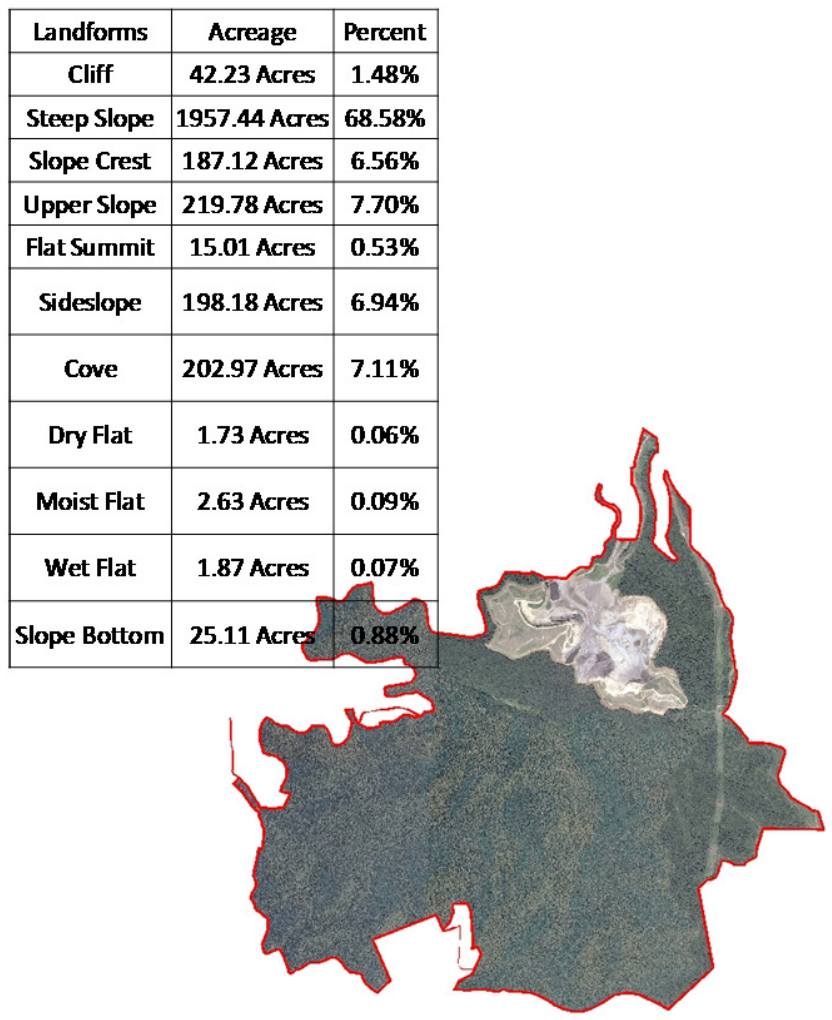




\section{Black Castle Contour Surface Mine Ecological Landscape Unit Coverage}

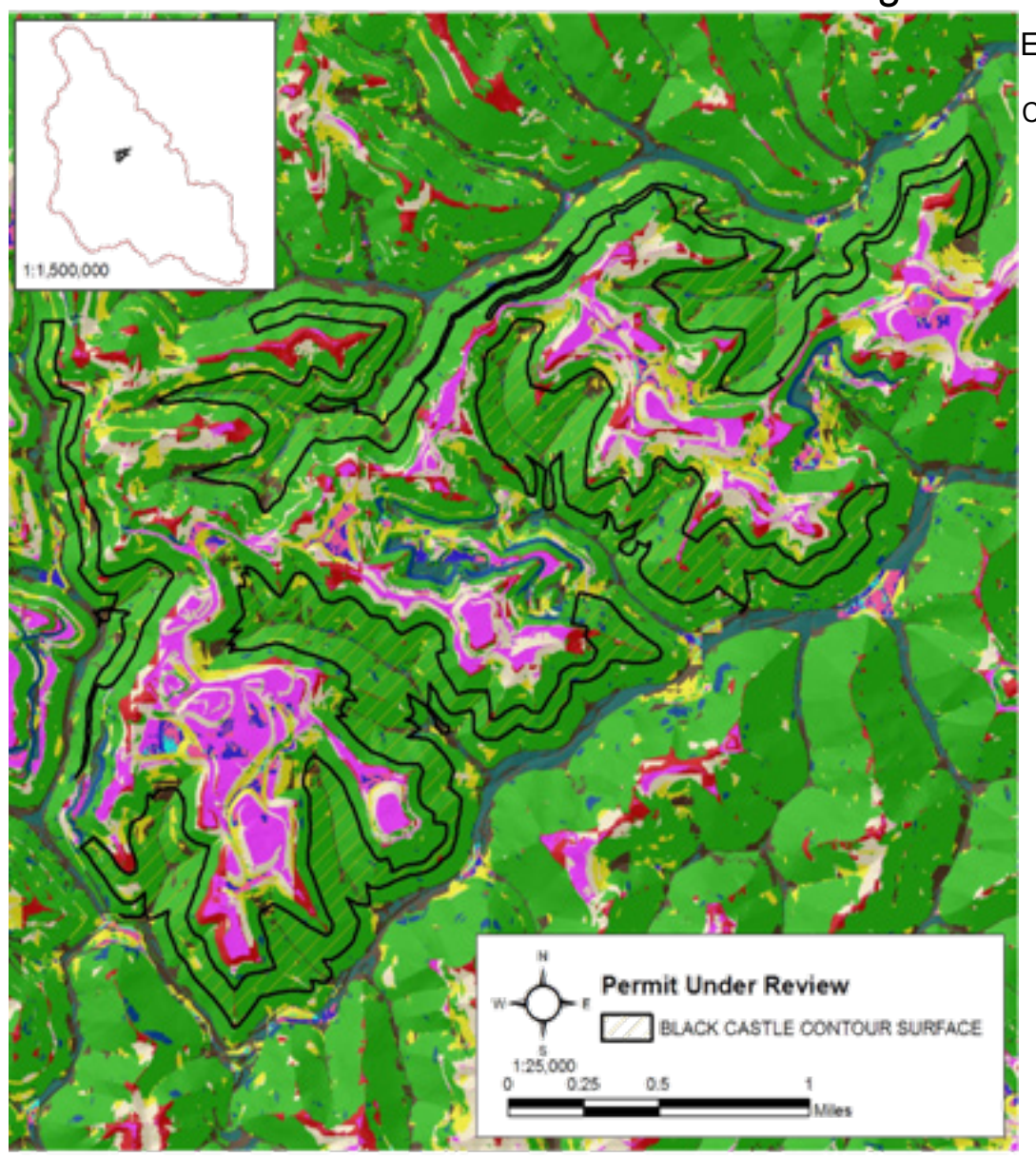

Ecological Landscape Unit Distribution $\%$ of Total Permit Boundary Under Review Covered by Each Ecological Landscape Unit

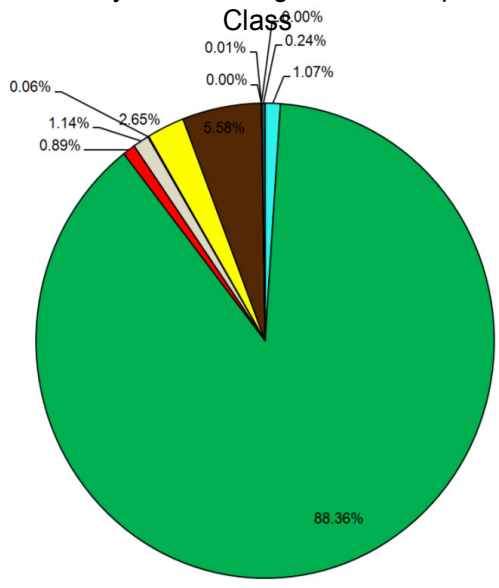

\section{Ecological Landscape Units}

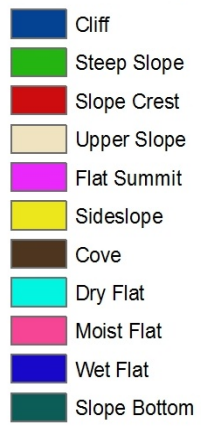

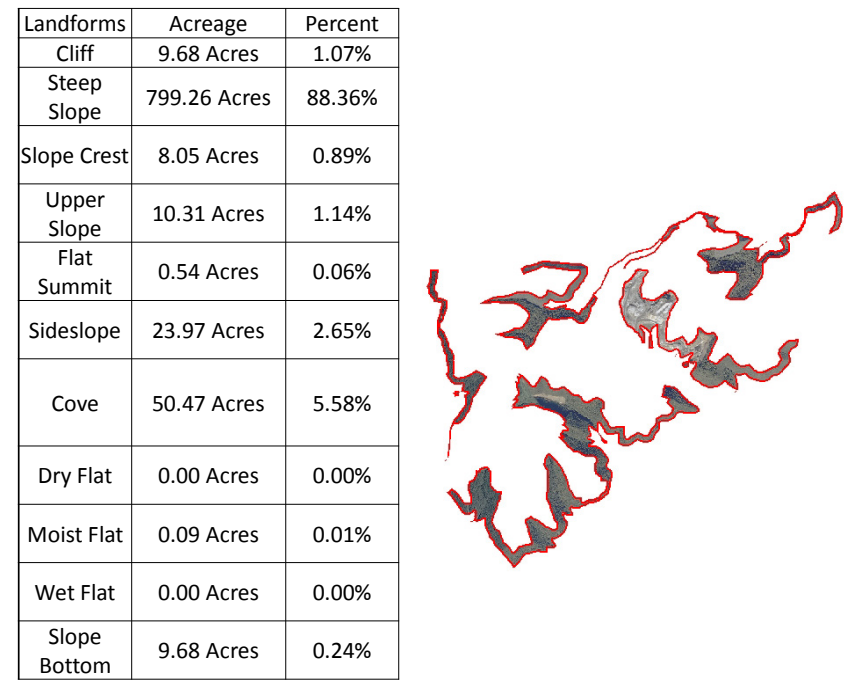




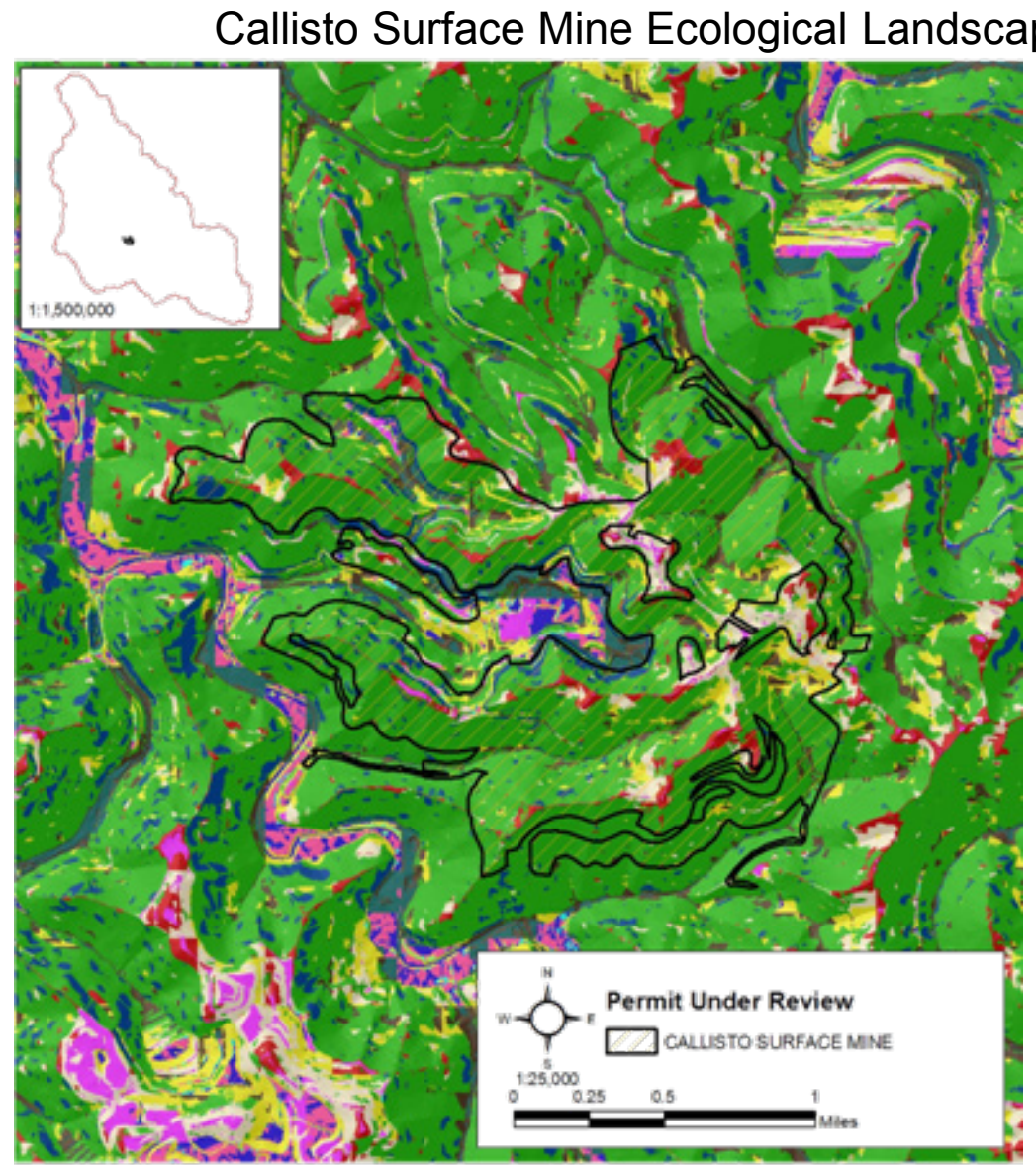

Ecological Landscape Unit Distribution $\%$ of Total Permit Boundary Under Review Covered by Each Ecological Landscape Unit

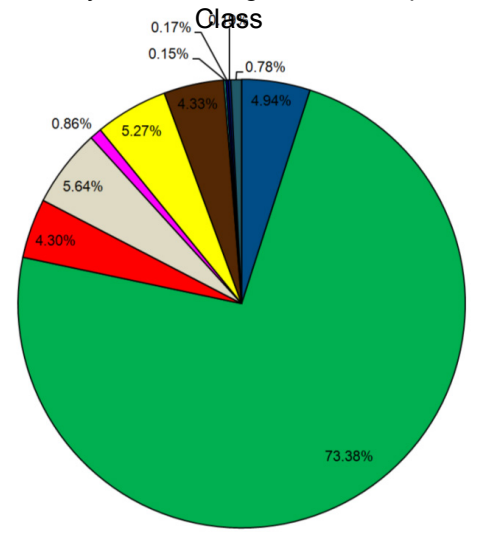

Ecological Landscape Units

\begin{tabular}{|l|l|}
\hline Cliff \\
Steep Slope \\
Slope Crest \\
\hline Upper Slope \\
Flat Summit \\
\hline$\square$ Sideslope \\
\hline Cove \\
Dry Flat \\
Moist Flat \\
Wet Flat \\
Slope Bottom
\end{tabular}

\begin{tabular}{|c|c|}
\hline \multicolumn{2}{|c|}{ Callisto Surface Mine } \\
\hline Size & 1209.52 Acres \\
\hline Current Disturbance & 303.09 Acres \\
\hline $\begin{array}{l}\text { Current \% } \\
\text { Disturbance }\end{array}$ & $25.06 \%$ \\
\hline $\begin{array}{c}\text { Area of Riparian } \\
\text { Forest } \\
\end{array}$ & 194.93 Acres \\
\hline $\begin{array}{c}\text { Area of Headwater } \\
\text { Forest }\end{array}$ & 614.15 Acres \\
\hline $\begin{array}{c}\text { Area of Forest over } \\
25^{\circ} \text { Slope }\end{array}$ & 625.40 Acres \\
\hline $\begin{array}{c}\text { Total Acres of Critical } \\
\text { Forest Present }\end{array}$ & 802.30 Acres \\
\hline $\begin{array}{c}\text { Potential Surface } \\
\text { Water Impact }\end{array}$ & Not In Vacinity \\
\hline $\begin{array}{c}\text { Un-Preferred Bird } \\
\text { Habitat }\end{array}$ & $\begin{array}{c}388.42 \text { Acres } \\
(32.10 \%)\end{array}$ \\
\hline $\begin{array}{c}\text { Generalist Bird } \\
\text { Habitat }\end{array}$ & $\begin{array}{c}173.37 \text { Acres } \\
(14.33 \%)\end{array}$ \\
\hline $\begin{array}{c}\text { Migratory Bird } \\
\text { Habitat }\end{array}$ & $\begin{array}{c}\text { 648.11 Acres } \\
(53.57 \%)\end{array}$ \\
\hline $\begin{array}{c}\text { Louisiana } \\
\text { Waterthrush Habitat } \\
\text { Loss }\end{array}$ & 165.67 Acres \\
\hline $\begin{array}{c}\text { Headwater } \\
\text { Watersheds Affected }\end{array}$ & 9 \\
\hline
\end{tabular}

\begin{tabular}{|c|c|c|}
\hline Landforms & Acreage & Percent \\
\hline Cliff & 4.48 Acres & $0.37 \%$ \\
\hline Steep Slope & 701.52 Acres & $58.00 \%$ \\
\hline Slope Crest & 102.69 Acres & $8.49 \%$ \\
\hline Upper Slope & 145.63 Acres & $12.04 \%$ \\
\hline Flat Summit & 22.50 Acres & $1.86 \%$ \\
\hline Sideslope & 116.11 Acres & $9.60 \%$ \\
\hline Cove & 71.60 Acres & $5.92 \%$ \\
\hline Dry Flat & 5.44 Acres & $0.45 \%$ \\
\hline Moist Flat & 13.43 Acres & $1.11 \%$ \\
\hline Wet Flat & 4.72 Acres & $0.39 \%$ \\
\hline Slope Bottom & 21.41 Acres & $1.77 \%$ \\
\hline
\end{tabular}




\section{Falcon Surface Mine Ecological Landscape Unit Coverage}

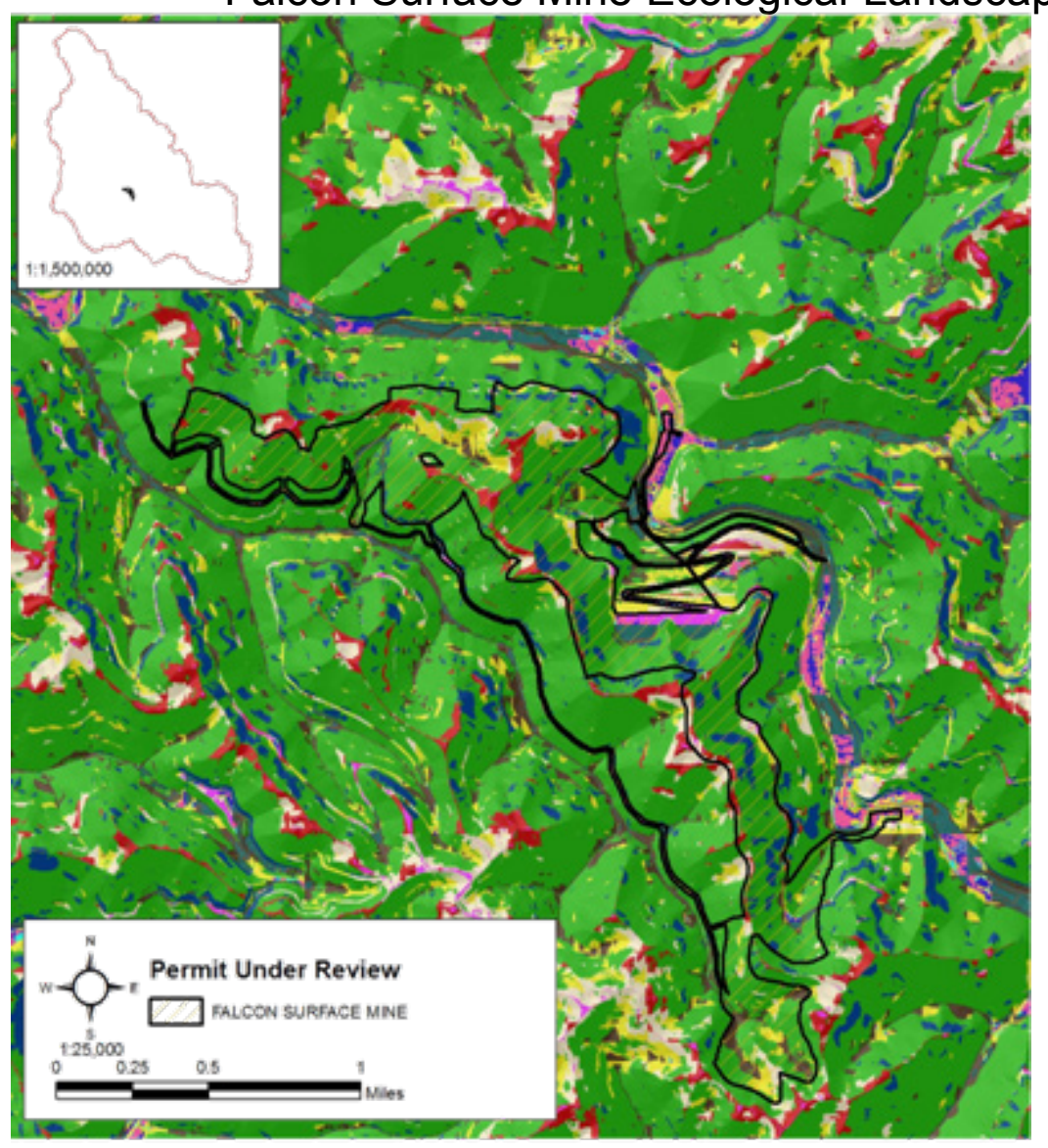

Ecological Landscape Unit Distribution $\%$ of Total Permit Boundary Under Review Covered by Each Ecological Landscape Unit

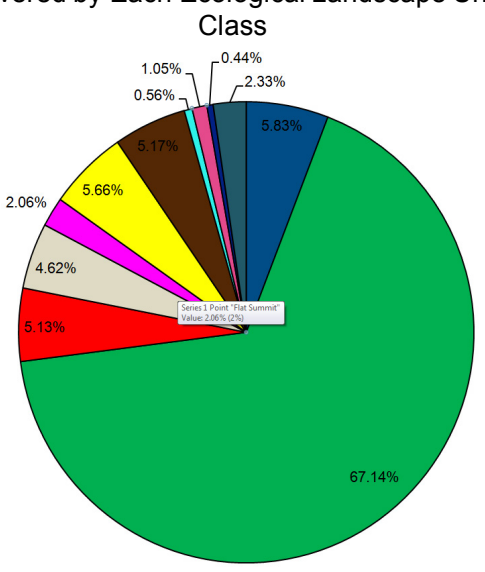

\section{Ecological Landscape Units}

\begin{tabular}{|l}
\hline Cliff \\
Steep Slope \\
Slope Crest \\
\hline Upper Slope \\
\hline Flat Summit \\
\hline Sideslope \\
Cove \\
Dry Flat \\
Moist Flat \\
Wet Flat \\
Slope Bottom
\end{tabular}

\begin{tabular}{|c|c|}
\hline \multicolumn{2}{|c|}{ Falcon Surface Mine } \\
\hline Size & 653.22 Acres \\
\hline Current Disturbance & 298.79 Acres \\
\hline Current \% Disturbance & $45.74 \%$ \\
\hline Area of Riparian Forest & 64.55 Acres \\
\hline Area of Headwater Forest & 101.79 Acres \\
\hline Area of Forest over $25^{\circ}$ Slope & 252.08 Acres \\
\hline $\begin{array}{c}\text { Total Acres of Critical Forest } \\
\text { Present }\end{array}$ & 306.22 Acres \\
\hline $\begin{array}{l}\text { Potential Surface Water } \\
\text { Impact }\end{array}$ & Not In Vacinity \\
\hline Un-Preferred Bird Habitat & $\begin{array}{c}300.33 \text { Acres } \\
(45.96 \%)\end{array}$ \\
\hline Generalist Bird Habitat & $\begin{array}{l}\text { 54.88 Acres } \\
(8.40 \%)\end{array}$ \\
\hline Migratory Bird Habitat & $\begin{array}{c}298.18 \text { Acres } \\
(45.64 \%)\end{array}$ \\
\hline $\begin{array}{c}\text { Louisiana Waterthrush } \\
\text { Habitat Loss }\end{array}$ & 30.12 Acres \\
\hline $\begin{array}{l}\text { Headwater Watersheds } \\
\text { Affected }\end{array}$ & 0 \\
\hline
\end{tabular}

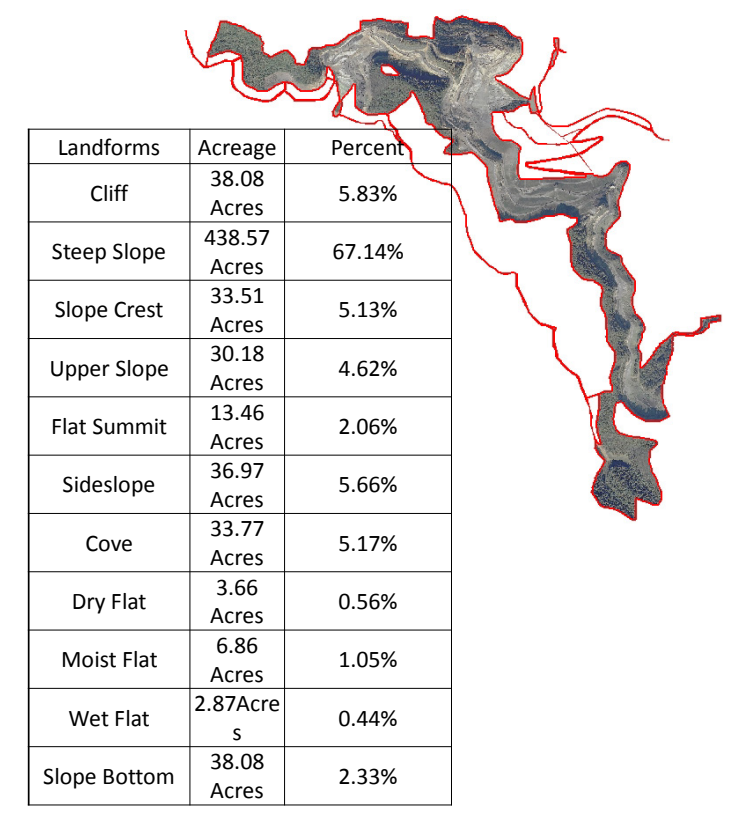




\section{Twilight MTR Surface Mine Ecological Landscape Unit Coverage}

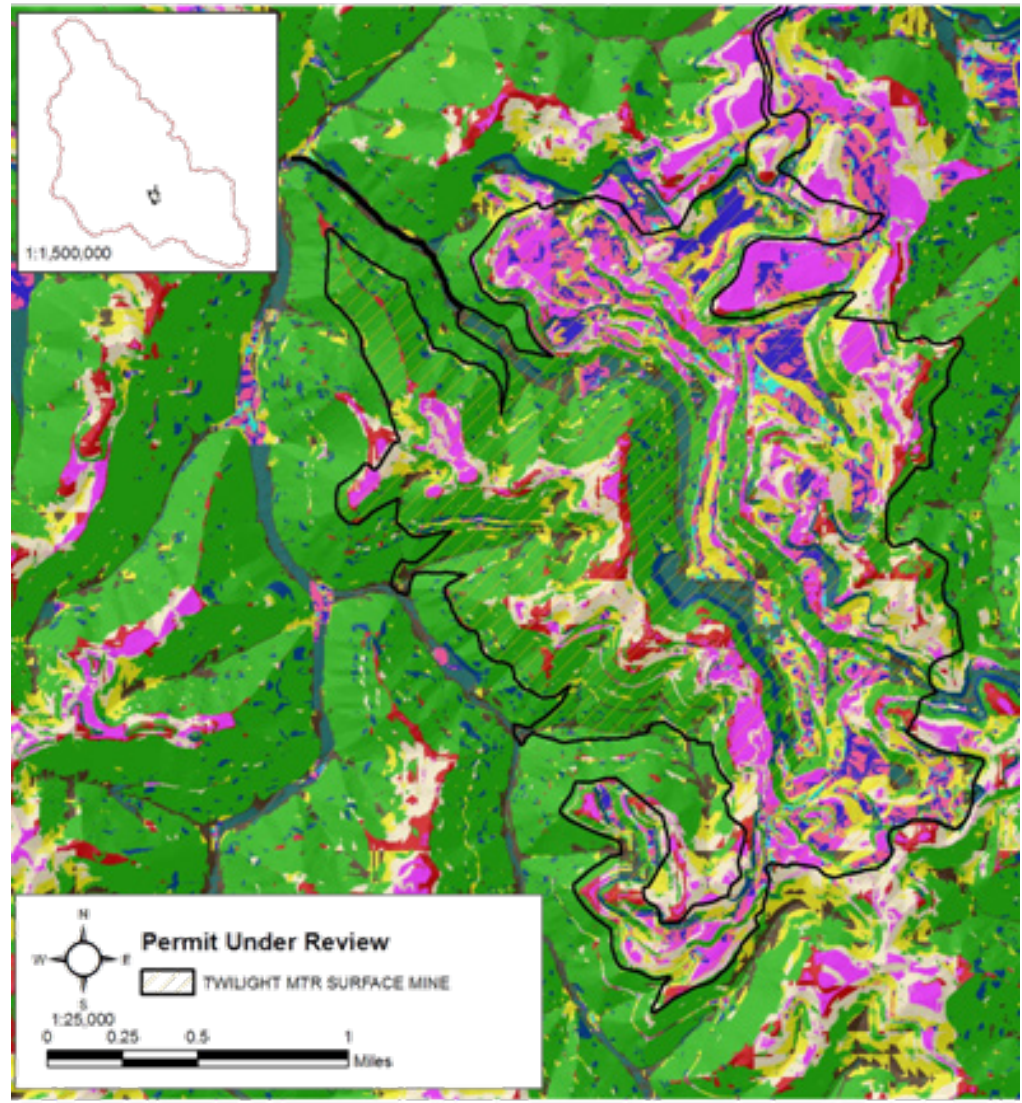

Ecological Landscape Unit Distribution $\%$ of Total Permit Boundary Under Review Covered by Each Ecological Landscape Unit Class

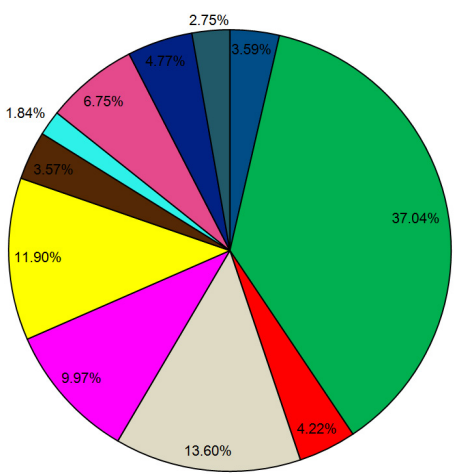

Ecological Landscape Units

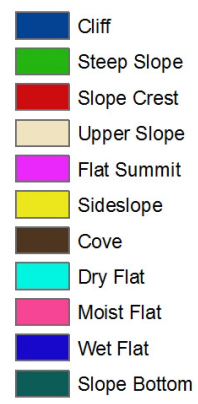

\begin{tabular}{|c|c|}
\hline \multicolumn{2}{|c|}{ Twilight MTR Surface } \\
\hline Size & 2141.29 Acres \\
\hline Current Disturbance & 1923.60 Acres \\
\hline Current \% Disturbance & $89.83 \%$ \\
\hline Area of Riparian Forest & 51.50 Acres \\
\hline $\begin{array}{c}\text { Area of Headwater } \\
\text { Forest }\end{array}$ & 161.03 Acres \\
\hline $\begin{array}{c}\text { Area of Forest over } 25^{\circ} \\
\text { Slope }\end{array}$ & 114.97 Acres \\
\hline $\begin{array}{c}\text { Total Acres of Critical } \\
\text { Forest Present }\end{array}$ & 194.67 Acres \\
\hline $\begin{array}{c}\text { Potential Surface } \\
\text { Water Impact }\end{array}$ & None in Vicinity \\
\hline $\begin{array}{c}\text { Un-Preferred Bird } \\
\text { Habitat }\end{array}$ & $\begin{array}{c}1942.30 \text { Acres } \\
(90.72 \%)\end{array}$ \\
\hline $\begin{array}{c}\text { Generalist Bird Habitat } \\
136.72 \text { Acres } \\
(6.39 \%)\end{array}$ \\
\hline $\begin{array}{c}\text { Migratory Bird Habitat } \\
61.88 \text { Acres } \\
(2.89 \%)\end{array}$ \\
\hline $\begin{array}{c}\text { Louisiana Waterthrush } \\
\text { Habitat Loss }\end{array}$ & 41.16 Acres \\
\hline $\begin{array}{c}\text { Headwater } \\
\text { Watersheds Affected }\end{array}$ & 21 \\
\hline
\end{tabular}

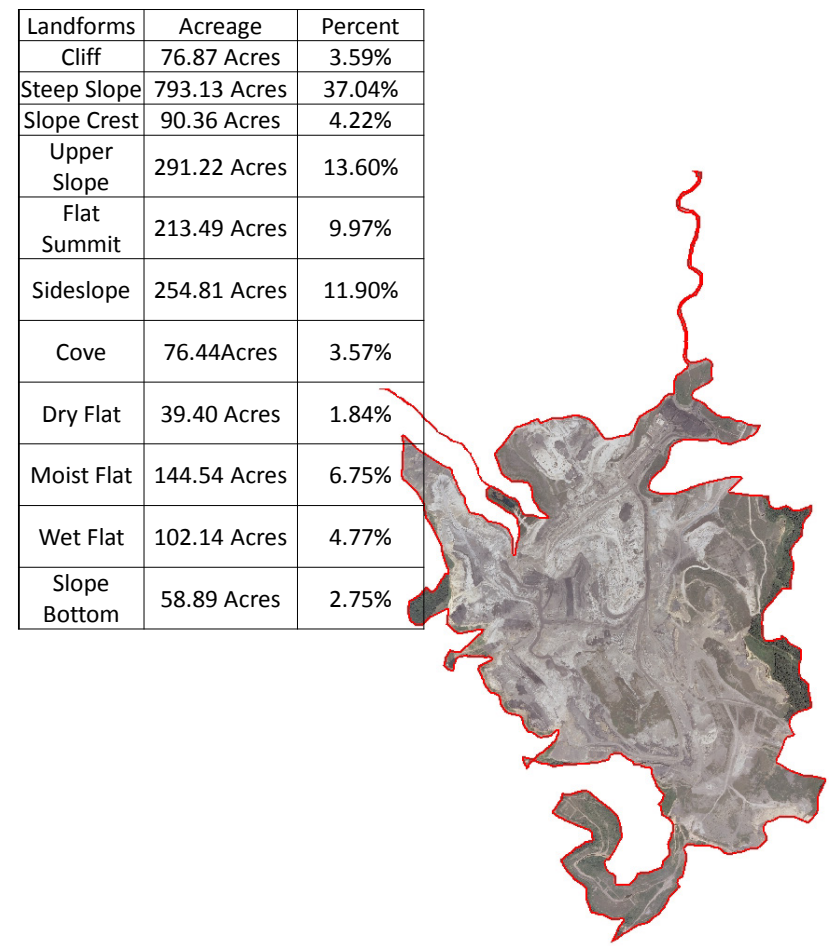




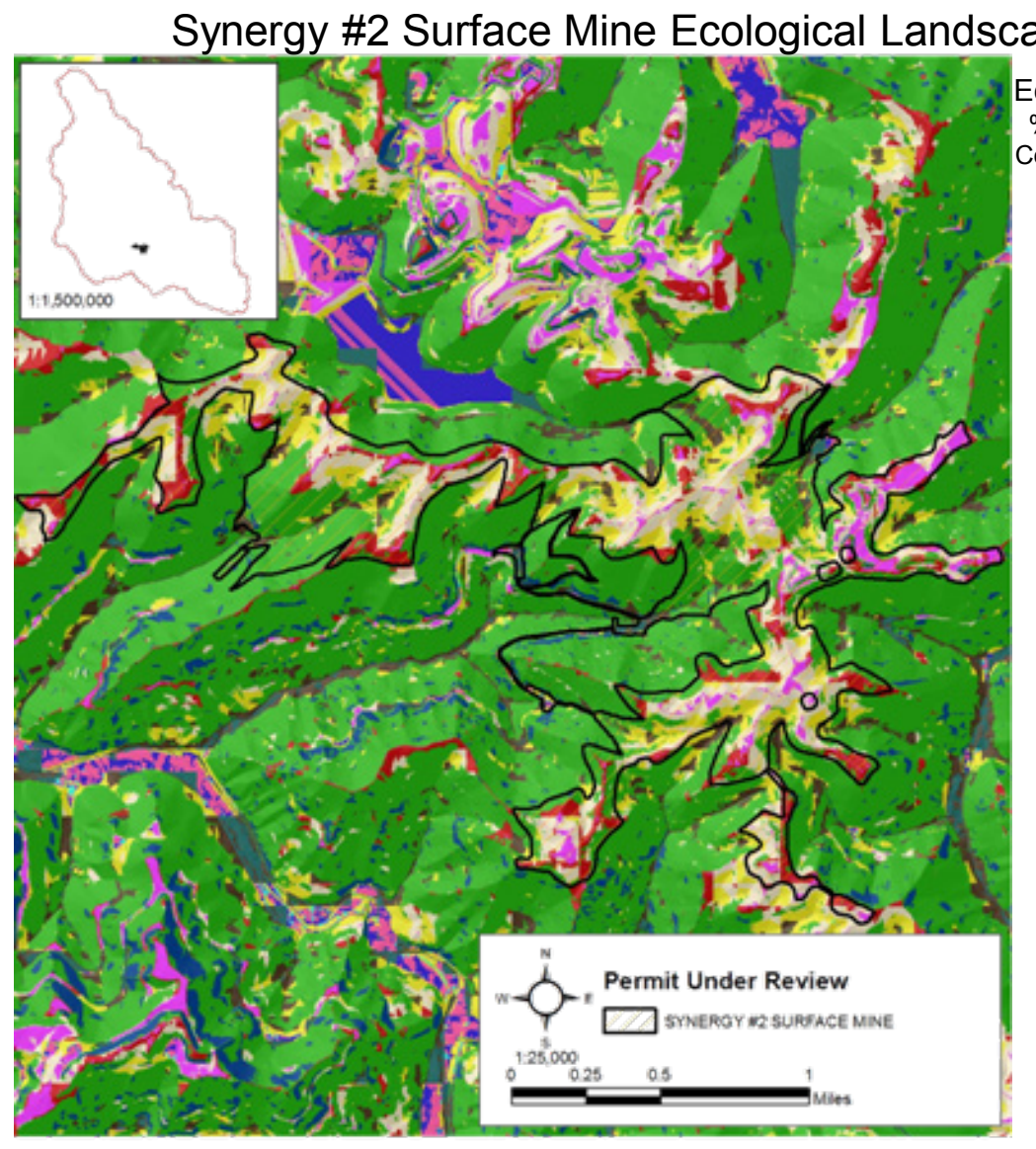

Ecological Landscape Unit Distribution $\%$ of Total Permit Boundary Under Review Covered by Each Ecological Landscape Unit

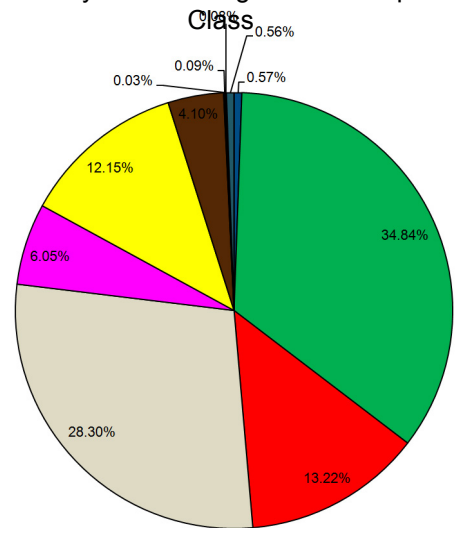

Ecological Landscape Units

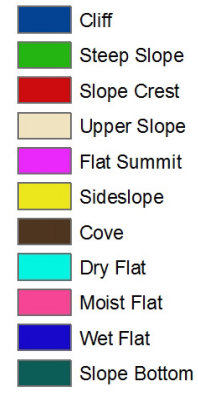

\begin{tabular}{|c|c|}
\hline \multicolumn{2}{|c|}{ Synergy No. 2 Mine } \\
\hline Size & 940.22 Acres \\
\hline Current Disturbance & 256.26 Acres \\
\hline Current \% Disturbance & $27.26 \%$ \\
\hline Area of Riparian Forest & 165.31 Acres \\
\hline Area of Headwater Forest & 509.93 Acres \\
\hline $\begin{array}{c}\text { Area of Forest over 25 } \\
\text { Slope }\end{array}$ & 234.72 Acres \\
\hline $\begin{array}{c}\text { Total Acres of Critical Forest } \\
\text { Present }\end{array}$ & 583.64 Acres \\
\hline $\begin{array}{c}\text { Potential Surface Water } \\
\text { Impact }\end{array}$ & $\begin{array}{c}\text { None in } \\
\text { Vicinity }\end{array}$ \\
\hline $\begin{array}{c}\text { Un-Preferred Bird Habitat } \\
258.94 \text { Acres } \\
(27.54 \%)\end{array}$ \\
\hline $\begin{array}{c}\text { Generalist Bird Habitat } \\
\text { 88.32 Acres } \\
\text { (9.40\%) }\end{array}$ \\
\hline $\begin{array}{c}\text { Migratory Bird Habitat } \\
\text { Louisiana Waterthrush } \\
\text { Habitat Loss }\end{array}$ & 137.83 Acres \\
\hline $\begin{array}{c}\text { Headwater Watersheds } \\
\text { Affected }\end{array}$ & 13 \\
\hline
\end{tabular}

\begin{tabular}{|c|c|c|}
\hline Landforms & Acreage & Percent \\
\hline Cliff & 5.36 Acres & $0.57 \%$ \\
\hline Steep Slope & 327.57 Acres & $34.84 \%$ \\
\hline Slope Crest & 124.30 Acres & $13.22 \%$ \\
\hline Upper Slope & 266.08 Acres & $28.30 \%$ \\
\hline Flat Summit & 56.88 Acres & $6.05 \%$ \\
\hline Sideslope & 114.24 Acres & $12.15 \%$ \\
\hline Cove & 38.55 Acres & $4.10 \%$ \\
\hline Dry Flat & 0.28 Acres & $0.03 \%$ \\
\hline Moist Flat & 0.85 Acres & $0.09 \%$ \\
\hline Wet Flat & 0.75 Acres & $0.08 \%$ \\
\hline Slope Bottom & 5.27 Acres & $0.56 \%$ \\
\hline & & \\
\hline
\end{tabular}




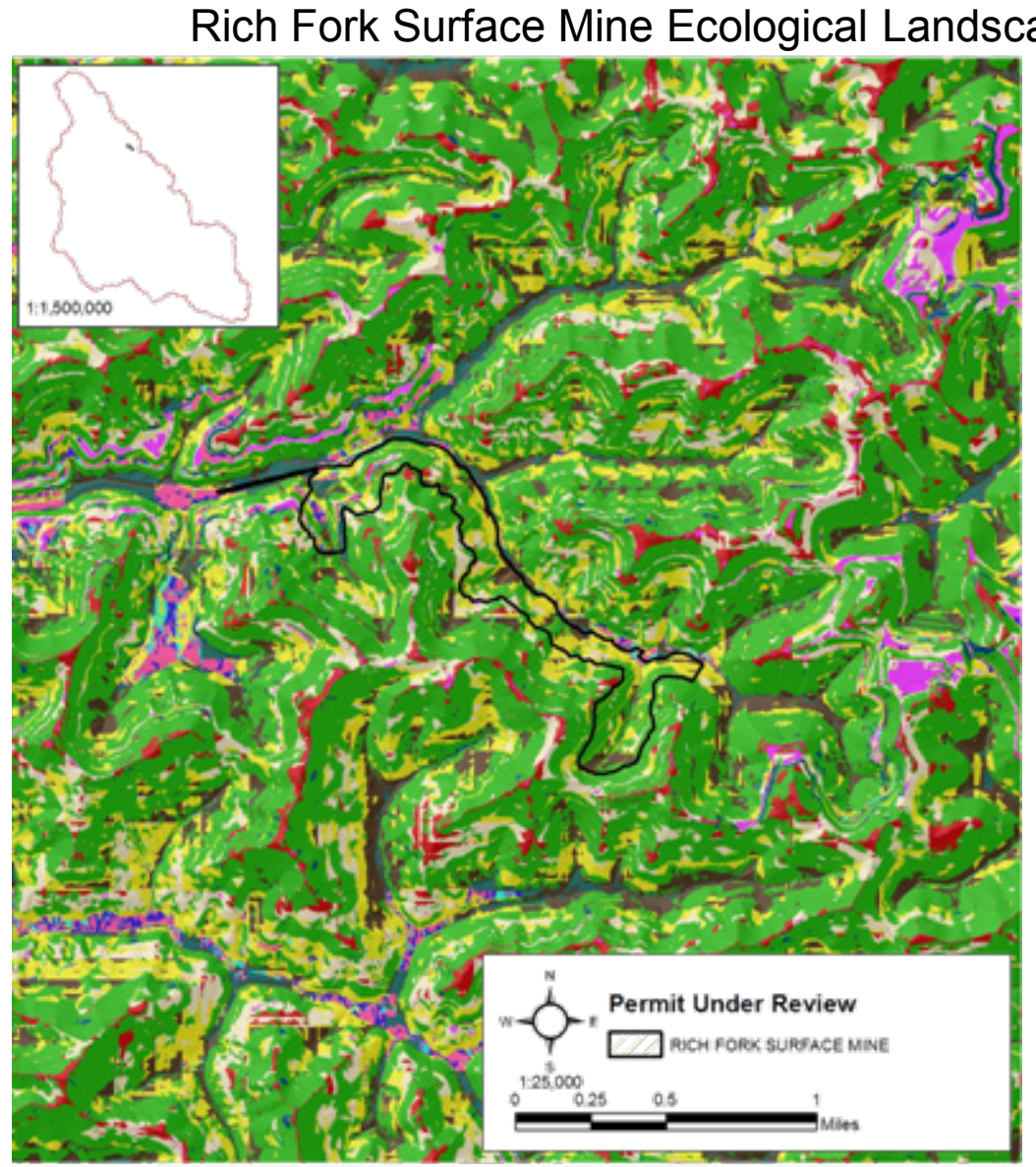

Ecological Landscape Unit Distribution $\%$ of Total Permit Boundary Under Review Covered by Each Ecological Landscape Unit

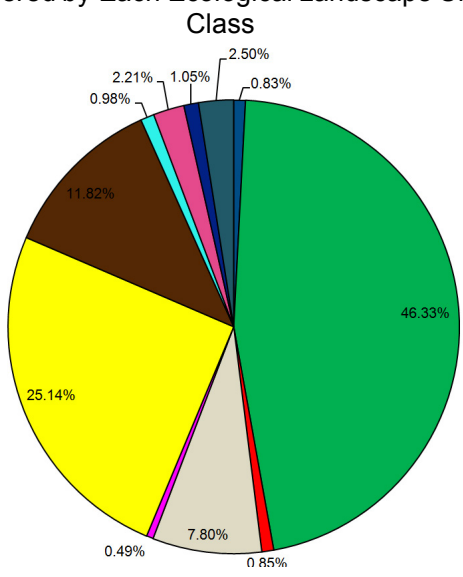

Ecological Landscape Units

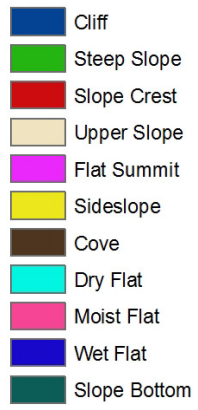

\begin{tabular}{|c|c|}
\hline \multicolumn{2}{|c|}{ Rich Fork Surface Mine } \\
\hline Size & 158.30 Acres \\
\hline Current Disturbance & 1.56 Acres \\
\hline Current \% Disturbance & $0.99 \%$ \\
\hline Area of Riparian Forest & 99.72 Acres \\
\hline $\begin{array}{c}\text { Area of Headwater } \\
\text { Forest } \\
\end{array}$ & 12.64 Acres \\
\hline $\begin{array}{c}\text { Area of Forest over } 25^{\circ} \\
\text { Slope }\end{array}$ & 63.82 Acres \\
\hline $\begin{array}{c}\text { Total Acres of Critical } \\
\text { Forest Present }\end{array}$ & 127.08 Acres \\
\hline $\begin{array}{l}\text { Potential Surface } \\
\text { Water Impact }\end{array}$ & $\begin{array}{l}\text { None in } \\
\text { Vicinity }\end{array}$ \\
\hline $\begin{array}{c}\text { Un-Preferred Bird } \\
\text { Habitat }\end{array}$ & $\begin{array}{c}\text { 7.64 Acres } \\
(4.83 \%)\end{array}$ \\
\hline Generalist Bird Habitat & $\begin{array}{c}25.65 \text { Acres } \\
(16.20 \%)\end{array}$ \\
\hline Migratory Bird Habitat & $\begin{array}{c}125.01 \text { Acres } \\
(78.97 \%)\end{array}$ \\
\hline $\begin{array}{c}\text { Louisiana Waterthrush } \\
\text { Habitat Loss }\end{array}$ & 12.09 Acres \\
\hline $\begin{array}{c}\text { Headwater } \\
\text { Watersheds Affected }\end{array}$ & 2 \\
\hline
\end{tabular}

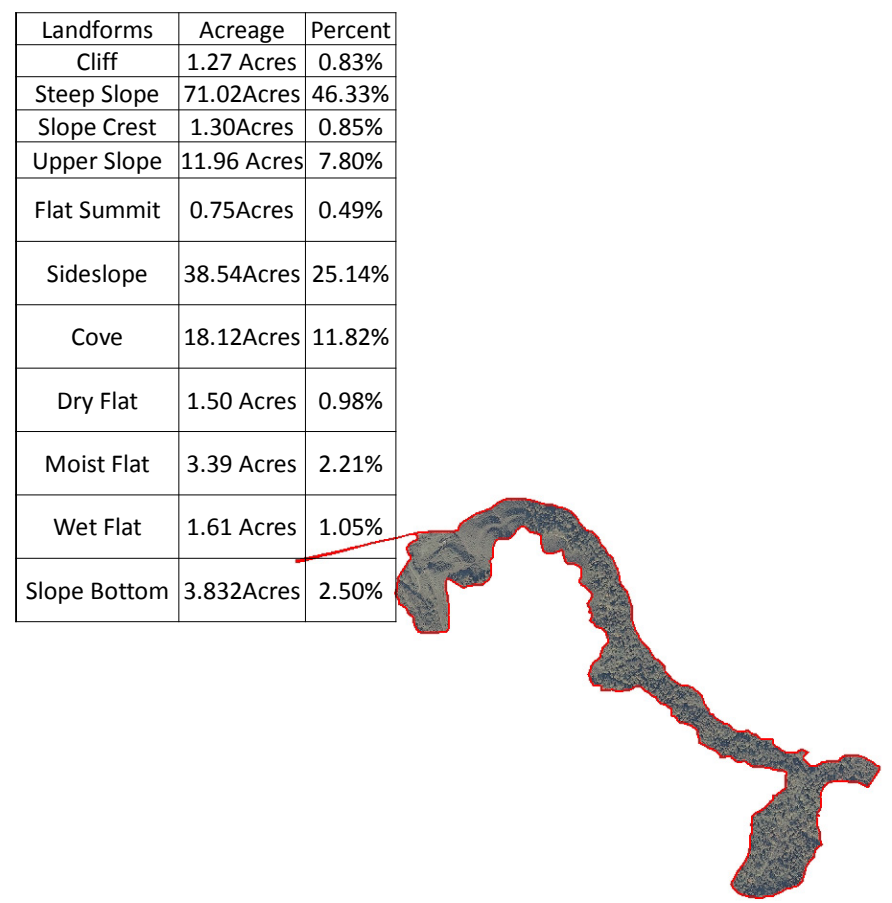




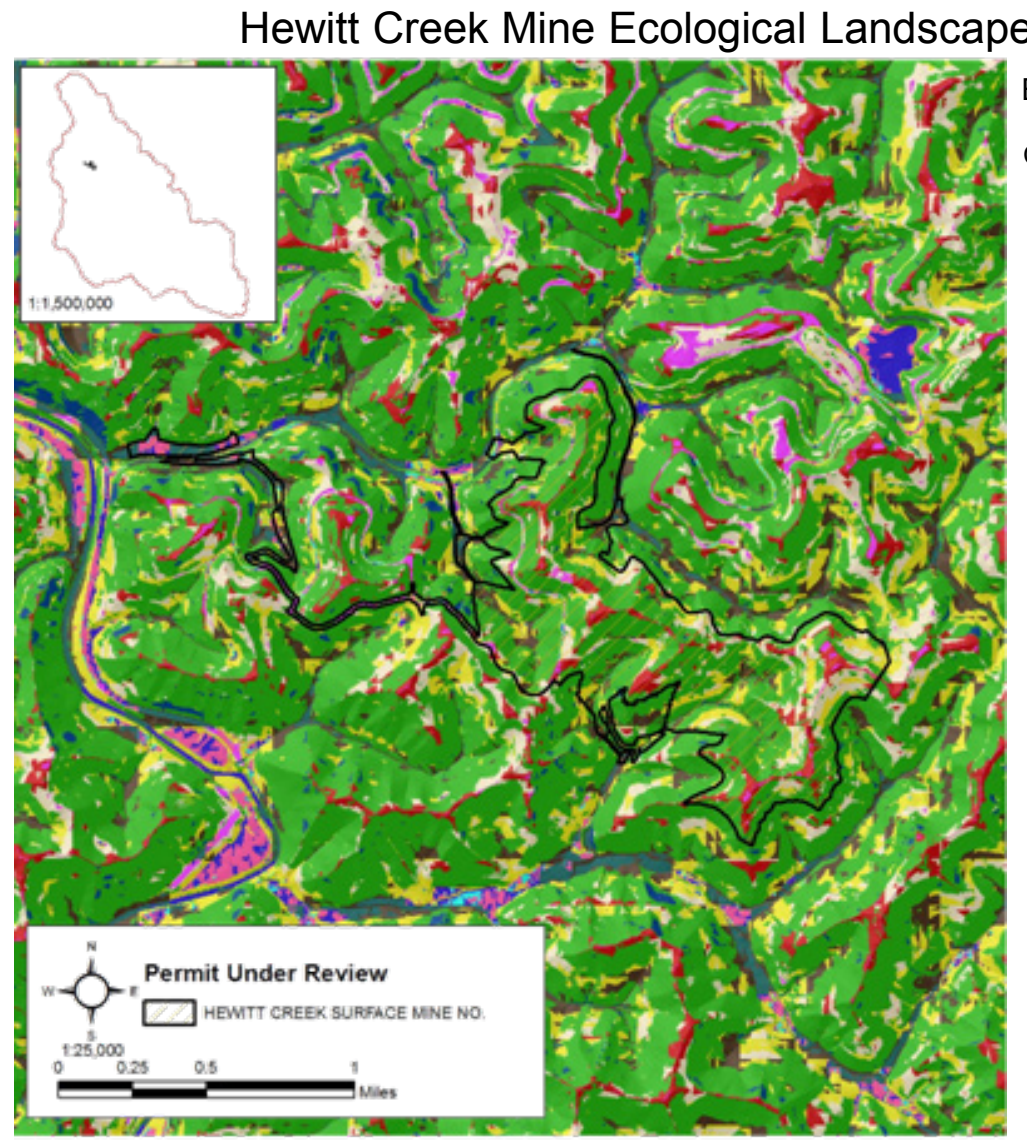

Unit Coverage

Ecological Landscape Unit Distribution $\%$ of Total Permit Boundary Under Review Covered by Each Ecological Landscape Unit

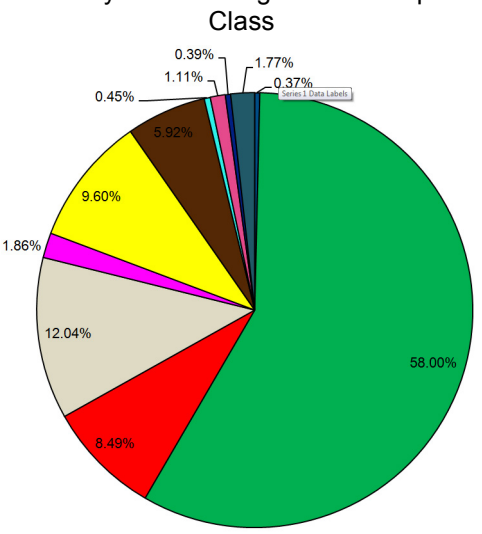

\section{Ecological Landscape Units}

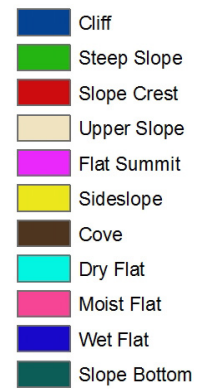

\begin{tabular}{|c|c|}
\hline \multicolumn{2}{|c|}{ Hewitt Creek Surface Mine No. } \\
\hline Size & 560.22 Acres \\
\hline Current Disturbance & 230.07 Acres \\
\hline Current \% Disturbance & $41.07 \%$ \\
\hline Area of Riparian Forest & 66.53 Acres \\
\hline Area of Headwater Forest & 260.66 Acres \\
\hline Area of Forest over $25^{\circ}$ Slope & 178.96 Acres \\
\hline $\begin{array}{c}\text { Total Acres of Critical Forest } \\
\text { Present } \\
\end{array}$ & 300.74 Acres \\
\hline Potential Surface Water Impact & Not In Vacinity \\
\hline Un-Preferred Bird Habitat & $\begin{array}{c}238.73 \text { Acres } \\
(42.62 \%)\end{array}$ \\
\hline Generalist Bird Habitat & $\begin{array}{c}\text { 90.34 Acres } \\
(16.13 \%)\end{array}$ \\
\hline Migratory Bird Habitat & $\begin{array}{c}231.04 \text { Acres } \\
(41.25 \%)\end{array}$ \\
\hline $\begin{array}{l}\text { Louisiana Waterthrush Habitat } \\
\text { Loss }\end{array}$ & 63.22 Acres \\
\hline Headwater Watersheds Affected & 7 \\
\hline
\end{tabular}

\begin{tabular}{|c|c|c|}
\hline Landforms & Acreage & Percent \\
\hline Cliff & 2.07 Acres & $0.37 \%$ \\
\hline Steep Slope & 324.93 Acres & $58.00 \%$ \\
\hline Slope Crest & 47.56 Acres & $8.49 \%$ \\
\hline Upper Slope & 67.45 Acres & $12.04 \%$ \\
\hline Flat Summit & 10.42 Acres & $1.86 \%$ \\
\hline Sideslope & 53.78 Acres & $9.60 \%$ \\
\hline Cove & 33.17 Acres & $5.92 \%$ \\
\hline Dry Flat & 2.52 Acres & $0.45 \%$ \\
\hline Moist Flat & 6.23 Acres & $1.11 \%$ \\
\hline Wet Flat & 2.18 Acres & $0.39 \%$ \\
\hline Slope Bottom & 9.92 Acres & $1.77 \%$ \\
\hline
\end{tabular}


Laxare East Surface Mine Ecological Landscape Unit Coverage

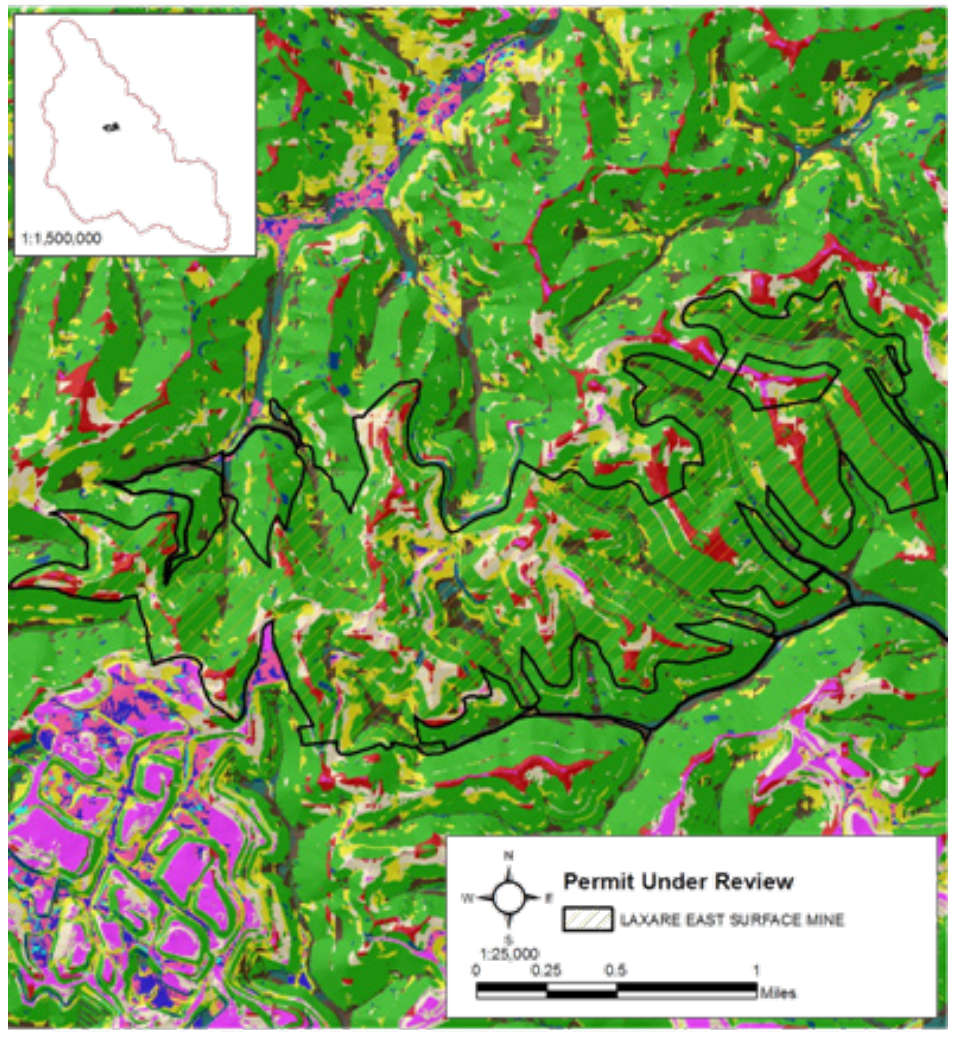

Ecological Landscape Unit Distribution $\%$ of Total Permit Boundary Under Review Covered by Each Ecological Landscape Unit

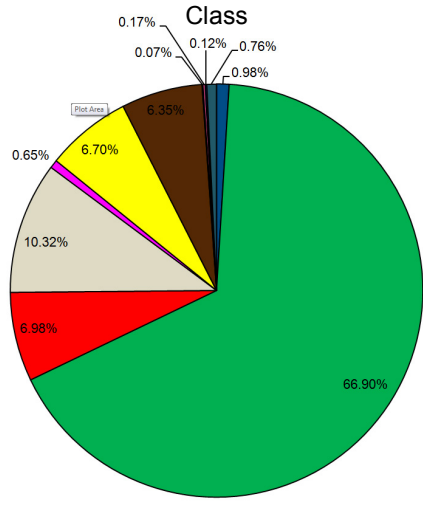

Ecological Landscape Units

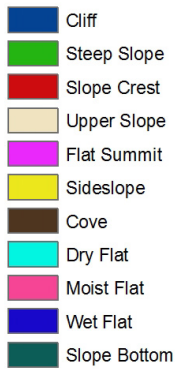

\begin{tabular}{|c|c|}
\hline \multicolumn{2}{|c|}{ Laxare East Surface Mine } \\
\hline Size & 1409.57 Acres \\
\hline Current Disturbance & 633.53 Acres \\
\hline Current \% Disturbance & $44.94 \%$ \\
\hline Area of Riparian Forest & 265.71 Acres \\
\hline Area of Headwater Forest & 723.83 Acres \\
\hline Area of Forest over 25 ${ }^{\circ}$ Slope & 546.72 Acres \\
\hline Total Acres of Critical Forest Present & 765.01 Acres \\
\hline Potential Surface Water Impact & Not In Vacinity \\
\hline Un-Preferred Bird Habitat & 662.27 Acres \\
& $(36.79 \%)$ \\
\hline Generalist Bird Habitat & 99.34 Acres \\
& $(5.52 \%)$ \\
\hline Migratory Bird Habitat & 1038.46 Acres \\
$(57.69 \%)$ \\
\hline Louisiana Waterthrush Habitat Loss & 258.55 Acres \\
\hline Headwater Watersheds Affected & 12 \\
\hline
\end{tabular}

\begin{tabular}{|c|c|c|}
\hline Landforms & Acreage & Percent \\
\hline Cliff & 13.81 Acres & $0.98 \%$ \\
\hline Steep Slope & 943.00 Acres & $66.90 \%$ \\
\hline Slope Crest & 98.39 Acres & $6.98 \%$ \\
\hline Upper Slope & 145.47 Acres & $10.32 \%$ \\
\hline Flat Summit & 9.16 Acres & $0.65 \%$ \\
\hline Sideslope & 94.44 Acres & $6.70 \%$ \\
\hline Cove & 89.51 Acres & $6.35 \%$ \\
\hline Dry Flat & 0.99 Acres & $0.07 \%$ \\
\hline Moist Flat & 2.40 Acres & $0.17 \%$ \\
\hline Wet Flat & \multirow{2}{*}{1.69 Acres } & $0.12 \%$ \\
\hline Slope Bottom & \multirow{2}{*}{10.71 Acres } & $0.76 \%$ \\
\hline
\end{tabular}

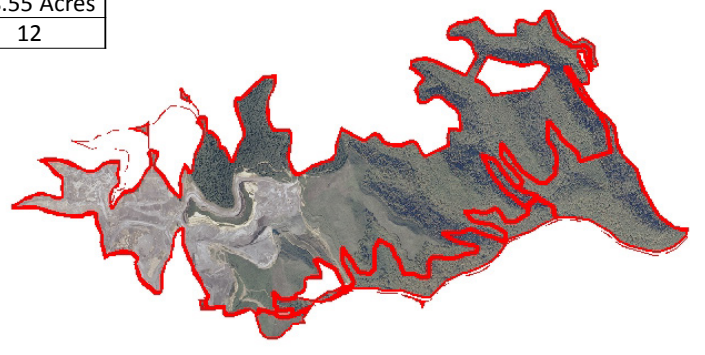




\section{Locust Fork Surface Mine Ecological Landscape Unit Coverage}

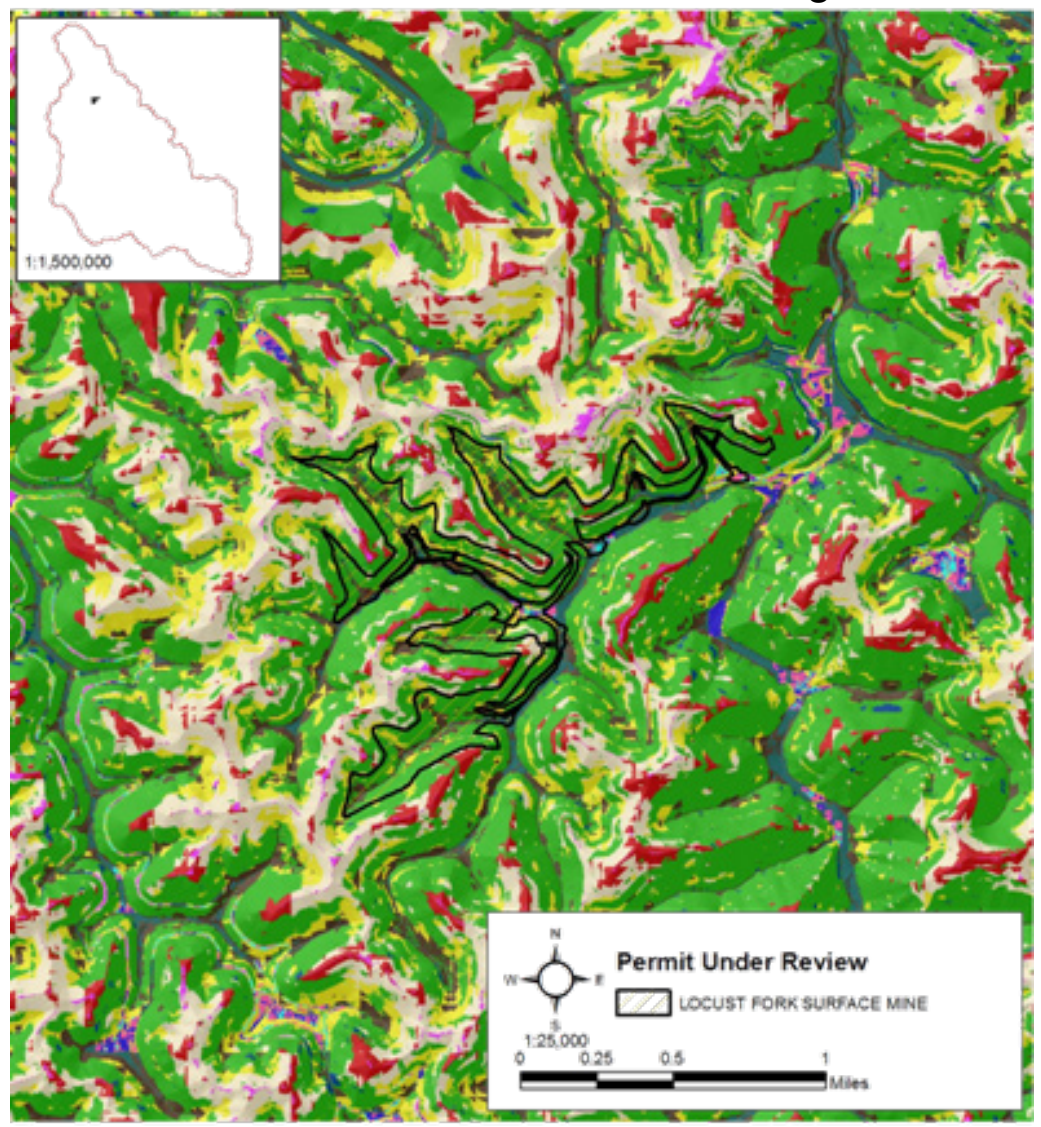

Ecological Landscape Unit Distribution $\%$ of Total Permit Boundary Under Review Covered by Each Ecological Landscape Unit

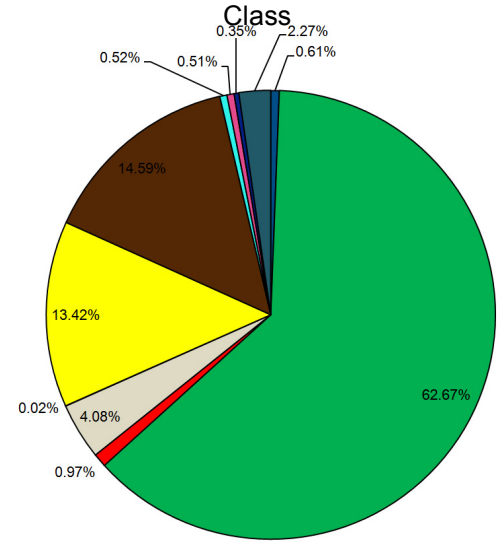

\section{Ecological Landscape Units}

\begin{tabular}{|l|l|}
\hline & Cliff \\
& Steep Slope \\
& Slope Crest \\
\hline & Upper Slope \\
\hline & Flat Summit \\
\hline & Sideslope \\
\hline & Cove \\
\hline & Dry Flat \\
Moist Flat \\
Wet Flat \\
Slope Bottom
\end{tabular}

\begin{tabular}{|c|c|}
\hline \multicolumn{2}{|c|}{ Locust Fork Surface Mine } \\
\hline Size & 253.63 Acres \\
\hline Current Disturbance & 13.48 Acres \\
\hline Current \% Disturbance & $5.31 \%$ \\
\hline Area of Riparian Forest & 166.89 Acres \\
\hline $\begin{array}{c}\text { Area of Headwater } \\
\text { Forest }\end{array}$ & 179.92 Acres \\
\hline $\begin{array}{c}\text { Area of Forest over } 25^{\circ} \\
\text { Slope }\end{array}$ & 137.62 Acres \\
\hline $\begin{array}{c}\text { Total Acres of Critical } \\
\text { Forest Present }\end{array}$ & 223.11 Acres \\
\hline $\begin{array}{c}\text { Potential Surface Water } \\
\text { Impact }\end{array}$ & $\begin{array}{c}\text { Intersects Zones of } \\
\text { Critical Concern }\end{array}$ \\
\hline $\begin{array}{c}\text { Un-Preferred Bird } \\
\text { Habitat }\end{array}$ & $\begin{array}{c}15.12 \text { Acres } \\
\text { (5.96\%) }\end{array}$ \\
\hline $\begin{array}{c}\text { Generalist Bird Habitat } \\
(14.39 \%)\end{array}$ \\
\hline $\begin{array}{c}\text { Migratory Bird Habitat } \\
\text { (79.06.65\%) }\end{array}$ \\
\hline $\begin{array}{c}\text { Louisiana Waterthrush } \\
\text { Habitat Loss }\end{array}$ & 147.64 Acres \\
\hline $\begin{array}{c}\text { Headwater Watersheds } \\
\text { Affected }\end{array}$ & 2 \\
\hline
\end{tabular}

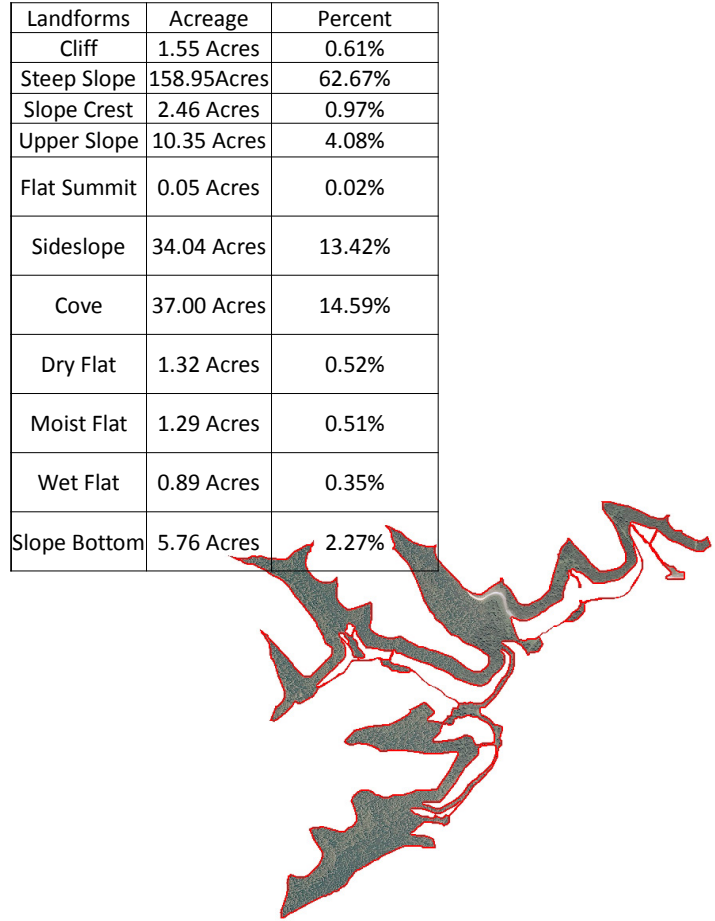




\section{Nellis Mine Ecological Landscape Unit Coverage}

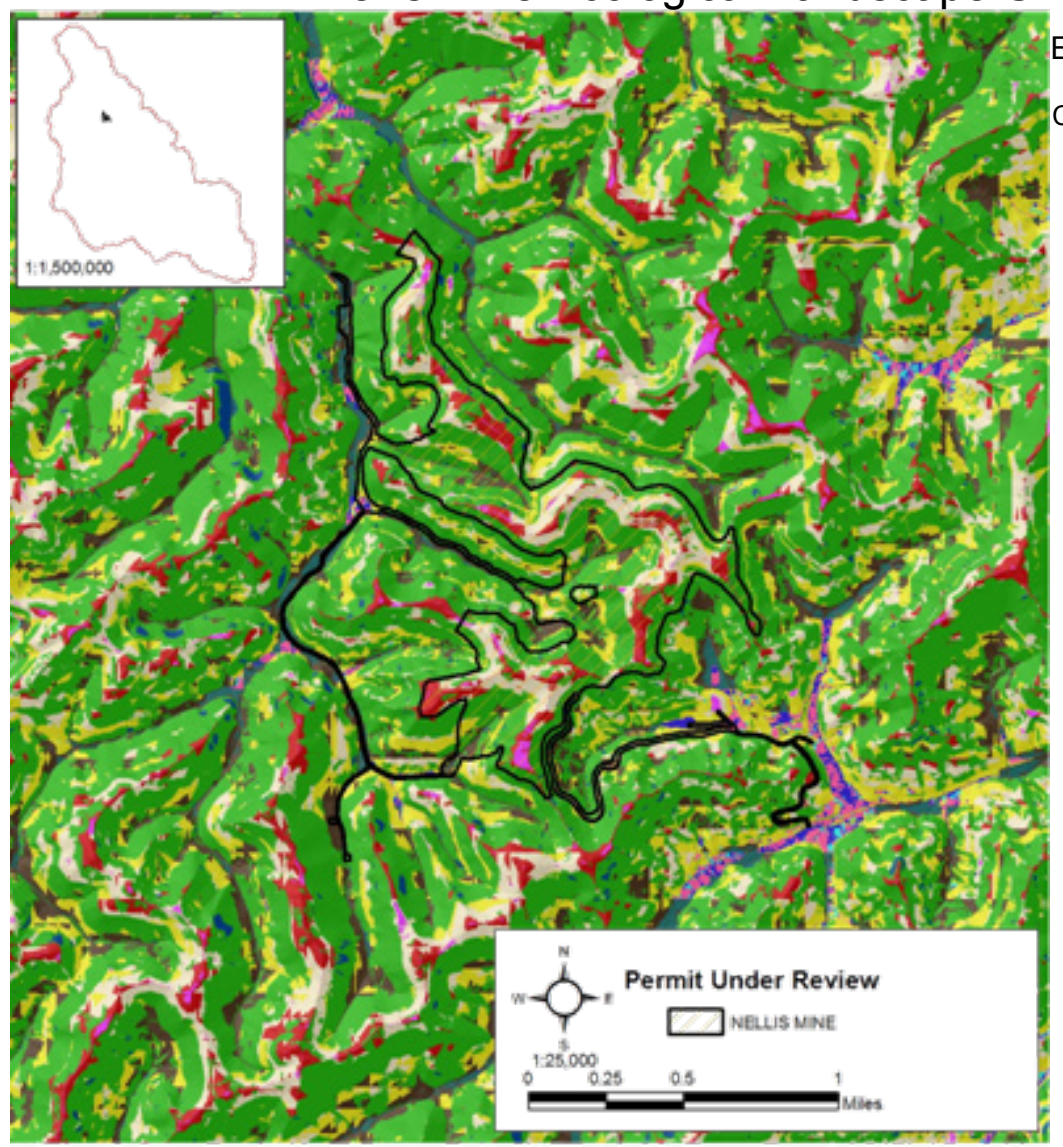

Ecological Landscape Unit Distribution $\%$ of Total Permit Boundary Under Review Covered by Each Ecological Landscape Unit

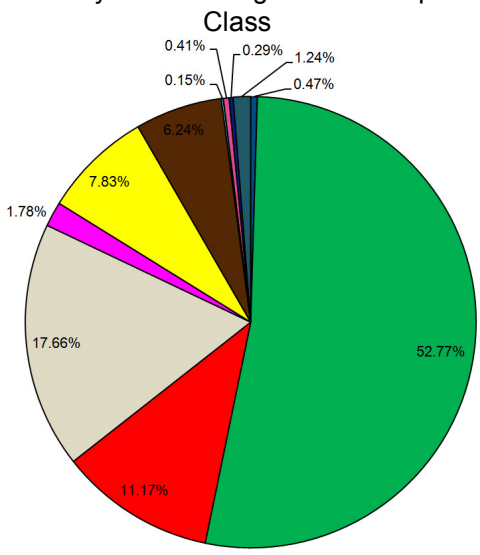

\section{Ecological Landscape Units}

\begin{tabular}{|l|}
\hline Cliff \\
Steep Slope \\
Slope Crest \\
\hline Upper Slope \\
Flat Summit \\
\hline Sideslope \\
Cove \\
\hline Dry Flat \\
Moist Flat \\
Wet Flat \\
Slope Bottom
\end{tabular}




\section{Boone North \#5 Surface Mine Ecological Landscape Unit Coverage}

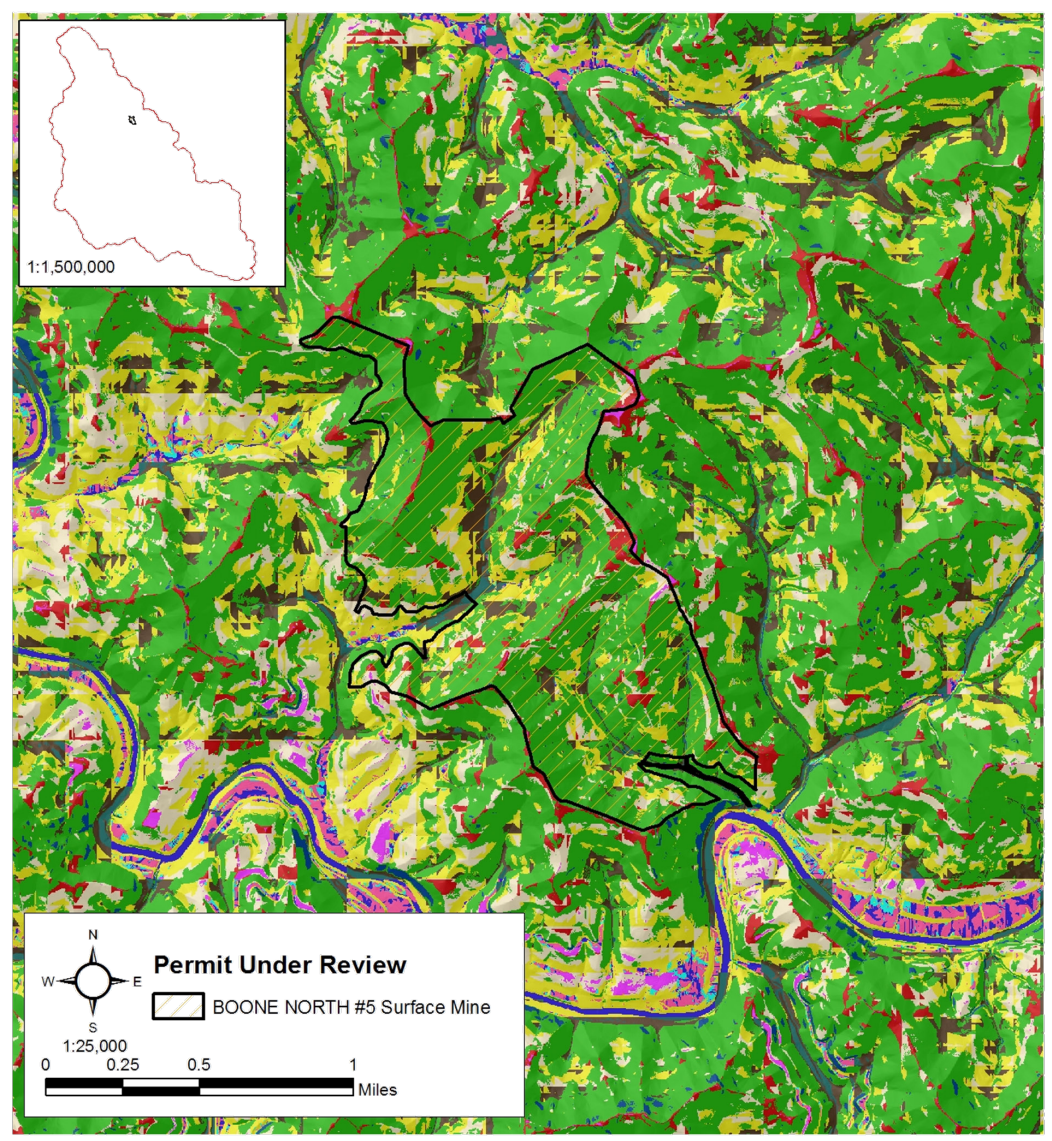

Ecological Landscape Unit Distribution $\%$ of Total Permit Boundary Under Review Covered by Each Ecological Landscape Unit

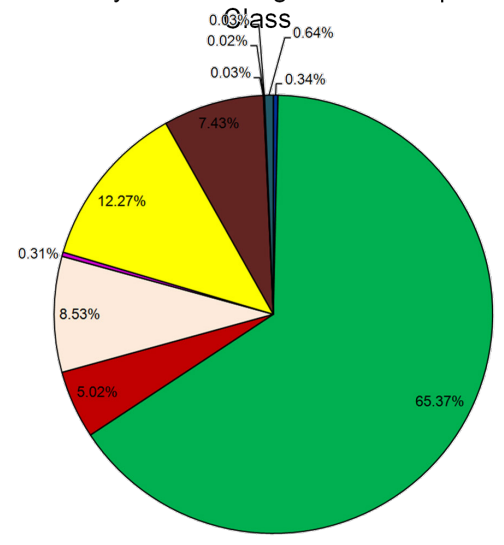

\section{Ecological Landscape Units}

\begin{tabular}{|l}
\hline Cliff \\
Steep Slope \\
Slope Crest \\
\hline$\square$ Upper Slope \\
\hline Flat Summit \\
\hline$\square$ Sideslope \\
Cove \\
Dry Flat \\
Moist Flat \\
Wet Flat \\
Slope Bottom
\end{tabular}




\section{Joes Creek Surface Mine Ecological Landscape Unit Coverage}

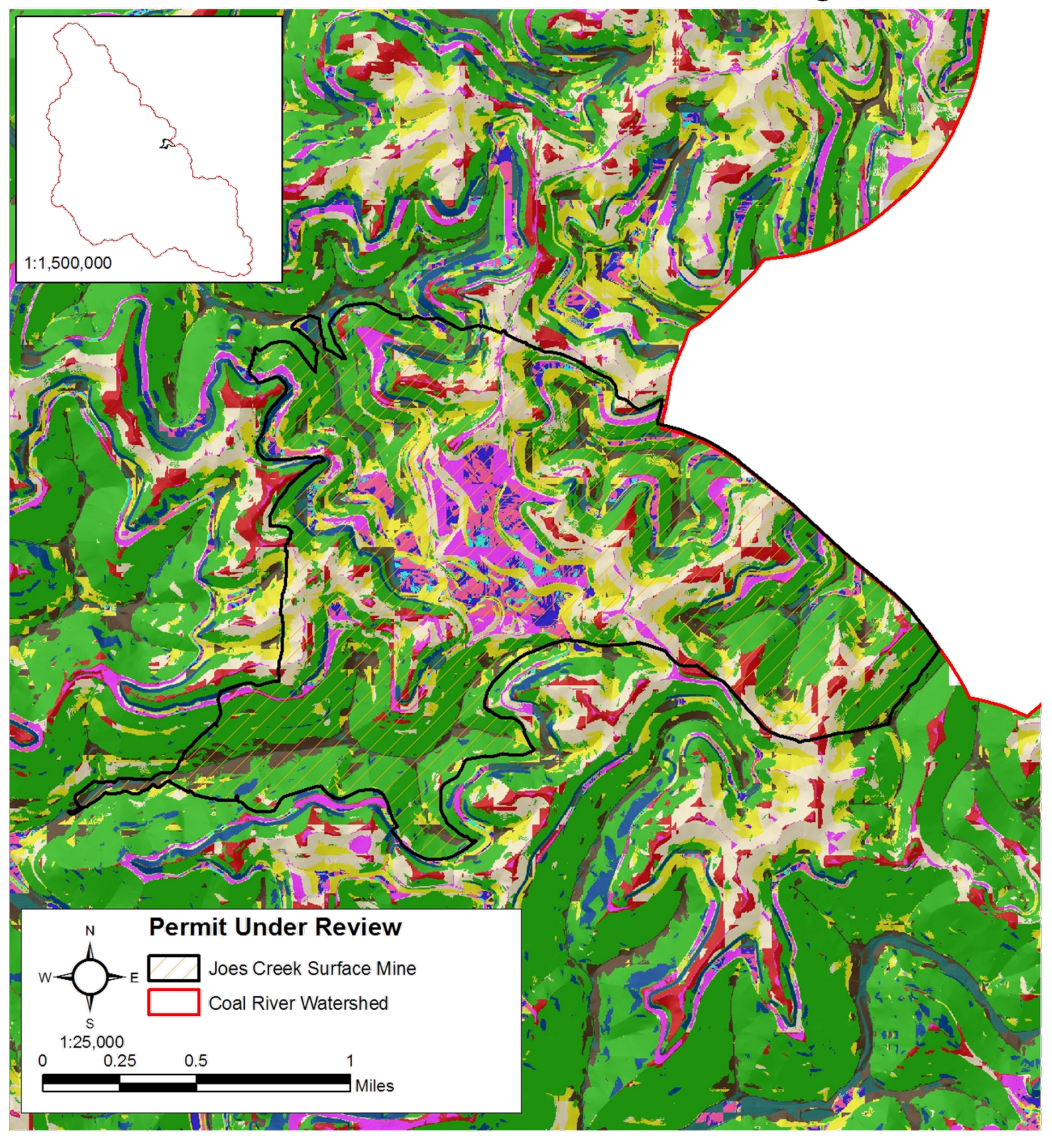

Ecological Landscape Unit Distribution $\%$ of Total Permit Boundary Under Review Covered by Each Ecological Landscape Unit Class

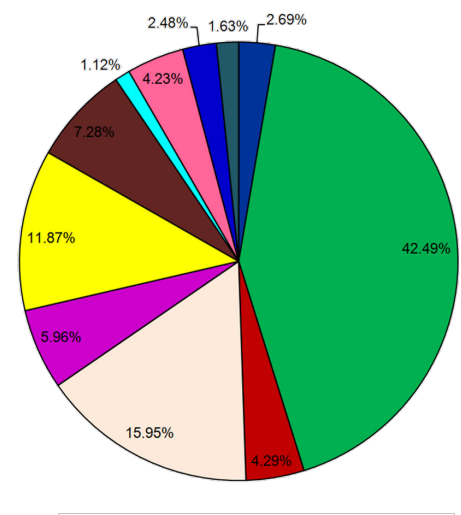

Ecological Landscape Units

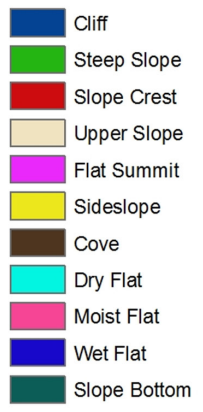




\section{MT-5B Surface Mine Ecological Landscape Unit Coverage}

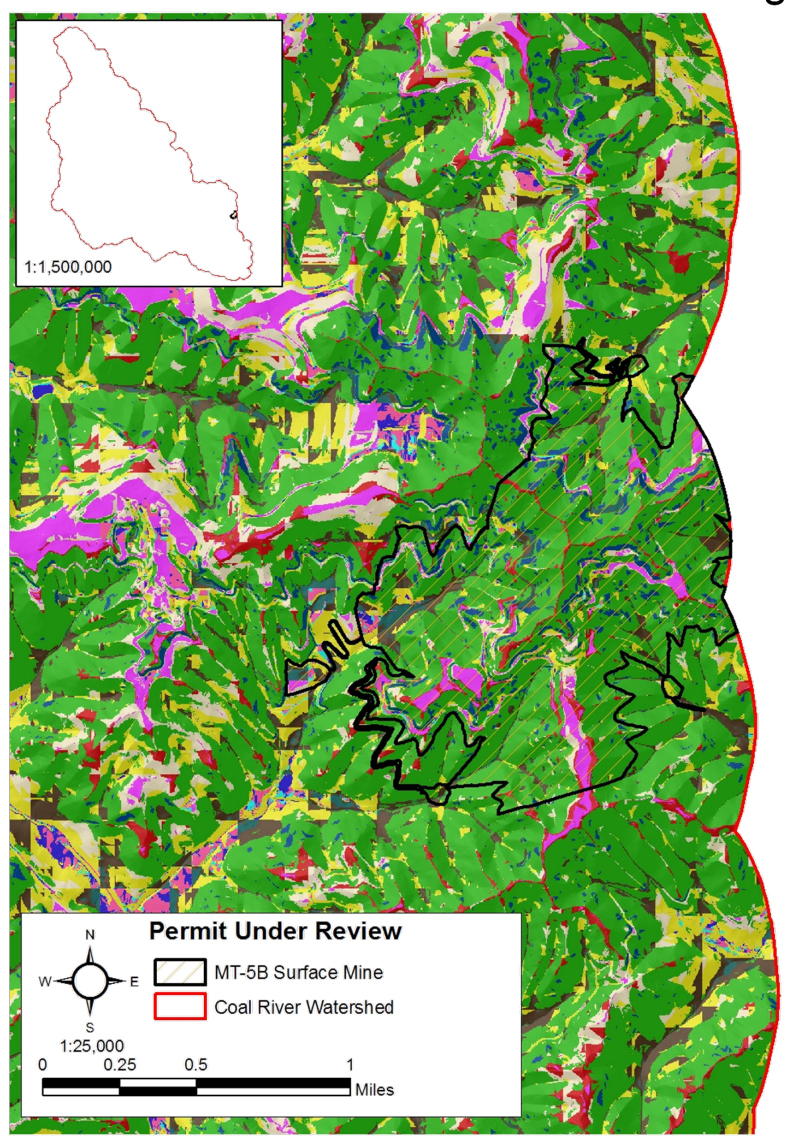

Ecological Landscape Unit Distribution $\%$ of Total Permit Boundary Under Review Covered by Each Ecological Landscape Unit

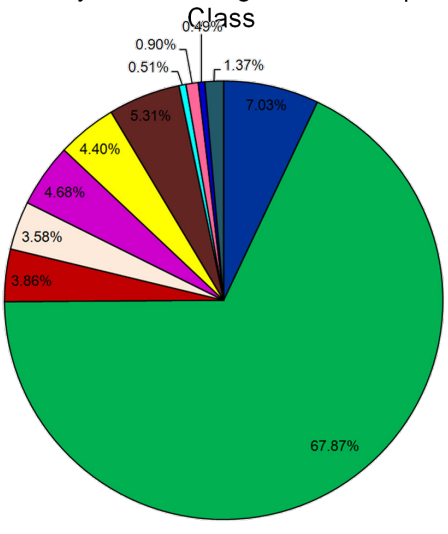

Ecological Landscape Units

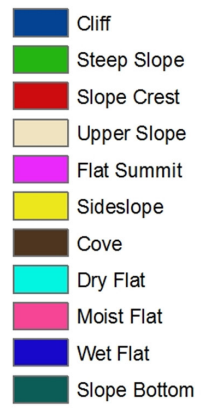


Con(condition, true expression, false expression) Forests are more critical within 100 meters of a 1:24,000 stream Con([dist2streams] > 200, 0, ((200 - [dist2streams]) / 200)) Forests are more critical in areas with at least 25 degree slopes Con([slope_degrees] < 50, 0, ((50 - [slope_degrees]) / 87.46)) 


\title{
A Landscape Analysis of Surface Coal Mine Permits in the Coal River Watershed of West Virginia
}

\author{
Lafe Joseph Kunkel \\ Thesis submitted to the \\ College of Agriculture, Natural Resources and Design \\ at West Virginia University \\ in partial fulfillment of the requirements \\ for the degree of \\ Master of Science \\ in \\ Agricultural and Resource Economics \\ Department of Resource Management
}

Approval of Examining Committee

Michael P. Strager, Ph.D., Chair

Jerald J. Fletcher, Ph.D

Charles B. Yuill

Date

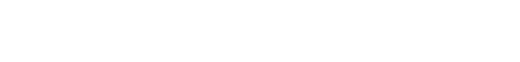

